\title{
Das Leben in der napoleonischen Armee - interdisziplinäre Untersuchung eines Massengrabs aus Kassel, Hessen
}

\author{
Dissertation \\ zur Erlangung des mathematisch-naturwissenschaftlichen Doktorgrades \\ "Doctor rerum naturalium" \\ der Georg-August-Universität Göttingen \\ im Promotionsprogramm Grundprogramm Biologie \\ der Georg-August University School of Science (GAUSS)
}

vorgelegt von

Philipp v. Grumbkow

aus Meißner-Wellingerode

Göttingen, 2013 
Betreuungsausschuss

Prof. Dr. Peter Kappeler

PD Dr. Thomas Hörnschemeyer

Dr. Susanne Hummel

Mitglieder der Prüfungskommission

Referent: Prof. Dr. Peter Kappeler

Korreferent: PD Thomas Hörnschemeyer

Weitere Mitglieder der Prüfungskommission:

Prof. Dr. Julia Ostner

Prof. Dr. Eckhard Heymann

PD Dr. Michael Hoppert

Dr. Susanne Hummel

Tag der mündlichen Prüfung: 23.10.2013 
Inhaltsverzeichnis

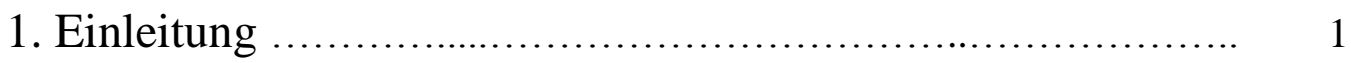

1.1. Das Massengrab aus Kassel............................... 1

1.2. Das Leben in der napoleonischen Armee........................ 6

1.3. Das Skelett als Informationsquelle........................ 8

1.4. aDNA-Forschung und Authentizitätssicherung (STR-Systeme) 32

1.5. Fragestellung und Zielsetzung der Arbeit................... 36

2. Material..................................................... 37

3. Methoden.................................................... 40

3.1. Zuordnen von Skelettelementen zu Individuen................ 40

3.2. Morphologische und morphometrische Befundung ........... 42

3.2.1. Geschlechtsbestimmung.......................... 42

3.2.2. Altersschätzung.............................. 42

3.2.3. Körperhöhenrekonstruktion..................... 42

3.2.4. Abweichungen von der Regelanatomie............... 43

3.3. Histologie.......................................... 44

3.4. DNA-Analytik ....................................... 45

3.4.1. Kontaminationsprävention...................... 45

3.4.2. DNA-Extraktion.................................. 46

3.4.3. Primerdesign................................. 49

3.4.4. Amplifikation autosomaler STR-Systeme

(genetischer Fingerabdruck)......................... 50

3.4.5. Amplifikation gonosomaler STR-Systeme (Sexplex)... 51

3.4.6. Amplifikation Y-chromosomaler STR-Systeme........ 53

3.4.7. Amplifikation humanpathogener Bakterien-DNA.... 55

3.4.8. Auswertung der Amplifikationen................... 57

3.4.9. Statistische Auswertung ...................... 59

4. Ergebnisse und Interpretation................................ 64

4.1. Bestandsaufnahme und Mindestindividuenzahl .............. 64

4.2. Geschlechterverteilung................................ 71

4.3. Altersverteilung ......................................... 73

4.4. Körperhöhenrekonstruktion............................ 77

4.5. Abweichungen von der Regelanatomie...................... 79 
Inhaltsverzeichnis

4.6. Geographische Herkunftsbestimmung..................... 87

4.6.1. Auswertung autosomaler Allelfrequenzen............ 87

4.6.2. Auswertung Y-chromosomaler STRs............... 93

4.7. Nachweis humanpathogener Bakterien-DNA............... 103

4.8. Zusammenführung und Kontextualisierung................. 108

5. Diskussion................................................. 111

5.1. Bestandsaufnahme und Mindestindividuenanzahl.............. 111

5.2. Biologische Basisdaten................................. 113

5.3. Abweichungen von der Regelanatomie.................... 114

5.4. Geographische Herkunftsbestimmung.................... 116

5.5. Hinweise auf die Todesursache.......................... 118

6. Zusammenfassung.......................................... 121

7. Literatur................................................ 123

8. Anhang.................................................. 140

8.1. Einheiten und Abkürzungen............................ 140

8.2. Verwendete Geräte, Chemikalien, Hilfsmittel und

Einwegmaterial......................................... 142

8.3. Verwendete Software, Internetseiten und Dateien auf der

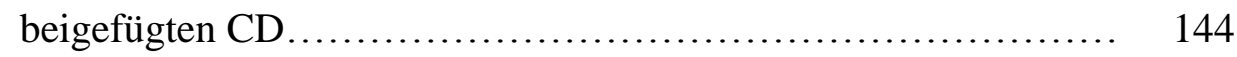

8.4. Längenstandards..................................... 145 


\section{Einleitung}

\subsection{Das Massengrab aus Kassel}

Am 01.01.2008 begannen Bauarbeiten für den Erweiterungsbau der Erziehungs- und Wirtschaftswissenschaften an der Kreuzung Kurt-Wolthers-Straße / An der Ahna auf dem Gelände der Universität Kassel (siehe Abb. 1.1). Am 16.01.2008 stießen die Bauarbeiter auf die ersten menschlichen Überreste, die Arbeiten wurden umgehend eingestellt. Bis Ende Januar wurde eine große Zahl weitere Skelette freigelegt, jedoch gab es keine Beifunde, die die Identität der Bestatteten hätten klären können.

Hinzugezogene Rechtsmediziner aus Gießen und Anthropologen aus Mainz, die jeweils eine Stichprobe der Individuen untersuchten, identifizierten nur männliche Bestattete, die überwiegend im adulten Lebensalter verstorben waren. Es ließen sich darüber hinaus jedoch nur wenige Informationen über die Identität der Individuen gewinnen. Es waren nur vereinzelte Pathologien zu beobachten, allerdings keine direkten Hinweise auf die Todesumstände. Die Alters- und Geschlechtsverteilung sowie das Fehlen von Hinweisen zur Todesursache sowie jeglicher Beifunde führte zu folgenden Theorien: Der große Anteil junger Männer deutet auf einen militärischen Hintergrund hin. Das Fehlen von Beifunden könnte bedeuten, dass die Individuen nackt oder mit nur wenig Bekleidung bestattet worden sind. Die Abwesenheit von Verletzungsspuren könnte mit einem möglichen Seuchengeschehen erklärt werden (siehe auch Roßbach und Alt 2008).

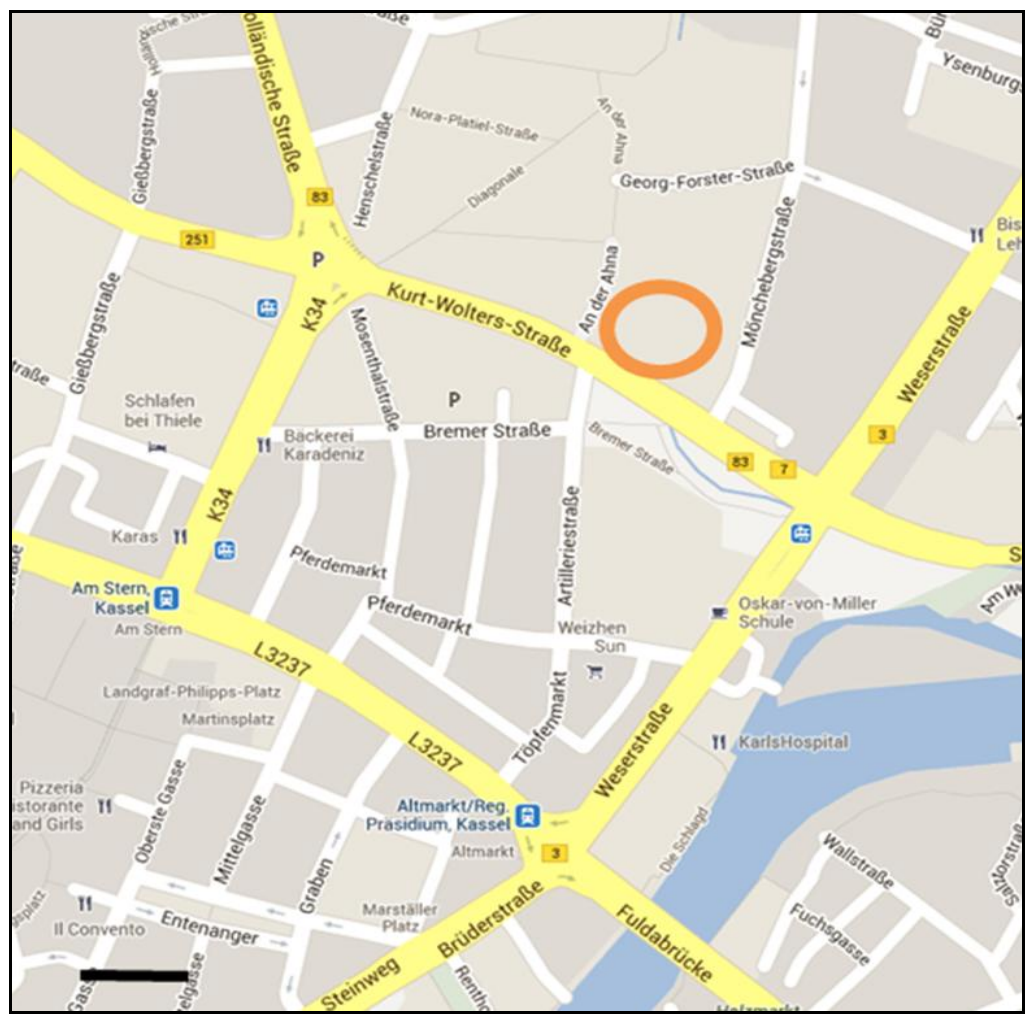

Abbildung 1.1: Karte des Auffindeortes des Massengrabes in Kassel (oranger Kreis). Der schwarze Balken entspricht 100 Metern (Karte von GoogleMaps, bearbeitet) 
Nachforschungen in der Historie des Fundorts sowie Analysen des Physikalischen Instituts der Universität Nürnberg-Erlangen konnten erste Spekulationen über die Identität der Toten als Zwangsarbeiter aus der NS-Zeit verwerfen: Die Individuen lagen unter Fundamenten von Gebäuden, die 1860 errichtet worden sind. Außerdem folgt die Anordnung der Skelette dem Verlauf eines Gebäudes, das im Jahr 1800 errichtet wurde und Ende der 1820er Jahre wieder abgerissen worden ist. Damit übereinstimmend konnte mit Hilfe von C14-Analysen das Alter der Individuen auf $195 \pm 41$ Jahre datiert werden. Das ermittelte Todesdatum liegt somit in beiden Analysen zu Beginn des 19. Jahrhunderts (Pressemitteilung des Präsidiums Nordhessen, http://www.presseportal.de/polizeipresse/pm/44143/1253528/polizeipraesidium_nordhessen_kassel.).

Der postulierte militärische Hintergrund in Verbindung mit dem ermittelten Todeszeitpunkt lässt einen Zusammenhang zu napoleonischen Truppen plausibel erscheinen. Die Stadt Kassel wurde am 1. November 1806 von französischen Truppen besetzt und war von 1807 bis 1813 Hauptstadt des Königreichs Westphalen, das von Napoleons Bruder Jérôme regiert wurde. Nach der verlorenen Völkerschlacht bei Leipzig im Oktober 1813 und dem Rückzug Napoleons wurde Kassel noch im selben Monat von russischen Truppen befreit. Ab dem 21. November 1813 regierte Kurfürst Wilhelm I. wieder in der Stadt, in den folgenden Monaten kam es zu großen Truppenbewegungen der Nordarmee unter dem schwedischen Kronprinzen und der Schlesischen Armee durch die Stadt (z.B. Piderit 1844). In der Stadtgeschichte Kassels ist im fraglichen Zeitraum kein größeres Seuchengeschehen dokumentiert, allerdings sind viele Unterlagen im Laufe der Zeit (insbesondere auch durch die Bombardierungen im Zweiten Weltkrieg) verloren gegangen.

Bereits vor Abschluss der Recherchen bzgl. des geschichtlichen Hintergrunds wurden die Individuen des Massengrabs von Polizeischülern geborgen und auf sechs große Särge verteilt. Es fand weder eine wissenschaftliche Dokumentation der Auffindesituation statt noch eine detaillierte Katalogisierung der Funde. Dies resultierte beispielsweise in der Aussage der Polizei, dass es sich „um mehr als 60 Individuen“ handelt, ohne dass es Kenntnis von der genauen Anzahl der gefundenen Individuen gab. Die Bergung sowie Verteilung auf sechs Särge geschah darüber hinaus nicht individuenweise, sondern rein willkürlich. Nach einem ökumenischen Gottesdienst am 08.02.2008 wurden die Särge auf dem Hauptfriedhof wieder bestattet. Jedoch gelang es dem Leiter des Naturkundemuseums im Ottoneum, Dr. Kai Füldner, einen der Särge für umfangreichere Untersuchungen zu exhumieren und an die Abteilung Historische Anthropologie der Georg-August-Universität Göttingen zu überführen. Im Rahmen von zwei Diplomarbeiten wurden morphologische (Diplomarbeit von Anna Zipp, Zipp 2010) und molekulargenetische (Diplomarbeit von Philipp v. Grumbkow, Grumbkow 2010) Analysen durchgeführt. Diese hatten die Überprüfung der Hypothese über die Identität der Toten als französische Seuchenopfer zum Ziele. Insgesamt konnten Skelettelemente von mindestens 18 Individuen morphologisch ermittelt werden. Dabei bestätigten sich auf morphologischer Ebene die Ergebnisse der Untersuchungen der Rechtsmediziner aus dem Jahr 2008, dass es sich um Män- 
ner handelt, die überwiegend im adulten Lebensalter verstorben sind. Neben auffällig häufigen periostalen Reaktionen konnten nur wenige individualspezifische $\mathrm{Pa}$ thologien gefunden werden (Zipp 2010). Auf genetischer Ebene ließen sich Hinweise auf eine Infektion mit einem humanpathogenen Bakterium finden (Grumbkow et al. 2011), das auch in anderen Studien mit napoleonischen Truppen in Verbindung gebracht werden konnte (Raoult et al. 2006). Die Herkunft von 15 Individuen konnte aufgrund der geringen Stichprobengröße nur auf Westeuropa eingegrenzt werden (Grumbkow et al. 2012). Aufgrund dieser vielversprechenden Ergebnisse wurden sowohl die Stichprobe der Mainzer Anthropologen an die Abteilung Historische Anthropologie der Georg-AugustUniversität Göttingen überführt als auch die verbliebenen fünf Särge im Mai 2012 exhumiert und standen für die vorliegende

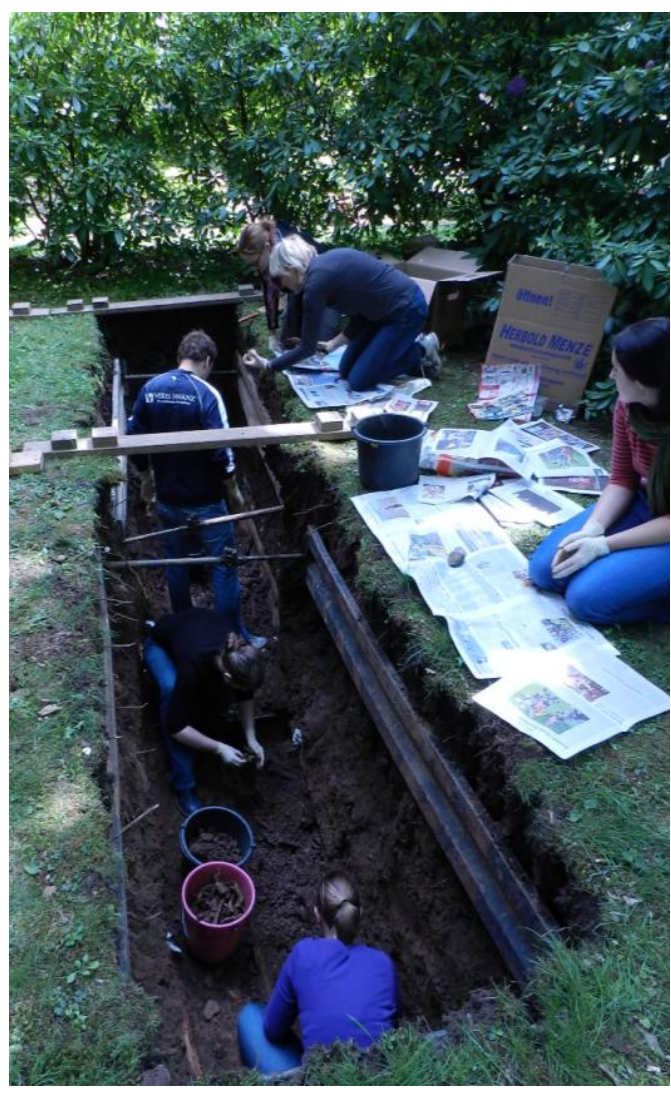

Abbildung 1.2: Exhumierung der Skelettelemente im Mai 2012.

Arbeit zur Verfügung (Abb. 1.2).

Durch umfangreiche Recherchen der Historiker C. Presche und C. von Klobuczynski in den letzten Jahren, u.a. in den Archiven der Städte Marburg und Frankfurt a. Main, konnten schließlich folgende Ereignisse rekonstruiert werden, die im Folgenden wiedergegeben werden (persönliches Gespräch v. Klobuczynski, Stand 2013):

Im Winter 1813/14 gab es im Stadtgebiet drei Hospitäler, in denen Soldaten versorgt worden sind. Dazu gehörte zum einen die Charité an der Leipziger Straße, die mit 450 Betten als Hauptlazarett zunächst für westphälische und französische, ab November 1813 für preußische und russische Soldaten diente. Zum anderen gab es ein Hilfslazarett in der Stadtkaserne an der heutigen Westendstraße, das den russischen und preußischen Offizieren vorbehalten war. Das dritte Lazarett war im sogenannten Modell-Haus (am heutigen Schützenplatz, siehe Abb. 1.3) untergebracht und beherbergte französische Soldaten. Durch Überbelegung der Lazarette kam es im Oktober und November 1813 zum Ausbruch eines Nervenfiebers, welches auch als LazarettFieber oder Typhus bezeichnet wird. Das erste Nervenfieber ist für den 23.10.1813 in der Charité nachgewiesen. Von den 603 westphälischen und französischen Soldaten waren etwa 200 erkrankt. Nach der verlorenen Völkerschlacht wurden die nun kriegsgefangenen erkrankten Soldaten in das Modellhaus-Lazarett verlegt und die Charité für die neuen Verbündeten geräumt. 


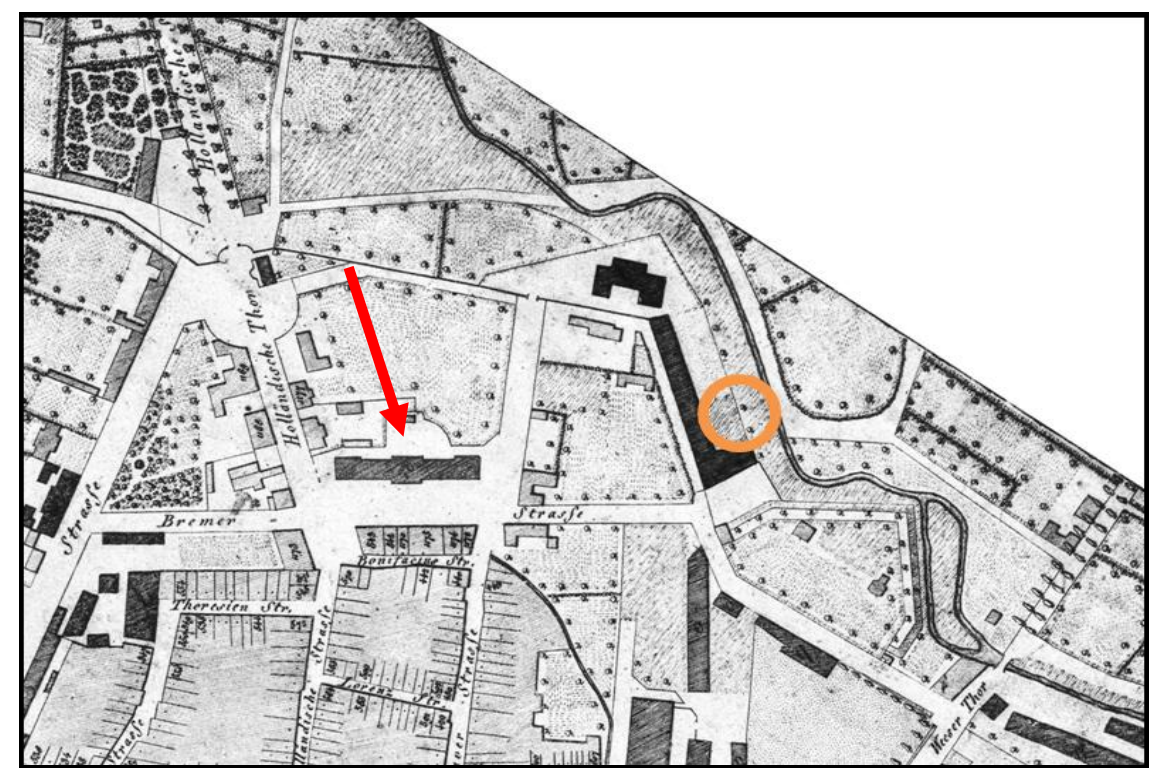

Abbildung 1.3: Karte von 1822 (nach Holtmeyer, Denkmälerinventar 1923, Tafel 16, Ausschnitt). Der orange Kreis markiert den Ort des Massengrabs, zu der Zeit eine unbebaute Fläche hinter einem Stall (L-förmiges Gebäude). Roter Pfeil = Modellhaus, das als Notlazarett diente

$\mathrm{Ab}$ Mitte November wurden weitere kriegsgefangene französische Soldaten aus Paderborn in dem Modellhaus-Lazarett untergebracht, etwas später zusätzliche russische Truppen. Insgesamt war dieses Lazarett mit etwa 600 Soldaten deutlich überbelegt. Anwohner des Lazaretts beschwerten sich beim Kurfürsten über den üblen Geruch und berichteten von ihrem Ekel vor den Kranken. Aufgrund der überaus schlechten hygienischen Bedingungen starben bis Ende November 95 französische Kriegsgefangene sowie ein Chirurg. Sämtliches Pflegepersonal, die Krankenwärter, der Dekan und die übrigen Chirurgen erkrankten ebenfalls. Zwar gibt es keine weiteren Hinweise, dass die Epidemie sich auch auf die allgemeine Bevölkerung übertragen hat, doch die Erinnerungen an dieses Ereignis blieben den Anwohnern präsent:

„Im Jahr 1814 brach in unserer Vaterstadt in einem ungewöhnlich hohen Grad in Folge der Durchmärsche von bedeutenden Truppenmassen ein sehr heftiger bösartiger Typhus aus, welcher viele Einwohner hinwegraffte. Da das damalige Militär-Hospital, die Charité, nicht mehr zur Unterbringung aller Militärkranken ausreichte, so wurde diese Kaserne sofort zu einem Militärlazareth verwendet, und es findet sich kein Gebäude in Cassel, aus welchem so viele Seelen in das Jenseits hinübergegangen sind, als aus diesem Hause; ja man hatte bei der überhand genommenen großen Sterblichkeit, um die Todten nicht die Treppen heruntertragen zu müssen, an der nordöstlichen Seite, dem Hofe zu, eine sogenannte Rutschbahn angebracht, auf welcher die Leichname in die daruntergefahrenen Kastenwagen, ohne die geringste Bekleidung, gleich weiter zur Ruhestätte befördert wurden. “ 
Obwohl die Zeitangabe nicht genau mit anderen Quellen übereinstimmt und das Ausmaß der Epidemie übertrieben dargestellt wird, scheint das Ereignis auch 50 Jahre später noch präsent zu sein. Während des Ausbruchs des Nervenfiebers bemühten sich die Verantwortlichen die Zustände im Lazarett schnellstmöglich zu verbessern, was in den folgenden Wochen auch gelang. Im Januar 1814 wurden nur noch 300 Kranke im Lazarett aufgeführt, wobei auch 130 Verwundete dazugezählt wurden. Zwar sind weiter keine Todesfälle bekannt, es ist allerdings anzunehmen, dass bis zum endgültigen Abklingen des Fiebers weitere Erkrankte verstorben sind. Erst am 01.07.1814 wurde das Modellhaus-Lazarett aufgrund des geringen Bedarfs aufgelöst.

Historische Quellen belegen dabei die tatsächliche französische Herkunft der Soldaten: Napoleon traute den einheimischen Westphalen nicht und riet seinem Bruder Jérôme, treue französische Truppen zum Schutz anzufordern. So ist belegt, dass gegen Ende 1813 elsässische und luxemburgische Truppen nach Kassel beordert worden sind (persönliche Mitteilung v. Klobuczynski), die nach dem Umsturz als Kriegsgefangene festgehalten wurden.

Die Theorie über die Identität der Toten als französische Seuchenopfer ist zwar weitgehend plausibel, Beweise dafür lagen aber nicht vor. So könnten auch verstorbene russische Soldaten bestattet worden sein, ebenso wie andere Kriegsgefangene. Auch die postulierte Epidemie erscheint aufgrund der fehlenden Verletzungsspuren die plausibelste Erklärung, bleibt aber nur eine mögliche Hypothese. 


\title{
1.2. Das Leben in der napoleonischen Armee
}

\begin{abstract}
„Die folgenden Tage führten uns in bitteren Märschen durch eisige Gewässer und über die steilen Höhen von Guyangos, und am 18. November erreichten unsere Truppen endlich Reynosa am Ebro. Meine Kräfte waren erschöpft und ich kämpfte oft einen bösen Streit in mir gegen die Versuchung, diese unerträglich gewordenen Leiden durch eine Kugel vor den Kopf zu enden. “
\end{abstract}

(v. Holzing (1937), S.46)

Auch wenn die Identität der Individuen grundsätzlich unsicher ist, deuten die durchgeführten Analysen auf einen militärischen Kontext im frühen 19. Jahrhundert hin. Diese Periode ist geprägt durch die napoleonischen Kriege, welche über einen Zeitraum von etwa 15 Jahren in ganz Europa geführt wurden und erst mit Napoleons endgültigem Machtverlust 1815 endeten. Im Laufe dieser Kriege kam es zu enormen Truppenbewegungen, alleine im Russlandfeldzug 1812 umfasste die Grande Armée über 600.000 Männer (Rothenberg 2000). Das Leben der einfachen Soldaten ist durch überlieferte Berichte nachvollziehbar, welche ein beschwerliches, entbehrungsreiches und gefährliches Leben skizzieren. Die folgenden Schilderungen stützen sich, wenn nicht anders angegeben, auf die von Mayer (2008) rekonstruierten Informationen, die auf Originalberichten von Soldaten basieren:

Grundsätzlich wurden die napoleonischen Kriege wie andere Kriege der vorhergehende Jahrhunderte geführt. Neu allerdings war, dass durch die Einsetzung einer allgemeinen Wehrpflicht die Soldaten nicht Söldner waren, sondern zum Großteil normale Bürger. Durch die Möglichkeit, einen Stellvertreter für sich selbst in der Armee schicken, wurde diese Pflicht jedoch häufig auf ärmere Bevölkerungsschichten weitergeben und wohlhabende Bürger waren deutlich unterrepräsentiert. Im Allgemeinen waren Männer ab dem 20. Lebensjahr wehrpflichtig, das Hauptkontingent stellten Männer zwischen 18 und 30 Jahren (Mayer 2008). Nicht zu vergessen ist dabei, dass auch Frauen ein fester Bestandteil der Armee waren und sich um die Grundversorgung der Soldaten kümmerten. Anders als zu früheren Zeiten, in denen die Trosse, die den Soldaten folgten, größere Dimensionen wie die eigentliche Armee annehmen konnten, war die Anzahl der Frauen unter Napoleon genau festgelegt: Um die Beweglichkeit der Truppen nicht zu gefährden, waren seit 1793 pro Bataillon (500 700 Mann) nur vier Wäscherinnen und zwei Marketenderinnen erlaubt (Mayer 2008). Die Soldaten erhielten meist nur eine rudimentäre Ausbildung, bevor sie auf die Regimenter verteilt wurde, da oft die Zeit für eine lange Ausbildung fehlte.

Napoleons Siege basierten zum Teil durch die große Mobilität der Truppen. Ständiges Marschieren, teilweise auch nachts, gehörte daher zum Alltag. Die Truppen gehörten damit zu schnellsten der Epoche, die bis zu 160 Kilometer in 36 Stunden zu- 
rücklegen konnte (Blaze, ohne Jahresangabe). Dabei wurde die gesamte Ausrüstung eines (einfachen) Soldaten in Tornistern auf dem Rücken transportiert, die dadurch entsprechend schwer waren; historische Quellen geben das durchschnittliche Gewicht eines Tornisters mit 33 Pfund 12 Unzen (etwa 17kg) an (von Segur 1835). In vielen Überlieferungen wird vor allem das Schuhwerk kritisiert, das trotz bekannter Belastung besonders minderwertig gewesen sein muss (Röhrig 1906).

Die Lebensmittelversorgung war in den meisten Zeiten mangelhaft. Zwar wurde, gerade bei großen Truppenbewegungen, versucht, durch Lebensmitteltransporte die Grundversorgung zu gewährleisten, die Schnelligkeit der Truppen ließ die Versorgung aber häufig zusammenbrechen. Meistens wurde das gegessen, was vor Ort zu finden war. Während der Märsche blieb außerdem kaum Zeit für Hygiene (Gill 1998), was häufig zu immer wiederkehrenden Krankheiten führte.

Wenn es um die medizinische Versorgung geht, muss bedacht werden, dass die Lazarette in der Wahrnehmung der Soldaten als Orte des Schreckens gesehen wurde, denn kaum einer kehrte geheilt aus ihnen zurück. Dies entspricht zwar der Realität, die Versorgung im Heer war jedoch seiner Zeit entsprechend auf einem guten Stand: In den kaiserlich-französischen Heeren standen jedem Bataillon ein Arzt (Chirurgien major) sowie meist ein bis zwei Assistenten (Chirurgien aides) zur Verfügung. Ab 1809 wurde jede Division zusätzlich mit einer Kompanie Krankenträger (compagnies de service de l'ambulance) ausgestattet, welche die Verwundeten zum nächsten Feldlazarett brachten (Sicard 1834). Trotz der Versorgung der Soldaten war die Sterblichkeit in den Lazaretten durch die schlechten hygienischen Bedingungen und mangelnde Kenntnisse sehr hoch, so dass häufig mehr Soldaten im Lazarett starben als in Kriegshandlungen (Werner 1885). Von den 17000 Männern, die zwischen 1812 und 1814 in britischen Hospitälern auf der iberischen Halbinsel starben, erlagen nur 2700 ihre Verletzungen aus der Schlacht, aber 11300 der Bakterienruhr oder dem Typhus bzw. einem ,anhaltendem Fieber“ (Mayer 2008).

Das Leben in der Armee war somit alles andere als einfach und es gibt zahllose Berichte, die Selbstverstümmelungen zum Zwecke des Ausscheidens der Armee oder gar Selbstmord (vgl. Zitat auf Seite 6) von Soldaten beschreiben. Ständige körperliche Belastung bis an die Grenzen, schlechte Ernährung und mangelnde Hygiene waren die ständigen Begleiter der Soldaten und führten in der Konsequenz zu mehr Todesopfern als die eigentlichen Kampfhandlungen (Mayer 2008). 


\subsection{Das Skelett als Informationsquelle}

Das folgende Kapitel gibt eine Übersicht über die wichtigsten Fragestellungen bei einer anthropologischen Skelettdiagnose und zeigt die daraus resultierenden Möglichkeiten der Interpretation von Bestattungen sowie verschiedene Herangehensweisen der Bearbeitung auf. Im Fokus stehen dabei solche Untersuchungen, die helfen, die Identität der Individuen aus dem Massengrab, deren Lebens- und Todesumstände näher zu charakterisieren.

Das Skelett stellt die häufigste Überlieferungsform eines Körpers nach dessen Tod dar. Neben der Deutung von Beifunden ist die Skelettdiagnostik somit der wichtigste Zugang zur Interpretation von historischen Individuen und Populationen (Herrmann et al. 1990). Die erhobenen Daten sind die Grundlage der Biologie einer Bevölkerung, dienen darüber hinaus aber häufig auch für Ableitungen von sozialen und kulturellen Charakteristika. Als Beispiel seien hierfür die Traufkinder von Aegerten genannt (Lassen et al. 2000): Bei der Untersuchung von Kleinkinderbestattungen rund um eine Kirche im schweizerischen Aegerten wurde zunächst eine Mehrheit an weiblichen Individuen identifiziert, was als mögliche intentionale Kindstötung von Mädchen interpretiert wurde. Bei einer folgenden genetischen Geschlechtsbestimmung wurden die Ergebnisse revidiert, da ein leichter Überschuss männlicher Individuen festgestellt wurde. Wenn möglich, sollten mehrere verschiedene Vorgehensweisen für die Bearbeitung einer Fragestellung angewendet werden, um etwaige Unsicherheiten zu minimieren.

\section{Geschlechtsdiagnose}

Eine der ersten Fragen nach Auffinden eines Skeletts ist die nach dem Geschlecht der Individuen. Die Ermittlung der Geschlechterrelation kann dabei helfen, die gefundene Bestattungen zu kontextualisieren. So sollten bei Bestattungen einer normalen Bevölkerung beide Geschlechter in etwa gleichen Teilen vorliegen. Ausnahmen davon finden sich z.B. in klösterlichen Zusammenhängen, bei denen die Geschlechter getrennt voneinander beigesetzt wurden, oder militärischen Kontexten, bei denen der Anteil von männlichen Individuen deutlich überwiegt. Die folgenden Kriterien werden alle für eine qualitative Diagnose herangezogen; osteometrische Ansätze, wie etwa der Index ischio pubico (Novotny 1972), werden in dieser Arbeit nicht angewendet.

Die sichersten Unterscheidungskriterien zwischen Männern und Frauen sind am Becken zu finden. Das Becken einer Frau muss für eine Geburt geeignet sein, somit haben Frauen in der Regel breitere und flachere Becken. Die zu beurteilenden Charakteristika sind folglich im Vergleich weiter bzw. ausladender als bei männlichen Individuen. Dabei muss jedoch berücksichtigt werden, dass diese Merkmale qualitativ betrachtet werden und sich einzelne Merkmale in bestimmten Populationen eventuell nicht für eine Differenzierung eignen. 
Bei einem isolierten Os coxa sind die wichtigsten Kriterien die Weite der Incisura ischiadica major, die Ausprägung des Arc composé sowie die Größe des Angulus' subpubicus. Auch ein tiefer Sulcus praeauricularis kann ein Kriterium für ein weibliches Individuum sein, wobei ein flacher bzw. fehlender Sulcus keinen Hinweis für einen Mann darstellt. Weitere Merkmale können die Form des Foramen obturatums, die Größe des Corpus ischiadicus sowie des Tuber ischiadicum sein. Liegen beide Ossa coxae sowie das Sacrum vor, können zusätzlich der Gesamtaspekt des Beckens sowie der Beckeneingang beurteilt werden (vgl. Abb. 1.4).

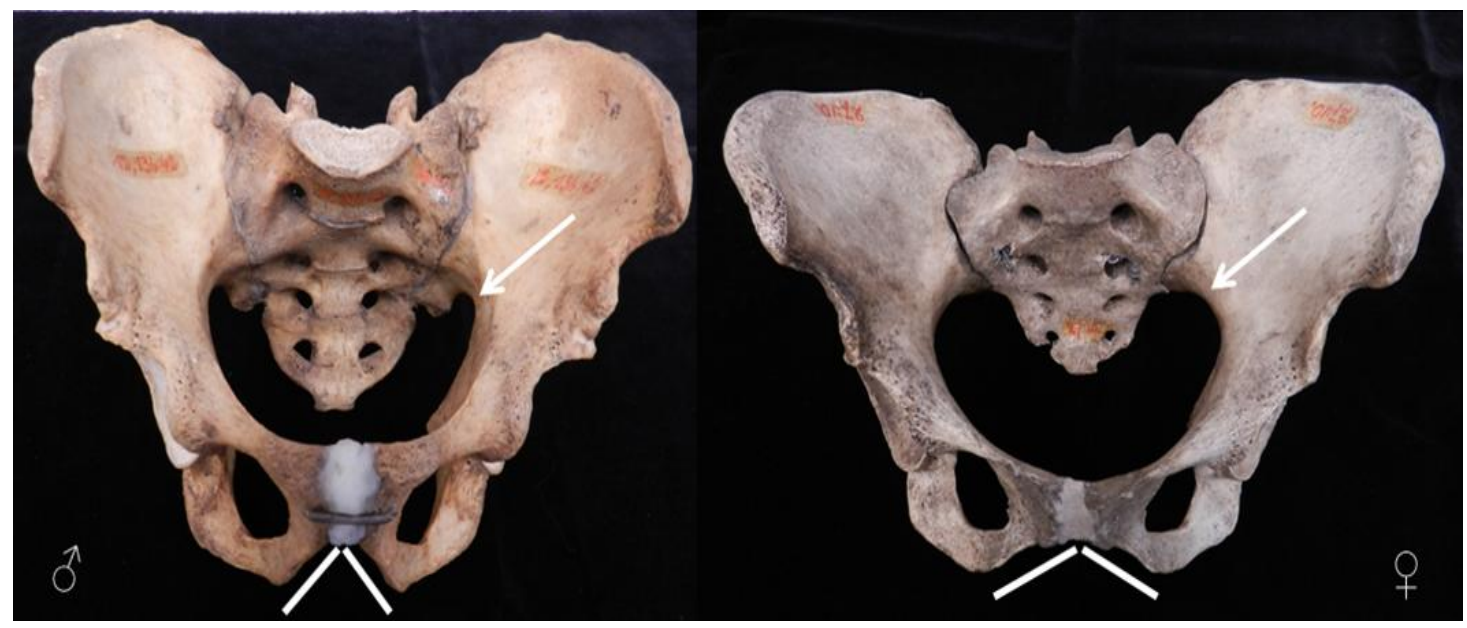

Abbildung 1.4: Männliches (links) und weibliches Becken im Vergleich. Es zeigt sich bei Männern eine enge Incisura ischiadica major (Pfeil) und ein enger Angulus subpubicus (weiße Striche) sowie ein deutlicher Unterschied im Beckeneingang.

Weitere geschlechtsdimorphe Merkmale finden sich am Schädel, deren Trennschärfe jedoch stärker zwischen den Populationen schwanken kann. Generell gilt hier, dass kräftigere Ausprägungen als Hinweis für ein männliches Individuum ausgelegt werden. Dabei sollte jedoch die jeweilige Herkunftspopulation sowie, wenn möglich, der jeweilige soziale Status bekannt sein. So können Unterscheidungsmerkmale, die sich für nord- und mitteleuropäische Populationen als zuverlässig erwiesen haben, in südeuropäischen Bevölkerungen keine sichere Geschlechtsbestimmung ermöglichen, da sie im Gegensatz zur Beckenmorphologie keinem eindeutigen evolutionären Druck unterliegen. Außerdem spielen hier - anders als beim Becken - auch individuelle Belastungen eine Rolle. So ist beispielsweise das Oberflächenrelief des Planum nuchale abhängig von der Beanspruchung der Nackenmuskulatur. In Populationen, die diese stark belasten, etwa durch häufiges gebeugtes Arbeiten, besitzen auch Frauen ein sehr reliefreiches Planum, welches folglich nicht als geschlechtsdifferenzierendes Merkmal hinzugezogen werden sollte (vgl. auch Herrmann et al. 1990).

Weitere Kriterien können z.B. die Ausprägung der Glabella und der Arci superciliari, die Scharfkantigkeit der Margo orbitalis sowie die Morphologie des Planum nuchale sein. An der Mandibula sprechen ein kräftiges Mentum und ein kräftiges, eher rechtwinliges Gonion für ein männliches Individuum. Als tendenziell schwächere Kriterien sind die Formen der Orbitae und die Ausprägung des Arcus zygomaticus zu 
betrachten (Grupe et al. 2005, Herrmann et al. 1990). Zu einer vollständigen Diagnose können im Weiteren auch noch die allgemeine Robustizität des Individuums sowie eventuelle weitere Funde (z.B. Beigaben) hinzugezogen werden. Während bei Kindern und Jugendlichen die auf morphologischen Kriterien beruhende Geschlechtsdiagnose aufgrund der noch unausgeprägten Charakteristika relativ große Fehlerraten besitzt, ist die Diagnose bei erwachsenen Individuen sehr zuverlässig. Die Bestimmungssicherheit kann je nach untersuchter Skelettserie und des Erhaltungszustandes bis zu 96\% betragen (Grupe et al. 2005).

Die morphologische Diagnostik wird in den letzten Jahren zunehmend durch die Analyse von DNA aus den Skeletten gestützt. Die genetische Diagnose wird dabei in der Regel mittels der Untersuchung eines Abschnitts des Amelogenin-Gens durchgeführt. Das Gen ist auf den Geschlechtschromosomen an Xp22.1-Xp22.3 und Yp11.2 lokalisiert (Nakahori et al. 1991) und weist einen Unterschied zwischen der X- und der Y-chromosomalen Variante auf: Im Intron 1 der X-Variante findet sich gegenüber der Y-Variante eine 6bp-Deletion (AAAGTG), was durch eine Polymerasekettenreaktion (PCR) und anschließender Gelelektrophorese leicht dargestellt werden kann. Die Anwesenheit von zwei verschieden langen Fragmenten weist auf die Anwesenheit eines X- und Y-Chromosoms und somit auf einen Mann hin, während ein (im Vergleich kürzeres) Fragment auf die ausschließliche Anwesenheit von XChromosomen deutet und entsprechend eine Frau identifiziert.

Die Sicherheit bei einer Geschlechtsbestimmung mit Hilfe des Amelogenins ist sehr hoch, nur in wenigen Fällen gab es durch Rekombinationsereignisse falsche Ergebnisse. Dabei scheint die Ausgangspopulation eine Rolle zu spielen: Während bei Frances und Kollegen gerade einmal zwei von 1224 spanischen Probanden falsch typisiert worden sind, lag bei Thangaraj und Kollegen die Rate bei fünf von 270 indischen Männern (Frances et al. 2007, Thangaraj et al. 2002). Weiterhin ist bei stark degradierter DNA die Gefahr eines allelic dropout, also das Ausbleiben eines Signals aufgrund zu niedriger intakter target-DNA Anzahl, und folglich einer Fehlinterpretation sehr hoch. Um die Geschlechtsdiagnose gerade in fraglichen Fällen weiter abzusichern, bietet es sich an, weitere zusätzliche geschlechtsdeteminierende Marker simultan mit zu untersuchen, etwa gonosomale STR-Systeme (vgl. Schmidt et al. 2003, Dicks 2012). In den standardmäßig verwendeten Multiplex-Kits für autosomale STR-Systeme ist in der Regel der Amelogenin-Marker mit enthalten.

\section{$\underline{\text { Altersdiagnose }}$}

Neben dem Geschlecht ist das Sterbealter des Individuums ein wichtiges Basisdatum. Durch Kenntnisse der Altersverteilung kann dabei Rückschluss auf die Lebenserwartung und somit auf die generellen Lebensbedingungen zulassen. So findet sich bei historischen Bevölkerungen oftmals eine hohe Kindersterblichkeit, während juvenile Individuen vergleichsweise selten sind. Es folgt eine erhöhte Sterblichkeit bei adulten Frauen, was auf Komplikationen während der Schwangerschaft zurückgeführt wird (Herrmann et al. 1990). Abweichungen von dieser Altersverteilung finden sich 
in Sonderbestattungen, etwa den genannten klösterlichen oder militärischen Kontexten, in denen andere Altersgruppen dominieren.

Bei der Diagnose muss bedacht werden, dass alle erfassten Kriterien nur das biologische Alter eines Individuums erfassen und nicht das chronologische Alter. Bei entsprechend starker Belastung können diese mitunter stark voneinander abweichen. Ohne weitere Quellen, wie etwa Kirchenbücher, bleibt das tatsächliche chronologische Alter jedoch unbekannt.

Während bei subadulten Individuen aufgrund des Zahnstatus' und des Epiphysenanschlusses das Alter bis auf wenige Jahre sehr genau bestimmt werden kann (siehe Abb. 1.5), ist nach Beendigung des regelhaften Knochenumbaus im Erwachsenenalter die morphologische Altersdiagnose nur über degenerative Prozesse mit entsprechend gröBeren Altersspannen zu bestimmen. Diese Altersklassen werden als Adultas (20 - 40 Jahre), Maturitas (40 - 60 Jahre) und Senilis (>60 Jahre) definiert. In den ersten beiden Altersklassen wird in der Regel noch in Sieben-Jahres-Kategorien früh-, mittel- und spät- unterteilt; in einigen Publikationen wird auch das Senilis in eine frühe $(60-$ ca. 80 Jahre) und späte Phase (>80 Jahre) geteilt. Da alle degenerativen Veränderungen zwar regelhaft erfolgen, das zeitliche Auftreten zwischen verschiedenen Individuen je-

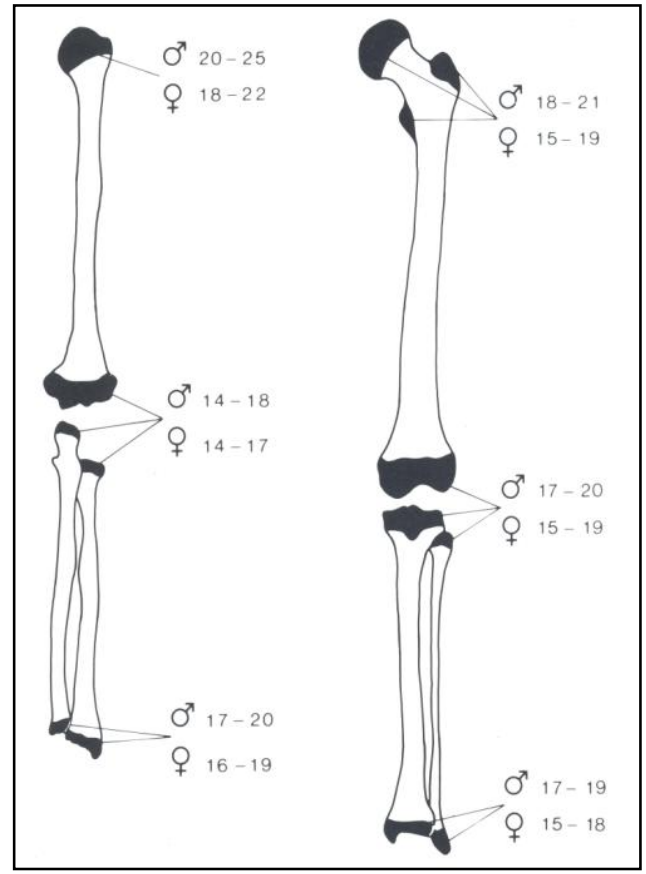

Abbildung 1.5: Schema des Epiphysenanschlusses der Langknochen. Die Zahlen geben das ungefähre Alter des Anschlusses nach Geschlecht getrennt an (nach Herrmann et al. 1990, S. 58). doch stark variiert, ist eine genauere Bestimmung auf morphologischer Basis in den meisten Fällen nicht möglich (Grupe et al. 2005, Herrmann et al. 1990).

Für eine morphologische Altersdiagnose stehen verschiedene Merkmale zur Verfügung, die nur in Kombination eine gute Abschätzung des Sterbealters erlauben. Die Veränderungen der Schambeinsymphyse ist dabei das am häufigsten herangezogene Kriterium (siehe Abb. 1.6). Auch der Rückzug der Spongiosa aus der proximalen Femur- und Humerusepiphyse sowie der Verschluss der Schädelnähte unterliegen regelhaften Abläufen (Herrmann et al. 1990). Weitere publizierte Merkmale sind z.B. die Veränderungen der Facies auricularis sowie der Abrasionsgrad des Zahnschmelzes. 


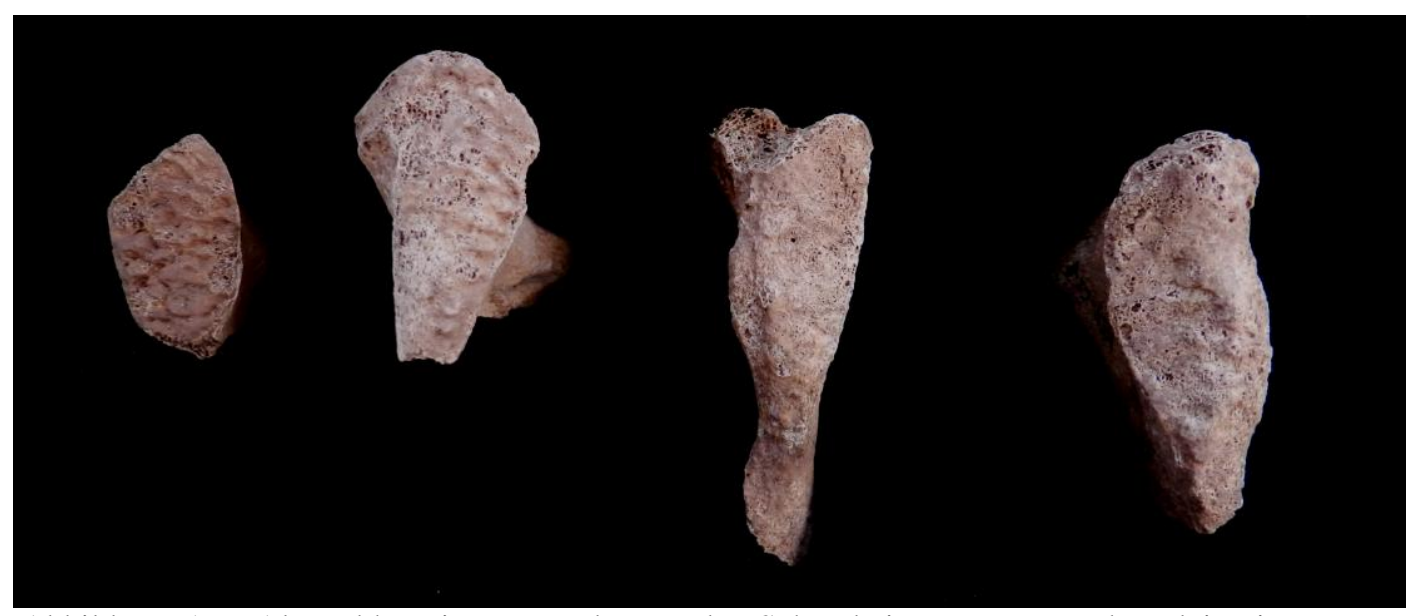

Abbildung 1.6: Altersabhängige Veränderung der Schambeinsympyse. Während im jungen Erwachsenenalter eine deutliche Querstreifung zu erkennen ist (links), nimmt diese im Laufe des Lebens ab, bis keine Streifung mehr sichtbar ist (rechts).

All diesen Charakteristika ist gemeinsam, dass der jeweilige Knochenabschnitt aufgrund seiner Beschaffenheit in eine von mehreren Kategorien eingeteilt wird, die einem alterstypischen Zustand entsprechen sollen. So etwa verliert die Schambeinsymphyse im Laufe des Lebens zunächst das querstreifige Relief, wird glatt und sinkt letztendlich konkav ein, während es zu einer Randleistenbildung kommen kann. Durch den Vergleich der zu untersuchenden Symphyse mit den unterschiedlichen Kategorien wird so rückführend ein biologisches Alter ermittelt. Dabei stellen die Kategorien einen ermittelten Durchschnitt für die jeweilige Altersklasse dar, der aus Reihenuntersuchungen altersbekannter Individuen abgeleitet worden ist (z.B. Acsadi und Nemeskeri 1970).

Eine weitere Untersuchungsmöglichkeit für die Altersbestimmung besteht in der Betrachtung der Binnenstruktur der Langknochenkompakta (für eine Übersicht z.B. Uytterschaut 1993): Üblicherweise wird für diese histologische Altersdiagnose die Femurkompakta untersucht, wobei als Alternative auch Humeruskompakta geeignet ist. Für eine Beurteilung der Mikrostrukturen werden Knochenquerschnitte angefer-

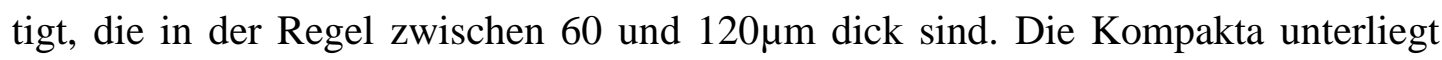
regelhaften Veränderungen, die bei guter Erhaltung und wenig mikrobiellem Befall eine entsprechend genaue Diagnose ermöglicht. Im Laufe des Lebens nimmt innerhalb der Kompakta beispielsweise die von Lamellenknochen eingenommene Fläche $\mathrm{ab}$ und wird durch sog. Osteonenknochen ersetzt; ab dem Maturitas findet sich gar kein Lamellenknochen mehr. Auch die Größe und Form der Haverschen Kanäle bzw. Osteone verändert sich: Während im Adultas die Form und Größe noch sehr unterschiedlich ist, sind sie im Maturitas sehr regelmäßig geformt und deutlich kleiner als in jüngeren Stadien. Im Senilis überwiegen erneut unregelmäßige Formen, während Resorptionslakunen häufiger und größer werden (vgl. Großkopf 2004). Weiter zu beurteilende Mikrostrukturen sind z.B. die Anzahl von Nicht-Haverschen Kanälen und das Vorhandensein der Generallamelle (siehe Abb. 1.7). Neben der rein qualitativen Beurteilung dieser Strukturen gibt es auch verschiedene Ansätze einer quantitativen Methodik, die z.B. das Auszählen bestimmter Strukturen in definierten Flächen 
beinhalten (für einen Überblick z.B. Stout und Gehlert, 1980). Der Vorteil der allgemeinen Reproduzierbarkeit, auch ohne Vergleichsmaterial, wird allerdings durch deutlich höhere Fehlerintervalle ausgeglichen.

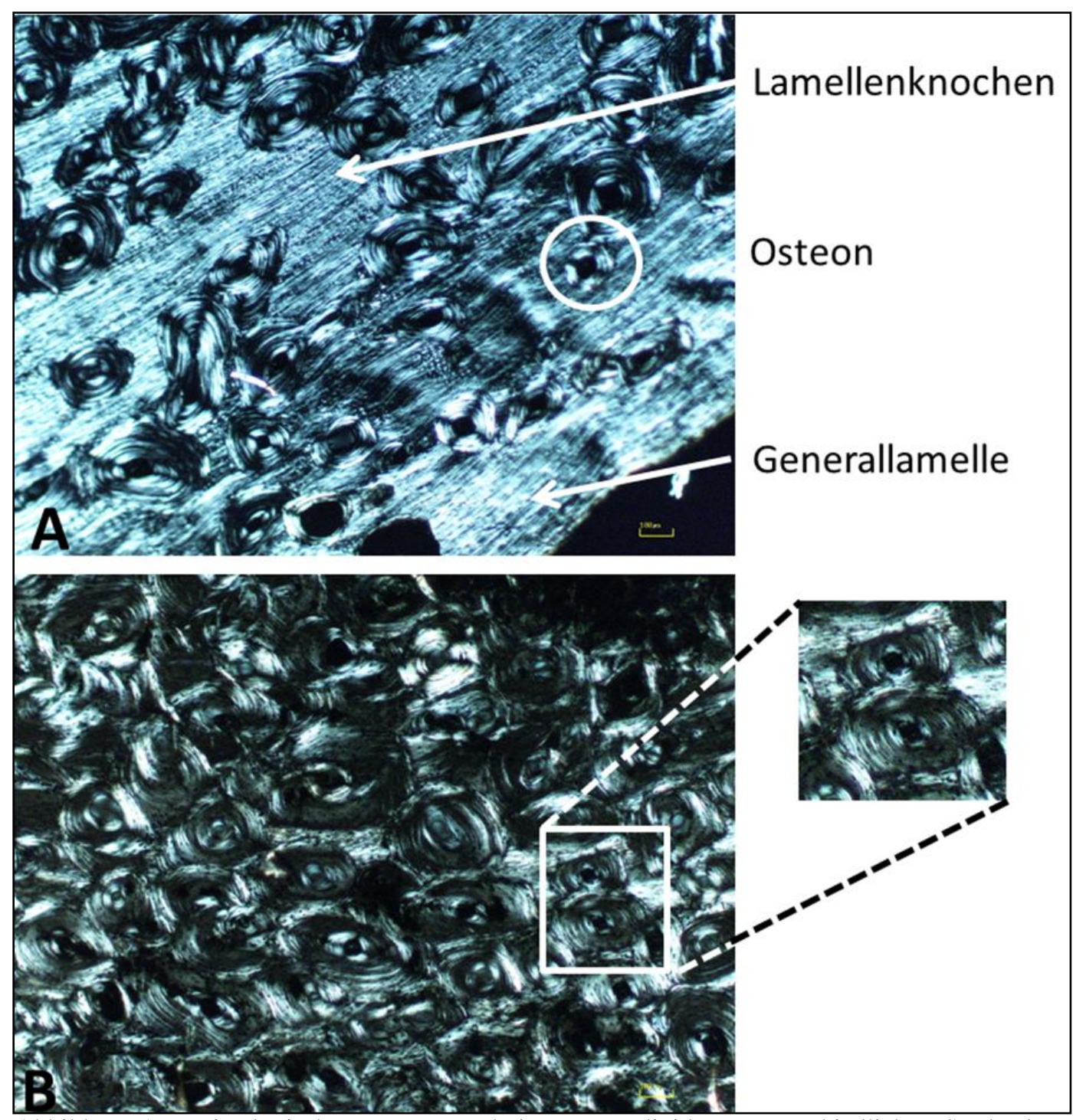

Abbildung 1.7: Histologische Femurquerschnitte von Individuen unterschiedlichen Sterbealters unter 40facher Vergrößerung mit Polfilter. A. Juveniles Individuum: Man erkennt noch viel Lamellenknochen und Generallamelle, aber nur vereinzelte Osteone. B. Mittel- bis Spätadultes Individuum. Im Vergleich sind deutlich mehr Osteone und kaum Lamellenknochen sowie erste Sekundärosteone (vergrößerter Abschnitt) erkennbar. Gelbe Markierung entspricht 100 $\mu \mathrm{m}$. 


\section{$\underline{\text { Körperhöhenrekonstruktion }}$}

Ein weiteres biologisches Datum ist die Körperhöhe eines Individuums. Der Berechnung liegt die Tatsache zugrunde, dass die Größe der Langknochen direkt mit der Körperhöhe korreliert. Dies gilt besonders für die Langknochen der unteren Extremität, während die Maße der oberen Extremität größere Varianzen aufweisen. Anhand von Individuen mit bekannter Höhe wurden Regressionsfunktionen für eine Vielzahl von Maßen ermittelt. Dabei ist zu bedenken, dass die Körperhöhe nicht nur im Laufe des Lebens, sondern auch im Laufe eines Tages im Zentimeterbereich schwankt. Die berechnete Körperhöhe kann daher nur eine ungefähre Näherung sein (vgl. Rösing 1988).

Die Körperhöhe ist im Allgemeinen zunächst von der individuellen Genausstattung abhängig, d.h. große Eltern haben im Vergleich auch größere Kinder. Ein weiterer Faktor findet sich aber auch in den Lebensumständen, wie etwa der Ernährung und Hygiene. Daher kam es in Europa seit Mitte des 19. Jahrhunderts aufgrund der allgemein besseren Lebensbedingungen von Generation zu Generation zu einer stetigen Zunahme der mittleren Körperhöhe, der Trend der so genannten säkularen Akzeleration (z.B. Zimmer 1989). Durch die Veränderung der Proportionen sind daher an Rezentpopulationen ermittelte Funktionen nur bedingt für eine historische Population geeignet. Im Weiteren müssen unterschiedliche Proportionen zwischen verschiedenen Bevölkerungen berücksichtigt werden, so dass für verschiedene Populationen verschiedene Schätzformeln angewendet werden müssen. Eine räumliche und zeitliche Verortung der Individuen ist daher zwingend notwendig, um verlässliche Aussagen treffen zu können.

Für (prä)-historische Individuen eignen sich die Schätzformeln nach Pearson (1899), da diese auf Daten vor dem Beginn der säkularen Akzeleration beruhen. Die Formeln sind aufgrund der unterschiedlichen Proportionen nach den Geschlechtern getrennt. Bei nicht erwachsenen Individuen kann auf ähnliche Schätzformeln zurückgegriffen werden (z.B. Telkkä et al. 1962), wobei auch nach den Geschlechtern getrennt wird und in der Regel die größte Länge der Langknochen ohne Epiphysen gemessen wird. Sollte das Geschlecht nicht bekannt sein, wird der Mittelwert der beiden Formeln verwendet. 


\section{$\underline{\text { Abweichungen von der Regelanatomie }}$}

Neben den genannten Daten lassen sich anhand von pathologischen oder degenerativen Veränderungen weitere Charakteristika ableiten, die zum einen nur das Individuum betreffen können, bei gehäuftem Auftreten zum anderen auch Rückschlüsse auf Belastungen der gesamten Population zulassen. Bei der Beurteilung von Abweichungen der Regelanatomie muss vor allem auf Veränderungen geachtet werden, die nach dem Tod des Individuums entstanden sind und somit nicht als Pathologie angesehen werden dürfen. Dies tritt besonders bei gestörter Fundsituation auf. Im Weiteren kann durch eventuelle Heilungsspuren ein Rückschluss auf eine zeitliche Abfolge gezogen werden; je nach Ausprägung kann eine Mindestdauer zwischen Ereignis und Tod des Individuums abgeleitet werden. Dabei werden die Pathologien in ,intravital“ (=im Leben) und ,perimortal“ (=um den Todeszeitpunkt) unterschieden. Außerdem muss bedacht werden, dass der Knochen nur eingeschränkte Reaktionsmöglichkeiten besitzt, so dass verschiedene Ursachen ähnliche oder gleiche Reaktionen hervorrufen können. Nur wenige Auffälligkeiten am Skelett lassen sich daher auf eine konkrete Ursache zurückführen.

Im Folgenden werden verschiedene Formen dieser Veränderungen beispielhaft erläutert. Darüber hinaus gibt es noch eine Vielzahl an weiteren Krankheitsbildern, die Spuren am Skelett hinterlassen können und somit für Anthropologen sichtbar sind (siehe dazu beispielsweise Ortner 2003). Es soll hier nur auf die Veränderungen eingegangen werden, die sich am wahrscheinlichsten in einem Skelettkollektiv frühneuzeitlicher Soldaten wieder finden.

\section{Traumata / Brüche}

Die offensichtlichsten Veränderungen von der Regelanatomie betreffen Auffälligkeiten, die sich auf traumatische Ereignisse zurückführen lassen. Durch die Folge einer direkten oder indirekten Gewalteinwirkung kommt es zu einem Bruch des Knochens. Im Regelfall bildet sich nach 10-14 Tagen ein knorpeliger Kallus, der nach und nach verknöchert und unter diesem die Heilung des Bruchs stattfindet (Ortner 2003). Der Kallus wird schließlich wieder resorbiert, so dass ein Bruch nur für eine bestimmte Zeit makroskopisch sichtbar sein kann. Durch Dislokation der Fragmente (Abb. 1.8) und entsprechende Verheilung in Fehlstellung kann ein solches Ereignis jedoch dauerhaft erkennbar bleiben, auch wenn dieses schon Jahre vor dem Tod aufgetreten ist (siehe auch Herrmann et al. 1990). Des Weiteren können Brüche auch durch akut einwirkende wiederholte Überlastung zustande kommen, sogenannte Ermüdungsbrüche. Das

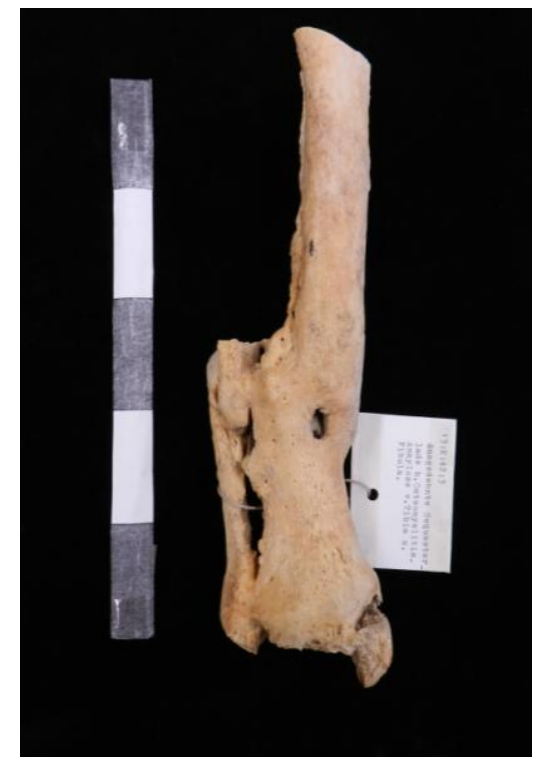

Abbildung 1.8: Dislozierter und entzündeter Bruch einer rechten Tibia und Fibula, Pathologische Sammlung der Historischen Anthropologie. 
häufigste Beispiel sind Brüche der Mittelfußknochen als Folge der Dauerbelastung bei langem Gehen (,Marschfraktur").

Als direkte Folge von Brüchen können auch Komplikationen auftreten, die je nach Schwere ebenfalls am Knochen sichtbar sein können. Dazu gehört zum Beispiel eine Infektion mit Bakterien, die eine Osteomyelitis, eine Entzündung des Knochen(marks), auslösen können (z.B. Zimmer 1982).

\section{Infektionserkrankungen}

Die Infektion mit einem Pathogen stellt eine starke Belastung für das Individuum dar, die sich in extremen Fällen auch auf den Knochen auswirken kann. Dabei ist es abhängig von der Art und Dauer der Infektion, ob diese später am Skelett sichtbar ist. Eine Infektion mit dem Pesterreger Yersinia pestis beispielsweise ist morphologisch am Knochen nicht sichtbar, da der Erreger in der Regel bereits kurz nach der Infektion zum Tode führt und das Skelettsystem nicht angegriffen wird (Herrmann et al. 1990).

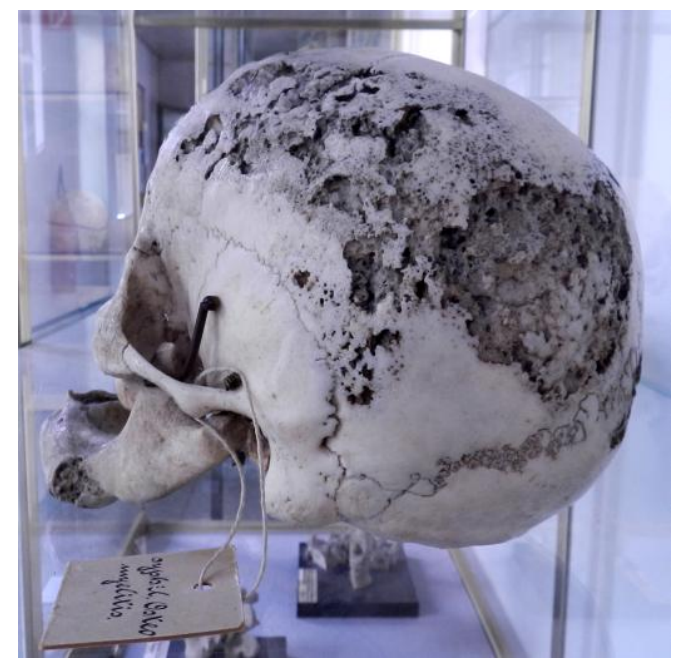

Abbildung 1.9: Großflächige Strukturauslöschungen am Cranium in Folge einer SyphilisInfektion, Pathologische Sammlung der Historischen Anthropologie.

Nur in einigen Fällen können durch typische Veränderungen der Knochen Rückschlüsse auf eine konkrete Krankheit gezogen werden. Dazu zählt z.B. die durch Mycobakterium tuberculosis ausgelöste Tuberkulose, die charakteristische Veränderungen der Wirbelsäule (,Spondylitis tuberculosa“) auslösen kann (z.B. Palfi et al. 2012). Ein weiteres klassisches Beispiel für eine gut dokumentierbare Erkrankung ist eine langjährige Infektion mit Treponema pallidum, dem Erreger der Syphilis. Der Ausdruck des ,Syphilis-Schädels" hat sich als Begriff für die typischen Strukturauslöschungen am Cranium im Endstadium der Krankheit gefestigt (Abb. 1.9, für einen Überblick z.B. Harper et al. 2011).

Darüber hinaus gibt es noch eine Vielzahl von Infektionskrankheiten, die bei entsprechender Wirkdauer Veränderungen am Skelett hervorrufen, deren Auftreten jedoch uncharakteristisch sind. So lassen sich z.B. periostale Reaktionen am Knochen sowohl nach lokalen Verletzungen als auch bei Skorbut, Rachitis oder Syphilis beobachten (Herrmann et al. 1990). Auf morphologischer Ebene ergibt sich somit zwar ein potentieller Hinweis auf eine Erkrankung, diese kann jedoch nicht näher eingegrenzt werden bzw. können andere Ursachen für ihr Auftreten, wie etwa Mangelernährung, nicht ausgeschlossen werden (z.B. Zimmer 1982). 


\section{Erkrankung der Zähne / des Zahnhalteapparats}

Eine der am häufigsten gestellten Diagnosen in historischem Skelettmaterial sind Veränderungen der Zähne bzw. des Zahnhalteapparats. Das Auftreten von Karies und Zahnstein kann dabei auf genetische Prädisposition, mangelnde Hygiene und/oder entsprechende Nahrung zurückgeführt werden (vgl. Ortner 2003), was letztendlich zu Zahnverlust bereits im jüngeren Erwachsenenalter führen kann. Fehlen Zähne und somit die Belastung beim Kauen, reagiert der Körper entsprechend und baut Knochenmaterial am Kiefer ab. In Extremfällen kann der Corpus mandibulae dabei mehr als die Hälfte seiner ursprünglichen Höhe verlieren (vgl. Abb. 1.10). Folglich können sich Strukturen und Winkel ändern, die normalerweise bei einer morphologischen Geschlechtsdiagnostik herangezogen werden, was entsprechend berücksichtigt werden muss.

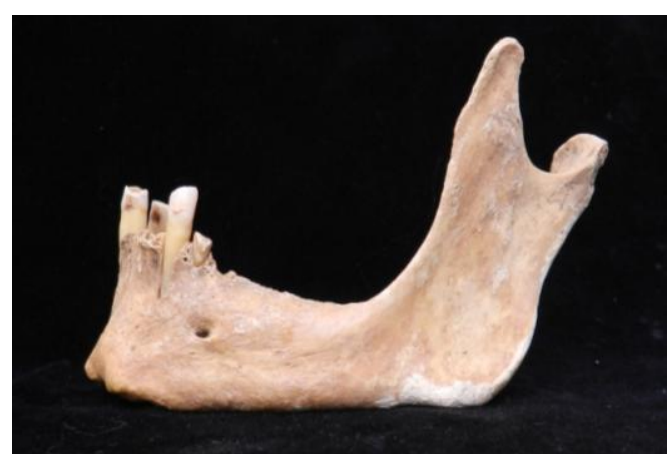

Abbildung 1.10: Kiefer mit intravitalem Zahnverlust der Molaren. Aufgrund der fehlenden Belastung wurde der Corpus stark reduziert.

Als Folge einer Entzündung des Zahnfleischs, die im chronischen Verlauf auf den Kieferknochen übergriff, können am Alveolarsaum Spuren einer Parodontitis sichtbar sein. Als Ursache kommen Vitaminmangel, Zahnsteinbildung und endogene Faktoren in Betracht (Wolf et al. 2004). Eine Zystenbildung kann als Folge entzündlicher Prozesse im Zahnwurzelbereich auftreten. Als apikale Zysten im Oberkieferbereich können diese Zysten lebensbedrohlich sein, da sie beim Durchbrechen in die Kieferhöhle eine Sepsis verursachen können (vgl. Großkopf 2004).

Eine weitere, häufig dokumentiere Auffälligkeit stellen die sogenannten Schmelzhypoplasien dar. Diese treten bei Störungen während der Schmelzbildung im frühen Kindesalter auf und können auf Infektionskrankheiten oder Mangelernährung hindeuten (King et al. 2005).

\section{Degenerative Veränderungen}

Aufgrund von andauernder oder starker Belastung können degenerative Veränderungen (Verschleißerscheinungen) der Knochen beobachtet werden. Dabei gilt, dass in einem gewissen Maße das Auftreten solcher Erscheinungen im fortgeschrittenen Lebensalter als regelhaft zu bewerten ist. Treten solche Veränderung jedoch in einer jüngeren Altersklasse auf bzw. handelt es sich um eine sehr starke Ausprägung, können Fehlbelastungen oder genetische Ursachen eine Rolle spielen (vgl. Ortner 2003).

Die bekannteste degenerative Erkrankung ist die Arthrose, bei der die Knorpelschicht der Gelenke abgebaut wird und in der Folge durch den Druck auf die Gelenkknochen neues Knochengewebe gebildet wird. Oft kommt es dabei zu einer Entzündung der Gelenkoberfläche, einer Arthritis (z.B. Zimmer 1982). 


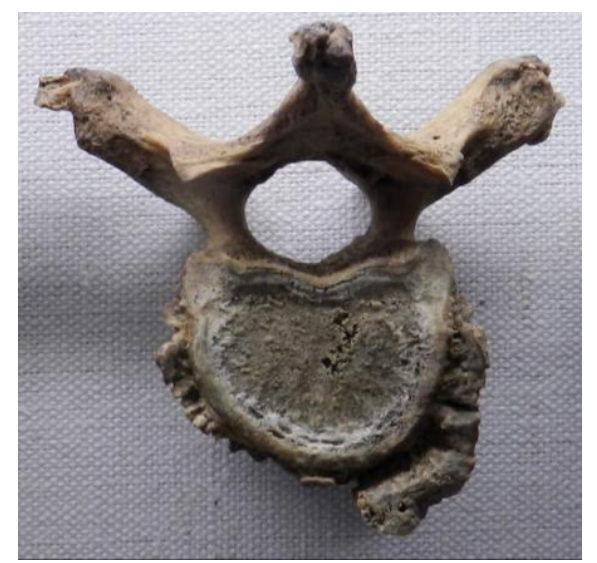

Abbildung 1.11: Osteophytenbildung an einem Brustwirbel. Pathologische Sammlung der Historischen Anthropologie.
Die häufigste degenerative Veränderung des postcranialen Skeletts ist die Spondylose (Spondylosis deformans), welche die Veränderungen an den Wirbelkörpern bezeichnet. Durch ständige Belastung kommt es zum Verschleiß der Bandscheiben, welche der Körper durch Ausbildung neuer, knöcherner Strukturen zu kompensieren versucht. Dabei sind vor allem die unteren Halswirbel und der Bereich der Lendenwirbel betroffen, da diese der größten Belastung ausgesetzt sind. Im fortgeschrittenen Stadium können diese Knochenneubildungen (Osteophyten oder Spondylophyten, Abb. 1.11) Überbrückungen zwischen Wirbeln bilden (z.B. Zimmer 1982).

\section{Hinweise auf Mangelernährung / physischen Stress}

Als direkte Folge einer Blutarmut (Anämie), die z.B. in Folge eines Eisenmangels auftritt, kann die Deckknochenschicht im Dach der Augenhöhle abgebaut werden, was als Cribra orbitalia bezeichnet wird (Abb. 1.12). Diese Abbauprozesse können allerdings auch entzündlich bedingt sein (Carli-Thiele 1996, Wapler et al. 2004).

Eine unspezifische Diagnose stellt die so genannte Periostitis (periostale Reaktion) dar. Die Entzündung der Knochenhaut führt $\mathrm{zu}$ einer streifigen Auflagerung auf dem Knochen und kann prinzipiell jeden Knochen betreffen. Ursa-

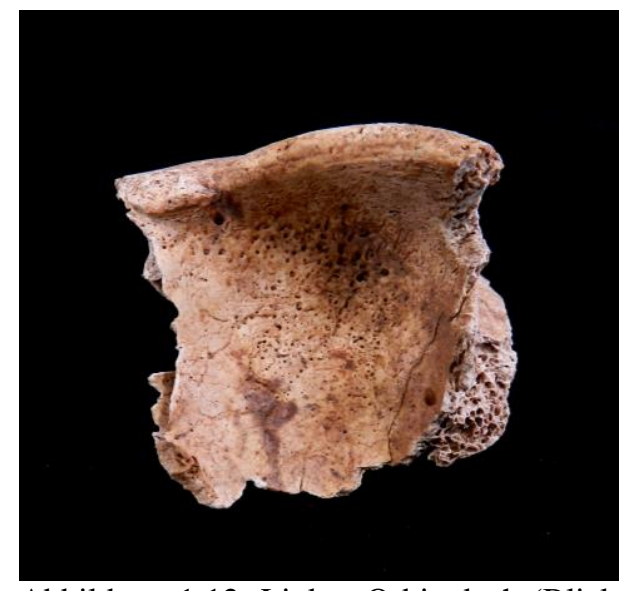

Abbildung 1.12: Linkes Orbitadach (Blick nach superior) mit Cribra orbitalia (punktförmige Strukturauslöschungen. chen können Mangelernährung, physischer Stress bzw. Dauerbelastung, entzündliche oder infektiöse Prozesse sowie neoplastische Veränderungen (etwa bei Tumoren) sein (Adler 1983). 
Populationsgenetik: Besiedlungsgeschichte und geographische Herkunft

\section{$\underline{\ddot{U} \text { berblick }}$}

Ein Teilaspekt vieler anthropologischer und archäologischer Fragestellungen behandelt Populationsdynamiken, Migration und Besiedlungsereignisse. Für die Fragen nach der Herkunft der Menschheit und der initialen Besiedlung der Kontinente wurden auf Basis molekulargenetischer Analysen zufrieden stellende Hypothesen entwickelt (z.B. Sykes 1999, Lell und Wallace 2000, Rebala et al. 2007). Hierbei stellten die genetischen Ergebnisse oftmals bis dahin verbreitete Annahmen in Frage, wie im Falle der Besiedlungsgeschichte Portugals (Pereira et al. 2000). Jüngste Forschungsergebnisse rekonstruieren die Besiedlungsgeschichte auch in regionalen Maßstäben mit Hilfe von genetischen Informationen (z.B. Gaiber et al. 2010, Ambrosio et al. 2010, Grugni et al. 2012, Regueiro et al. 2012). Die Daten, welche die Grundlage für die Formulierung der Besiedlungsszenarien bilden, setzen sich dabei aus der Rekonstruktion von väterlichen und mütterlichen Familienlinien zusammen (z.B. Garrigan und Hammer 2006). Hierfür nutzt man die Eigenschaft der uniparentalen Vererbung zweier haploider DNA-Abschnitte: Für die Analysen der väterlichen Linien werden Y-chromosomale Sequenzen untersucht, welche nur von Vätern auf ihre Söhne übertragen werden. Die mütterlichen Linien können mit Hilfe mitochondrialer DNA (mtDNA) analysiert werden, welche nur von Müttern an alle ihre Kinder weitergegeben wird. Innerhalb der Y-chromosomalen und mitochondrialen DNA gibt es selektionsneutrale und daher hochpolymorphe Marker, die aufgrund der fehlenden Rekombination nur durch Mutation verändert werden. Wegen der geringen Mutationsraten (Kayser et al. 2000) teilen in der Regel alle Familienmitglieder dieselben Polymorphismen (den sog. Haplotypen), während zwei nicht verwandte Individuen unterschiedliche Haplotypen aufweisen. Mehrere Haplotypen, die gemeinsame Polymorphismen aufweisen und einander phylogenetisch nahe stehen, können dabei zu Haplogruppen zusammengefasst werden. Aufgrund der unterschiedlichen Verteilung der Haplogruppen über die Kontinente können Aussagen zu möglichen Besiedlungsszenarien getroffen werden (z.B. Roewer et al. 2005, Deguilloux et al. 2011, Nikitin et al. 2012).

Hochpolymorphe, autosomale Marker, wie etwa short tandem repeats (= Mikrosatelliten, STRs [vgl. Kap. 1.4.]), zeigen hingegen aufgrund von Rekombinationsereignissen - wenn überhaupt - nur im kontinentalen Vergleich Frequenzunterschiede, die auch nur in großen Stichproben sichtbar werden (z.B. Egyed et al. 2006a, Czarny et al. 2005, Gaibar et al. 2010). Weiterhin können lange Zeit isoliert lebende Populationen signifikante Auffälligkeiten in einigen Systemen zeigen (Egyed et al. 2006b, Müller-Scholtz 2003). Ein weiterer Ansatz, mit deutlich geringerer Auflösungskraft, wurde über die Bestimmung von autosomalen Mini-Insertionen bzw. -Deletionen (InDels) verfolgt (z.B. Pereira et al. 2012). 
Die Einteilung der mitochondrialen Haplogruppe erfolgt über single nucleotide polymorphisms (SNPs), die sich über das gesamte, in der Regel 16569 bp große, ringförmige DNA-Molekül verteilen. Eine ausführliche Übersicht findet sich z.B. unter van Oven und Kayser (2009) bzw. www.phylotree.org. Dabei ist zu beachten, dass der Einfachheit halber lediglich Mutationen zu einer Referenzsequenz angegeben werden. Diese Referenzsequenz (Anderson Reference Sequence bzw. Cambridge Reference Sequence, rCRS) entspricht der in Europa vorherrschenden Haplogruppe H (Subgruppe H2a2a), wurde jedoch im Jahre 1981 rein zufällig ausgewählt. Bis auf ihre Dominanz in Europa ist diese Haplogruppe weder die diverseste, noch phylogenetisch älteste oder jüngste Haplogruppe. Dieser Umstand erschwert die Interpretation von genetischen Studien (etwa im Bereich der Populationsgenetik und Besiedlungsgeschichte) und führt zu Fehlern oder Missinterpretationen (Behar et al. 2012). Auf Basis der Analysen von über 8000 modernen Mitogenomen sowie der verfügbaren Neanderthaler-Mitogenome wurde daher von Behar und Kollegen (2012) eine Alternativreferenz (Reconstructed Sapiens Reference Sequence, RSRS) vorgeschlagen, die die „Ur-Sequenz“ der Mitochondrien darstellt. Berechnungsfehler oder Fehlinterpretationen sollen so zukünftig vermieden werden. Ob sich dieser Vorschlag jenseits der Populationsgenetik jedoch durchsetzen kann, bleibt abzuwarten.

Auf Basis der von Sykes (1999) entdeckten sieben Haplogruppen werden in der neueren Literatur zehn bis zwölf Hauptgruppen für Europa definiert. Diese Gruppen sind aus der ursprünglichen Haplogruppe $\mathrm{N}$ hervorgegangen und werden als I (=N1), W $(=\mathrm{N} 2), \mathrm{U}, \mathrm{K}(=\mathrm{U} 8), \mathrm{X}, \mathrm{M}, \mathrm{T}, \mathrm{J}, \mathrm{H}$ und V bezeichnet, wobei eine Vielzahl an Subhaplogruppen gefunden worden sind (Abb. 1.13). Für die Bestimmung von europäischen Haplogruppen reicht es in der Regel aus, Teile der zwei Hypervariablen Regionen (HVR1, np 16001 - 16568 bzw. HVR2, np 001 - 574) zu untersuchen. Obwohl die Haplogruppen per Definition durch SNPs außerhalb dieses Bereichs charakterisiert werden, finden sich typische Mutationen innerhalb dieser Sequenzabschnitte, die eine Zuweisung zu einer der Haupthaplogruppen ermöglicht.

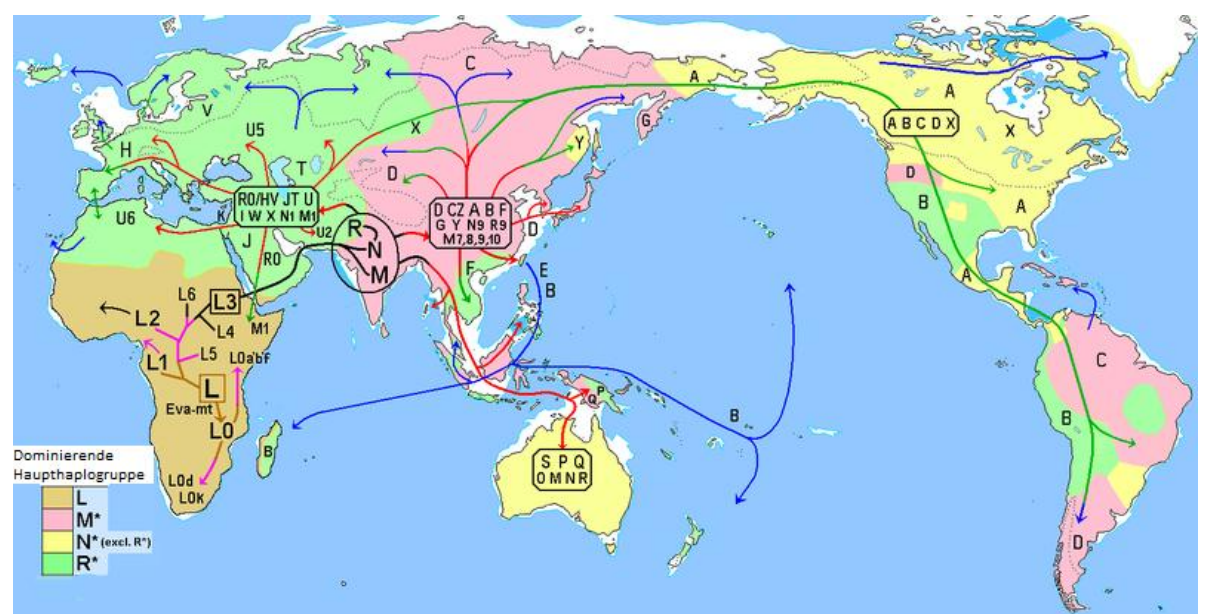

Abbildung 1.13: Besiedlungsweg der Gattung Homo sapiens und Verteilung der mitochondrialen Haplogruppen über die Kontinente. In Europa dominiert die Haplogruppe H. Karte von Mauricio Lucioni, Nutzung gestattet. 10.07.2013

http://commons.wikimedia.org/wiki/File:Migraciones_humanas_en_haplogrupos_mitocondriales.PNG 


\section{$\underline{\text { Y-Chromosomale Haplogruppen }}$}

Analog zum mitochondrialen Haplotypen kann auch ein Y-chromosomaler Haplotyp ermittelt werden. Auch hier erfolgt die Zuweisung zu den Haplotypen über SNPs, die in diesem Fall außerhalb der Pseudoautosomalen Regionen (PAR1 bzw. PAR2, jeweils an den Telomeren des Chromosoms lokalisiert) liegen. So z.B. wird die Haplogruppe R über die Mutation M207 definiert, die Untergruppe R1 über die Anwesenheit von M173 und deren Untergruppe R1a über L62. Dabei steht der Buchstabe für das jeweilige Labor, das den SNP entdeckt hat, in diesem Fall die Stanford University $(=\mathrm{M})$ bzw. das Family Tree DNA Genomic Research Center in Houston Texas (=L); die Zahl bedeutet, dass dieser SNP der n-te SNP dieses Labors ist. Eine Übersicht über die Abkürzungen gibt es z.B. über www.familytreedna.com/faq. Eine vollständige Übersicht über die aktuellen Haplogruppen ist unter http://ytree.ftdna.com/ zu finden, die auch weiterführende Informationen enthält. Der SNP M207 ist beispielsweise an Position 14091377 des +-Stranges des Chromosoms lokalisiert und es handelt sich um eine $\mathrm{A}<\mathrm{G}-$ Mutation. Die Haupthaplogruppen in Europa werden mit R1a, R1b, I, E1b1, J, G, N und T bezeichnet, wobei auch hier eine Vielzahl von Subhaplogruppen existiert (Abb. 1.14). Neben der Rekonstruktion von Besiedlungsprozessen können die Haplogruppen auch für Abstammungsuntersuchungen über lange Zeiträume hinweg eingesetzt werden (z.B. Wang et al. 2012).

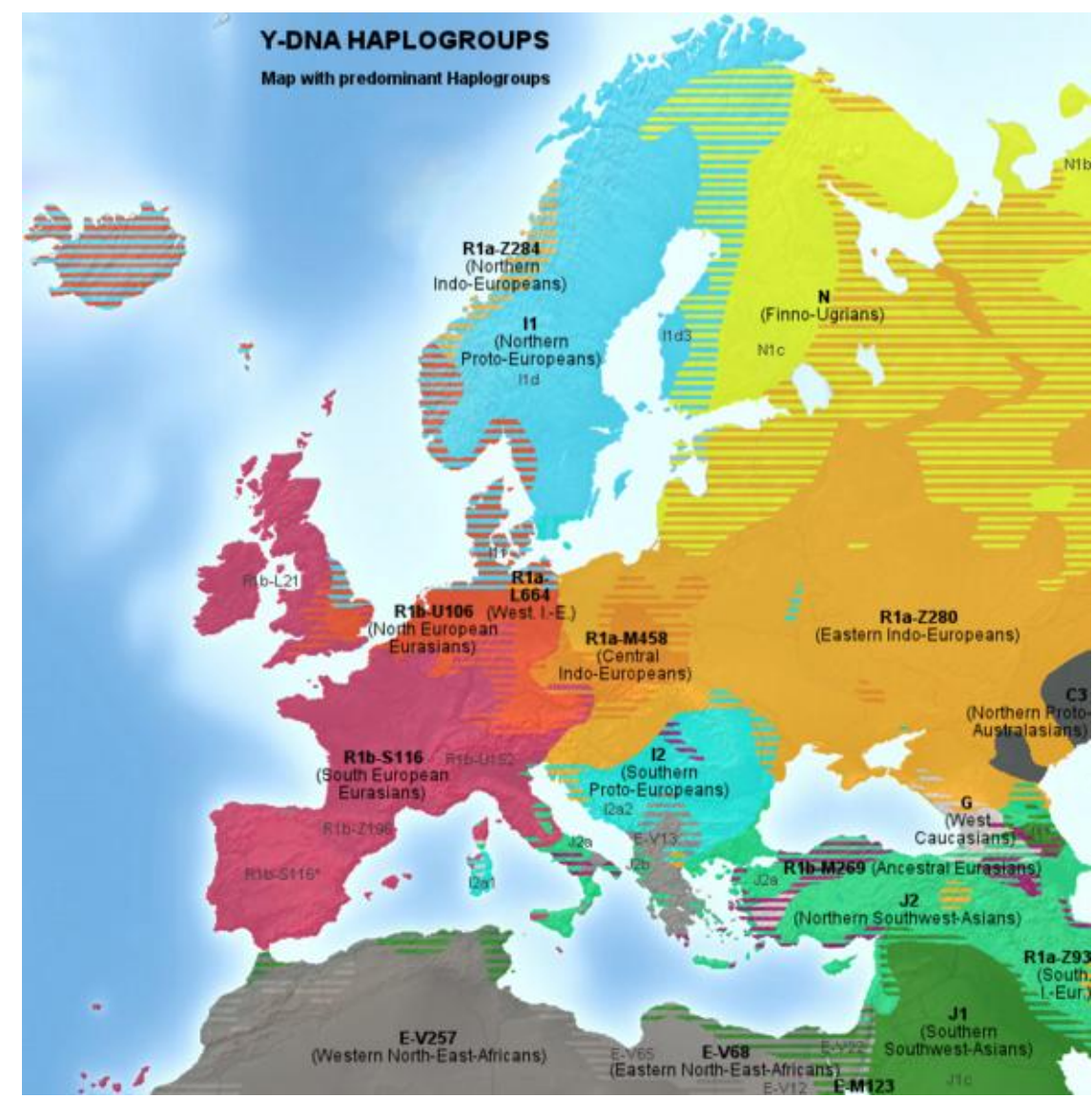

Abbildung 1.14: Verteilung der Y-chromosomalen Haupthaplogruppen über Europa inkl. charakterisierendem SNP. Gut zu erkennen ist die Trennung von west- und osteuropäischen Haplogruppen. Karte von Robert Gabel, Nutzung gestattet. http://commons.wikimedia.org/wiki/File:Haplogroups_europe.png, 10.07.2013 


\section{$\underline{Y \text {-chromosomale STR-Systeme }}$}

Das Y-Chromosom weist wie jedes Chromosom ebenfalls STR-Systeme auf (vgl. Kap. 1.4.). Diese im Gegensatz zu den SNPs hochpolymorphen Marker bilden ebenso einen Haplotypen wie die SNP-Kombinationen. Da die Vererbung genau wie die der erwähnten SNPs gleich ist, können mit Hilfe dieser Systeme ebenso väterliche Linien identifiziert werden. Die Auflösung dieses Haplotypen ist jedoch wesentlich höher, so dass - je nach Anzahl der untersuchten Systeme - auch einzelne Familienlinien identifiziert werden können Die höhere Auflösung der Systeme wird dabei unter anderem für Abstammungsgutachten und in der Forensik eingesetzt.

Mittlerweile wurden neun (DYS19, DYS385a, DYS385b, DYS389I, DYS389II, DYS390, DYS391, DYS392, DYS393 = minimal haplotype, minHT) bzw. 16 (zusätzlich DYS437, DYS438, DYS439, DYS448, DYS456, DYS458, DYS635, YGATHA4 =extended haplotype, exHT) Systeme als Standard etabliert. Dabei wird die kombinierte Mutationsrate der Systeme des minHT mit etwa 2,8 x $10^{-3}$ pro Meiose angegeben (Kayser et al. 2000). Die Lokalisation der Systeme auf dem Chromosom und weiterführende Informationen können z.B. unter http://ymap.ftdna.com/cgibin/gb2/gbrowse/hs_chrY/ abgerufen werden. Neueste Multiplex-Kits, z.B. der PowerPlex Y23-Kit der Firma Promega, beinhalten sogar bis zu 23 Y-STR-Systeme, die z.T. deutlich höhere Mutationsraten aufweisen und entsprechend höhere Auflösung an der Grenze der Individualisierung bieten. Die Validierung und Etablierung dieser Systeme findet gerade statt. Der größte Teil der Y-Daten, der in Datenbanken (z.B. YHRD.org) zugänglich ist, basiert momentan noch auf den oben genannten Systemen.

Zwischen den SNP- und den STR-basierten Haplotypen existiert einen Zusammenhang, der für europäische Populationen statistisch belegt wurde. Athey (2005) hat einen Bayesischen Ansatz für die Berechnung der SNP-Haplogruppe auf Basis der STR-Daten publiziert. Auf dessen Grundlage entstand ein Algorithmus, der für jeden beliebigen STR-Haplotypen die wahrscheinlichste Haplogruppe bestimmt (Athey 2006). Mit Hilfe eines frei zugänglichen online-Eingabetools kann dies einfach durchgeführt werden (http://www.hprg.com/hapest5/).

\section{Ancient DNA-Studien mit mt- und Y-chromosomalen Daten}

Die Ableitungen über die Besiedlungsgeschichte und -kontinuität stützen sich vor allem auf Untersuchungen moderner Populationen (z.B. Underhill et al. 2000). In den letzten Jahren gab es allerdings einen enormen Erkenntnisgewinn durch Analysen an historischen Populationen und den diachronen Vergleichen verschiedener Zeitstellungen zueinander (z.B. Bramanti et al. 2009, Lee et al. 2012, Soares et al. 2010). Aufgrund der generell besseren Erhaltung muss sich dabei hauptsächlich auf mitochondriale Daten gestützt werden. So z.B. konnte durch ancient DNA-Analysen (aDNA-Analysen) ein deutlicheres Bild in der komplexen Besiedlungsgeschichte Nordosteuropas gewonnen werden (Der Sarkissian et al. 2013) und Melchior und 
Kollegen wiesen seltene sowie bislang unbekannte mitochondriale Haplotypen in 1000 Jahre alten dänischen Skeletten nach (Melchior et al. 2008). Haak und Kollegen zeigten einen Unterschied in den Frequenzen mitochondrialer Haplogruppen zwischen neolithischen und rezenten Bevölkerungen Deutschlands (Haak et al. 2010). Auch neueste Besiedlungsszenarien für Europa stützen sich auf mitochondriale Ergebnisse (z.B. Fu et al. 2012, Hervella et al. 2012, Pala et al. 2012). Es ist jedoch bekannt, dass die Historie der mütterlichen Linien signifikant von der der väterlichen Linien abweichen und eine einseitige Betrachtung $\mathrm{zu}$ Fehlinterpretationen führen kann (z.B. Badro et al. 2013, Pilkington et al. 2008).

$\mathrm{Zu}$ den wenigen Studien, die Y-chromosomale Daten untersuchen, zählen in erster Linie Verwandtschaftsanalysen zwischen den Bestatteten. So untersuchten beispielsweise Baca und Kollegen archäologische Funde in Peru; von den 41 analysierten Individuen konnten 24 mt-Daten und elf Y-chromosomale STR-Haplotypen gewonnen werden. Während die mt-DNA keinen Unterschied zu heutigen dort lebenden Populationen zeigte, wurden die Y-Daten ausschließlich für eine Verwandtschaftsanalyse genutzt (Baca et al. 2012). Nunez und Kollegen nutzen Ychromosomale SNPs für eine Verwandtschaftsanalyse mittelalterlicher Skelette ebenso wie Hawass und Kollegen ägyptische Mumien im Kontext von Ramses III. und Kim und Kollegen koreanische Mumien typisierten (Hawass et al. 2012, Kim et al. 2011, Nunez et al. 2011).

Im Gegensatz dazu analysierten Lacan und Kollegen sowohl mitochondriale als auch nukleare Marker, um zu zeigen, dass die Rolle der Männer während der neolithischen Expansion wahrscheinlich größer war als bislang angenommen (Lacan et al. 2011). Fehren-Schmitz und Kollegen stützen die Rekonstruktion der Besiedlung des Südens von Peru z.T. auf Y-chromosomale SNPs (Fehren-Schmitz et al. 2011), ebenso wie Li und Kollegen bei der Interpretation der Besiedlung des westlichen LiaoTals (Li et al. 2011). In der Diplomarbeit von Stephanie Huhn wurden Y-STRs typisiert um die Besiedlung der Stadt Lübeck während des Mittelalters zu rekonstruieren (Huhn 2008).

Für alle diese Studien gilt jedoch, dass, falls überhaupt Y-Daten erhoben werden, meist nur SNPs typisiert werden und nur in den wenigsten Fällen STRs analysiert werden. Somit bleiben Referenzdaten für eventuelle diachrone Vergleiche eine Seltenheit. 


\section{Ermittlung der geographischen Herkunft in Europa}

Die Bestimmung der Haplogruppen kann u.a. durchgeführt werden um unbekannte Individuen geographisch zu verordnen. Durch die relative Stabilität der Haplogruppenverteilung nach der initialen Besiedlung Europas über einen langen Zeitraum hinweg (Csanyi et al. 2008, Melchior et al. 2010, Roewer et al. 2005) ist es möglich, auch unbekannte historische Populationen aufgrund der vorliegenden Haplogruppen geographisch einzuordnen (Fu et al. 2009). Dabei muss jedoch beachtet werden, dass die Daten eines einzelnen Individuums durch die persönliche Familiengeschichte auch falsche Hinweise liefern kann. So z.B. fand sich bei einem weißen Mann aus England eine afrikanische Y-Haplogruppe, die wahrscheinlich während der Zeit des Sklavenhandels in die Familie eingebracht wurde (King et al. 2007). Bei der alleinigen Betrachtung der Y-Daten wäre dieser Mann so als afrikanisch definiert worden, obwohl seine Familienlinie seit Jahrhunderten in England lebt. Zwar ist die Gefahr einer solchen Diskrepanz bei der Betrachtung historischer Individuen überaus gering, jedoch sollte dies bei einer möglichen Interpretation berücksichtigt werden. Ebenso gilt dies für mögliche Besiedlungsprozesse, die Einfluss auf die Haplogruppenfrequenzen gehabt haben könnten (vgl. Roewer et al. 2005).

Für Europa hat sich eine relative Gleichverteilung der mitochondrialen Haplogruppen über den Kontinent herausgestellt (z.B. Richards et al. 2002, Simoni 2000), wobei die größten Unterschiede durch An- oder Abwesenheit seltener Subhaplogruppen, meist an den Rändern des Kontinents, entstehen (z.B. Loogväli et al. 2004). Umso stärker zeigt sich eine klinale Verteilung der Y-Haplogruppen (z.B. Noveletto 2007, Roewer et al. 2001). Die Haplogruppe R1b beispielsweise tritt in Westeuropa mit einer Frequenz von bis zu 90\% auf, die Häufigkeit nimmt nach Osten und Süden jedoch stark ab. Analog dazu nimmt die Frequenz der Haplogruppe R1a nach Osten zu, während sie in Westeuropa fast gar nicht zu finden ist (Abb. 1.15). Ähnlich verhält es sich mit starken Frequenzunterschieden der anderen Haplogruppen. Darüber hinaus sind die Vorkommen von STR-basierten Y-Haplotypen in Datenbanken (beispielsweise YHRD, siehe S.22) erfasst und können - je nach Häufigkeit des Haplotyps - eine regionale Eingrenzung der Herkunft ermöglichen. 


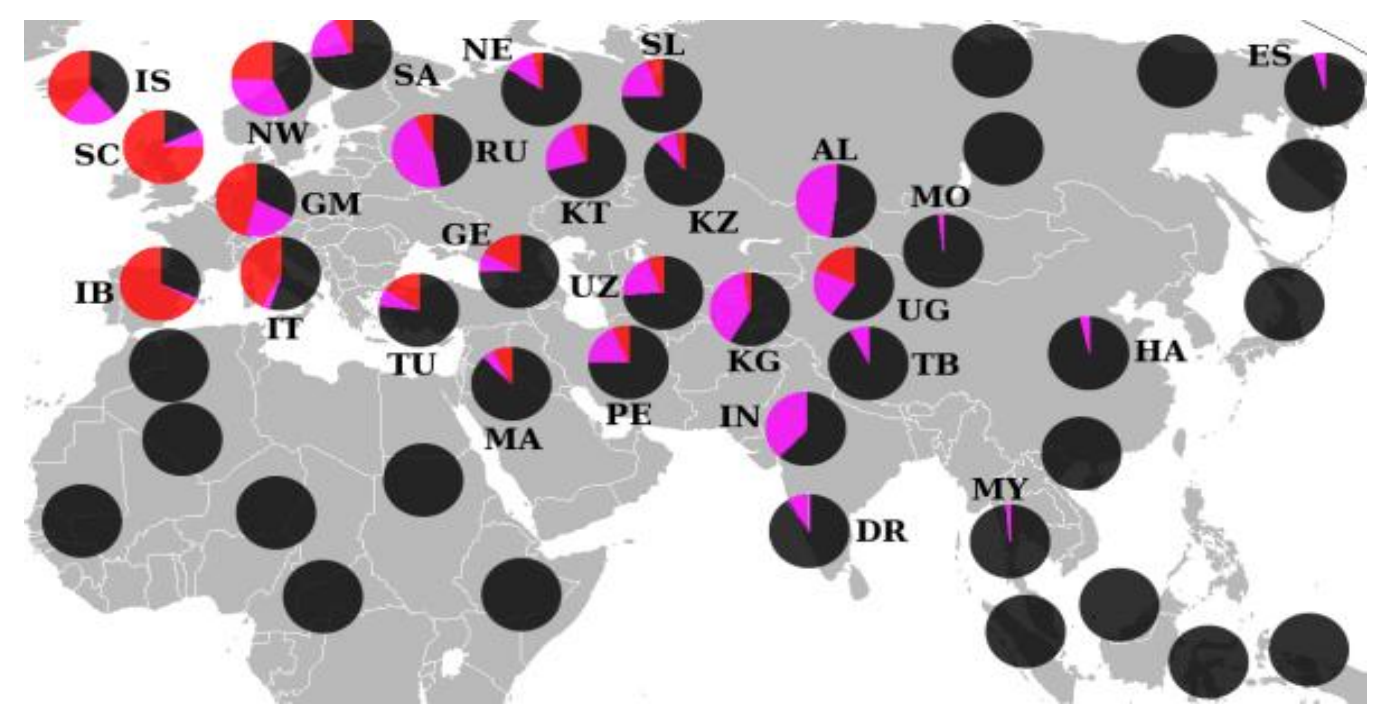

Abbildung 1.15: Frequenzunterschiede der Y-chromosomalen Haplogruppen R1a (lila) und R1b (rot) über Eurasien. Während in Westeuropa R1b dominiert, kommt R1a in Osteuropa und Zentralasien gehäuft vor. AL Altaians

DR India, Dravidian population, ES Inuit, GE Georgia and Armenia, GM Germany, HA Han Chinese, IB Iberian peninsula, IS Iceland, IN India, Indo-Aryan population, IT Italy, KG Kyrgyzstan, KT Kazan Tatar, KZ Kazakhstan, MA Mideast Arabs, MO Mongols, MY Malaysia, NE Nenets, NW Norwegians, PE Persians (Iran), RU Russians, SA Saami, SC Scotland, SL Selkups, TB Tibet, TU Turks, UG Uygurs, UZ Uzbekistan. Karte nach J.D. McDonald (Nutzung gestattet). http://commons.wikimedia.org/wiki/File:Y-Haplogroup_R1_distribution.png, 10.07.2013

Für die Identitätsklärung der Individuen aus dem Massengrab aus Kassel könnte die Ermittlung der Y-Haplotypen bzw. Y-Haplogruppe somit entscheidend sein. Aus den historischen Quellen ist $\mathrm{zu}$ entnehmen, dass sich luxemburgische, elsässische und russische Truppen in dem Lazarett befunden haben (vgl. Kap. 1.1.). Aufgrund der deutlichen Unterschiede zwischen östlichen und westlichen Y-chromosomalen Daten können russische und (im weitesten Sinne) französische Soldaten mit hoher Wahrscheinlichkeit identifiziert werden. Eine Trennung von elsässischen und luxemburgischen Soldaten wäre jedoch aufgrund der engen Verwandtschaft nicht zu erwarten. 


\section{Paläopathologie und Paläomikrobiologie}

\section{$\underline{\ddot{U} \text { berblick }}$}

Weitere zentrale Punkte in den Untersuchungen historischer Populationen sind die Rekonstruktion von Lebensumständen sowie die Identifikation möglicher Todesursachen der Individuen. Pathologische Auffälligkeiten, wie etwa Traumata und Strukturauffälligkeiten am Skelettmaterial können Hinweise auf die Todesursache sowie die Lebensweise geben (Herrmann et al. 1990, Ortner 2003). Bis vor kurzem waren nur Krankheitsbilder diagnostizierbar, die Spuren an den Knochen hinterlassen, etwa Tuberkulose oder Syphilis. Die meisten Infektionskrankheiten haben jedoch keinen oder nur unregelmäßigen Einfluss auf die Knochenstruktur, so dass mit morphologischen Methoden keine Informationen gewonnen werden können. Mit Hilfe der aDNA-Analytik wurde die Möglichkeit zur Identifikation von Infektionskrankheiten erweitert. Wie die menschliche DNA kann auch mikrobielle DNA von Erregern im Knochen jahrhundertelang überdauern. Der Nachweis von solchen DNA-Abschnitten im Knochenmaterial kann als Nachweis für eine Infektion zu Lebzeiten dienen, sofern der ausgewählte DNA-Abschnitt spezifisch für eine bestimmte Spezies ist und eine Kontamination auf anderem Wege, etwa bei Erdbestattungen durch bodenlebende, phylogenetisch nahe stehende Spezies, auszuschließen ist. Voraussetzung für einen Nachweis ist auch die Art der Infektion, da der Erreger über die Blutbahn transportiert werden muss, damit nach dem Tod des Individuums bakterielle DNA im Knochen identifiziert werden kann. Somit ist beispielsweise Yersinia pestis, der Auslöser der großen Pestepidemien im 14. Jahrhundert, ein geeigneter Organismus, während Vibrio cholerae, die Ursache für die Cholera, nur den Darm infiziert und daher nicht im Knochen gefunden werden kann. Erfolgreiche Nachweise konnten bisher u.a. für Yersinia pestis (Wichmann und Grupe 2005) Mycobacterium tuberculosis (z.B. Donoghue et al. 2004, Zink et al. 2005), Mycobacterium leprae (Haas et al. 2000, Matheson et al. 2009) und Plasmodium falciparum (Fornaciari et al. 2010, Nerlich et al. 2008) erbracht werden. Im Zusammenhang mit napoleonischen Truppen konnten Infektionen mit Rickettsia prowazekii und Bartonella quintana als mögliche Ursachen für die verheerenden Epidemien unter den Soldaten identifiziert werden (Raoult et al. 2006).

Mit Hilfe der Untersuchung der Erreger von Infektionskrankheiten können nicht nur der individuelle Infekt nachgewiesen werden, sondern auch Erkenntnisse in Bezug auf die hygienischen Bedingungen, die Ernährungssituation (Wilbur et al. 2008), die Entstehungsgeschichte von Infektionskrankheiten (Nerlich und Lösch 2009, Schuenemann et al. 2013, Taylor et al. 2007, Zink et al. 2003) und die Besiedlung der Kontinente durch den Menschen (Moodley et al. 2009) gewonnen werden. Weiterhin ist es möglich, historische Epidemien durch den Nachweis spezifischer Stämme genau zu charakterisieren (Vergnaud et al. 2007). Darüber hinaus lassen sich durch Sequenzanalysen der historischen, bakteriellen DNA-Sequenzen Hinweise auf die Evolution dieser Organismen finden (Watson und Lockwood 2009), etwa in Be- 
zug auf mögliche Selektionsdrücke und Änderungen in der Pathogenität (zum Beispiel der historischen Pestepidemie siehe Bos et al. 2011 und Haensch et al. 2010).

Der Nachweis von Krankheitserregern und die Authentizitätssicherung der Ergebnisse gestalten sich dabei im Versuchsdesign wesentlich komplexer als die Untersuchung polymorpher DNA-Abschnitte: Da die speziesspezifischen DNA-Abschnitte in der Regel wenig variabel sind, können Kontaminationen, etwa durch Kreuzkontamination oder durch Positivkontrollen, nicht ohne Weiteres erkannt werden. Erst der mehrfache Nachweis in unabhängigen Extrakten sowie vielfache Kontrollen (z.B. die Koamplifikation mit Extrakten aus Bodenproben) sichern die Authentizität der Ergebnisse. Weiterhin muss bedacht werden, dass aufgrund von Degradierungsereignissen der DNA die Abwesenheit von Analysesignalen nicht zwangsläufig bedeutet, dass das gesuchte Bakterium nicht vorhanden war. Hier bildet zum einen die vielfache Wiederholung des Experiments sowie insbesondere auf die Fragestellung angepasste Kontrolluntersuchungen die Grundlage für eine möglichst hohe Aussagekraft der Ergebnisse (Baron et al. 1996).

\section{Historische Diagnose "Nervenfieber"}

Im Zusammenhang mit dem Kasseler Massengrab geben die historischen Quellen das Krankheitsbild als „gutartiges, hochansteckendes Nervenfiebers“, „LazarettFiebers“ oder auch „Typhus“ an. Dabei gilt der Begriff Nervenfieber als Synonym des Typhus, dessen Name durch Boissier de Sauvages 1760 vorgeschlagen wurde. Dabei bezeichnet diese Diagnose verschiedene ,[...] unter heftigem Fieber verlaufender Krankheitszustände, bei denen das Nervensystem in der schwersten Weise ergriffen zu sein und der Kranke in einem anhaltenden Zustand von Betäubung sich zu befinden pflegt [...].“ (Meyers Großes Konversationslexikon, Band 19, Leipzig 1909, S.848). Bei der historischen Diagnose Typhus muss somit berücksichtigt werden, dass die Ärzte bis Mitte des 19. Jahrhunderts nur die Möglichkeit hatten, Krankheiten auf Basis ihrer Symptomatik zu diagnostizieren. Folglich wurden lange Zeit Erkrankungen unter einer Diagnose zusammengefasst, die heute als eigenständige Krankheiten erkannt wurden, allerdings sehr ähnliche Symptome auslösen. Genauso verhält es sich mit der historischen Diagnose des Nervenfiebers bzw. des Typhus. Erst 1847, also deutlich nach dem ermittelten Todeszeitpunkts der Individuen, entdeckte Sir William Jenner, dass es sich bei Typhus in Wirklichkeit um verschiedene Krankheiten handelt (Seddon 2004). Heute ist eine Vielzahl von unterschiedlichen Bakterien bekannt, deren Infektionen typhusähnliche Symptomatik auslösen. $\mathrm{Zu}$ den häufigsten Infektionskrankheiten zählen:

1. Die durch das Bakterium Salmonella enterica ssp. enterica Serovar Typhi (S. typhi) ausgelöste eigentliche Typhus- Erkrankung (Typhus abdominalis).

2. Eine leicht abgeschwächte Form des Typhus, den sogenannten Paratyphus. Verantwortlich für diese Form ist Salmonella enterica ssp. enterica Serovar Paratyphi, 
ein enger Verwandter von S. typhi, der in drei unterschiedlichen Varianten vorkommt (auch als $S$. paratyphi $A, B$ und $C$ bezeichnet).

3. Das durch Rickettsia prowazekii (R. prowazekii) ausgelöste Fleckfieber, auch Flecktyphus oder Typhus exanthematicus genannt.

4. Das durch Bartonella quintana (B. quintana) ausgelöste Fünf-Tage-Fieber oder Wolhynisches Fieber (englisch: trench fever = Schützengrabenfieber).

5. Das sogenannte Läuserückfallfieber (englisch: Louse-borne relapsing fever), ausgelöst durch Borrelia recurrentis.

Aufgrund ihrer Infektionsweise und des typischen Krankheitsverlaufes kann man diese fünf Erreger in zwei Gruppen einteilen: Die Salmonella-Spezies werden in der Regel durch verunreinigte Nahrungsmittel aufgenommen; Rickettsia, Bartonella und Borrelia werden vorwiegend durch die humane Kleiderlaus (Pediculus humanus var. corporis/capitis) übertragen. Diese fünf Erreger stellen vermutlich das Hauptreservoir des „Typhus“ in historischen Zeiten dar. Andere Erreger, wie z.B. weitere humanpathogene Rickettsien und Borrelien, lösen zwar ebenfalls vergleichbare Symptome aus, deren Hauptmerkmale ein hohes Fieber und starke Schmerzen sind, jedoch sind solche Erkrankungen im Vergleich eher selten. Die im Folgenden dargestellten Informationen wurden - falls nicht anders angegeben - aus den Ratgebern für Ärzte des Robert-Koch-Instituts (www.rki.de) entnommen.

\section{Typhus Abdominalis / Paratyphus}

Typhus und Paratyphus besitzen eine Vielzahl von Gemeinsamkeiten, sowohl auf Ebene des Erregers als auch im klinischen Verlauf. Beide auslösende Erregerarten sind gramnegative, bewegliche, nicht sporenbildende und fakultativ anaerobe Bakterien, die ausschließlich humanpathogen sind. Sie gehören zur Subspezies Salmonella enterica ssp. Enterica (Abb. 1.16), zu der 99,5\% der für den Menschen und Tiere infektiösen Arten gehören, und sind weltweit verbreitet. Das Hauptreservoir ist der Mensch, wobei klinisch unauffällige Personen sowie Daueraus-

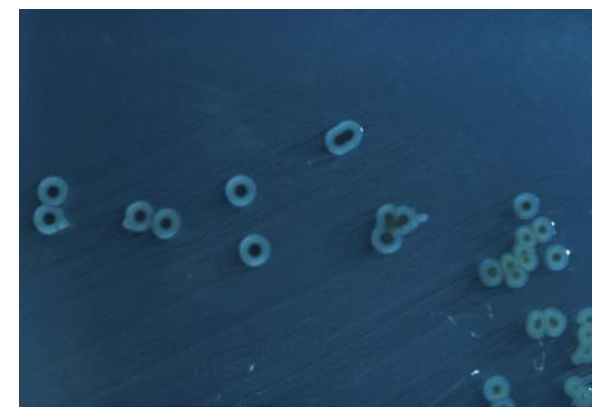

Abbildung 1.16: Salmonella enterica (typhimurium) auf einer Agarplatte. Foto: CDC (Verwendung gestattet)

http://commons.wikimedia.org/wiki/File:Salmonell a_enterica_serovar_typhimurium_01.jpg, 10.07.2013 scheider eine besondere Rolle einnehmen. Die Infektion findet vorwiegend über die Aufnahme von kontaminierten Lebensmitteln und Wasser statt, eine direkte Übertragung von Mensch zu Mensch ist möglich, aber selten. Die Inkubationszeit beträgt zwischen 3 bis 60 Tage, im Durchschnitt etwa 18 - 14 Tage (Paratyphus ca. 1-10 Tage). Die Infektion äußert sich zunächst mit uncharakteristischen Beschwerden wie etwa Kopf- und Gliederschmerzen, wobei nach 2 - 3 Tagen ein hohes Fieber zwischen $39^{\circ} \mathrm{C}$ und $41^{\circ} \mathrm{C}$ auftritt, das bis zu drei Wochen anhalten kann. Typisch, aber selten, sind sogenannte Reseolen (nichtjuckende Hautfloreszenzen), zumeist auf der 
Bauchhaut, sowie eine relative Bradykardie (langsamer Herzschlag). Komplikationen wie Osteomyelitis, Endokarditis oder Meningitis können auftreten, sind aber nicht regelhaft. Bei Paratyphus ist der klinische Verlauf meist leichter ausgeprägt. Da die Infektion nur durch orale Aufnahme erfolgt, treten Typhus- und Paratyphusfälle meist dann gehäuft auf, wenn generell schlechte hygienische Bedingungen herrschen. Heutige Endemiegebiete beschränken sich vorrangig auf Afrika, Südostasien und Südamerika, wobei die Erreger jedoch weltweit verbreitet sind. Jährlich sterben etwa 600.000 Menschen an diesen Erkrankungen. In Deutschland liegt die Inzidenz sowohl für Typhus als auch für Paratyphus bei unter 0,1 Erkrankungen pro 100.000 Einwohner, wobei die meisten Fälle importiert werden. Bei Behandlung mit Antibiotika liegt die Letalität im Allgemeinen unter 1\% (Robert-Koch-Institut - Ratgeber für Ärzte 2011).

S. typhi wurde in einem Athener Massengrab nachgewiesen, dass auf die Zeit um eine „Pestepidemie“ im 4. Jahrhundert vor Christus datiert (Papagrigorakis et al. 2006). Allerdings wird dieser Fund bzw. die abgeleitete Aussage kontrovers diskutiert (vgl. Shapiro et al. 2006; Papagrigorakis et al. 2007).

\section{Fleckfieber (Typhus exanthematicus)}

Das Fleckfieber wird von Rickettsia prowazekii ausgelöst. Die Gattung Rickettsia ist wie die Gattung Salmonella gramnegativ und nicht sporenbildend und wird aufgrund ihrer Humanpathogenität in drei Gruppen unterteilt:

- $\quad$ Spotted fever-Gruppe (z.B. R. rickettsi, R. conorri, R. japonica) (Abb. 1.17)

- $\quad$ Typhus-Gruppe (z.B. R. prowazekii, R. typhus)

- Tsutsugamushi-Gruppe (R. tsutsugamushi; Einordnung jedoch unklar, eventuell auch eigene Gattung Orientia)

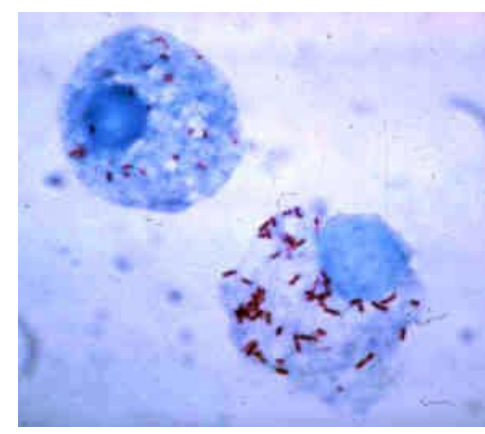

Abbildung 1.17: Rickettsia rickettsii (gefärbt) in einer Wirtszelle. Foto: CDC (Verwendung gestattet)

http://commons.wikimedia.org/wiki/File: Rickettsia_rickettsii.jpg, 10.07.2013

R. prowazekii ist das bekannteste Beispiel der Typhus-Gruppe. Das einzige Reservoir für dieses Bakterium ist der Mensch. Es wird hauptsächlich durch die Kleiderlaus übertragen: Die Laus saugt das Blut einer infizierten Person und scheidet die Bakterien in ihren Exkrementen aus. Die Exkremente werden sekundär durch den Juckreiz nach dem Stich durch eine infizierte Laus in die Wunde eingekratzt. Auch ein Inhalieren von kontaminiertem Staub, der die getrockneten Exkremente enthält, kann zu einer Infektion führen. Die durchschnittliche Inkubationszeit beträgt etwa 12 Tage. Die häufigsten Symptome sind plötzliches starkes Fieber, starke Kopf-, Rücken- und Gliederschmerzen sowie ein charakteristisches fleckenförmiges Exanthem, das etwa vier bis sechs Tage nach Ausbruch der Krankheit zunächst am Oberkörper auftritt und sich im weiteren Verlauf über den ganzen Körper ausbreiten kann. Eine Beteiligung des zentralen Nervensystems ist typisch, etwa Somnolenz oder Enzephalitis. 
Die Letalität einer unbehandelten Erkrankung beträgt etwa 10 - 40\%, wobei Mangelernährung und schlechte allgemeine Immunitätslage das Risiko weiter erhöhen. Bei frühzeitiger Therapie ist die Prognose jedoch gut (Robert-Koch-Institut 1997 und 2007).

Fleckfieber tritt vor allem unter schlechten hygienischen Bedingungen auf, wie sie heute z.B. in Massenquartieren und Flüchtlingslagern gegeben sind. So führten beispielsweise Bürgerkriege und Flüchtlingsbewegungen in Afrika in den vergangenen Jahren zu lokalen Epidemien (Robert-Koch-Institut 2007). In früheren Zeiten werden Epidemien mit großen Truppenbewegungen in Verbindung gebracht. Raoult et al. (2006) wiesen u.a. $R$. prowazekii-DNA in der Zahnpulpa von napoleonischen Truppen nach, die nach dem Rückzug aus dem verlorenen Russlandfeldzug 1812 durch die Stadt Vilnius zogen. Die katastrophalen hygienischen Bedingungen führten zu einer generellen Läuseverseuchung der Soldaten, so dass sich das Fleckfieber leicht ausbreiten konnte. Tatsächlich starben gut ein Drittel der Soldaten während des Feldzuges an Infektionskrankheiten und nicht durch feindliche Auseinandersetzung (Mayer 2008). Im Weiteren gab es einen positiven Nachweis von $R$. prowazekii in einem weiteren Massengrab in Frankreich (Nguyen-Hieu et al. 2010). Die enge Beziehung dieser Rickettsiose zu den Typhus-Erkrankungen erkennt man auch in ihren englischen Bezeichnungen: Das Fleckfieber wird als (epidemic) typhus bezeichnet, während der eigentliche Typhus typhoid fever genannt wird.

\section{Fünf-Tage-Fieber / Wolhynisches Fieber}

1915 wurde im Zuge des 1. Weltkrieges das FünfTage-Fieber (,Schützengrabenfieber“) erstmals beschrieben, 1919 wurde zuerst ein Zusammenhang mit Läusen und später mit Bartonella quintana als eigentliche Ursache hergestellt (Foucault et al. 2006, Abb. 1.18). Die Gattung Bartonella wurde zum ersten Mal von A. L. Barton im Jahre 1909 beschrieben. Es handelt sich um gramnegative Stäbchen, die an der Oberfläche Pilli besitzen, mit denen sie sich an Zelloberflächen anhaften. Drei Bartonella-

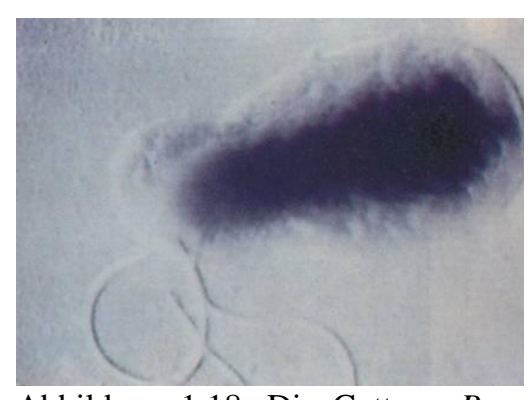

Abbildung 1.18: Die Gattung Bartonella. Foto: Ceshencam (Verwendung gestattet) http://commons.wikimedia.org/wiki/File:Bart onella.jpg, 10.07.2013

Spezies sind humanpathogen, wobei B. bacilliformes nur in den Anden zwischen 1000 und 3000 Höhenmeter vorkommt. B. henselae ist weltweit verbreitet und mit Katzen assoziiert zu sein, während $B$. quintana, wie auch $R$. prowazekii, die Kleiderlaus als Reservoir nutzt. Bartonella ist der Verursacher der bacilliormen Angiomatose und der sogenannten Katzen-Kratz-Krankheit. Nach der Infektion, die gewöhnlich wie bei $R$. prowazekii stattfindet, befällt Bartonella in der Regel die Endothelzellen. Nach 3 - 38 Tagen treten die ersten Symptome auf, dazu zählen Schüttelfrost und Fieber, das bis zu drei Wochen anhalten kann. Zu einem typischen Krankheitsverlauf zählen Kopf-, Glieder- und Muskelschmerzen, geschwollene Lymphknoten und Nystagmus (,Augenzittern“). An der Haut und im Lymphknotenbereich kann sich 
eine epitheloide Angiomatose ausbilden, Hautläsionen mit einem Durchmesser von wenigen Millimetern bis Zentimetern (Robert-Koch-Institut 2007).

Während des 1.Weltkrieges waren über eine Millionen Menschen an diesem 5-TageFieber erkrankt (Karem et al. 2000). Die Inzidenz für das Grabenfieber nahm nach dem 1. Weltkrieg deutlich ab, stieg aber während des 2. Weltkrieges wieder an (Kostrzewski 1949). Heute beobachtet man eine erneute Verbreitung des Erregers aufgrund der unhygienischen Lebensbedingungen bei Obdachlosen in den großen Städten, sowohl in Europa als auch in Amerika (Alcantara et al. 2009, Brouqui et al. 1999, Spach et al. 1995). B. quintana wurde bereits wie $R$. prowazekii in Skeletten napoleonischer Soldaten nachgewiesen, die im Russlandfeldzug 1812 zu Tode kamen (Raoult et al. 2006). Außerdem gab es einen positiven Nachweis in weiteren Massengräbern in Frankreich (Nguyen-Hieu et al. 2010) und Italien (Tran et al. 2011) sowie in einer 4000 Jahre alten Zahnpulpa aus Südfrankreich (Drancout et al. 2005).

\section{Läuserückfallfieber}

Das Läuserückfallfieber oder epidemisches Rückfallfieber wird durch eine Infektion mit Borrelia recurrentis verursacht. Dieses Bakterium wurde als erster menschlicher Infektionserreger bereits 1868 von Otto Obermeier entdeckt. B. recurrentis ist ein Vertreter der Spirochäten (Abb. 1.19) und daher sehr beweglich und schraubenförmig. Ebenso wie bei $R$. prowazekii und B. quintana ist der Mensch der einzige Wirt und die Übertragung findet wie zuvor beschrieben statt. Unter schlechten hygienischen Bedingungen tritt das Läuserückfallfieber auch heute noch auf. Geographisch begrenzte Endemieherde

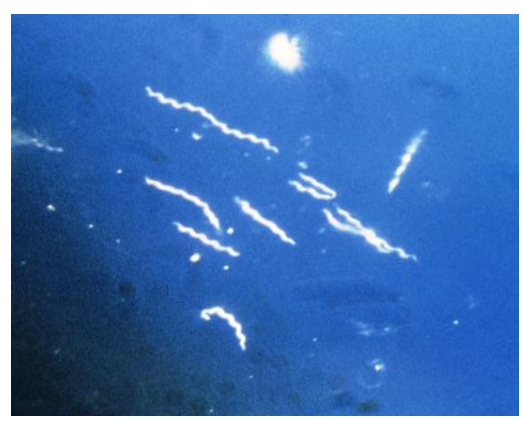

Abbildung 1.19: Borrelia burgdorferi, 400fach vergrößert. Foto: CDC (Verwendung gestattet) http://commons.wikimedia.org/wiki/File:Bor relia_burgdorferi_\%28CDC-PHIL_631\%29_lores.jpg, 10.07.2013 sind in Afrika, Asien und Südamerika zu finden, wobei die Anzahl rückläufig ist. Nach einer Inkubationszeit von 5-15 Tage beginnt die Erkrankung mit Schüttelfrost, hohem Fieber, starken Kopf-, Muskel- und Gelenkschmerzen. Der erste Fieberschub dauert in der Regel 3-6 Tage, wobei nach einem fieberfreien, etwa einwöchigen Intervall ein zweiter, 2-3 Tage andauernder, Fieberanfall auftritt. Häufig wird eine Hepatosplenomegalie beobachtet, Komplikationen können Myokardschaden, Bronchopneumonie und Arthritis sein. Ohne Behandlung liegt die Letalität bei 2-10\% (Robert-Koch-Institut 2007). Im Gegensatz zu R. prowazekii und B. quintana konnte bisher B. recurrentis noch nicht in Skelettmaterial nachgewiesen werden (z.B. Raoult et al. 2006). Stattdessen wurde eine nahverwandte Borrelia-Spezies, B. burgdorferi, im Tiroler Eismann entdeckt (Keller et al. 2012).

Um eine mögliche Infektion mit einem „Nervenfieber“ über den Nachweis von Erreger-DNA in den Skeletten zu identifizieren, muss folglich auf die Anwesenheit aller fünf in Frage kommenden Bakterien getestet werden. 


\section{4. aDNA-Forschung und Authentizitätssicherung (STR-Systeme)}

Etwa zwei Jahrzehnte sind seit den ersten erfolgreichen Nachweisen von DNA aus menschlichem Skelettmaterial (Hagelberg et al. 1989; Hummel und Herrmann 1991) vergangen. Nach den anfänglichen Nachweisen der Überdauerungsfähigkeit genetischen Materials entwickelte sich die Paläogenetik schnell zu einem Instrument, das als Grundlage für die Bereitstellung biologischer Basisdaten dient. Neben den überwiegend naturwissenschaftlich ausgerichteten Forschungsgebieten der Evolutionsbiologie und Conservation Genetics (z.B. Gilbert et al. 2008, Hofreiter et al. 2007) können besonders in den Bereichen der Archäologie (z.B. Haak et al. 2005, Khairat et al. 2013, Fehren-Schmitz et al. 2010), der Anthropologie (z.B. Lassen et al. 2000) und der Umweltgeschichte (z.B. Willerslev et al. 2007) molekulargenetische Ansätze zur Klärung von kultur- und sozialwissenschaftlichen Fragestellungen beitragen.

Eine zentrale Rolle in der aDNA-Analytik nimmt die Frage nach der Authentizitätssicherung von Ergebnissen und den daraus entwickelten Bearbeitungsstandards ein. Hintergrund der Bemühung um Analysestandards ist die Tatsache, dass altes Probenmaterial meist nur geringste Mengen an indigener DNA enthält, so dass bereits kleine Mengen kontaminierender DNA zu fehlerhaften Ergebnissen führen können.

Grundsätzlich wurden im letzten Jahrzehnt der Forschung an degradierter DNA zwei Konzepte zur Bewältigung der Problematik verfolgt. Das eine Vorgehen fordert die Einbindung eines zweiten Labors zur unabhängigen Replikation der Untersuchung (Cooper und Poinar 2000, Hofreiter et al. 2001). Diese Herangehensweise bietet sich an, wenn vergleichsweise konservative (= wenig variable) DNA-Sequenzen untersucht werden, etwa bei Untersuchungen zur Phylogenie und zur Evolution von Organismen. Werden dagegen hochpolymorphe (= variable) Sequenzen untersucht, so hat sich das Verfahren des genetischen Fingerprintings (s.u.) als besonders geeignet erwiesen, mögliche Kontaminationen zu identifizieren (Alonso et al. 2001, Bouakaze et al. 2009, Capelli et al. 2003, Hummel 2003).

In den letzten Jahren wurde durch die Einführung der neuen Methodiken des NextGeneration-Sequencings die Möglichkeiten der Datengewinnung und der Authentizitätssicherung entscheidend erweitert. Durch die Sequenzierung kürzester DNAAbschnitte können Analysen auch an Proben mit sehr fortgeschrittener DNADegradierung durchgeführt werden. Gleichzeitig werden genomweit enorme Datenmengen generiert, die eine Authentifizierung zulassen. Die Anwendung dieser kostenintensiven Methode in der routinemäßigen Bearbeitung von aDNA-Proben ist derzeit noch zu aufwendig. Zusätzlich ist die Generierung großer Datenmengen für eine Vielzahl von Fragestellungen, z.B. genealogischer Verwandtschaftsrekonstruktionen, nicht erforderlich. Andere Fragestellungen profitieren von den großen Datenmengen erheblich i.S. großer Erkenntnisgewinne, wie etwa eine BorreliaInfektion bei der Gletschermumie vom Ötztal (Keller et al. 2012), die Untersuchungen großer Pandemien (Schuenemann et al. 2011) oder stammesgeschichtlicher Rekonstruktionen (Reich et al. 2010). 


\section{$\underline{\text { Short Tandem Repeat-Systeme (genetischer Fingerabdruck) }}$}

Bereits 1984 entdeckte Alec Jeffreys, dass es im menschlichen Genom Sequenzabschnitte gibt, die sich in ihrer Länge zwischen einzelnen Menschen unterscheiden können. Bei näherer Untersuchung dieser Systeme wurde der repetitive Aufbau aus sich wiederholenden Sequenzeinheiten erkennbar und somit der Grund für ihre unterschiedliche Länge: Die Anzahl der Wiederholungseinheiten kann variieren, was in längeren oder kürzeren Ausprägungen (Allele) der Systeme resultiert. Je nach Länge der Systeme unterscheidet man heute drei Arten dieser „Satelliten“-DNA:

1. Die klassischen Satelliten-Systeme sind zwischen 100 Basenpaaren (=bp) und $5000 \mathrm{~kb}$ groß und bestehen aus bis zu einer Millionen Wiederholungseinheiten, die selbst zwischen 5 und 300bp groß sind.

2. Minisatelliten sind kürzer und normalerweise zwischen $100 \mathrm{bp}$ und $20 \mathrm{kbp}$ lang, die Wiederholungseinheiten sind dabei höchstens 15 Basen lang. Häufig werden diese auch als variable number of tandem repeats (=VNTRs) bezeichnet.

3. Mikrosatelliten sind die kleinsten Vertreter und in der Regel maximal einige 100 Basen lang, die Wiederholungseinheit besteht aus 1 bis 6bp langen Sequenzen. Aufgrund ihrer Beschaffenheit werden diese auch als short tandem repeats ( $=$ STRs) bezeichnet.

Im Laufe der Zeit wurde eine Vielzahl von diesen Systemen auf allen Chromosomen gefunden (z.B. Butler 2005). Aufgrund des diploiden Chromosomensatzes (ein Satz je Elternteil) kann jeder gesunde Mensch maximal zwei unterschiedliche Allele pro System aufweisen. Aufgrund der geringen Länge und einfacheren Handhabung im Labor haben sich für die meisten Fragestellungen STR-Systeme durchgesetzt. Die Bezeichnung dieser Systeme folgt dabei einem einfachen Muster und wird am folgenden Beispiel erläutert:

\section{D1S1656 / D2S411 / D22S1045}

Das D steht jeweils für DNA, die folgende Zahl für das Chromosom, auf dem der STR lokalisiert ist. S steht für einen single copy-Locus und die zweite Zahl ist der nte STR, der auf diesem Chromosom beschrieben wurde. Nur wenige STR-Systeme weichen von diesem Muster ab: Nach ihrer Entdeckung in den Anfangsjahren wurden die Systeme noch nach den Genen benannt, in deren Nähe sie lagen. Das System TH01 beispielsweise liegt im Intron 1 der Tyrosin-Hydroxylase, vWA im Intron 40 des von Willebrand-Faktors usw. Die Allele der STR-Systeme werden nach der Anzahl der Wiederholungseinheiten benannt:

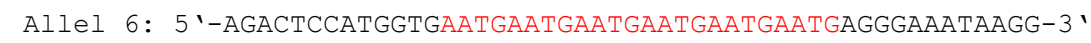

Allel 7: 5'-AgACtCCATGGTGAATGAATGAATGAATGAATGAATGAATGAGGGAAATAAgG-3'

Das Beispiel zeigt das System TH01 auf Chromosom 11 mit der Wiederholungseinheit $(\text { AATG })_{n}$. Allel 6 besitzt somit sechs Wiederholungseinheiten usw. 
Abweichend davon gibt es auch Allele, die sich in ihrer Länge nicht um eine ganze Wiederholungseinheit unterscheiden, sog. Interallele. In ihrer repeat-Struktur befinden zusätzliche Basen, die nicht in das eigentliche Schema passen. Die Benennung der Interallele richtet sich nach der Anzahl der vollständigen Wiederholungseinheiten und der Anzahl zusätzlicher Basen, die mit einem Punkt getrennt sind. Als Beispiel ist das Allel 9.3 des Systems TH01 gezeigt, das 9 vollständige Wiederholungseinheiten [AATG] und die drei zusätzliche Basen [ATG] aufweist:

5 '-AGACTCCATGGTGAATGAATGAATGAATGAATGAATGATGAATGAATGAATGAGGGAAATAAGG-3 '

Grundsätzlich werden heutzutage STRs für zwei verschiedene Fragestellungen genutzt: die eindeutige Identifizierung von Personen, z.B. im forensischen Bereich, und der Verwandtschaftsrekonstruktion, etwa im Bereich der Vaterschaftsanalyse (z.B. Goodwin et al. 2011). Um für diese Anwendungen geeignet zu sein, müssen die STR-Systeme gewisse Eigenschaften aufweisen: Zunächst müssen sie einen hohen Grad an Polymorphie in der Bevölkerung aufweisen und die Häufigkeit der Allele sollten möglichst gleichmäßig in der Bevölkerung verteilt sein. Bei nur wenigen Allelen oder einem stark dominierenden Allel ist die Aussagekraft des Systems stark eingeschränkt. Weiterhin darf das System keinem Selektionsdruck unterliegen, das heißt z.B. nicht mit Krankheiten assoziiert sein. Liegt ein STR beispielsweise in einem proteinkodierenden Gen, so ist seine Länge für die korrekte Funktion des Proteins wichtig. Abweichungen davon können mitunter schwere Krankheiten auslösen und unterliegen somit einem Selektionsdruck. Das klassische Beispiel für eine solche Krankheit ist Chorea Huntington, welche durch eine Expansion des Trinukleotids CAG im Huntingtin-Gen entsteht: Während gesunde Menschen zwischen 9 und 35 CAG-Tripletts besitzen, bricht die Krankheit bei mehr als 40 Wiederholungen aus, die Betroffenen sterben in der Regel innerhalb von 15 Jahren nach Ausbruch (z.B. Roos 2010). Auch STRs, die in Introns von Genen lokalisiert sind, können Erkrankungen auslösen (z.B. Friedreich Ataxie, GAA-Triplett-Expansion im Intron 1 des FXN-Gens, Koeppen 2011). Für verwandtschaftliche oder forensische Untersuchungen müssen STRs nach der Gesetzgebung völlig neutrale Marker sein, das heißt sie dürfen keine Rückschlüsse auf irgendwelche Eigenschaften des Trägers zulassen (mehr zu STRs z.B. in Butler 2005).

Bei einer ausreichenden Anzahl an untersuchten Systemen ist das erhaltene Allelprofil statistisch gesehen einmalig in der Weltbevölkerung, d.h. es gibt keine zweite unverwandte Person, die genau dieselben Allele besitzt (Goodwin et al. 2011). Man spricht daher auch von einem genetischen Fingerabdruck, welcher in der Forensik bereits zu einer Routineuntersuchung geworden ist. In Europa hat sich ein Standard von zwölf STR-Systemen etabliert (D1S1656, D2S411, D3S1358, D8S1179, D10S1248, D12S391, D18S51, D21S11, D22S1045, TH01, vWA, FGA), wobei in Deutschland vier weitere Systeme (D2S1338, D16S539, D19S433, SE33) zusätzlich untersucht werden (Tab. 1.1). Die durchschnittliche Wahrscheinlichkeit, dass eine unverwandte Person dasselbe Allelprofil aufweist, beträgt etwa $6 \times 10^{-21}$ (van Oers 2012). 
Tabelle 1.1: Beispiel eines genetischen Fingerabdrucks (hier: des Autors).

\begin{tabular}{cc||cc}
\hline \hline D1S1656 & $16 / 19.3$ & D18S51 & $11 / 17$ \\
\hline D2S411 & $10 / 15$ & D19S433 & $13 / 14$ \\
\hline D2S1338 & $20 / 25$ & D21S11 & $28 / 29$ \\
\hline D3S1358 & $14 / 17$ & D22S1045 & $14 / 16$ \\
\hline D8S1179 & $11 / 14$ & TH01 & $6 / 9$ \\
\hline D10S1248 & $13 / 13$ & vWA & $16 / 17$ \\
\hline D12S391 & $18 / 19$ & FGA & $20 / 21$ \\
\hline D16S539 & $12 / 12$ & SE33 & $21 / 21$ \\
\hline \hline
\end{tabular}

Um den genetischen Fingerabdruck zu untersuchen, verwendet man das Prinzip der Polymerasekettenreaktion (PCR), das Standardverfahren für die Vervielfältigung von spezifischen DNA-Abschnitten (eine Übersicht z.B. Linz und Degenhardt 1990). Für die Auftrennung der Fragmente macht man sich das Verfahren der Kapillarelektrophorese zunutze: Die DNA-Moleküle wandern entlang eines elektrischen Feldes und werden durch ein Polyacrylamid-Gel nach Größe aufgetrennt. Die Detektion geschieht mittels Fluoreszenz: In der PCR wird ein Primer mit einem Fluoreszenzfarbstoff verwendet, der durch Anregung durch den Laser Licht einer bestimmten Wellenlänge emittiert. Die Zeit, die ein Molekül benötigt, um die Länge der Kapillare zurückzulegen, ist dabei direkt abhängig von der Molekülgröße, welche somit aus der Zeit errechnet werden kann. In modernen STR-Kits werden bis zu fünf verschiedene Farbstoffe gleichzeitig verwendet, die jeweils Licht in einem anderen Wellenlängenbereich emittieren (Abb. 1.20).

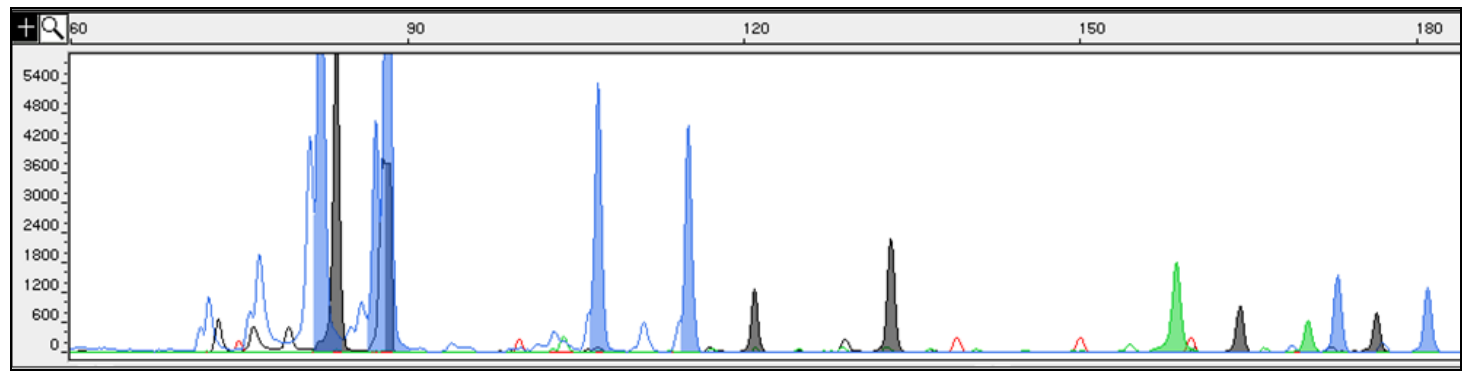

Abbildung 1.20: Elektropherogramm einer Multiplex-STR-Analyse (Beispielbild). Insgesamt wurden sechs STR-Systeme plus Amelogenin untersucht, davon sind die Fragmente je dreier Systeme blau bzw. gelb (dargestellt in schwarz) markiert und eines Systems grün. Trotz ähnlicher Fragmentlängen sind die beiden Allele der jeweiligen Systeme durch die Farbmarkierung voneinander eindeutig zu unterscheiden. $\mathrm{x}$-Achse $=$ Länge in Basenpaaren, $\mathrm{y}$-Achse $=$ relative Fluoreszenzintensität

Für die Anwendung an altem Material (aDNA) eignen sich die meisten kommerziellen Kits nur bedingt. Da durch Degradierungsprozesse die DNA fragmentiert wird, können nicht mehr ausreichend lange Fragmente im DNA-Extrakt vorhanden sein (Hummel 2003). Daher ist in den meisten Fällen eine spezielle Optimierung auf aDNA-Anwendungen nötig (vgl. Kap. 3.4.4. - 3.4.6.). Die ersten Versuche, mit Hilfe der Next-Generation-Sequencing-Methoden STRs zu typisieren, waren nur begrenzt erfolgreich: Während die kurzen Systeme problemlos darstellbar waren, waren die Geräte nicht in der Lage, einige Allele langer Systeme korrekt darzustellen. Somit kommt diese neueste Technologie für diese Aufgaben zunächst noch nicht zur Anwendung (Bornman et al. 2013). 


\subsection{Fragestellung und Zielsetzung der Arbeit}

In dieser Arbeit wurden die menschlichen Überreste des Massengrabs aus Kassel zum ersten Mal in ihrer Gesamtheit anthropologisch untersucht. Aufgrund der suboptimalen Bergungsbedingungen, mangelnder Dokumentation und nachfolgender Durchmischung aller Skelettelemente mussten zunächst vorbereitende Maßnahmen durchgeführt werden, um eine weitere wissenschaftliche Untersuchung abzusichern. Dazu zählte nach der Säuberung die Beschreibung und Katalogisierung jedes Knochens in einer Datenbank, um einen Überblick über den Gesamtfund zu erhalten. Im Folgenden wurden verschiedene Daten über die Individuen erhoben, wobei je nach Fragestellung sich ergänzende Methodenansätze zum Einsatz kamen.

Die morphologischen Arbeiten begannen mit der Bestimmung der Mindestindividuenzahl sowie der Zuordnung der einzelnen Skelettelemente zu Individuen. Die morphologische Zuordnung wurde stichprobenartig genetisch überprüft. Dazu wurden autosomale STR-Profile (=genetische Fingerabdrücke) der Skelettelemente erstellt und gegeneinander abgeglichen. Nach der Rekonstruktion von Individuen wurden die anthropologischen Basisdaten erhoben, um den Kontext der Bestatteten eingrenzen können sowie Hinweise auf Lebens- und Todesumstände zu erhalten. Dazu zählten die Ermittlung der Alters- und Geschlechterverteilung, die Körperhöhenrekonstruktion sowie die Erfassung pathologischer und degenerativer Veränderungen. Auch nicht zugeordnete Skelettelemente wurden dabei entsprechend ihres Aussagewertes mit berücksichtigt. Die morphologischen Methoden wurden dabei um histologische und genetische Analysen erweitert.

Um eine Aussage über die geographische Herkunft der Individuen treffen zu können, wurden die Y-Haplotypen der Individuen analysiert. Dazu wurde eine MultiplexPCR entwickelt, die speziell für die Kriterien von aDNA ausgelegt ist. Durch statistische Auswertung wurde untersucht mit welcher rezenten Population die Individuen die größten Ähnlichkeiten aufweisen. Des Weiteren wurde das postulierte Seuchengeschehen näher untersucht. Dazu wurde in den Knochen auf Anwesenheit von humanpathogenen Bakterien getestet, die im Zusammenhang mit einer historischen „Typhus“- bzw. Nervenfieber-Epidemie stehen könnten.

Die Ergebnisse wurden mit der Historie kontextualisiert bzw. mit den aufgestellten Theorien abgeglichen. Letztendlich wurde eine endgültige Klärung über die Frage der Identität der Individuen als mögliche französische Soldaten sowie deren Lebensund Todesumstände angestrebt. 


\section{Material}

\section{Historisches Material}

Mit der Exhumierung der restlichen Särge im Mai 2012 stand für diese Arbeit das gesamte ergrabene Skelettkollektiv zur Verfügung. Alle Skelettelemente wurden zunächst unter einem Wasserstrahl gereinigt und anschließend getrocknet. Nach einer ersten Betrachtung und Kleben von Bruchstücken (Abb. 2.1) folgten die oberflächliche Deskription der Knochen und die Katalogisierung in einer AccessDatenbank. Die Benennung der Elemente erfolgte dabei nach folgendem Schema: KS\# - Bezeichnung des Knochens - \#\#

Dabei bezeichnet „KS\#“ den jeweiligen Sarg, in dem der Knochen gelagert wurde. „KS1“ steht für den ersten Sarg, der bereits im Sommer 2009 das Institut für Historische Anthropologie erreicht hat. „KSM“ steht für die Knochen, die aus der Stichprobe stammen, die in Mainz bearbeitet worden sind. „KS2“ bis „KS6“ sind schließlich die verbliebenen fünf Särge. Mit einem Bindestrich getrennt folgt eine Abkürzung der wissenschaftlichen Bezeichnung des Knochens, also z.B. „Fe“ = Femur, „Hu“ = Humerus, ,Ti““ = Tibia etc. Eine vollständige Übersicht über die Abkürzungen findet sich in Tabelle 2.1. Die Benennung endet mit einer Zahl aus zwei Ziffern, wobei bei paarigen Skelettelementen ungerade Zahlen ein linkes Element und gerade Zahlen ein rechtes Element bezeichnen. So steht z.B. KS2-Fe-11 für einen linken Femur aus dem zweiten Sarg, KSM-Md-1 für eine Mandibula, die aus der Mainzer Stichprobe stammt usw.

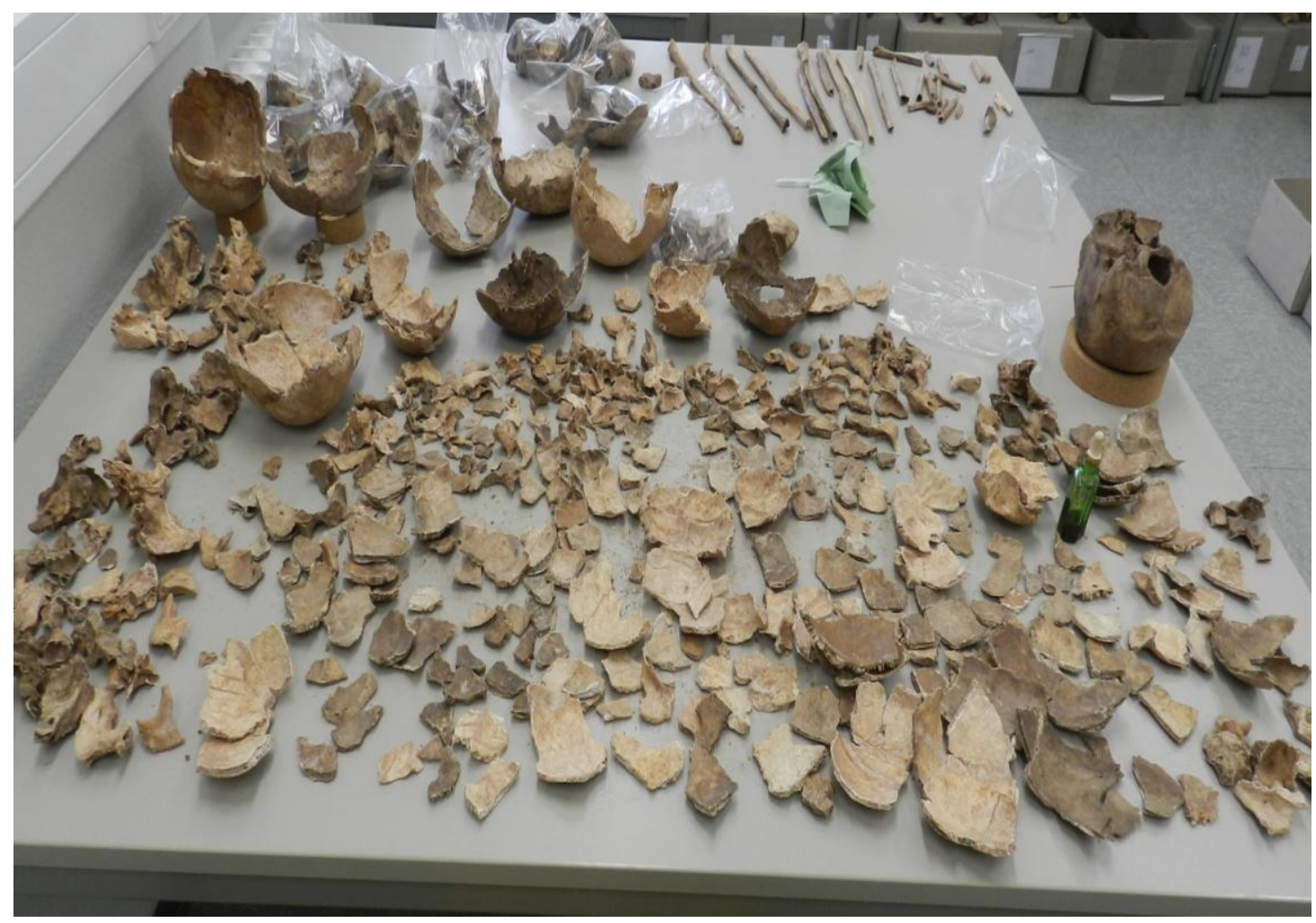

Abbildung 2.1: Rekonstruktion von Schädeln aus stark fragmentierten Bruchstücken. Gezeigt sind nur die rekonstruierten Schädel und Bruchstücke eines einzelnen Sarges (Nr. 4). 
Tabelle 2.1: Übersicht über die verwendeten Abkürzungen für den jeweiligen Knochentyp.

\begin{tabular}{c|c||c|c||c|c} 
Knochentyp & Abkürzung & Knochentyp & Abkürzung & Knochentyp & Abkürzung \\
\hline \hline Femur & $\mathrm{Fe}$ & Clavicula & $\mathrm{Cl}$ & Sacrum & $\mathrm{Sa}$ \\
\hline Tibia & $\mathrm{Ti}$ & Scapula & $\mathrm{Sc}$ & Os coxae & $\mathrm{Cx}$ \\
\hline Fibula & $\mathrm{Fb}$ & Calvarium & $\mathrm{Cv}$ & Dens & $\mathrm{De}$ \\
\hline Humerus & $\mathrm{Hu}$ & Mandibula & $\mathrm{Md}$ & Costa & $\mathrm{Cs}$ \\
\hline Radius & $\mathrm{Ra}$ & Maxilla & $\mathrm{Mx}$ & Patella & $\mathrm{Pt}$ \\
\hline Ulna & $\mathrm{Ul}$ & Vertebrae & $\mathrm{Ve}$ & Sternum & $\mathrm{St}$
\end{tabular}

Insgesamt finden sich in der Datenbank über 1750 Einträge. Nicht mitgezählt sind dabei die so genannten Sammelfunde, d.h. mehrere Knochen selben Typs, die zusammengefasst worden sind. Dabei handelt es sich hauptsächlich um Hand- und Fußknochen, Rippen(-fragmente) sowie Becken und Schädelelemente, aber auch Langknochenfragmente und isolierte Zähne, deren sichere Zuordnung zu einem Knochen bzw. Individuum ohne genetische Analysen faktisch kaum möglich ist. Die Datenbank beinhaltet auch weiterführende Informationen wie die Zuordnung zu einem Individuum, die Alters- und Geschlechtsdiagnose sowie Besonderheiten (Abb. 2.2). Die vollständige Version der Datenbank befindet sich auf der angefügten $C D$ (Datenbank_Kassel.mdb).

\begin{tabular}{|c|c|c|c|c|c|c|c|c|c|c|c|c|c|}
\hline \multicolumn{14}{|l|}{ F Fundkatalog KS } \\
\hline Fundnummi $\uparrow$ & o Skelet. & Typ . & Anz. & recht. & links . & Tier - & vollst. & - annäl. & fragn - & gekle . & isolie. & - Zuord 1 & vorhandene(r) Abschnitt(e) \\
\hline † KS3-UI-15 & Ulna & & & $\square$ & ఐ & $\square$ & 口 & $\square$ & 田 & $\square$ & $\square$ & KSO7 & prox Hälfte \\
\hline I KS4-Cx-26 & Os coxa & & & 四 & $\square$ & $\square$ & $\square$ & $\square$ & 四 & $\square$ & $\square$ & KSO7 & Ilium-Fragment \\
\hline$\mp$ KS5-UI-18 & Ulna & & & 甲 & $\square$ & $\square$ & $\square$ & $\square$ & 四 & $\square$ & $\square$ & KSO7 & prox Hälfte (Olecranon beschädigt) \\
\hline$\pm \mathrm{KS} 1-\mathrm{Cl}-07$ & Clavicula & & & $\square$ & 四 & $\square$ & $\square$ & 四 & $\square$ & 四 & 曰 & KSO8 & \\
\hline$\mp \mathrm{KS} 1-\mathrm{Cl}-08$ & Clavicula & & & 甲 & $\square$ & $\square$ & $\square$ & $\square$ & 四 & $\square$ & $\square$ & KSOB & sternale Hälfte \\
\hline I KS1-CX-28 & Os coxae & & & 曰 & $\square$ & $\square$ & $\square$ & $\square$ & 四 & $\square$ & $\square$ & KSOB & Os ilium: Facies auricularis, Incisura ischiadica major bis Linea arcuata ossis il \\
\hline I KS1-CX-31 & Os coxae & & & $\square$ & 田 & $\square$ & $\square$ & $\square$ & 甲 & $\square$ & $\square$ & KSO8 & Os ilium: Facies auricularis, Incisura ischiadica major bis Linea arcuata ossis il \\
\hline Ð KS1-Fe-11 & Femur & & & $\square$ & 四 & $\square$ & $\square$ & $\square$ & 田 & $\square$ & $\square$ & KSO8 & Diaphyse prox bis Trochanter minor \\
\hline ‡ KS1-HU-02 & Humerus & & & 甲 & $\square$ & $\square$ & $\square$ & $\square$ & 四 & $\square$ & $\square$ & KSO8 & dist $2 / 3$ und Teile dist Epiphyse \\
\hline I KS1-Ra-19 & Radius & & & $\square$ & 田 & $\square$ & $\square$ & $\square$ & 田 & $\square$ & $\square$ & KSO8 & Diaphyse, prox Epiphyse \\
\hline \pm KS1-Ra-20 & Radius & & & $\square$ & $\square$ & $\square$ & $\square$ & $\square$ & 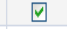 & $\square$ & $\square$ & KSO8 & Diaphyse, prox Metaphyse \\
\hline$\pm \mathrm{KS} 1-\mathrm{SC}-12$ & Scapula & & & $\square$ & $\square$ & $\square$ & $\square$ & $\square$ & $\square$ & $\square$ & $\square$ & KSO8 & Cavitas glenoidalis, Proc coracoideus und Hälfte Margo lateralis \\
\hline \pm KS1-UI-04 & Ulna & & & 四 & $\square$ & $\square$ & $\square$ & $\square$ & 四 & $\square$ & $\square$ & KSO8 & prox Epiphyse, Diaphyse \\
\hline \pm KS1-UI-09 & Ulna & & & $\square$ & 四 & $\square$ & $\square$ & $\square$ & 曰 & $\square$ & $\square$ & KSO8 & prox Epiphyse, Diaphyse \\
\hline \pm KS1-Ve-05 & Vertebra & a Cervic 1 & & $\square$ & $\square$ & $\square$ & $\square$ & $\square$ & 甲 & $\square$ & $\square$ & KSO8 & 2 Cervical-, 9 Thoracal-, 5 Lumbalwirbel (z.T. beschädigt) \\
\hline I KS3-CV-20 & Calvariur & & & $\square$ & $\square$ & $\square$ & $\square$ & $\square$ & 四 & 四 & $\square$ & KSO8 & 2 Fragmente: Parietel re/li (fragm.), Frontale (fragm.) \\
\hline$\mp$ KS3-Md-03 & Mandibu & & & $\square$ & $\square$ & $\square$ & $\square$ & $\square$ & 田 & 田 & $\square$ & KSO8 & Alveolarsaum fragmentiert \\
\hline & & & & m & $\square$ & $\square$ & $\square$ & $\square$ & 网 & ח & $\square$ & & \\
\hline
\end{tabular}

Abbildung 2.2: Screenshot der Access-Datenbank. Die erste Spalte gibt die Bezeichnung des Knochens nach dem vorher benannten System an, es folgen weitere Informationen wie etwa Körperseite, Fragmentierunggrad, Zuordnung und Deskription (nicht im Bild).

\section{Bodenproben}

Bevor die Knochen dem Prozess der Reinigung unterworfen wurden, wurde ein wenig anhaftendes Erdreich sichergestellt. Von diesen Bodenproben wurden ebenfalls DNA-Extrakte hergestellt (s. Kap. 3.4.2.), um die mikrobielle Fauna des Liegemilieus zu qualifizieren. Das entworfene Analysesystem für Krankheitserreger muss hochspezifisch für ebendiese Organismen sein und darf keine Amplifikationen bei anderen Bakterienarten aufweisen. Von den getrockneten Bodenproben wurden 0,2g abgewogen und in ein $2 \mathrm{ml}$ Eppendorf-Cup überführt, die bei $4^{\circ}$ Celsius im Kühlschrank bis zur Extraktion gelagert wurden. 


\section{$\underline{\text { Positivkontrollen der Krankheitserreger }}$}

Als Positivkontrolle für das Analysesystem von S. typhi resp. S. paratyphi dienten Bakterienlysate, die von Prof. Dr. Uwe Groß vom Institut für Medizinische Mikrobiologie, Göttingen, bereitgestellt wurden. Die Bakterienstämme S. typhi E005 und $S$. paratyphi A wurden auf einer Agarplatte etwa eine Woche lang angezüchtet und die entstandenen Kolonien anschließend in Wasser suspendiert. Die Bakterien wurden dann durch Hitze getötet und mittels Ultraschallbehandlung zerstört, so dass die DNA frei in Lösung gehen konnte. Diese Lysate wurden für 5 Minuten bei 6000rpm zentrifugiert, 10 $\mu 1$ des Überstandes wurden abgenommen und 1:10 mit HPLCWasser verdünnt. Bei Bedarf wurde eine Verdünnungsreihe angelegt.

Für Positivkontrollen von Bartonella quintana wurden von zwei Stämmen (JK31 bzw. Toulouse) je ein Lysat von Prof. Volkhard Kempf von der Universität Frankfurt bereitgestellt. Die Lysate wurden wie vorher beschrieben behandelt.

Positivkontrollen für Rickettsia prowazekii sind schwierig zu bekommen, da das Bakterium schwer zu kultivieren ist, daher wurde auf eine Gendatenbank zurückgegriffen. Von Prof. Siv Andersson von der Universität Uppsala, Schweden, wurden Klone bereitgestellt, die das gesuchte Zielgen von $R$. prowazekii enthalten. Die Lysate wurden wie vorher beschrieben behandelt.

Von Borrelia recurrentis wurden Proben von Herrn Prof. Dr. Reinhard Wallich und Christiane Brenner aus dem Institut für Immunologie der Universität Heidelberg bereitgestellt.

\section{$\underline{\text { Rezente Kontrollproben }}$}

Zum Erkennen von Kontaminationen durch den Bearbeiter und als Positivkontrolle wurden Speichelextrakte von Bearbeitern des Skelettkollektivs und des anthropologischen Institutes verwendet. Die Extrakte wurden in den meisten Fällen bereits zu früheren Zeitpunkten gewonnen und lagern tiefgekühlt bei $-20^{\circ}$ Celsius. Die Typisierungen der Mitarbeiter und Bearbeiter (u.a. genetische Fingerabdrücke) sind in einer internen Datenbank der Abteilung Historische Anthropologie gespeichert. 


\section{Methoden}

\subsection{Zuordnung von Skelettelementen zu Individuen}

Die Zuordnung geschah nach dem in Zipp (2010) und Grumbkow et al. (2012) geschilderten Vorgehen und wird im Folgenden nur kurz skizziert. Nach der Identifizierung und Seitenzuweisung der Skelettelemente begann die schrittweise Zuordnung der Knochen zu Individuen. Zunächst wurden jeweils linke und rechte Stücke gleicher Knochentypen zu Paaren geordnet. Dies geschah jeweils erst für die Knochen eines Sarges und erst im Anschluss sargübergreifend. Im Weiteren wurden Humeri, Radii und Ulnae zu oberen sowie Femora, Tibiae und Fibulae zu unteren Extremitäten zugeordnet. Abschließend wurden obere und untere Extremitäten zusammengeführt und mit Schulter- und Beckengürtel, Vertebrae und cranialen Elementen ergänzt. Die Individuen erhielten abschließend eine zufällige Nummerierung, die sich aus „KS“ und zwei Ziffern zusammensetzt (z.B. KS01, KS02, usw.). Die Zuordnung stützt sich dabei auf mehrere Kriterien, die im Folgenden kurz erläutert werden. Dabei stehen die Kriterien nicht immer streng hierarchisch übereinander, sondern können sich ergänzen oder bauen aufeinander auf.

Bedingt durch den bilateralen Aufbau des menschlichen Körpers sind die paarigen Knochen der beiden Körperhälften annähernd symmetrisch beschaffen und stimmen beim gesunden Menschen in der Regel in Größe und Robustizität überein. Bei paarigen Knochen, die sich deutlich in ihrer Größe unterscheiden, ist davon auszugehen, dass sie zu verschiedenen Individuen gehören (Brothwell 1972). Geringe Asymmetrien finden sich jedoch auch innerhalb eines Individuums wieder und zeigen sich bei bestimmten Knochentypen fast schon regelhaft (Martin und Saller 1959). So wird die Robustizität eines Knochens maßgeblich von der Belastung bestimmt, so dass bei einer einseitigen Nutzung einer Körperhälfte (etwa durch Händigkeit oder Standbein) die Knochen der bevorzugten Seite robuster erscheinen können als die der Gegenseite. Bei der Zuordnung von oberen und unteren Extremitäten sollte eine Stimmigkeit in den Proportionen erreicht werden.

Damit im Zusammenhang und ebenfalls von der Beanspruchung abhängig sind die Ausprägungen zahlreicher Oberflächenstrukturen, die als Ansatzstelle für Muskeln, Sehnen und Bänder dienen. Durch unterschiedliche Belastung erscheinen z.B. Sulci, Cristae, Tubera oder Processus unterschiedlich stark und geben dem Knochen, obwohl im Grundaufbau natürlich gleich, eine variable Erscheinungsform. Auch hier gilt, dass sich die paarigen Knochen eines Individuums stärker ähneln sollten als zwischen verschiedenen Individuen.

Gerade für die Zuordnung zu Extremitäten ist weiterhin die Passform der Gelenke zueinander zu berücksichtigen. Die Epiphysen zueinander gehöriger Knochen müssen gemeinsam ein passendes und funktionsfähiges Gelenk bilden. Dies gilt vornehmlich für die Verbindung des Caput femoris mit dem Acetabulum (Hüftgelenk), 
der Femurcondylen mit dem proximalen Ende der Tibia (Kniegelenk) und des distalen Humerusendes mit den proximalen Ulna- und Radiusende (Ellbogengelenk).

Auch Hinweise auf das Alter eines Individuums können für eine Zuordnung von entscheidender Bedeutung sein. Gerade in den Altersklassen Juvenis und frühes Adultas, in denen das regelhafte Anwachsen der Epi- und Apophysen charakteristisch ist, können auch isolierte Knochen eine sehr enge Eingrenzung des Sterbealters ermöglichen. Somit kann z.B. ein Femur, dessen proximale Epiphyse noch nicht angewachsen ist, nicht zu einem Individuum gehören, dessen proximalen Humerusepiphysen bereits angewachsen sind (vgl. Kap. 1.3.).

Bedingt durch chemische und physikalische Faktoren des direkten Liegemilieus kommt es am bodengelagerten Knochen zu postmortalen Veränderungen (Dekompositionsphänomenen). Dabei kann die Knochenoberfläche durch Einwanderung mineralischer und organischer Bodenstoffe verschiedene Färbungen annehmen (Hunger 1978; Wieberg und Wescott 2008), die für nahe zusammenliegende Knochen eines Individuums in der Regel ähnlicher sein sollten als für Knochen verschiedener Individuen. Da die genaue Bestattungslage der vorliegenden Individuen jedoch nicht bekannt ist, wurde dieses Kriterium eher untergeordnet betrachtet. Obwohl die Knochen zum Teil sehr auffällige farbliche Musterungen zeigen, wurde versucht, dieses Merkmal bei den meisten Skelettelementen lediglich unterstützend einzubeziehen.

Auf eine Zuordnung von Skelettelementen, deren Zugehörigkeit nicht mit den genannten, morphologischen Kriterien überprüft werden konnte, wurde an dieser Stelle verzichtet. Dies betrifft insbesondere Hand- und Fußknochen, Rippen, Becken-, Kiefer- und Schädelstücke. Zwar wäre eine Zuordnung zumindest auf Plausibilitätsniveau für einige der Stücke möglich (etwa durch eine auffällige Färbung), jedoch lassen sich die generellen großen Unsicherheiten und die geringe Überprüfbarkeit eine definitive Zuordnung zu einem Individuum kaum wissenschaftlich begründen. Abbildung 3.1 zeigt an Beispielen von rechten Humeri die Variabilität der Skelettelemente in den oben genannten Kriterien.

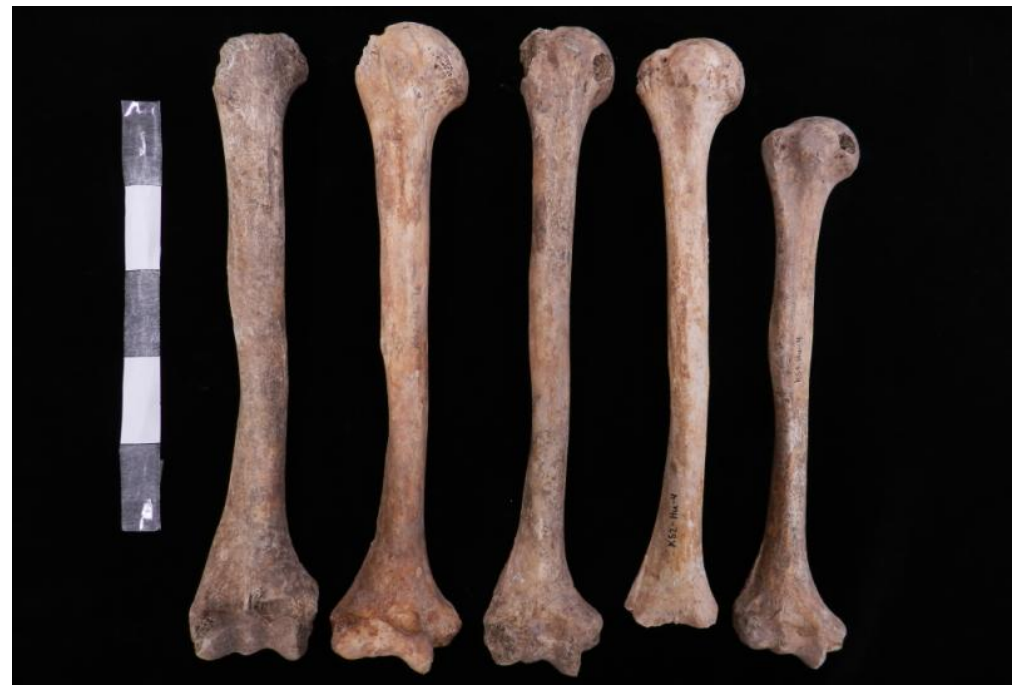

Abbildung 3.1: Rechte Oberarmknochen (Humeri). Die Variabilität in Größe, Robustizität, Alter und Färbung ermöglicht eine Zuordnung zu Individuen. 


\subsection{Morphologische und morphometrische Befundung}

Nach der Zuordnung der Skelettelemente und stichprobenartigen Überprüfung (vgl. Kap. 3.4.4.) wurden die Individuen morphologisch und morphometrisch befundet. Dazu wurde eine morphologische Alters- und Geschlechtsdiagnose erstellt, wenn möglich eine Körperhöhenrekonstruktion durchgeführt, und auf Abweichungen der Regelanatomie geachtet (vgl. Kap. 1.3.). Durch den hohen Fragmentierungsgrad der Knochen konnten die meisten Kriterien für eine Alters- und Geschlechtsdiagnose dabei nicht angewendet werden. Für jedes Individuum wurde eine Übersichtsaufnahme der vorliegenden Skelettelemente erstellt.

\subsubsection{Geschlechtsbestimmung}

Die häufigsten zu beurteilenden Merkmale für die Geschlechtsdiagnose waren die Weite der Incisura ischiadica major und der Arc composé. Nur in seltenen Fällen waren komplette Ossa coxae überliefert, die eine Beurteilung weiterer Merkmale, etwa der S-Krümmung der Crista iliaca oder des Angulus' subpubicus erlaubten. Von den Kriterien des Schädels war das Planum nuchale noch vergleichsweise häufig überliefert, wobei auch hier in den meisten Fällen eine starke Fragmentierung nur eingeschränkte Aussagen ermöglichte. Die Ausprägung der Merkmale wurde mit Referenzmaterial verglichen und eine Tendenz für jedes Merkmal einzeln festgestellt. Schließlich wurde die endgültige Diagnose über alle Merkmale gestellt. Bei Abweichungen zwischen den Merkmalen wurde denjenigen des Beckens der Vorzug gegeben.

\subsubsection{Altersschätzung}

Für die Altersdiagnose konnten in der Regel der Verknöcherungsgrad der Schädelnähte (wenngleich oft nur fragmentarisch), der Abrasionsgrad der Zähne sowie in einigen Fällen der Epiphysenstatus beurteilt werden. Für die Nähte und den Abrasionsgrad wurde dabei nach der Methode von Herrmann et al. (1990) vorgegangen: Die Ausprägungen der Merkmale wurde in altersabhängige Kategorien eingeteilt, welche eine Ermittlung des ungefähren Sterbealters erlaubt. Die Definitionen der einzelnen Kategorie sind dort nachzulesen. Bei offenen oder gerade angewachsenen Epiphysen konnte durch den Vergleich mit publizierten Daten des regelhaften Anwachsens das Sterbealter relativ genau bestimmt werden.

\subsubsection{Körperhöhenrekonstruktion}

Für die Berechnung der Körperhöhe wurden die intakten Langknochen mit Hilfe eines Messbretts vermessen. Dabei wurden die entsprechenden Messstrecken nach Pearson (1899) verwendet und der gemessene Wert in die Schätzformel eingesetzt (Tab. 3.1). Konnten mehrere Knochen für die Berechnung herangezogen werden, wurde der Mittelwert der Berechnungen gebildet. 
Tabelle 3.1: Regressionsformeln für die Körperhöhenrekonstruktion nach Pearson (1899).

\begin{tabular}{|c|c|c|c|c|c|}
\hline \multirow{4}{*}{$\begin{array}{l}\text { Erwachsene } \\
\text { männliche } \\
\text { Individuen }\end{array}$} & $70,641+2,894 * \mathrm{H} 1$ & $\pm 3,3 \mathrm{~cm}$ & \multirow{4}{*}{$\begin{array}{c}\text { Erwachsene } \\
\text { weibliche } \\
\text { Individuen }\end{array}$} & $71,475+2,754 * \mathrm{H} 1$ & $\pm 3,5 \mathrm{~cm}$ \\
\hline & $85,925+3,271 * \mathrm{R} 1$ & $\pm 4,0 \mathrm{~cm}$ & & $81,224+3,343 * R 1$ & $\pm 4,1 \mathrm{~cm}$ \\
\hline & $81,306+1,880 * \mathrm{~F} 1$ & $\pm 3,3 \mathrm{~cm}$ & & $72,844+1,945 * \mathrm{~F} 1$ & $\pm 3,3 \mathrm{~cm}$ \\
\hline & $78,664+2,376 * \mathrm{~T} 1$ & $\pm 3,5 \mathrm{~cm}$ & & $74,774+2,352 * \mathrm{~T} 1$ & $\pm 3,4 \mathrm{~cm}$ \\
\hline
\end{tabular}

Die Formeln benutzen dabei jeweils die größte Länge des Humerus (=H1), des Radius (=R1) und des Femur (=F1) sowie die ganze Länge der Tibia (= der Abstand der Facies articularis cranialis der lateralen Condyle bis zur Spitze des Malleolus medialis, T1) (aus Herrmann et al. 1990).

\subsubsection{Abweichungen von der Regelanatomie}

Alle Skelettelemente wurden auf Abweichungen von ihrer Regelanatomie hin untersucht. Dafür wurden die Knochen mit Referenzmaterial aus der Sammlung der Abteilung Historische Anthropologie verglichen. Dies gilt auch für Skelettelemente, die aufgrund ihrer Beschaffenheit und/oder des Fragmentierungsgrads nicht zu Individuen zugeordnet werden konnten. Die Befunde wurden fotographisch dokumentiert. 


\subsection{Histologie}

Für die Beurteilung der Knochenbinnenstruktur wurde aus den linken Femora (falls nicht vorhanden: rechte Femora, im Einzelfall Humeri) der Individuen mittels einer Dentalbohrmaschine (Dremel®Multi ${ }^{\mathrm{TM}}$ ) mit aufgesetztem Diamantsägeblatt (Horico) ein etwa 1 x $2 \mathrm{~cm}$ großes Stück der anterioren Diaphysenmitte herausgesägt. Die Proben wurden in Silikonformen gebettet, mit einer Mischung aus 100 Gewichtsteilen des erwärmten Epoxidharzes „Biodur ${ }^{\circledR}$ E12“ mit 28 Teilen des Härters „Biodur® E1“ überschichtet und für drei Tage ausgehärtet. Nach Entfernung der Einbettungsformen wurden die Präparate zunächst getrimmt und anschließend mit Hilfe eines Sägeschnittmikrotoms (Leitz SP 1600) planparallele Dünnschnitte angefertigt (Abb. 3.2). Diese wurden, nach einer Qualitätskontrolle unter dem Mikroskop, zwischen Objektträgern getrocknet und dabei zur Vermeidung von Aufwerfungen gepresst. Die Schnitte wiesen dabei Stärken zwischen $80 \mu \mathrm{m}$ und $120 \mu \mathrm{m}$ auf, abhängig von der Qualität des Knochens. Die trockenen Dünnschnitte wurden unter Verwendung des Einschlussharzes Eukitt® auf Objektträger aufgeklebt und mit einem Deckglas fixiert. Nach einer erneuten 24stündigen Trocknung in horizontaler Lage erfolgte die Auswertung am Durchlichtmikroskop bei 40-facher Vergrößerung. Durch Einsatz eines Polarisationsfilters konnte eine stärkere Kontrastierung der Präparate erreicht werden. Zur besseren Einordnung in die Altersklassen wurden die Präparate mit Dünnschnitten von Referenzserien bekannter Altersklassen und den jeweiligen mikrostrukturellen Merkmalen verglichen.

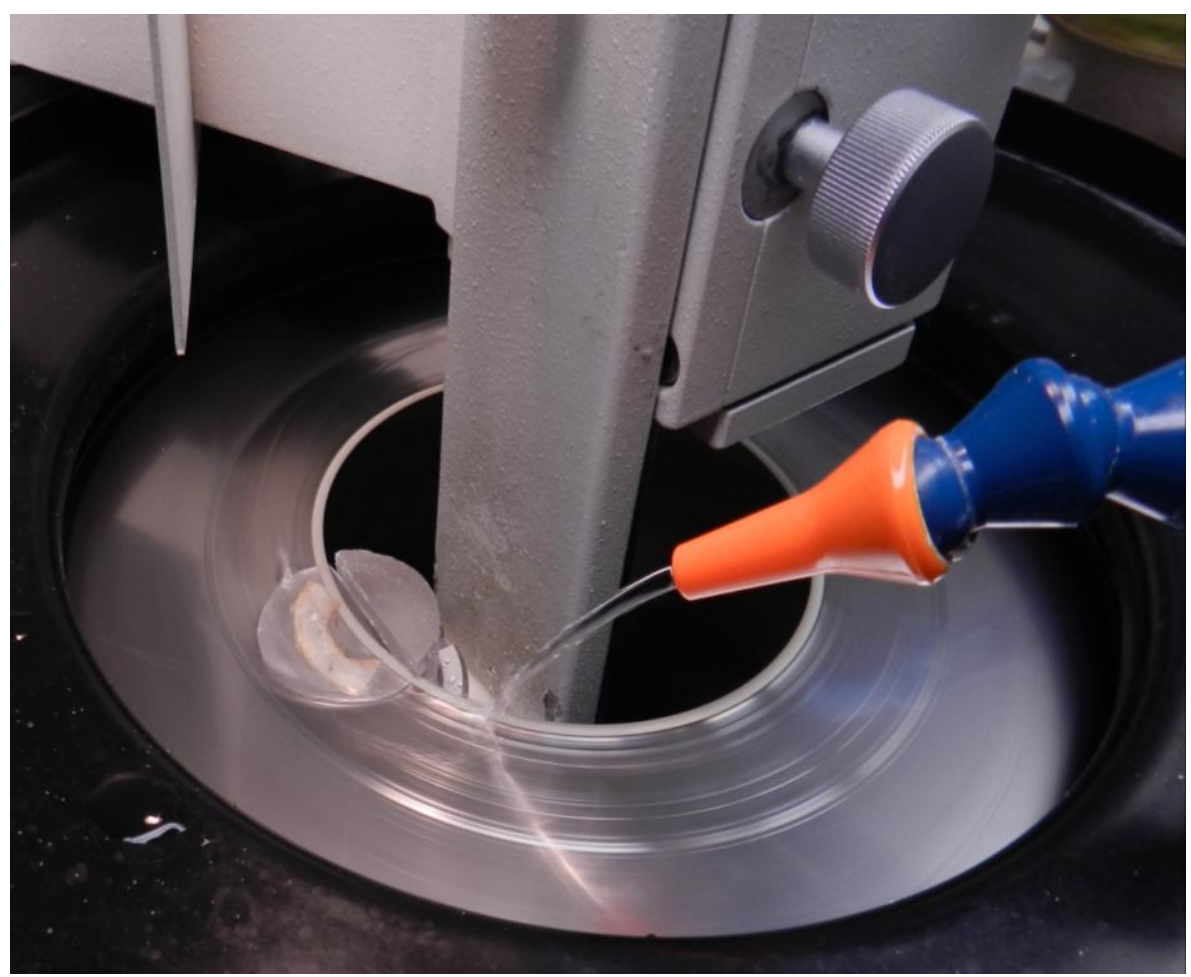

Abbildung 3.2: Anfertigung eines Knochendünnschnitts mit Hilfe eines Mikrotoms unter Wasserfluss. 


\subsection{DNA-Analytik}

\section{$\underline{\text { 3.4.1. Kontaminationsprävention }}$}

Die Analyse von alter bzw. degradierter DNA, die meistens in geringen Mengen vorliegt, ist überhaupt erst durch das Konzept der PCR möglich geworden. Die hohe Sensitivität dieser Reaktion, die es gewährleistet, auch geringste Spuren von DNA zu vervielfältigen, ist gleichzeitig aber auch ihr größter Nachteil: bereits ein Eintrag kleinster Mengen rezenter DNA reicht aus, um die Analyse der eigentlichen Probe zu überdecken und kann so zu falschen Ergebnissen führen. Deswegen muss beim Bearbeiten der Proben das Kontaminationsrisiko so gering wie möglich gehalten werden. Um den Erfolg der Prävention zu überprüfen, wurden regelmäßig Leerkontrollen in die PCR mit eingebracht.

\section{$\underline{\text { Kontamination durch den Bearbeiter }}$}

Die größte Gefahr durch rezente Kontamination geht vom Bearbeiter selbst aus: Hautschuppen, Haare, Speichel oder Tränenflüssigkeit können in die PCR eingebracht werden, selbst geringste Mengen an rezenter DNA können dann zu falschpositiven Ergebnissen führen (Kitchin et al. 1990). Um dieses Risiko zu senken, wurde während der gesamten Probenvorbereitung und im Prä-PCR-Bereich ein Schutzkittel sowie Mundschutz, OP-Haube und Einmalhandschuhe getragen. Um mögliche Kontaminationen sofort als solche zu identifizieren, wurde außerdem der genetische Fingerabdruck und weitere genetische Daten aller im Institut Arbeitenden in einer Datenbank gespeichert, so dass die gewonnenen Ergebnisse abgeglichen werden können.

\section{$\underline{\text { Kontamination durch das verwendete Material }}$}

Auch das verwendete Material, wie z.B. die Eppendorf-Cups, die Pipettenspitzen und die verwendeten Chemikalien, können mit DNA verunreinigt sein (Schmidt et al. 1995). Um die Möglichkeit von falschen Ergebnissen durch solche Verunreinigungen zu minimieren, wurden die Materialien vor der Benutzung mit UV-Licht bestrahlt, die enthaltene DNA also künstlich degradiert. Zusätzlich wurde in einem speziellen UV-Kabinett pipettiert, bei dem nach erfolgter Arbeit alle Oberflächen mit UV-Licht bestrahlt wurden. Somit soll die Anzahl intakter Zielsequenzen möglichst unter die Nachweisgrenze gebracht werden.

\section{$\underline{\text { Kreuzkontamination zwischen den Proben }}$}

Um eine Kontamination zwischen den Proben zu verhindern, wurden hauptsächlich Einwegmaterialien (z.B. Pipettenspitzen) verwendet. Wo diese Praxis unrentabel wäre, also z.B. bei Bohrköpfen, Pinzetten oder Skalpellen, wurden die verwendeten Materialien nach jeder Benutzung gründlich mit Seife (Alconox®), destilliertem Wasser und 70\%igem Ethanol gereinigt. Dies gilt auch für die gesamten Arbeitsflächen sowie alle Oberflächen, an denen es zu Kontamination von z.B. Knochenpulver hätte kommen können. 


\section{Carry-over}

Als Carry-over wird das Verschleppen von PCR-Produkten vorhergehender Amplifikationen in die Gefäße der aktuellen PCR bezeichnet, wo sie bevorzugt amplifiziertwerden (Kwok 1990). Um solches zu verhindern, wurde eine strikte Trennung von Prä- und Post-PCR-Laboren eingeführt. Außerdem gilt die Einbahnstraßenregelung, d.h. die Bearbeiter dürfen die Laboratorien mit derselben Kleidung nur von Prä- in Richtung Post-PCR-Bereich betreten.

\subsubsection{DNA-Extraktion}

Im Laufe dieser Arbeit wurden die Extraktionsverfahren mehrfach überarbeitet und weiter optimiert. Grundsätzlich kamen zwei verschiedenen Vorgehen zum Einsatz: zum einen die Verwendung des Biorobot EZ1@ der Firma Qiagen, zum anderen eine manuelle Extraktion mit Hilfe der MinElute ${ }^{\circledR}$ Säulchen (ebenfalls Fa. Qiagen). Beide Vorgehen haben Vor- und Nachteile, die sich gemeinsam jedoch gut ergänzen können. So stellt der Biorobot eine gleich bleibende Probenbehandlung sicher und liefert hochreine DNA-Extrakte, es kommt jedoch zu einem gewissen Grad zu einem DNAVerlust, d.h. nur eine bestimmte Menge an DNA kann aus der Probe gewonnen werden. Bei dem manuellen Extraktionsverfahren hingegen kann deutlich mehr DNA pro Probe isoliert werden, wobei die Aufreinigung unter Umständen nicht vollständig stattfindet und Spuren von Inhibitoren weiterhin im Extrakt vorhanden sind. Je nach Probenbeschaffenheit kann sich eine der beiden Verfahren als das bessere herausstellen, wobei aufgrund der höheren DNA-Ausbeute und der geringeren Kosten zunächst immer das manuelle Protokoll angewendet worden ist. Nur bei offensichtlich stark inhibierten Extrakten wurde zusätzlich das Biorobot-Protokoll durchgeführt. Im Folgenden sind die einzelnen Schritte der Protokolle aufgeführt. Dabei sind die Vorbereitung und die Lyse des Knochenpulvers bei beiden Vorgehensweisen gleich, nur die Aufreinigungsschritte unterscheiden sich. Die Volumina der Reagenzien sind auf den Einsatz von 0,25g Knochenpulver optimiert. Entsprechend kann das Protokoll für mehr oder weniger Knochenpulver angepasst werden.

\section{Vorbereitung}

Für beide Protokolle muss der Knochen zunächst pulverisiert werden. Dazu wurde ein etwa 1 x $2 \mathrm{~cm}$ großes Stück mit Hilfe eines Handbohrers mit Diamantsägeblatt herausgesägt, die Oberfläche zum Schutz vor anhaftender Kontamination abgetragen und anschließend mittels Stahlmörser zerkleinert. Die erhaltenen Fragmente wurden in einer Kugelschwingmühle bei 24 Schwingungen pro Sekunde für eine Minute zu einem feinen Pulver zerstoßen. Bei längerer Lagerung wurde das Pulver bei $-20^{\circ} \mathrm{C}$ tiefgefroren. Die eingesetzte Knochenmenge pro Extrakt betrug in der Regel 0,25g, die mittels Feinwaage abgewogen wurden.

Lyse

Während im Folgenden das eingesetzte EDTA die Auflösung der Knochenmatrix durch Bindung der Calcium-Ionen bewirkt, ist die Zugabe von Proteinase K als auch 
SDS notwendig für den Abbau von Proteinstrukturen, damit sich die DNA anschließend frei in der Lösung befindet. 0,25g Knochenpulver wurden mit 3900 $\mu$ l EDTA $(0,5 \mathrm{M}, \mathrm{pH} 8,0, \mathrm{Fa}$. Invitrogen) und $100 \mu \mathrm{l}$ Proteinase $\mathrm{K}$ (Fa. Merck) versetzt und über Nacht bei $37^{\circ} \mathrm{C}$ für $18 \mathrm{Std}$. im Rotator inkubiert. Es folgte eine weitere Zugabe von $50 \mu l$ Proteinase $\mathrm{K}$ und eine Inkubation für $2 \mathrm{~h}$ bei $56^{\circ} \mathrm{C}$. Für einen letzten Inkubationsschritt wurden $50 \mu 1$ SDS $(20 \mathrm{mg} / \mathrm{ml}$, Fa. Sigma Life Science) zugegeben und bei $65^{\circ} \mathrm{C} 5 \mathrm{~min}$ rotiert. Zur Sedimentierung von nicht löslichen Feststoffen wurde abschließend für $3 \mathrm{~min}$ bei $3300 \mathrm{rcf}$ zentrifugiert.

\section{Aufreinigung (manuelles Protokoll)}

Durch die verschiedenen Waschpuffer soll die DNA von anderen Bestandteilen des Lysats getrennt werden. Im ersten Waschschritt wurden 16ml PB-Buffer (Qiagen) und 100 $\mu 1$ Natriumacetatpuffer (pH 5.2, Fa. Sigma Life Science) in einem FalconTube (Fa. Sarstedt) vorgelegt und das zentrifugierte Lysat hinzugefügt. Nach manueller Mischung und anschließender Zentrifugation bei 3300rcf für 3min wurde das Gemisch mittels Vakuum über MinElute-Säulchen (Qiagen) abgesaugt. Dafür wurde das QiaVac-System (Qiagen) mit entsprechender Ausstattung inkl. Trichteraufsatz für große Volumina genutzt (Abb. 3.3). Das angelegte Vakuum betrug -800mbar. Nach erfolgreicher Durchführung erfolgten weitere Waschschritte jeweils mittels PE-Buffer (Qiagen). In einem ersten Durchgang wurden $700 \mu 1$ Puffer auf die Säule gegeben und nach $5 \mathrm{~min}$ abgesaugt. Es folgte eine zweimalige Wiederholung mit $700 \mu 1$ Puffer ohne Wartezeit. Um den ethanolhaltigen Puffer vollständig aus der Säule zu entfernen, wurde abschließend für $1 \mathrm{~min}$ bei $16.100 \mathrm{rcf}$ zentrifugiert und die Säule bei geöffnetem Deckel 15min

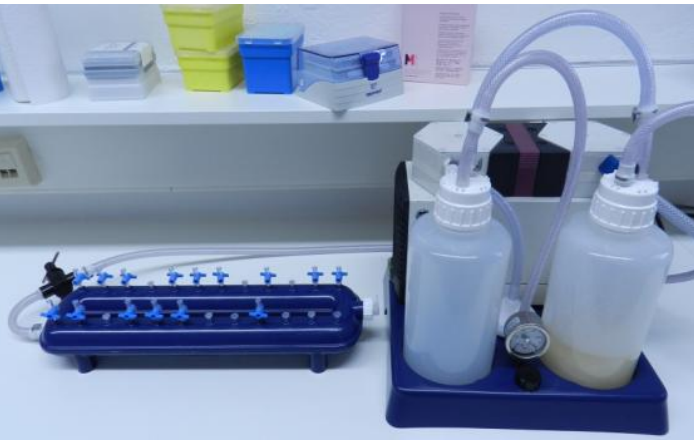

Abbildung 3.3: QiaVac-System. Die Vakuumpumpe (rechts) baut das Vakuum für den Probenständer (links) auf. stehen gelassen.

Die Säulen wurden für die Eluierung der DNA auf 1,7ml-Cups (Sarstedt) gesteckt. $30 \mu 1$ des auf $56^{\circ} \mathrm{C}$ erhitzten Wassers (Ambion) wurde auf die Säule pipettiert und nach $5 \mathrm{~min}$ bei $16.100 \mathrm{rcf}$ für $1 \mathrm{~min}$ zentrifugiert. In einem zweiten Schritt wurden

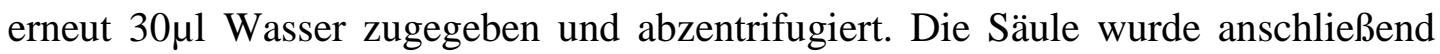
verworfen und das Extrakt bis zur weiteren Verwendung bei $4^{\circ} \mathrm{C}$ bzw. bei längerer Lagerung bei $-20^{\circ} \mathrm{C}$ gelagert. 


\section{$\underline{\text { Aufreinigung (EZ1) }}$}

Statt die etwa 4ml Lysat über die Waschpuffer zu reinigen, konnten alternativ Protokolle für den EZ1-Roboter (Qiagen) angewendet werden (Abb. 3.4), wofür das Volumen jedoch zunächst mittels Zentrifugation verkleinert werden musste. Die Zentrifugation wurde über Amicons (Fa. Merck) mit einer Trenngröße von 30kDa bei 3300rcf so lange durchgeführt, bis das gewünschte Volumen erreicht wurde. Zwei unterschiedliche EZ1Protokolle kamen zum Einsatz: für das trace-Protokoll der forensic card musste das Volumen $200 \mu 1$ betragen, für das large volume-Protokoll der bone card $1500 \mu 1$. Der EZ1 wurde entsprechend den Herstellerangaben mit dem jeweiligen Kit ausgestattet und das Protokoll nach Herstellerangaben durchgeführt. Das Elutionsvolumen

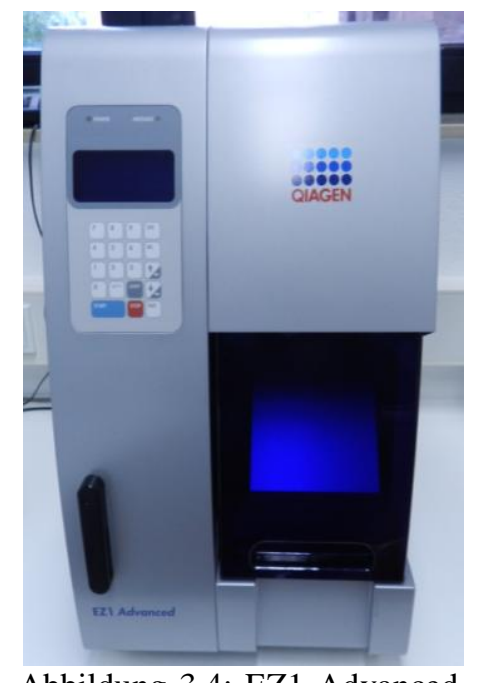

Abbildung 3.4: EZ1 Advanced (Qiagen). betrug $50 \mu 1$, die Extrakte wurden ebenfalls bis zur weiteren Verwendung bei $4^{\circ} \mathrm{C}$ bzw. bei längerer Lagerung bei $-20^{\circ} \mathrm{C}$ gelagert.

\section{DNA-Extraktion aus Bodenproben}

Für die Extraktion von DNA aus Bodenproben wurden 0,2g Sediment abgewogen und mit einem Mörser fein zerstoßen. Nach Zugabe von 400 $\mu 1$ G2-Puffer (Qiagen) und $30 \mu \mathrm{l}$ Proteinase K wurden nach Inkubation bei $56^{\circ} \mathrm{C}$ für $2 \mathrm{~h} 200 \mu \mathrm{l}$ Überstand in den EZ1 überführt und nach dem trace-Protokoll extrahiert. Das Elutionsvolumen betrug $100 \mu 1$, die Lagerung fand analog wie bereits erwähnt statt.

\section{DNA-Extraktion aus menschlichen Kontrollproben}

Für die Extraktion von rezenten, menschlichen Kontrollproben wurde ein Mundschleimhautabstrich mit Hilfe eines Wattestäbchens angefertigt. Die Watte wurde in ein $2 \mathrm{ml}$ Eppendorf-Cup überführt und mit $400 \mu \mathrm{l}$ G2-Puffer (Qiagen) versetzt. Anschließend wurden $10 \mu 1$ Proteinase K zugegeben und bei $56^{\circ} \mathrm{C}$ bei $350 \mathrm{rpm}$ auf dem Heizblock für eine Stunde inkubiert. 200 $\mu 1$ Volumen wurden anschließend in den EZ1 überführt und nach dem trace-Protokoll extrahiert. Das Elutionsvolumen betrug $100 \mu 1$, die Lagerung fand analog wie bereits erwähnt statt.

\section{DNA-Extraktion bakterieller Proben}

Von $R$. prowazekii wurden bereits DNA-Isolate aus der Gendatenbank geschickt (vgl. Kap. 2.). Für die restlichen Bakterienzelllysate wurde keine gesonderte Extraktion durchgeführt. Da die Bakterien kultiviert worden waren und die Zellen im jeweiligen Labor zunächst in Wasser suspendiert und anschließend mittels Ultraschall oder Hitze zerstört wurden (vgl. Kap. 2.), lag die DNA bereits in einem für eine PCR geeigneten Medium vor. 


\subsubsection{Primerdesign}

Neben der DNA-Extraktion ist ein hochsensitives Analysesystem entscheidend für eine erfolgreiche, PCR-gestützte Analyse. Neben den optimalen Verhältnissen der Chemikalien zueinander wird dies durch die Wahl der Primer erreicht. Die Primer müssen zum einen spezifisch für den zu untersuchenden Genort sein, gleichzeitig dürfen keine unspezifischen Nebenprodukte gebildet werden. Zum anderen müssen sie hochsensitiv sein, um selbst geringste Mengen an DNA analysieren zu können.

Die Spezifität wird entscheidend durch die Länge der Primer beeinflusst. Für das menschliche Genom mit etwa 3,2 Milliarden Basen wird statistisch gesehen ab einer Länge von 18 Basen die Sequenz eines Primers einmalig. Dies gilt jedoch nur für eine rein zufällige Basenabfolge - Sequenzdopplungen im Genom oder Analogien zu anderen Spezies müssen immer überprüft werden. Gerade in den letzten Jahren hat sich die Überprüfung der Spezifität durch die Möglichkeiten des basic local alignment search tools (BLAST, http://blast.ncbi.nlm.nih.gov/Blast.cgi) entscheidend vereinfacht. Durch eine einfache Eingabemaske kann durch Zugriff auf die Sequenzbibliothek des National Centre for Biotechnological Information (NCBI, http://www.ncbi.nlm.nih.gov/) auf mögliche Nebenprodukte geprüft werden.

Die Spezifität der Primer kann weiter entscheidend durch ein geeignetes Energieprofil beeinflusst werden (vgl. Abb. 3.5, Hummel 2003). Durch eine hohe Bindungsenergie am 5'-Ende der Primer und eine relativ niedrige Bindungsenergie am 3'-Ende wird eine Amplifikation nur dann stattfinden, wenn der Primer tatsächlich komplett auf die Bindungsstelle passt. Stattdessen könnte ein umgekehrtes Energieprofil dazu führen, dass auch unspezifische Nebenprodukte entstehen können: Ein fest gebundenes 3'-

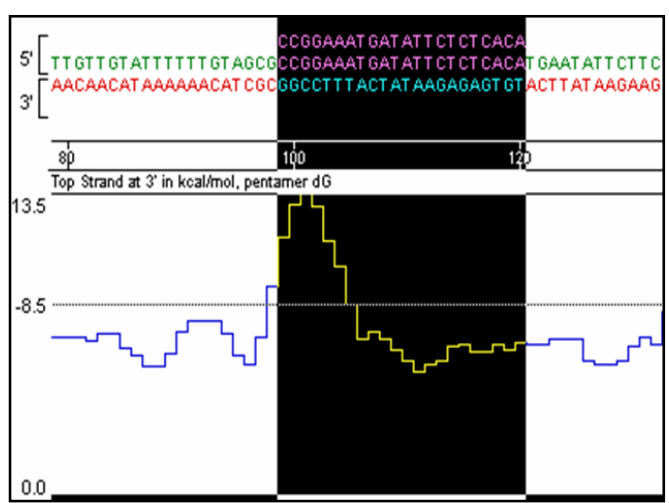

Abbildung 3.5: Optimales Energieprofil eines hypothetischen Primers. Die Bindung am 5'Ende ist wesentlich höher als am 3'-Ende. yAchse $=$ Bindungsenergie in $\mathrm{kcal} / \mathrm{mol}$. Ende ermöglicht dann eine Amplifikation, auch wenn das 5'-Ende nicht passt.

Die Sensitivität des Analysesystems wird durch die Vermeidung von primerinternen Strukturen, wie beispielsweise Dimere oder Hairpins, bedingt. In der Literatur wird deshalb häufig eine obere Grenze für Primer bei 30 Basen angegeben, um die Gefahr der Bildung primerinterener Strukturen zu reduzieren. Heutige Software kann diese Strukturen jedoch sehr effizient voraussagen, so dass auch Primer über 30 Basen Länge keinen Tabu mehr darstellen. Das Primerdesign wurde mit Hilfe der Software PrimerSelect des Softwarepakets Lasergene 10 (Fa. DNASTAR) durchgeführt. 


\subsubsection{Amplifikation autosomaler STR-Systeme (genetischer Fingerabdruck)}

Für die Überprüfung der morphologischen Zuordnung sowie die Sicherstellung der Authentizität der nachfolgenden Analysen wurden genetische Fingerabdrücke für jedes Individuum erstellt. Im Weiteren kann diese erste genetische Analyse einen Eindruck über die DNA-Erhaltung eines Knochens geben und nachfolgende Analysen vereinfachen.

Für die Generierung des genetischen Fingerabdrucks wurde ein laboreigenes Analysesystem verwendet, das die sechs autosomalen STR-Systeme D5S818, D13S317, D18S51, D21S11, FGA und TH01 sowie den Geschlechtsmarker Amelogenin enthält. Diese Heptaplex (Abb. 3.6) wurde in mehreren Schritten zunächst durch Schilz (2003) und Pfister (2008) entwickelt und nach weiteren Optimierungen abschließend von Seidenberg und Kollegen publiziert (Seidenberg et al. 2012). Produktlängen, Farbmarkierungen und Konzentrationen sind dort ebenfalls angegeben und wurden für diese Arbeit entsprechend verwendet. Einzige Ausnahme dazu bildet das Primerpaar für Amelogenin, das nicht mit dem grün fluoreszierenden HEX markiert worden ist, sondern mit dem blau fluoreszierenden 6-FAM.

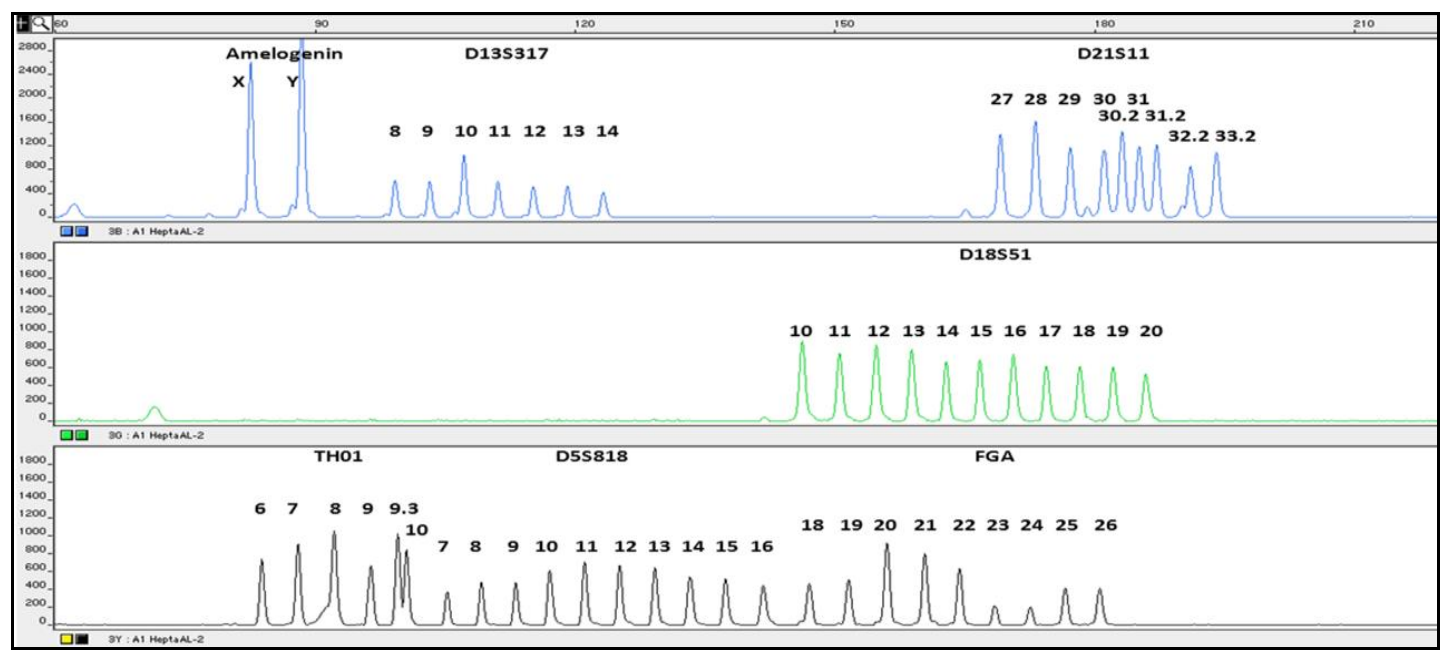

Abbildung 3.6: Allelleiter der Heptaplex nach Seidenberg et al. 2012. Abweichend von der Veröffentlichung wurde in dieser Arbeit ein mit 6-FAM markierter Amelogeninprimer verwendet. xAchse $=$ Länge der Produkte in Basenpaaren .

Ein Standardansatz einer Amplifikation mit 25 $\mu 1$-Volumen und variablem DNAEinsatz setzte sich somit aus folgenden Komponenten zusammen (Tab. 3.2):

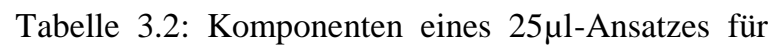
die Analyse autosomaler STRs.

\begin{tabular}{lc} 
Komponente & $\mu 1$ je Probe \\
\hline \hline Qiagen 2x Mastermix plus & 12,5 \\
Primerset (Seidenberg et al. 2012) & 2,85 \\
$\mathrm{H}_{2} \mathrm{O}$ (Fa. Ambion) & $9,15-0$ \\
DNA-Extrakt & $0,5-9,65$ \\
\hline \hline Gesamtvolumen & 25
\end{tabular}


Die Cycling-Parameter entsprachen (Tab. 3.3):

Tabelle 3.3: Cycling-Parameter für die Analyse autosomaler STRs.

\begin{tabular}{cccc} 
Schritt & Temperatur $\left({ }^{\circ} \mathrm{C}\right)$ & Dauer $(\mathrm{min})$ & Zyklen \\
\hline \hline Initial & 95 & 5 & \\
Denaturation & 94 & 1 & \\
Annealing / Elongation & 59 & 2,5 & $40-45$ \\
Delay & 60 & 45 & \\
Soak & 10 & 10
\end{tabular}

Alle PCRs wurden in einem DNA Thermal Cycler Typ Mastercycler ${ }^{\circledR}$ gradient bzw. personal der Firma Eppendorf durchgeführt.

\section{$\underline{\text { 3.4.5. Amplifikation gonosomaler Systeme (Sexplex) }}$}

Für eine absichernde Geschlechtsbestimmung für weibliche Individuen über den Marker Amelogenin hinaus (vgl. Kap. 1.3.) wurde eine Amplifikation von gonosomalen STR-Systemen in einer Multiplex (Sexplex) durchgeführt. Diese Multiplex wurde von Schmidt et al. (2003) entwickelt und im Laufe der Zeit nur durch einen leicht veränderten Primer für Amelogenin (Seidenberg et al. 2012, siehe Kap. 3.4.4.) modifiziert. Neben diesem werden je zwei Y-chromosomale (DYS391 und DYS392) und X-chromosomale (DXS6789 und DXS9898) STR-Systeme amplifiziert (Abb. 3.7).

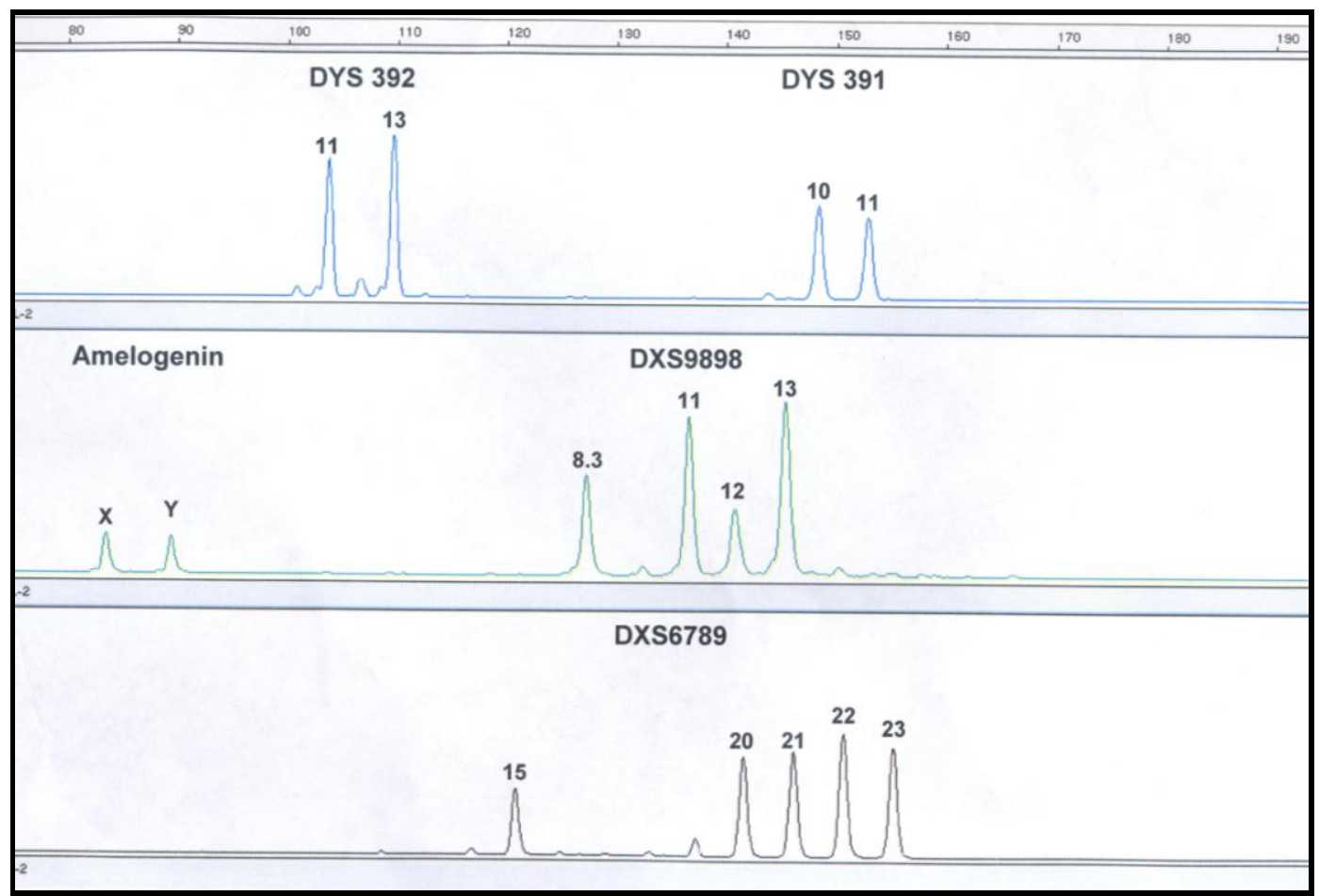

Abbildung 3.7: Allelleiter der Multiplex-PCR gonosomaler STR-Systeme nach Schmidt et al. 2003. Abweichend von dieser Darstellung wurde in dieser Arbeit ein mit 6-FAM markierter Amelogeninprimer verwendet. $\mathrm{x}$-Achse $=$ Länge der Produkte in Basenpaaren. 
Primersequenzen, Farbmarkierungen und Konzentrationen sind bei Schmidt et al. 2003, für Amelogenin bei Seidenberg et al. 2012, nachzulesen. Ein Standardansatz mit $25 \mu 1$ Volumen und variablen DNA-Einsatz setzte sich somit aus folgenden Komponenten zusammen (Tab. 3.4):

Tabelle 3.4: Komponenten eines 25 $\mu 1$-Ansatzes für die Analyse gonosomaler STRs.

\begin{tabular}{lc} 
Komponente & $\mu 1$ je Probe \\
\hline \hline Qiagen 2x Mastermix plus & 12,5 \\
Primerset (Schmidt et al. 2003) & 2,55 \\
$\mathrm{H}_{2} \mathrm{O}$ (Fa. Ambion) & $9,45-4,95$ \\
DNA-Extrakt & $0,5-5$ \\
\hline \hline Gesamtvolumen & 25
\end{tabular}

Die Cycling-Parameter entsprachen (Tab. 3.5):

Tabelle 3.5: Cycling-Parameter für die Analyse gonosomaler STRs.

\begin{tabular}{cccc} 
Schritt & Temperatur $\left({ }^{\circ} \mathrm{C}\right)$ & Dauer $(\mathrm{min})$ & Zyklen \\
\hline \hline Initial & 95 & 5 & \\
\hline Denaturation & 94 & 0,6 & \\
Annealing & 50 & 0,6 & 40 \\
Elongation & 72 & 0,6 & \\
Delay & 60 & 45 & \\
Soak & 10 & 10 &
\end{tabular}

Alle PCRs wurden in einem DNA Thermal Cycler Typ Mastercycler ${ }^{\circledR}$ gradient bzw. personal der Firma Eppendorf durchgeführt. 


\subsubsection{Amplifikation Y-chromosomaler STR-Systeme}

Für die Analyse der Y-Haplotypen wurde in einem ersten Schritt zusammen mit Verena Seidenberg eine Dekaplex nach den genannten Kriterien für Primerdesign entwickelt (vgl. Kap. 3.4.3.), wobei das Hauptaugenmerk auf der Anwendung auf stark degradierter DNA lag. Die Produktlängen sind daher so kurz wie möglich gewählt, alle Systeme (außer DYS389II) sind kleiner als 200bp. Als Referenzsequenz wurde die Sequenz „Homo sapiens chromosome Y, GCRh37.p10“ (Accession: NC_000024.9) verwendet. Die Auswahl der Systeme orientiert sich an den Systemen des minimal haplotypes (minHT, vgl. Kap. 1.3.) ergänzt durch drei weitere Systeme, die sich in dem Kit Y-PowerPlex (Fa. Promega) befinden. Zwei Systeme weisen dabei Besonderheiten auf: 1. Bei dem System DYS389 fand im 3'-Bereich des repeats eine Sequenzverdopplung statt, so dass der lower-Primer an zwei nahe beieinander liegenden Stellen binden kann. Die Sequenzverdopplung umfasst dabei ein weiteres STR-System, in der Auswertung erscheinen aufgrund des gleichen upper-Primers ein kurzes und ein langes Produkt. Das Primerpaar für DYS389 amplifiziert somit zwei Systeme (DYS389I und II), welche unabhängig voneinander ausgewertet werden. 2. Das System DYS385 liegt komplett verdoppelt auf dem Y-Chromosom vor. Auch hier werden mit einem Primerpaar zwei Systeme amplifiziert, die in der Auswertung nicht zu unterscheiden sind. Für dieses System werden beide Allele zusammen aufgenommen (z.B. DYS385: 11,14). Abbildung 3.8 stellt die Allelleiter der YDekaplex dar. Tabelle 3.6 zeigt die Sequenzen der Primer, ihre Farbmarkierung, die jeweilige Konzentration je Primer pro $25 \mu 1-P C R-A n s a t z$ und die erwartete Produktlänge. Der jeweilige upper-Primer ist mit dem entsprechenden Fluoreszenzfarbstoff markiert.

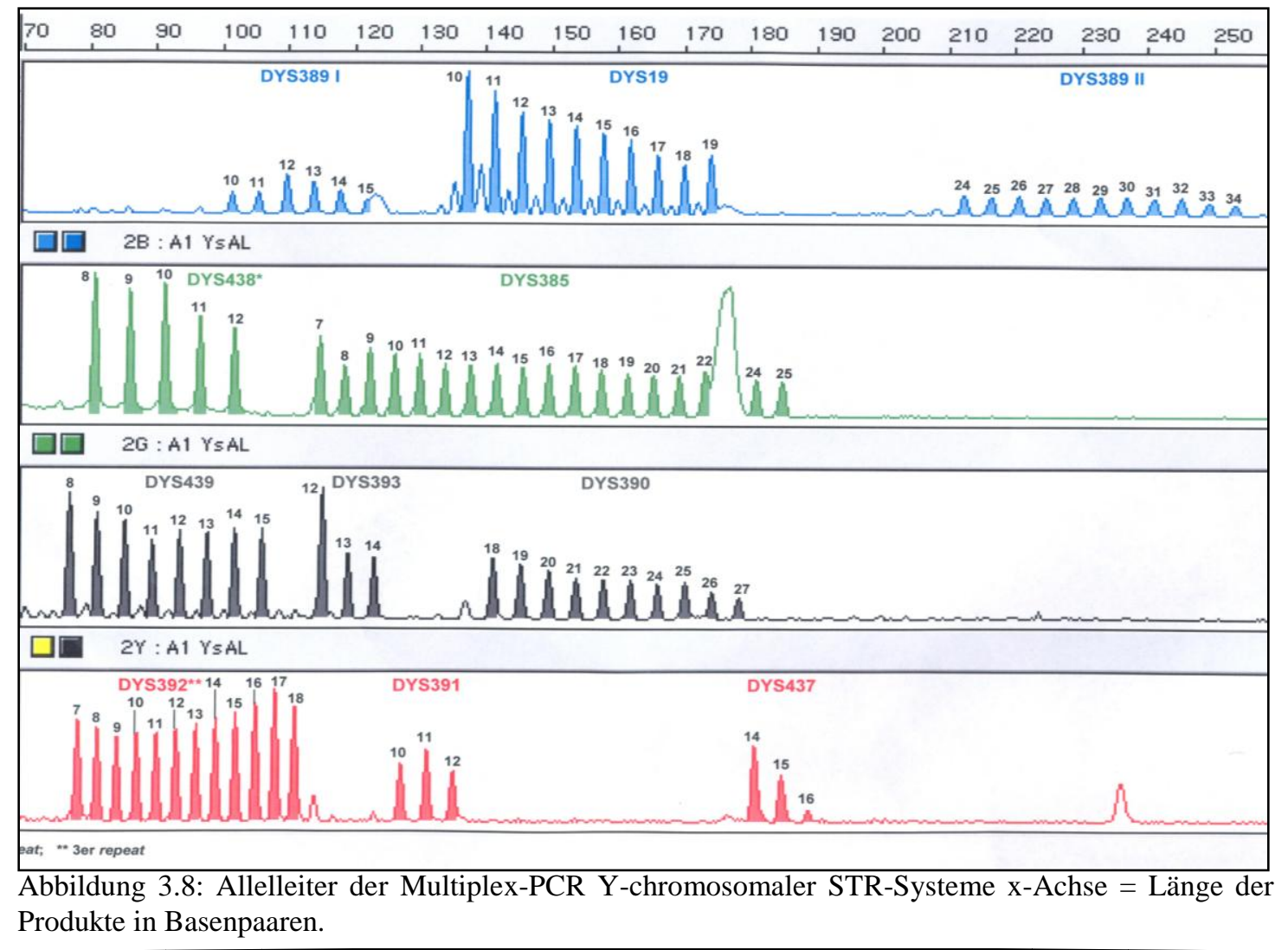


Tabelle 3.6: Sequenzen, Farbmarkierung und Konzentration in einem 25 $\mu 1$-Ansatz der Primer sowie die Produktlänge der amplifizierten Systeme. *Konzentration der Primer je Ansatz.

\begin{tabular}{|c|c|c|c|c|}
\hline System & Sequenz $\left(5^{6}-3^{6}\right)$ & $\begin{array}{c}\text { Markie- } \\
\text { rung }\end{array}$ & {$[\mu \mathbf{M}]^{*}$} & $\begin{array}{l}\text { Produkt- } \\
\text { länge (bp) }\end{array}$ \\
\hline \multirow{2}{*}{ DYS19 } & CTGAGTTCTGTTATAGTGTTTTTTAATATAT & \multirow{2}{*}{ 6-FAM } & \multirow{2}{*}{0,15} & \multirow{2}{*}{$154-190$} \\
\hline & ATGGGTTAAGGAGAGTGTCACTATAT & & & \\
\hline \multirow{2}{*}{ DYS385 } & AGAGAAAGAGGAAAGAGAAAGAAAG & \multirow{2}{*}{ HEX } & \multirow{2}{*}{0,4} & \multirow{2}{*}{$120-204$} \\
\hline & AAAAATAATCTATCTATTCCAATTACATAGTC & & & \\
\hline \multirow{2}{*}{ DYS389 } & ATCCAACTCTCATCTGTATTATCTATGT & \multirow{2}{*}{ 6-FAM } & \multirow{2}{*}{0,4} & I: $103-135$ \\
\hline & GACTGCTAGATAAATAGATAGATTGATAGAG & & & II: $199-239$ \\
\hline \multirow{2}{*}{ DYS390 } & CATTTTGGTACCCCATAATATATTC & \multirow{2}{*}{ NED } & \multirow{2}{*}{0,2} & \multirow{2}{*}{ 144-184 } \\
\hline & AGCAATGTGTATACTCAGAAACAAG & & & \\
\hline \multirow{2}{*}{ DYS391 } & CTCTTGTGTATCTATTCATTCAATCATA & \multirow{2}{*}{ ROX } & \multirow{2}{*}{0,2} & \multirow{2}{*}{$113-145$} \\
\hline & AAATTGCCATAGAGGGATAGGTAG & & & \\
\hline \multirow{2}{*}{ DYS392 } & CTACCAATCCCATTCCTTAGTAAA & \multirow{2}{*}{ ROX } & \multirow{2}{*}{0,2} & \multirow{2}{*}{$81-111$} \\
\hline & AAGGAAAACAAATTTTTTTCTTGTA & & & \\
\hline \multirow{2}{*}{ DYS393 } & GTGGTCTTCTACTTGTGTCAATAC & \multirow{2}{*}{ NED } & \multirow{2}{*}{0,15} & \multirow{2}{*}{ 109-141 } \\
\hline & AAAACTCAAGTCCAAAAAATGAGG & & & \\
\hline \multirow{2}{*}{ DYS437 } & AGTGATCCTCCTACCTCAGTCTC & \multirow{2}{*}{ ROX } & \multirow{2}{*}{0,25} & \multirow{2}{*}{ 177-193 } \\
\hline & ACCACAGATAAATATCATTCATAGATAA & & & \\
\hline \multirow{2}{*}{ DYS438 } & GAATAGTTGAACGGTAAACAGTATATTT & \multirow{2}{*}{ HEX } & \multirow{2}{*}{0,2} & \multirow{2}{*}{$77-117$} \\
\hline & GAGTGAAACTCCATTTCAAATAGAA & & & \\
\hline \multirow{2}{*}{ DYS439 } & GGAGACAGATAGATGATAAATAGAAGAT & NFD & 01 & $87-107$ \\
\hline & ACCATCATCTCTTTACTTATACTTTCTATC & & & \\
\hline
\end{tabular}

Zur Vermeidung von unspezifischen Nebenprodukten wurde eine geringe Menge Ammoniumsulfat in jeden Ansatz zugegeben. Ein Standardansatz mit $25 \mu$ l Volumen und variablem DNA-Einsatz setzte sich somit aus folgenden Komponenten zusammen (Tab. 3.7):

\begin{tabular}{lc}
\multicolumn{2}{l}{$\begin{array}{l}\text { Tabelle 3.7: Komponenten eines } \\
\text { die Analyse Y-chromosomaler STRs. }\end{array}$} \\
\begin{tabular}{lc} 
Komponsatzes für \\
Komte & $\mu 1$ je Probe \\
\hline Qiagen 2x Mastermix plus & 12,5 \\
Primerset & 2,25 \\
Ammoniumsulfat (3M) & 0,2 \\
$\mathrm{H}_{2} \mathrm{O}$ (Fa. Ambion) & $9,55-0$ \\
DNA-Extrakt & $0,5-10,05$ \\
\hline \hline Gesamtvolumen & 25
\end{tabular}
\end{tabular}

Die Cycling-Parameter orientierten sich an den Herstellerempfehlungen für das YPowerplex-Kit (Fa. Promega) und beinhalten zwei unterschiedliche AnnealingTemperaturen zur Reduzierung unspezifischer Produkte (Tab. 3.8): 
Tabelle 3.8: Cycling-Parameter für die Analyse Y-chromosomaler STRs.

\begin{tabular}{cccc} 
Schritt & Temperatur $\left({ }^{\circ} \mathrm{C}\right)$ & Dauer $(\mathrm{min})$ & Zyklen \\
\hline \hline Initial & 95 & 5 & \\
\hline Denaturation & 94 & 1 & \\
Annealing & 62 & 1,5 & 10 \\
Elongation & 70 & 1 & \\
\hline Denaturation & 90 & 1 & \\
Annealing & 59 & 1,5 & $30-40$ \\
Elongation & 70 & 1 & \\
Delay & 60 & 45 & \\
Soak & 10 & 10 &
\end{tabular}

Alle PCRs wurden in einem DNA Thermal Cycler Typ Mastercycler ${ }^{\circledR}$ gradient bzw. personal der Firma Eppendorf durchgeführt.

\subsubsection{Amplifikation humanpathogener Bakterien-DNA}

In Zusammenarbeit mit Johanna Schröder wurden zwei Analysesysteme für die Untersuchung der Knochen auf humanpathogene Bakterien-DNA entwickelt. Dabei stehen besonders solche Spezies im Fokus, die eine typhus-ähnliche Symptomatik hervorrufen (vgl. Kap. 1.3.). In dieser Arbeit wurde sich auf Salomonella typhi, S. paratyphi, Bartonella quintana, Borrelia recurrentis und Rickettsia prowazekii konzentriert. Dabei wurde sich auf die jeweiligen Zielgene gestützt, die bereits für andere Nachweise in altem Skelettmaterial genutzt wurde (z.B. Raoult et al. 2006). Die Sequenzen, an denen die Primer designt wurden, sind auf NCBI abrufbar: STY0312/6: NC_003198.1; recN-Gen: NC_011244.1; dnaA-Gen: NC_000963.1; hbpE-Gen: NC_005955.1. Zur Entstehung der Nachweissysteme und Genauswahl siehe auch Schröder (2013). Während der Entstehung des Systems zeigte sich, dass das vorliegende Nachweissystem nicht zwischen $S$. paratyphi $A$ und einer weiteren Salmonellen-Spezies (S. weltevreden, Brankatschk et al. 2011) unterscheiden kann, was die Aussagekraft an dieser Stelle einschränkt. Da beide Spezies jedoch sehr ähnlich zueinander sind, wurde das System trotzdem in dieser Form angewendet. Die Tabellen 3.9 und 3.10 zeigen die Primersequenzen und Produktlängen des Duplexbzw. Triplex-Systems.

Tabelle 3.9: Primersequenzen und Produktlängen der Duplex-PCR für den Nachweis von Bartonella und Rickettsia.

\begin{tabular}{|c|c|c|c|}
\hline Genort & Primersequenz $\left(5^{6}-3^{6}\right)$ & $\begin{array}{c}\text { Produktlänge } \\
{[\text { bp] }}\end{array}$ & Amplifikation bei \\
\hline \multirow{2}{*}{ hbpE } & AGGCTGCAGATGTAATAGTTC & \multirow{2}{*}{103} & \multirow{2}{*}{ B. quintana } \\
\hline & ATCTGTCCTCCAAAATAAAAG & & \\
\hline dnaA & GCAGTGATAGAATCACCTACTAA & 87 & R. prowazekii \\
\hline
\end{tabular}


Tabelle 3.10: Primersequenzen und Produktlängen der Triplex-PCR für den Nachweis von Salmonella und Borrelia.

\begin{tabular}{|c|c|c|c|}
\hline Genort & Primersequenz & $\begin{array}{c}\text { Produktlänge } \\
\text { [bp] }\end{array}$ & Amplifikation bei \\
\hline \multirow[b]{2}{*}{ STY0312 } & GGGCTTGCCGAGACACAG & \multirow{2}{*}{100} & \multirow{2}{*}{$\begin{array}{c}\text { Salmonella typhi / } \\
\text { paratyphi A / } \\
\text { weltevreden }\end{array}$} \\
\hline & TTAAGGCCTCGTCCATAAAAAC & & \\
\hline \multirow{2}{*}{ STY0316 } & AGGAGGGGAATATCTCACTGG & \multirow{2}{*}{88} & \multirow{2}{*}{$\begin{array}{c}\text { S. enterica spec. } \\
\text { (außer paratyphi A } \\
\text { / weltevreden) }\end{array}$} \\
\hline & TGATCCCGTACAGACTGGTTATC & & \\
\hline $\mathrm{recN}$ & $\begin{array}{l}\text { TTATTTGGTTACAAAATTAAAGATGATG } \\
\text { CCTAAAAAATAAACAACGTCTAAACTCA }\end{array}$ & 111 & B. recurrentis \\
\hline
\end{tabular}

In ersten Test-PCRs wurde ein Protokoll für die erfolgreiche Amplifikation mit Hilfe diverser Kontrollproben optimiert. Dazu gehören Positivkontrollen, menschliche Kontrollproben sowie DNA-Extrakte aus Bodenproben (im Detail siehe Schröder 2013). Das optimierte Protokoll setzte sich aus folgenden Parametern zusammen (Tabellen 3.11 und 3.12):

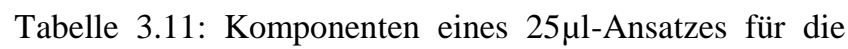
Amplifikation humanpathogener Sequenzen.

\begin{tabular}{lc} 
Komponente & $\mu 1$ je Probe \\
\hline \hline AmpliTaq Gold 360 MasterMix & 12,5 \\
Primer je & 0,5 \\
$\mathrm{H}_{2} \mathrm{O}$ (Fa. Ambion) & $9,5-0$ \\
DNA-Extrakt & $0,5-10,0$ \\
\hline \hline Gesamtvolumen & 25
\end{tabular}

Tabelle 3.12: Cycling-Parameter für die Amplifikation humanpathogener Sequenzen.

\begin{tabular}{cccc} 
Schritt & Temperatur $\left({ }^{\circ} \mathrm{C}\right)$ & Dauer $(\min )$ & Zyklen \\
\hline \hline Initial & 95 & 5 & \\
\hline Denaturation & 94 & 1 & \\
Annealing & $*$ & 1 & $40-50$ \\
Elongation & 72 & 1 & \\
\hline Delay & 72 & 7 & \\
\hline Soak & 10 & 10
\end{tabular}

* Annealing Temperatur: bei Bartonella/Rickettsia: $56^{\circ} \mathrm{C}$; bei Salmonella/Borrelia: $54^{\circ} \mathrm{C}$;

Alle PCRs wurden in einem DNA Thermal Cycler Typ Mastercycler ${ }^{\circledR}$ gradient bzw. personal der Firma Eppendorf durchgeführt. 


\subsubsection{Auswertung der Amplifikationen}

Nach der Durchführung einer PCR wurden die Proben auf eine erfolgreiche Amplifikation überprüft. In einer horizontalen Elektrophoresekammer wurden die Produkte der Länge nach aufgetrennt und unter UV-Licht sichtbar gemacht und fotografiert. Dafür wurde der $\mathrm{Gel}$ Jet Imager \& Analyser mit der Software GelCapture der Firma Intas verwendet (Abb. 3.9). Je $6 \mu 1$ PCR-Produkt wurden auf ein 2,5\%iges Agarosegel aufgetragen, das genaue Rezept und die Vorgehensweise finden sich in Hummel

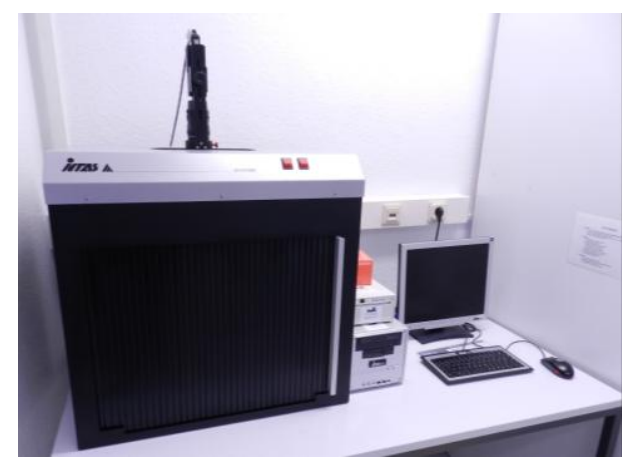

Abbildung 3.9: Gel Jet Imager der Firma Intas mit angeschlossenen Peripheriegeräten 2003 (S. 250ff). Anhand der Stärke der Signale konnte abgeschätzt werden, wie viel Produkt in die weiteren Analyseschritte eingebracht werden müssen.

\section{Fragmentlängenanalyse}

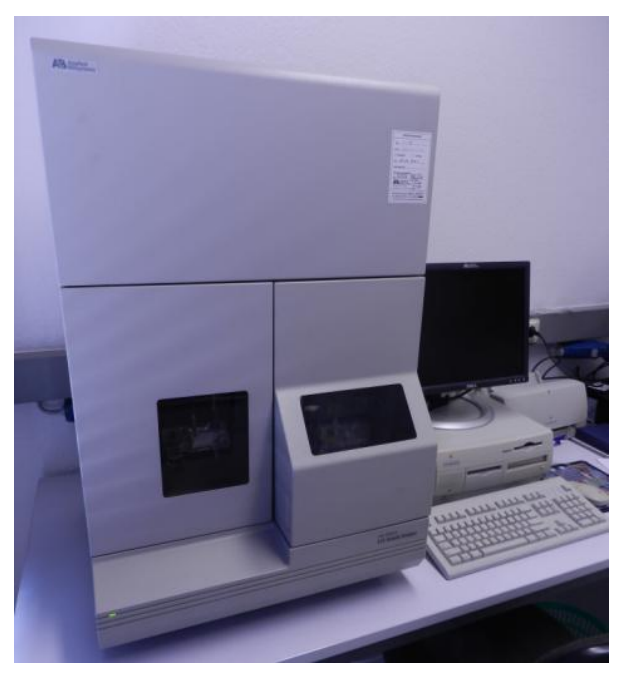

Abbildung 3.10. ABI Prism 310 Genetic Analyzer mit angeschlossenen Peripherigeräten
Die Analyse der STRs erfolgt mit Hilfe eines Polyacrylamidgels (Pop-4®, PE Applied Biosystems) in einer Kapillargelektrophorese (ABI Prism 310 Genetic Analyzer, Abb. 3.10). Die Fragmente werden dabei durch die unterschiedlichen Farbmarkierungen von einem Laser detektiert, der die Laufzeit mit einem mitgeführten Längenstandard (GS ROX 500 für die Heptaplex- und Sexplex-Ansätze, LIZ 600 für YSTR-Ansätze) mittels einer Software (672 Genescan-Analysis Software und GenescanCollection Software (Version 2.0.2.) zur Fragmentlängenanalyse, PE Applied Biosystems) vergleicht. Die Software stellt die erhaltenen Fragmente in Peaks der jeweiligen Farbe dar. Die Probenvorbereitung und Methodik findet sich in Hummel 2003 (S. 255ff). Eine mitgeführte Allelleiter der häufigsten Fragmentlängen in Europa erlaubt eine direkte Bestimmung der Allele des Individuums (Bär et al. 1997). Für jede Elektrophorese muss dabei eine Allelleiter mitgeführt werden, da es zwischen den einzelnen Durchführungen zu Laufunterschieden kommen kann. Die Nomenklatur der Allele richtet sich dabei nach der Anzahl der gefundenen Wiederholungseinheiten.

\section{Sequenzierung}

Bevor die PCR-Produkte in das Taq-Cycle-Sequencing eingebracht werden konnten, mussten diese aufgereinigt werden. Die Taq-Polymerase, nicht verbrauchte dNTPs, Magnesium- und Chloridionen sowie überschüssige Primer sollen dabei entfernt 
werden und nur das amplifizierte Produkt übrig bleiben. Für die Aufreinigung wurde ein kommerzielles Kit (MinElute® PCR Purification Kit, Qiagen) nach Herstelleranleitung verwendet. Doppelsträngige DNA-Fragmente, die länger als 70 Basenpaare sind, werden an einer silikatbeschichteten Membran zurückgehalten, während sie für die übrigen Komponenten durchlässig ist.

Die aufgereinigten Produkte wurden mit Hilfe der Cycle-Sequencing-Reaktion von Sanger et al. (1977) direktsequenziert. Dabei wurden für alle Proben sowohl forward-Sequenzierungen (H-Strang) als auch reverse-Sequenzierungen (L-Strang)

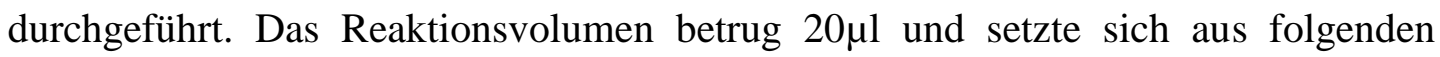
Komponenten zusammen (Tab. 3.13):

\begin{tabular}{|c|c|}
\hline Komponente & $\mu l$ je Probe \\
\hline $\begin{array}{l}\text { BigDye }^{\mathrm{TM}} \text { Terminator Ready Re- } \\
\text { action Mix (PE Applied Biosystems) }\end{array}$ & 2 \\
\hline $\begin{array}{l}\text { Sequencing Buffer }(5 \mathrm{x}) \\
\text { (PE Applied Biosystems) }\end{array}$ & 3 \\
\hline Primer & 0,6 \\
\hline Aufgereinigtes PCR-Produkt & $0,5-1$ \\
\hline Ampuwa & $13,9-13,4$ \\
\hline
\end{tabular}

Die Sequenzierreaktion fand mit folgenden Parametern statt (Tab. 3.14):

Tabelle 3.14: PCR-Parameter für die Sequenzierungsreaktion.

\begin{tabular}{cccc} 
Schritt & Temperatur $\left({ }^{\circ} \mathrm{C}\right)$ & Dauer $(\mathrm{min})$ & Zyklen \\
\hline Initial & 96 & 10 & \\
Denaturation & 96 & $10 \mathrm{sec}$ & \\
Annealing & 50 & $5 \mathrm{sec}$ & 25 \\
Elongation & 60 & 4 & \\
Soak & 10 & 10
\end{tabular}

Nach dieser Sequenzierungs-PCR mussten die erhaltenen Produkte erneut gereinigt werden, da überschüssige, fluoreszenzmarkierte ddNTPS, Nukleotide und Polymerase zu einem starken Hintergrundrauschen führen bzw. die Analysierbarkeit der Probe stark einschränken. Für die Aufreinigung wurde das NucleoSeq Kit der Firma Macherey-Nagel verwendet, das auf dem Prinzip der Gelfiltration beruht. Die Durchführung wurde nach Angaben des Herstellers vorgenommen. 
Nach der Aufreinigung wurde der gesamte Überstand in den Sequenzierer (DNASequencer Modell ABI Prism® 310Genetic Analyser, PE Applied Biosystems) eingebracht. Die Produkte wurden mittels elektrophoretischer Auftrennung unter Verwendung des Polymers Pop-6® (PE Applied Biosystems) analysiert, die Signale wurden mit Hilfe der Analyse-Software ABI Prism ${ }^{\circledR}$ Sequencing Analysis (PE Applied Biosystems) ausgewertet. Die Software stellt die Sequenz der Basen innerhalb eines Elektropherogramms mittels spezifischer Farben dar (Adenin = grün, Cytosin = blau, Guanin = schwarz und Thymin $=$ rot $)$.

Die ermittelten Sequenzdaten wurden anschließend mit der SeqMan Software (Lasergene Software Paket, DNASTAR) überprüft und von Analyse- bzw. Lesefehlern der Sequenzer-Software bereinigt (Salas et al. 2005). Für Nukleotidpositionen, an denen mehr als eine Base realisiert war, wurde der entsprechende IUB-Code eingesetzt. Die abschließende Auswertung und der Abgleich mit der Referenzsequenz erfolgte mit Hilfe der Programme SeqMan und MegAlign (Lasergene Software Paket, DNASTAR).

\subsubsection{Statistische Auswertung}

\section{Autosomale STRs und Y-chromosomale Haplogruppen}

Für die Genotypen der Individuen wurden zunächst die beobachtete und die erwartete Heterozygotie bestimmt sowie auf Abweichungen zum Hardy-WeinbergGleichgewichtet getestet. Dafür wurde die Software Arlequin Version 3.5.1.2 (Excoffier et al. 2005) verwendet. Der exakte Test wurde exakt mit der MarkovChain-Methode mit 1000000 Schritten durchgeführt, die dememorization stepsAnzahl betrug 100000. Anschließend wurden die Häufigkeiten der Allele sowie der Y-Haplogruppen verschiedener europäischer Populationen mit den gefundenen Häufigkeiten aus der Kasseler Serie verglichen.

Exkurs: $\chi^{2}-$ Tests

In der Statistik gibt es eine Reihe von Hypothesentests, deren Testprüfgröße $\chi^{2}$ verteilt ist. Die $\chi^{2}$-Verteilung kann dabei von der Normalverteilung abgeleitet werden: bei $n$ unabhängigen und normalverteilten Zufallsvariablen $\mathrm{Z}_{\mathrm{i}}$ ist sie mit $\mathrm{n}$ Freiheitsgraden definiert als die Verteilung der Summe der quadrierten Zufallsvariablen $\mathrm{Z}_{1}^{2}+\mathrm{Z}_{2}^{2}+\ldots+\mathrm{Z}_{\mathrm{n}}^{2}$. Die $\chi^{2}$-Verteilung wurde von Friedrich Robert Helmert im Jahr 1876 eingeführt und von Karl Pearson im Jahr 1900 so bezeichnet (Schmetterer 1966).

Die Hypothesentests, die auf der $\chi^{2}$-Verteilung basieren, werden vorrangig für drei Arten des Testens verwendet:

- Unabhängigkeitstest (stochastische Unabhängigkeit zweier Merkmale)

- Verteilungstest (Sind die Daten auf eine bestimmte Weise verteilt?)

- Homogenitätstest (Entstammen zwei oder mehr Stichproben einer homogenen Grundgesamtheit?) 
Für den Vergleich von autosomalen Allelfrequenzen sowie Y-chromosomaler Haplogruppen verschiedener Populationen zueinander ist folglich die letzte Testvariante von Bedeutung und soll kurz vorgestellt werden:

Beim Homogenitätstest soll überprüft werden, ob 2 oder mehr Stichproben diskreter Merkmale $\mathrm{X}_{1}, \ldots, \mathrm{X}_{\mathrm{m}}$ mit den Umfängen $\mathrm{n}_{1}, \ldots, \mathrm{n}_{\mathrm{m}}$ aus derselben Grundgesamtheit stammen.

Die Nullhypothese lautet

$\mathrm{H}_{0}$ : Die Merkmale $\mathrm{X}_{1}, \ldots, \mathrm{X}_{\mathrm{m}}$ stammen aus derselben Grundgesamtheit

und entsprechend

$\mathrm{H}_{1}$ : Die Merkmale $\mathrm{X}_{1}, \ldots, \mathrm{X}_{\mathrm{m}}$ stammen nicht aus derselben Grundgesamtheit

Die untersuchte Zufallsvariable (z.B. die Allele eines STR-Systems) besitzt dabei k Merkmalskategorien (z.B. Allel 5 bis Allel 8 ohne Interallele, dann wäre k=4). Die Stichproben $X_{i}$ könnten in diesem Beispiel die verschiedenen Populationen sein. Die Frage wäre nun, ob sich die Allelhäufigkeiten zwischen den Populationen signifikant unterscheiden. Die Ergebnisse der Beobachtungen je Stichprobe (=Population) und Kategorie (=Allel) werden entsprechend in eine Kreuztabelle eingetragen:

\begin{tabular}{|c|c|c|c|c|c|}
\hline & \multicolumn{4}{|c|}{ Merkmale (=Allele) j } & \multirow[b]{2}{*}{ Summe } \\
\hline $\begin{array}{c}\text { Stichprobe } \\
\text { (=Population) }\end{array}$ & Allel 5 & Allel 6 & Allel 7 & Allel 8 & \\
\hline $\mathrm{X}_{1}$ & $\mathrm{n}_{11}$ & $\mathrm{n}_{12}$ & $\mathrm{n}_{13}$ & $\mathrm{n}_{14}$ & $\mathrm{n}_{1 *}$ \\
\hline $\mathbf{X}_{2}$ & $\mathrm{n}_{21}$ & $\mathrm{n}_{22}$ & $\mathrm{n}_{23}$ & $\mathrm{n}_{24}$ & $\mathrm{n}_{2 *}$ \\
\hline $\mathbf{X}_{3}$ & $\mathrm{n}_{31}$ & $\mathrm{n}_{32}$ & $\mathrm{n}_{33}$ & $\mathrm{n}_{34}$ & $\mathrm{n}_{3 *}$ \\
\hline Summe & $\mathrm{n}_{11}+\mathrm{n}_{21}+\mathrm{n}_{31}=\mathrm{n}_{* 1}$ & $\overline{\mathrm{n} * 2}$ & $\mathrm{n}_{* 3}$ & $\overline{\mathrm{n} * 4}$ & $\mathrm{n}$ \\
\hline
\end{tabular}

Aus den Randverteilungen können nun im Folgenden die erwarteten Zellhäufigkeiten für jede Zelle unter der Annahme des Zutreffens der Nullhypothese bestimmt werden:

$$
E_{i j}=\frac{n_{i \bullet} n_{\bullet j}}{n}
$$

Mit Hilfe dieser Größe kann näherungsweise die $\chi^{2}$-verteilte Prüfgröße berechnet werden:

$$
\chi^{2}=\sum_{j=1}^{k} \sum_{i=1}^{m} \frac{\left(n_{i j}-E_{i j}\right)^{2}}{E_{i j}}
$$


Um zu einer Testentscheidung zu gelangen, wird entweder der Wert der Prüfgröße mit einem zugehörigen kritischen Wert verglichen (einem entsprechendem Quantil der $\chi^{2}$-Verteilung, abhängig von der Anzahl der Freiheitsgrade und des Signifikanzniveaus) oder der p-Wert direkt ermittelt. Die Nullhypothese wird abgelehnt, wenn mindestens zwei Stichprobenverteilungen signifikant verschieden sind. Um diesen Test anwenden zu dürfen, müssen mehrere Bedingungen erfüllt sein:

- Der Stichprobenumfang n muss $>30$ sein.

- Der Erwartungswert $\mathrm{E}_{\mathrm{i}, \mathrm{j}}$ muss immer größer als 1 sein (d.h. keine Zelle darf „leer“" sein).

- Mindestens $80 \%$ der $\mathrm{E}_{\mathrm{i}, \mathrm{j}}$ müssen größer als 5 sein.

Gilt dies nicht, müssen Kategorien zusammengefasst werden, bis diese Bedingungen eingehalten werden.

Für die Anwendung des Homogenitätstest für den Frequenzvergleich der autosomalen STR-Allele wurde zunächst die Anzahl der erhaltenen Allele bestimmt und eine entsprechende Frequenz berechnet. Die Frequenzdaten der weiteren Populationen wurden von der Datenbank ALLST*R (www.allstr.de, Qualitype AG, Deutschland) abgerufen. Um die Häufigkeiten vergleichen zu können, wurde der Erwartungswert bei $\mathrm{n}$ erfolgreich typisierten Allelen berechnet (Binomialverteilung, $\mathrm{E}=\mathrm{n} * \mathrm{p}$ ). Die Tabelle zeigt eine Beispielverteilung für das System TH01 und die Frequenzen einer belgischen Population.

\begin{tabular}{cccccc} 
TH01 & $\mathbf{5 6}$ & $\mathbf{7}$ & $\mathbf{8}$ & $\mathbf{9}$ & $\mathbf{2 9 . 3}$ \\
\hline Belgien & 0,2387 & 0,1347 & 0,1347 & 0,1449 & 0,347 \\
\hline Bei 252 Allelen erwartet & 60 & 34 & 34 & 37 & 87
\end{tabular}

Für jeden Y-Haplotyp wurde mit Hilfe des online verfügbaren haplogroup predictors (http://www.hprg.com/hapest5/, Athey 2006) die jeweilige Haplogruppe bestimmt. Die Häufigkeiten der Y-Haplogruppen wurde aus verschiedenen Publikationen (z.B. Semino et al. 2000) zusammengetragen und analog vorgegangen.

Alle Häufigkeitsvergleiche wurden mit Hilfe eines Online-Tools, entwickelt von Preacher (2001, http://www.quantpsy.org/), durchgeführt.

\section{$\underline{\text { Y-chromosomale STRs }}$}

Im Gegensatz zu den autosomalen STRs, bei denen weniger die individuelle Ausstattung als die allgemeinen Frequenzen der Allele von Interesse sind, ist bei den gekoppelten Y-STRs die jeweilige Kombination von Bedeutung. Da bei der Vielzahl der Haplotypen ein direkter Frequenzvergleich statistisch wenig Sinn ergibt, müssen andere Verfahren genutzt werden. 


\section{Exkurs: Analysis of molecular variance (AMOVA)}

Diese Methode erlaubt die Untersuchung der in einer Population und zwischen Populationen angetroffenen Variation der genetischen Struktur auf molekularer Ebene (Excoffier et al. 1992). Das Verfahren berücksichtigt dabei nicht nur die Frequenz von Variationen, sondern auch deren molekulare Beziehung. Unterscheiden sich zwei Haplotypen z.B. nur in einem Locus um eine Wiederholungseinheit, sind sie sich sehr ähnlich. Diese Ähnlichkeit wird nicht berücksichtigt, wenn nur die identischen Haplotypen betrachtet werden.

Die AMOVA basiert auf Wrights F-Statistik (Wright 1950), dem am häufigsten verwendeten Modell zum Testen von Hypothesen bezüglich Genfluss und Isolation innerhalb von Spezies. Auf Basis der F-Werte wurden mehrere Analoge dazu entwickelt, die speziell die evolutive Dynamik der untersuchten Marker berücksichtigen. Für mitochondriale Haplotypen wurde von Excoffier 1992 ein F-Analogon, die sogenannten $\varphi$-Werte, vorgeschlagen. Das Modell beruht auf der sogenannten single step mutation-Annahme (Ohta und Kimura 1973): Die durchschnittliche Entfernung des Haplotypes eines Individuums wird von jedem anderen analysierten Individuum in Form von 1-Schritt-Mutations-Unterschieden berechnet und durch die gesamte molekulare Varianz $\sigma^{2}$ beschrieben. Durch die Berücksichtigung des ÄhnlichkeitsKriteriums ist es möglich, genaue Aussagen über Populationen auf Basis der Haplotypen zu erbringen. Der verwendete Signifikanztest ermöglicht es, die Unterschiede in der Varianz zweier Populationen statistisch zu bewerten: nicht-signifikante Unterschiede zeigen an, dass sich zwei Populationen aufgrund der gefundenen Varianz sehr ähnlich sind, was auf engere Verwandtschaft hindeutet. Das Modell setzt eine kontinuierliche Mutationsrate voraus und berücksichtigt keine Rückmutationsereignisse.

Daher ist diese Grundannahme für mt-Haplogruppen nur eingeschränkt für STRSysteme anwendbar, da diese mit gleicher Wahrscheinlichkeit sowohl eine Wiederholungseinheit länger als auch kürzer werden können. Ohta und Kimura schlugen 1973 ein weiteres Modell vor, das stepwise mutation-Modell, das die Dynamik dieser Systemen besser beschreibt. Basierend darauf entwickelte Slatkin 1995 daher eine abgewandelte Form der $\varphi$-Werte, die R-Werte.

Insgesamt kann die Varianz-Korrelation für drei Ebenen ermittelt werden (analog zu den F-Werten von Excoffier et al. 1992):

- Die Varianz innerhalb von Populationen relativ zum Gesamtdatensatz $\left(\mathrm{R}_{\mathrm{ST}}\right)$

- Die Korrelation der Varianz von Populationen einer definierten Gruppe relativ zum Gesamtdatensatz $\left(\mathrm{R}_{\mathrm{CT}}\right)$

- Die Korrelation der Varianz von Populationen relativ zu der Varianz von zufälligen Datensätzen einer Region $\left(\mathrm{R}_{\mathrm{SC}}\right)$ 
Die AMOVA wurde mit Hilfe der Website www.yhrd.org berechnet. Die Website ermöglicht eine Berechnung von paarweisen $\mathrm{R}_{\mathrm{ST}_{\mathrm{T}}}$ Werten von maximal zehn dort erfassten Populationen mit 10.000 Permutationen.

Die $\mathrm{R}_{\mathrm{ST}}$-Werte liegen in der Regel zwischen 0 für identische Populationen und 1 für sich absolut unterscheidende Populationen. Bei sehr nahverwandten Populationen können die Werte auch leicht negativ sein. Auf Grundlage der erhaltenen Distanzmatrizen wurden die Abstände für eine bessere Interpretation in einem Baumdiagramm dargestellt, dazu wurde die Neighbor Joining-Methode (NJ) gewählt (Saitou u. Nei 1987). Im Gegensatz zur UPGMA-Methode wird hierbei nicht nur ein Ausgangspunkt für alle Populationen berechnet, sondern auch die genauen Beziehungen untereinander. NJ basiert auf dem minimum evolution-Kriterium (Cavalli-Sforza $u$. Edwards 1967), setzt jedoch keine molekulare Uhr voraus, so dass ein unbalancierter Baum entsteht. Aufgrund der Einschränkungen bei der AMOVA über das WebsiteTool können als Grundlage für die Bäume nur die Distanzmatrices genutzt werden, was zur Folge hat, dass keine bootstrap-Werte berechnet werden können. Da bei der NJ-Methode nicht alle möglichen Bäume berechnet werden, kann es möglich sein, dass nicht der optimale Baum dargestellt wird. Die Bäume wurden mit Hilfe der Website http://mobyle.pasteur.fr/cgi-bin/portal.py?form=quicktree erstellt. 


\section{Ergebnisse und Interpretation}

\subsection{Bestandsaufnahme und Mindestindividuenzahl}

Es zeigte sich ein hoher Fragmentierungsgrad der Knochen sowie eine ungleiche Anzahl paariger Skelettelemente, was sich durch unsachgemäße Bergung und der zwischenzeitlichen Lagerung zumindest teilweise erklären lässt. So z.B. sind nur wenige fragile Knochentypen (etwa Scapulae und Fibulae) unbeschadet überliefert, während stabilere Knochen in der Regel weniger stark fragmentiert vorliegen. Jedoch zeigen selbst die Femora in der Mehrheit der Fälle postmortale Beschädigungen wie etwa fehlende Epiphysen, die z.T. gefunden und wieder angeklebt werden konnten (Abb. 4.1 und 4.2).

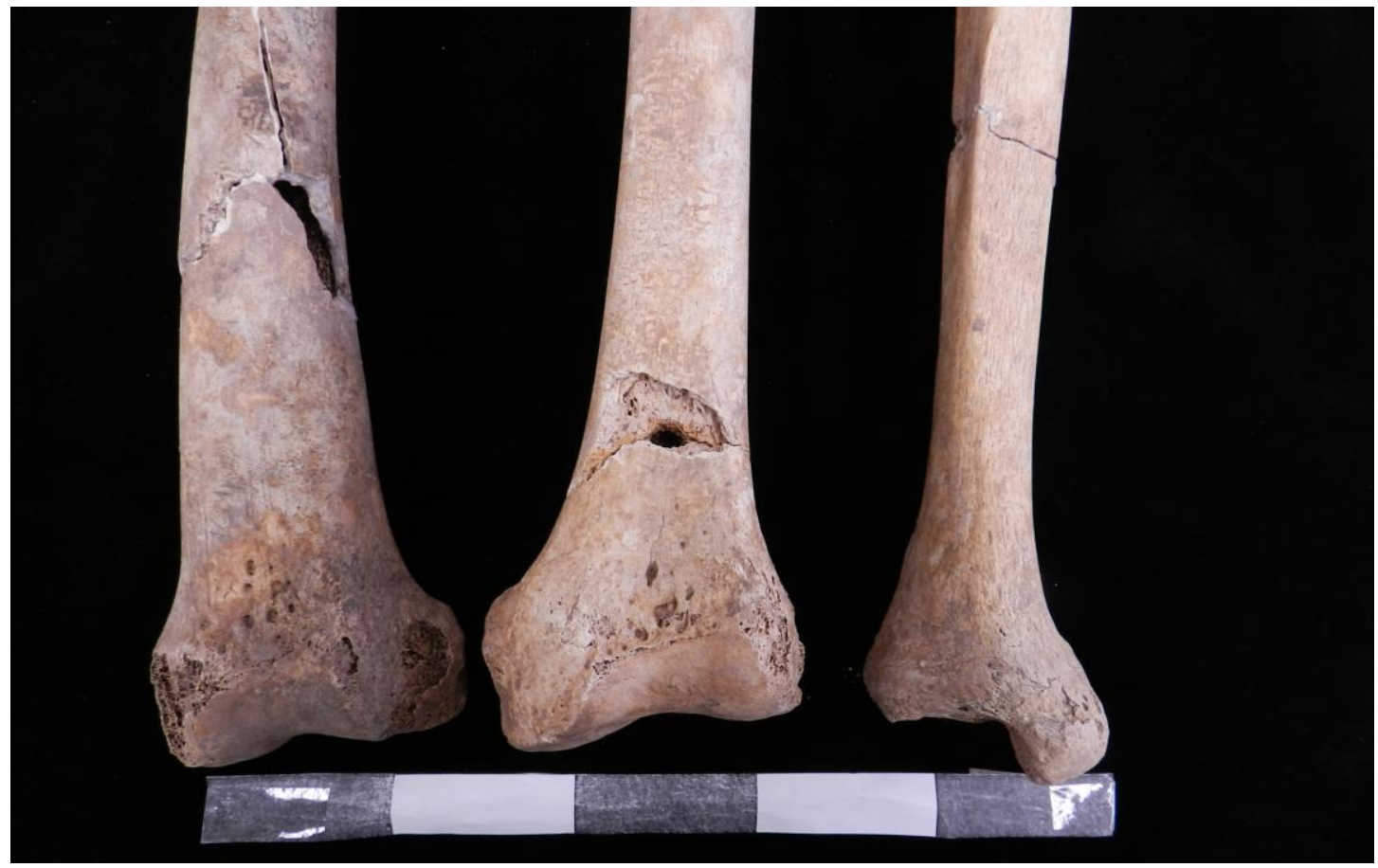

Abbildung 4.1: Rekonstruierte Knochen (hier zwei Femora und eine Tibia)

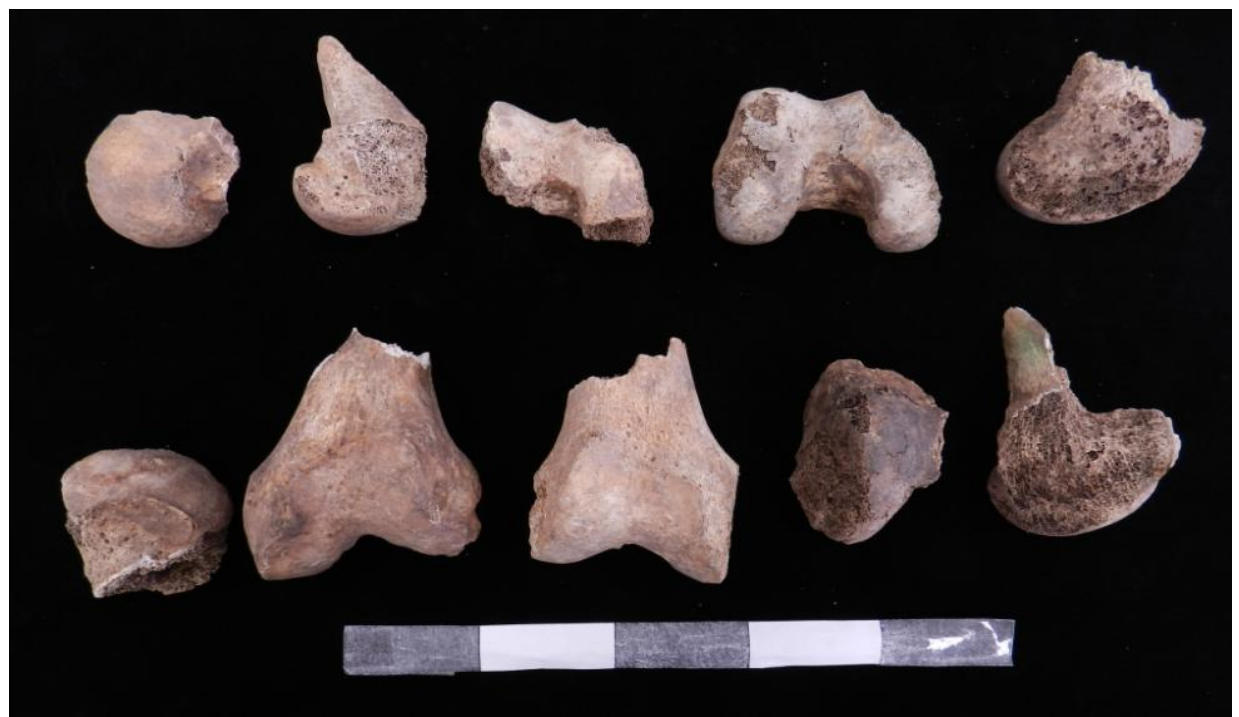

Abbildung 4.2: Einige Fragmente distaler Femurepiphysen, die keiner Diaphyse zugeordnet werden konnten. 
Das häufigste Skelettelement stellen Femora dar, wobei sich insgesamt 106 linke bzw. rechte Femora in den Särgen befanden, was somit die morphologisch nachweisbare Mindestindividuenzahl darstellt. Die Anzahl der anderen Langknochen ist dagegen deutlich geringer: Insgesamt 179 Tibiae, 169 Humeri, 141 Ulnae, 137 Radii und nur 125 Fibulae sind überliefert worden (Tab. 4.1).

Von den weiteren paarigen Skelettelementen sind z.T. deutlich weniger überliefert. So z.B. befinden sich 123 Claviculae unter den Knochen, aber nur 81 Scapulae. Von den Ossa pedes sind die großen Knochen Calcaneus (104) und Talus (95) noch vergleichsweise häufig. Von den Ossa manus sind dagegen die Metacarpalia die häufigsten, während Carpalia deutlich unterrepräsentiert sind. Die Ossa coxae sind in der Regel stark fragmentiert, dennoch ließen sich die Fragmente zu 182 verschiedenen Os coxae zuordnen. Die Schädelfragmente ließen sich zu 94 verschiedenen Individuen zuordnen, wobei viele kleinere Fragmente isoliert blieben. Insgesamt fanden sich über 1600 Wirbel, die z.T. zu Wirbelsäulen(-abschnitten) rekonstruiert werden konnten.

Die Verteilung der Knochentypen über die Särge ist stark unterschiedlich. Tabelle 4.1 zeigt die starke Diskrepanz zwischen Knochentypen der Langknochen in den jeweiligen Särgen. Während z.B. 25 rechte Femora aus der Mainzer Stichprobe überliefert worden sind, wurden nur acht aus Sarg 3 geborgen.

Tabelle 4.1: Anzahl gefundener Langknochen je Sarg. Fe $=$ Femur, Ti $=$ Tibia, Fb $=$ Fibula, $\mathrm{Hu}=$ Humerus, $\mathrm{Ul}=$ Ulna, $\mathrm{Ra}=$ Radius, $\mathrm{re}=$ rechts, $\mathrm{li}=$ links

\begin{tabular}{c||c|c|c|c|c|c|c|c|c|c|c|c||c}
\multicolumn{1}{c|}{} & \multicolumn{2}{c|}{ Fe } & \multicolumn{2}{c|}{ Ti } & \multicolumn{2}{c|}{$\mathrm{Fb}$} & \multicolumn{2}{c|}{$\mathrm{Hu}$} & \multicolumn{2}{c|}{ Ul } & \multicolumn{2}{c||}{ Ra } & $\Sigma$ \\
& re & li & re & li & re & li & re & li & re & li & re & li & \\
\hline \hline Sarg 1 & 17 & 16 & 10 & 11 & 9 & 8 & 17 & 14 & 11 & 13 & 14 & 16 & 156 \\
\hline Sarg 2 & 16 & 19 & 18 & 21 & 11 & 16 & 12 & 15 & 14 & 8 & 13 & 10 & 173 \\
\hline Sarg 3 & 15 & 8 & 10 & 9 & 7 & 6 & 15 & 11 & 12 & 12 & 11 & 9 & 125 \\
\hline Sarg 4 & 10 & 12 & 11 & 12 & 10 & 9 & 13 & 10 & 8 & 7 & 9 & 7 & 118 \\
\hline Sarg 5 & 15 & 15 & 15 & 15 & 11 & 13 & 15 & 15 & 13 & 10 & 11 & 9 & 157 \\
\hline Sarg 6 & 8 & 11 & 10 & 11 & 5 & 5 & 5 & 8 & 6 & 6 & 6 & 7 & 88 \\
\hline Sarg M & 25 & 25 & 12 & 14 & 9 & 6 & 9 & 10 & 12 & 9 & 7 & 8 & 146 \\
\hline \hline$\Sigma$ & 106 & 106 & 86 & 93 & 62 & 63 & 86 & 83 & 76 & 65 & 71 & 66 & 963
\end{tabular}

$\mathrm{Zu} 104$ Femora konnte weitere Skelettelemente zugeordnet werden. Diese Individuen wurden mit „KS“ und einer fortlaufenden, zweiziffrigen Nummer bezeichnet (z.B. KS01, KS02 usw.). Abbildung 4.3 zeigt beispielhaft die Individuen KS05 und KS88. Nur wenige Individuen sind vollständig überliefert worden, was sich durch das Ungleichgewicht in der Anzahl der überlieferten Knochentypen bereits andeutete. Den meisten Individuen fehlen beispielsweise Scapulae. $\mathrm{Zu}$ einige Individuen konnten nur wenige Knochen zugeordnet werden, meist unteren Extremitätenknochen. Übersichtsfotos aller Individuen sind auf der beigelegten CD zu finden. Die Individuen KS01 bis KS18 wurden, mit einigen Neusortierungen, von Zipp (2010) übernommen. 

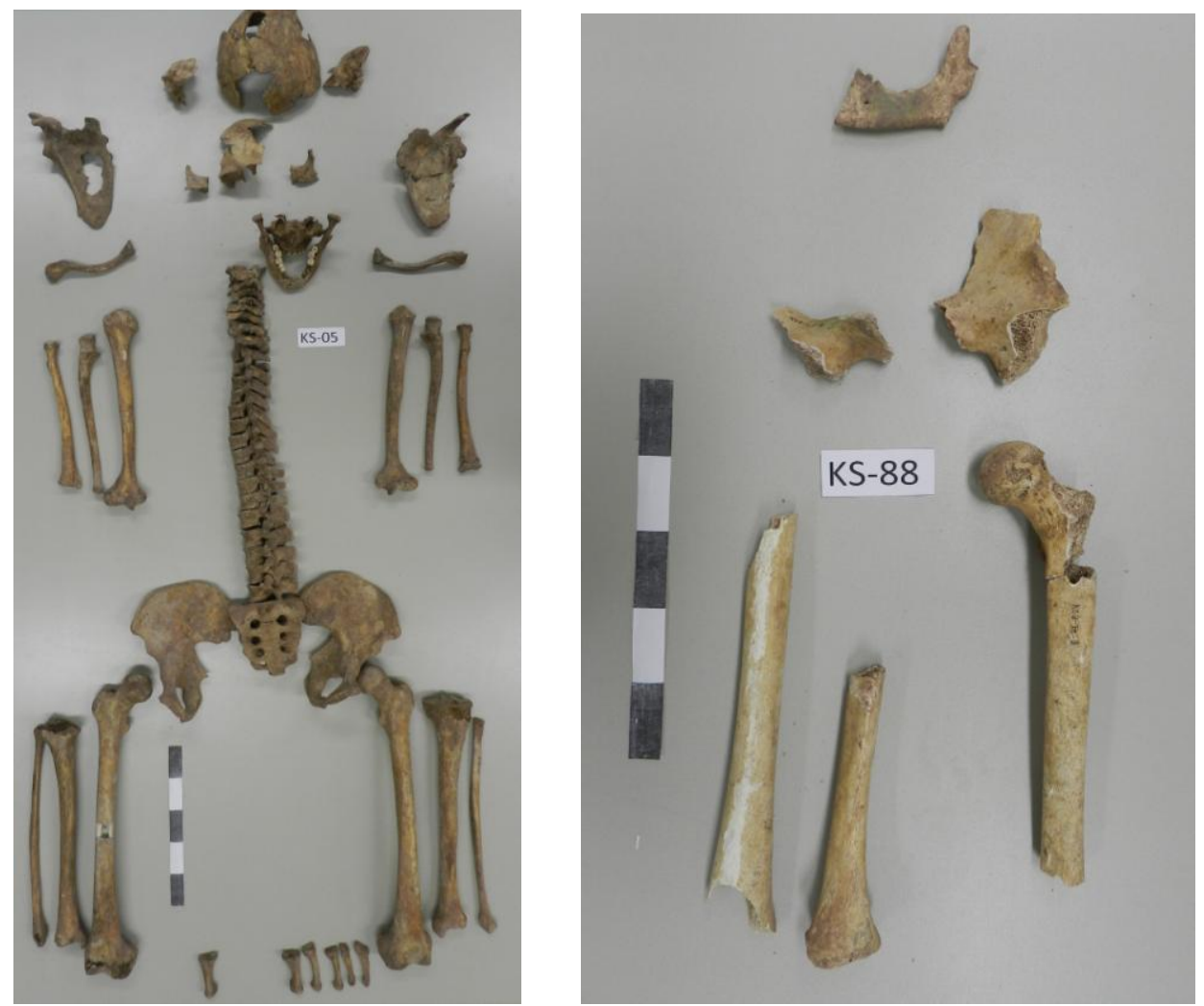

Abbildung 4.3: Individuum KS05 und KS88. Während KS05 annähernd vollständig überliefert wurde, konnten zu KS88 nur wenige Skelettelemente zugeordnet werden.

Die DNA-Erhaltung in den Knochen war für bodengelagertes Material in den meisten Fällen gut bis sehr gut. Die durchgeführten stichprobenartige Quantifizierung einiger Femora-Extrakte ergaben einen durchschnittlichen humanen DNA-Gehalt von etwa 100pg/ $\mu 1$, was für Knochenmaterial ein sehr gutes Ergebnis ist (Seidenberg et al. 2012). Dementsprechend erfolgreich war auch die Ermittlung des genetischen Fingerabdrucks (Abb. 4.4, vgl. Kap. 3.4.4.) der Individuen und die Überprüfung der morphologischen Zuordnung. Dabei zeigte sich jedoch, dass die großen, kompakten Femora und Tibiae im Allgemeinen bessere DNA-Erhaltung aufwiesen als beispielsweise Humeri oder Zähne.

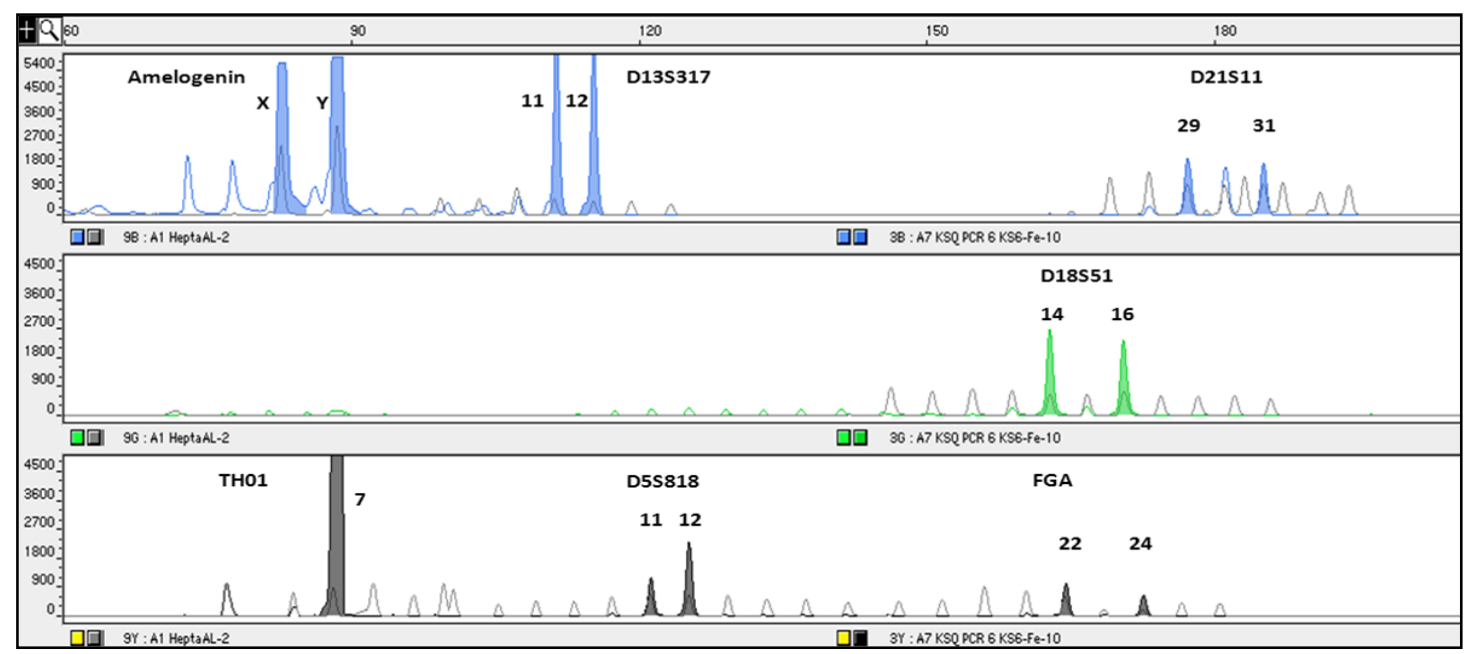

Abbildung 4.4: Elektropherogramm einer Heptaplex-Amplifikation mit DNA-Extrakt des Femurs KS6Fe-21 (Individuum KS102). Durch den sehr guten DNA-Erhalt war eine vollständige Typisierung aller Systeme möglich. 
Bei der stichprobenartigen Überprüfung stellte sich heraus, dass zu den 104 benannten Individuen 22 Skelettelemente auf Grundlage ihres Fingerabdrucks diesen nicht zugeordnet werden können und somit isoliert bleiben. Es handelt sich dabei um 18 Femora, zwei Humeri, eine Tibia und eine Maxilla (Abb. 4.5). Dadurch erhöht sich die Mindestindividuenzahl auf 126. Mehr Details zu einzelnen Überprüfungen kann bei Holzgräfe (2013) nachgelesen werden. Insgesamt konnten 109 Individuen vollständig typisiert werden. Es war eine vollständige Typisierung der kurzen Systeme TH01 und D13S317 möglich. Die Ergebnisse aller Einzelamplifikationen sowie der jeweiligen Bearbeiter sind in der Excel-Tabelle Einzelamplifikationen.xlsx auf der beigefügten CD. Tabelle 4.2 zeigt den Konsensus-Genotyp der Individuen.

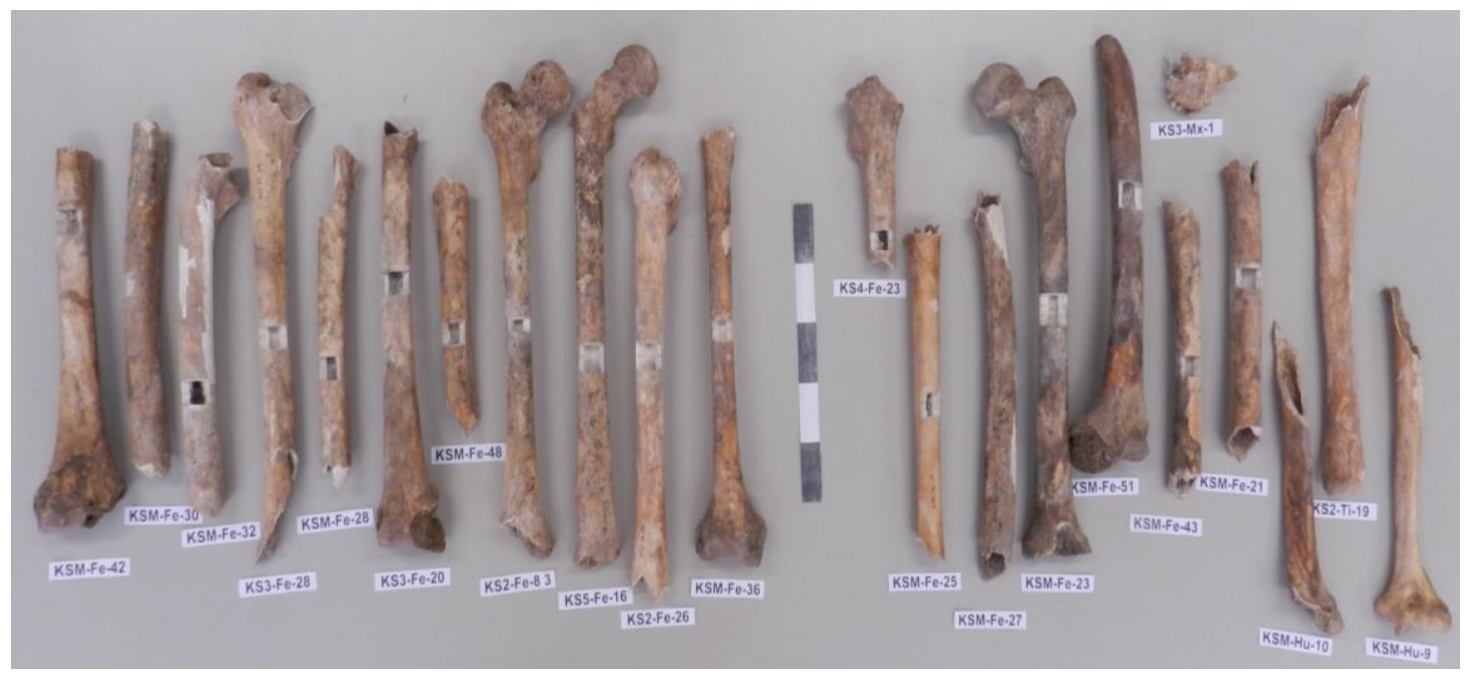

Abbildung 4.5: Isolierte Skelettelemente, die aufgrund ihres genetischen Fingerabdrucks isoliert bleiben und somit die Mindestindividuenzahl auf 126 erhöhen.

Aufgrund des hohen Fragmentierungsgrades blieben diverse Bruchstücke ohne Zuordnung zu Individuen. Dazu zählen in erster Linie Epiphysenfragmente der Langknochen, die nicht sicher einer Diaphyse zugeordnet werden konnten, sowie stark fragmentiertes Material von Schädeln und Becken.

Neben den menschlichen Skelettelementen fanden sich auch einige Knochen tierlichen Ursprungs. Diese überwiegend stark fragmentierten Knochen konnten z.T. equiden Spezies oder Schweinen zugeordnet werden. Sie traten jedoch nur vereinzelt auf und nicht alle anatomischen Regionen sind vertreten, so dass eine „Bestattung“ von vollständigen Tieren höchst unwahrscheinlich ist. So z.B. fanden sich mehrere Kieferfragmente unterschiedlicher Schweine (Abb. 4.3), aber nur wenige Wirbelfragmente.

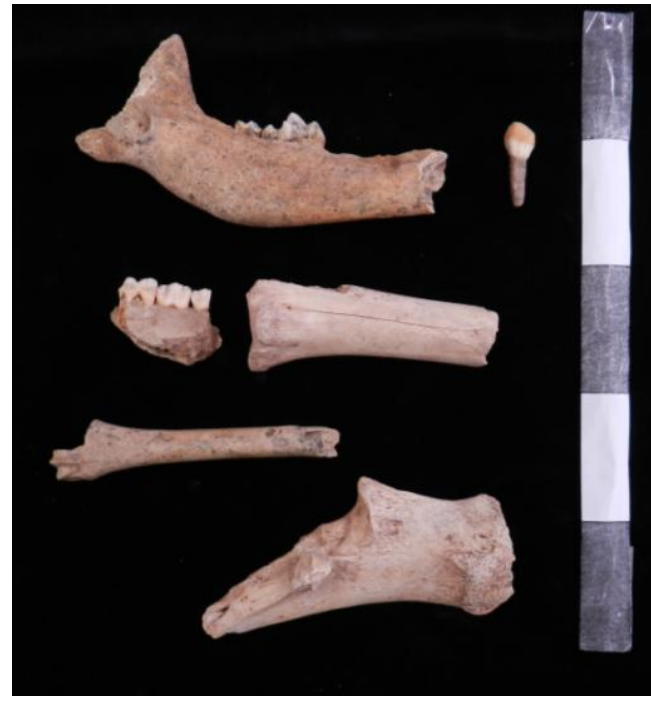

Abbildung 4.2: Auswahl an tierlichen Knochen, die Schweinen oder equiden Spezies zugeordnet werden konnten. 
Ergebnisse - Kapitel 4.1.

Tabelle 4.2: Konsensus-Genotyp der Individuen. Ind. = Individuum. ( ) = Allel nur einmal amplifiziert. Fortsetzung auf den nächsten zwei Seiten.

\begin{tabular}{|c|c|c|c|c|c|c|}
\hline Ind. & D13S317 & D21S11 & D18S51 & TH01 & D5S818 & FGA \\
\hline KS01 & $10 / 11$ & $31 / 33.2$ & $13 / 18$ & $6 / 8$ & $11 / 13$ & $22 / 25$ \\
\hline KSO2 & $11 / 12$ & $30 / 32.2$ & $12 / 14$ & 8/- & $11 / 12$ & $19 / 23$ \\
\hline KS03 & $11 / 13$ & $28 / 32.2$ & $12 /-$ & 9.3/- & $13 /-$ & $23 /-$ \\
\hline KSO4 & $8 / 12$ & $29 / 30.2$ & $12 / 16$ & $6 /-$ & $10 /-$ & $20 / 23$ \\
\hline KS05 & $9 / 11$ & $29 /-$ & $15 / 17$ & $6 / 8$ & $11 /-$ & $22 / 24$ \\
\hline KS06 & $8 /-$ & $28 / 30$ & $12 / 17$ & $6 / 8$ & $12 /-$ & $21 /-$ \\
\hline KS07 & $12 /-$ & - & $10 /(20)$ & $7 / 9.3$ & $12 /-$ & $(20) /-$ \\
\hline KS08 & $11 / 12$ & $29 / 30$ & $12 /-$ & $7 / 9$ & $11 / 13$ & $22 / 24$ \\
\hline KS09 & $11 / 12$ & $(28) / 31$ & $15 / 17$ & 9.3/- & $11 /-$ & $19 / 20$ \\
\hline KS10 & $11 / 12$ & $29 / 33.2$ & $(15) / 16$ & $6 / 8$ & ('11)/12 & $21 / 24$ \\
\hline KS11 & $11 / 12$ & $27 / 28$ & $14 / 18$ & $9.3 /-$ & $12 /-$ & $21 / 24$ \\
\hline KS12 & $10 / 11$ & $29 / 30$ & $12 / 18$ & $6 / 7$ & $11 /-$ & $18 / 20$ \\
\hline KS13 & $11 / 13$ & $29 / 30$ & $13 / 14$ & $6 / 9$ & $12 /-$ & $21 / 23$ \\
\hline KS14 & $11 /-$ & $31 / 32.2$ & $12 / 21$ & $7 / 9.3$ & $11 / 12$ & $24 /-$ \\
\hline KS15 & $8 / 12$ & $30 / 31$ & $12 / 16$ & $6 / 7$ & $11 / 13$ & $21 / 21.2$ \\
\hline KS16 & $12 /-$ & $31.2 / 32.2$ & $12 / 16$ & $7 /-$ & $12 / 13$ & $20 /-$ \\
\hline KS17 & $11 / 12$ & $27 / 28$ & $14 / 16$ & $6 / 9.3$ & $10 / 11$ & $20 / 24$ \\
\hline KS18 & $8 / 12$ & $28 /-$ & $10 / 16$ & $7 / 9$ & $11 /-$ & $24 /-$ \\
\hline KS19 & $8 / 9$ & $28 / 29$ & $16 / 18$ & $7 / 9$ & $12 /-$ & $21 /-$ \\
\hline KS20 & $8 / 11$ & $31.2 / 33.2$ & $12 /(16)$ & 9.3/- & $11 / 12$ & $21 / 24$ \\
\hline KS21 & $12 / 14$ & $30 / 32$ & $14 / 19$ & $8 / 9.3$ & $11 / 12$ & $23 / 26$ \\
\hline KS22 & $11 / 13$ & $28 / 30$ & $12 / 15$ & $8 / 9.3$ & $11 /-$ & $22 / 23$ \\
\hline KS23 & $11 / 13$ & $28 / 29$ & $13 / 15$ & 9/9.3 & $11 / 12$ & $22 / 24$ \\
\hline KS24 & $9 / 13$ & $28 / 33.2$ & $15 / 16$ & 9.3/- & $12 / 13$ & $18 / 21$ \\
\hline KS25 & $10 / 12$ & $28 / 33.2$ & $13 / 18$ & $6 / 9.3$ & $11 / 12$ & $20 / 24$ \\
\hline KS26 & $10 / 12$ & $29 / 32.2$ & $16 / 17$ & $8 / 9.3$ & $11 / 13$ & $20 / 25$ \\
\hline KS27 & $12 /-$ & $29 / 30.2$ & $14 / 16$ & $8 / 9.3$ & $12 /-$ & $21 / 24$ \\
\hline KS28 & $8 / 12$ & $27 / 30$ & $15 / 18$ & 9.3/- & $11 / 12$ & $22 / 24$ \\
\hline KS29 & $12 /-$ & $29 / 30$ & $14 / 16$ & $7 /-$ & $11 / 12$ & $24 / 25$ \\
\hline KS30 & $10 / 12$ & $29 / 31$ & $12 / 15$ & $7 / 9.3$ & $12 /-$ & $23 / 24$ \\
\hline KS31 & $8 / 12$ & $28 / 32$ & $11 / 20$ & $7 / 8$ & $11 / 12$ & $24 /(25)$ \\
\hline KS32 & $12 /-$ & $28 / 31$ & $14 / 15$ & $7 / 9.3$ & $12 /(13)$ & $22 / 24$ \\
\hline KS33 & $10 / 12$ & $29 / 33.2$ & $14 / 15$ & $5 / 7$ & $12 /-$ & $19 /(26)$ \\
\hline KS34 & $11 / 12$ & $31.2 / 33.2$ & $13 / 15$ & $8 / 9.3$ & $12 /-$ & $22 / 24$ \\
\hline KS35 & $8 /-$ & $29 / 30$ & $13 /-$ & 9/9.3 & $12 /-$ & $19 / 24$ \\
\hline KS36 & $10 / 12$ & $29 / 30$ & $15 / 17$ & $7 / 9.3$ & $11 / 12$ & $22 / 25$ \\
\hline KS37 & $11 / 13$ & $28 /-$ & $11 /-$ & 9.3/- & $11 /-$ & $19 /-$ \\
\hline KS38 & $8 / 11$ & $28 / 31$ & $12 / 14$ & $8 / 9$ & $13 /-$ & $24 / 25$ \\
\hline KS39 & $11 /-$ & $29 / 32$ & $15 / 16$ & $7 /-$ & $11 /-$ & $21 / 22$ \\
\hline KS40 & $10 / 12$ & $30 /-$ & $11 / 12$ & $6 /-$ & $11 / 12$ & $23 / 23.2$ \\
\hline KS41 & $13 /-$ & $28 / 30$ & $11 / 14$ & $8 / 9$ & $11 /-$ & $21.2 / 22$ \\
\hline KS42 & $11 / 13$ & $(30) /-$ & $14 / 15$ & $7 /-$ & $12 /-$ & 19/- \\
\hline
\end{tabular}


Ergebnisse - Kapitel 4.1.

\begin{tabular}{|c|c|c|c|c|c|c|}
\hline Ind. & D13S317 & D21S11 & D18S51 & TH01 & D5S818 & FGA \\
\hline KS43 & $12 / 14$ & $27 / 29$ & $13 / 16$ & $8 / 9$ & $12 /-$ & $21 / 24$ \\
\hline KS44 & $9 / 11$ & $32.2 / 33.2$ & $12 / 21$ & $8 / 9.3$ & $11 / 13$ & $21 / 24$ \\
\hline KS45 & $13 /-$ & $30 /(31.2)$ & $13 / 14$ & $7 / 9.3$ & $11 / 13$ & $21 /(26)$ \\
\hline KS46 & $11 / 12$ & $(30) /-$ & $11 / 18$ & $7 / 9$ & $12 /-$ & - \\
\hline KS47 & $11 / 13$ & $(30) /-$ & $12 /-$ & $7 / 9$ & $11 /(12)$ & $21 /-$ \\
\hline KS48 & $12 / 14$ & - & - & 9.3/- & $11 /(12)$ & - \\
\hline KS49 & $11 / 12$ & $(29 /-)$ & - & $7 / 9.3$ & $11 / 13$ & $(23 /-)$ \\
\hline KS50 & $9 / 11$ & - & - & 9.3/- & $12 / 13$ & - \\
\hline KS51 & $11 / 12$ & $29 /-$ & $(12) /-$ & $6 / 7$ & - & $21 /-$ \\
\hline KS52 & $10 / 12$ & $30 / 31.2$ & $15 / 23$ & $8 / 9.3$ & $10 / 11$ & $19 / 26$ \\
\hline KS53 & $9 / 11$ & $31 / 31.2$ & $10 / 18$ & $7 / 9.3$ & $12 /-$ & $18 / 25$ \\
\hline KS54 & $12 /-$ & - & - & $6 / 7$ & - & - \\
\hline KS55 & $9 / 11$ & $28 / 30$ & $13 / 15$ & $9.3 /-$ & $12 / 13$ & $22 / 23$ \\
\hline KS56 & $12 /-$ & $29 / 31.2$ & $14 / 20$ & $8 / 9.3$ & $12 / 13$ & $20 / 22$ \\
\hline KS57 & $11 / 13$ & $29 / 30$ & $13 / 14$ & $7 / 9$ & $10 / 11$ & $19 / 21$ \\
\hline KS58 & $11 / 13$ & $28 / 31.2$ & $12 / 17$ & $6 / 7$ & $12 / 13$ & $20 / 22$ \\
\hline KS59 & 9/- & $29 / 31.2$ & $12 /(14)$ & $6 / 7$ & $(12) / 13$ & $(22) / 24$ \\
\hline KS60 & $8 / 11$ & $27 / 30$ & $14 / 20$ & $6 / 8$ & $12 / 13$ & $24 /-$ \\
\hline KS61 & $11 / 12$ & $27 / 30$ & $13 / 15$ & 9/9.3 & $11 / 13$ & $19 / 23$ \\
\hline KS62 & $11 / 12$ & $30 / 33.2$ & $12 / 14$ & $9.3 / 10$ & $11 /-$ & $21 / 22.2$ \\
\hline KS63 & $10 / 12$ & $28 / 30$ & $13 / 16$ & $6 / 7$ & $11 / 14$ & $22 / 25$ \\
\hline KS64 & $9 / 12$ & $28 / 31.2$ & $(12) / 13$ & $7 / 9.3$ & $11 / 12$ & $20 / 23$ \\
\hline KS65 & $8 / 12$ & $30 /(31.2)$ & $(14 / 15)$ & $7 / 9.3$ & $12 / 13$ & $(20 / 23)$ \\
\hline KS66 & $9 / 13$ & $27 / 32$ & $13 / 18$ & $6 / 9$ & $(11) / 13$ & $23 / 25$ \\
\hline KS67 & $8 / 11$ & $30 / 31.2$ & $10 / 16$ & $7 / 9.3$ & $11 / 12$ & $21 / 22$ \\
\hline KS68 & $13 / 14$ & $(28 / 29)$ & $16 /(17)$ & $6 / 9$ & $12 /-$ & $21 /(22)$ \\
\hline KS69 & $8 / 11$ & $(29) / 30$ & $15 /(17)$ & $6 / 9$ & $12 /-$ & $20 / 21$ \\
\hline KS70 & $11 /-$ & $31.2 / 32.2$ & $22 /-$ & $6 / 9.3$ & $12 / 13$ & $23 / 25$ \\
\hline KS71 & $8 / 13$ & $28 / 32$ & $14 / 16$ & 9.3/- & $10 / 12$ & $22 / 23$ \\
\hline KS72 & $9 / 13$ & $29 / 30$ & $13 / 14$ & $7 / 9.3$ & $12 /-$ & $24 / 26$ \\
\hline KS73 & $12 / 13$ & $31.2 /-$ & $12 / 16$ & $6 / 9.3$ & $11 /-$ & $22 /-$ \\
\hline KS74 & $11 / 12$ & $30 / 31$ & $14 / 16$ & $6 /-$ & $11 / 13$ & $21 /-$ \\
\hline KS75 & $10 / 11$ & $30.2 / 32.2$ & $15 / 16$ & $7 / 9.3$ & $12 / 13$ & $20 / 25$ \\
\hline KS76 & $8 / 11$ & $29 / 31.2$ & $13 / 17$ & 9.3/- & $11 / 12$ & $21 / 22$ \\
\hline KS77 & $13 /-$ & $29 / 30$ & $15 / 17$ & 9/9.3 & $12 / 13$ & $19 /(25)$ \\
\hline KS78 & $12 / 13$ & $(28 / 31)$ & $16 / 20$ & $7 / 9$ & $12 /(13)$ & $(20 /-)$ \\
\hline KS79 & $11 / 12$ & $29 / 30$ & $14 / 15$ & $8 / 9.3$ & $12 /-$ & $22 / 24$ \\
\hline KS80 & $12 / 14$ & $30 / 31$ & $18 / 19$ & 6/9.3 & $12 /-$ & $19 / 21$ \\
\hline KS81 & $8 / 11$ & $28 / 32.2$ & $14 / 17$ & $6 / 9$ & $11 /-$ & $23 / 24$ \\
\hline KS82 & $10 / 12$ & $(32.2 /-)$ & $(16 / 19)$ & $7 /-$ & $11 / 12$ & $20 /(21)$ \\
\hline KS83 & $9 / 11$ & $28 / 29$ & $12 / 15$ & $6 /-$ & $11 / 13$ & $23 / 24$ \\
\hline KS84 & $12 /-$ & $29 / 31$ & $12 / 18$ & $6 / 7$ & $10 / 12$ & $23 /-$ \\
\hline KS85 & $13 / 14$ & $29 /-$ & $12 / 13$ & $8 / 9$ & $11 /(12)$ & $(23 / 26)$ \\
\hline
\end{tabular}


Ergebnisse - Kapitel 4.1.

\begin{tabular}{|c|c|c|c|c|c|c|}
\hline Ind. & D13S317 & D21S11 & D18S51 & TH01 & D5S818 & FGA \\
\hline KS86 & $10 / 11$ & $29 / 33.2$ & $15 / 18$ & $9 / 10$ & $(12 /-)$ & $(23.2) /-$ \\
\hline KS87 & $9 / 11$ & $29 /-$ & $13 / 17$ & 9/9.3 & $11 / 15$ & $23 /-$ \\
\hline KS88 & $10 / 12$ & $29 / 30.2$ & $15 /-$ & 9/9.3 & $9 / 11$ & $22 / 23.2$ \\
\hline KS89 & $11 / 12$ & $28 / 30$ & $13 / 17$ & 9/9.3 & $12 /-$ & $21 /(23)$ \\
\hline KS90 & $8 / 12$ & $30 / 31.2$ & $15 /-$ & $8 / 9.3$ & $11 / 12$ & $22 / 25$ \\
\hline KS91 & $8 / 11$ & $29 / 30.2$ & $12 / 13$ & $7 / 9.3$ & $11 /-$ & $20 / 24$ \\
\hline KS92 & $8 / 12$ & $29 / 31.2$ & $17 / 19$ & $6 / 9.3$ & $11 / 12$ & $24 / 25$ \\
\hline KS93 & $12 / 13$ & $28 / 30.2$ & $18 / 20$ & 9/9.3 & $12 /-$ & $20 / 23$ \\
\hline KS94 & $11 / 12$ & $(29) /-$ & $(15) /(16)$ & $6 / 8$ & $(11) / 12$ & $(21) /-$ \\
\hline KS95 & $11 / 12$ & $29 /-$ & $14 / 15$ & $6 / 9.3$ & $11 / 13$ & $22 / 25$ \\
\hline KS96 & $10 / 13$ & $28 / 30$ & $15 / 18$ & $6 / 8$ & $12 /-$ & $20 / 26$ \\
\hline KS97 & $11 /-$ & $31.2 /-$ & $17 / 18$ & 9.3/- & $11 / 13$ & $20 / 25$ \\
\hline KS98 & $11 / 13$ & $28 / 31.2$ & $12 / 13$ & $6 / 9.3$ & $10 / 11$ & $20 / 23$ \\
\hline KS99 & $12 /-$ & $30 / 31$ & $12 / 16$ & $6 / 9.3$ & $11 / 13$ & $22 /(24)$ \\
\hline KS100 & $11 / 12$ & $29 / 31.2$ & $11 / 14$ & $6 / 9$ & $13 / 14$ & $21 / 24$ \\
\hline KS101 & $8 / 11$ & $28 / 31$ & $13 /-$ & $8 /-$ & $11 / 12$ & $22 / 23$ \\
\hline KS102 & $11 / 12$ & $29 / 31$ & $14 / 16$ & $7 /-$ & $11 / 12$ & $22 / 24$ \\
\hline KS103 & $10 / 11$ & $30 / 33.2$ & $17 / 18$ & 9.3/- & $11 /-$ & $22 /-$ \\
\hline KS104 & $11 / 14$ & $29 / 30$ & $13 / 15$ & $6 / 7$ & $11 /-$ & $24 /-$ \\
\hline KS3-Fe-20 & $8 /-$ & $29 / 32.2$ & $15 / 16$ & $6 / 9.3$ & $11 / 12$ & $19 / 22$ \\
\hline KS3-Fe-28 & $11 / 13$ & $28 / 29$ & $13 /-$ & 9.3/- & $11 /-$ & $(19) / 21$ \\
\hline KS4-Fe-23 & $12 /-$ & $28 / 30$ & $12 /-$ & $6 / 9.3$ & $11 /-$ & $22 / 24$ \\
\hline KSM-Fe-21 & $9 / 12$ & $29 /-$ & $14 / 15$ & $7 / 9$ & $11 / 12$ & $20 /-$ \\
\hline KSM-Fe-23 & $11 / 12$ & $27 / 28$ & $18 /-$ & $6 / 9$ & $11 / 12$ & $19 / 22$ \\
\hline KSM-Fe-25 & $11 /-$ & $31.2 / 32.2$ & $12 / 16$ & $6 /-$ & $12 /-$ & $21 / 24$ \\
\hline KSM-Fe-27 & $12 /-$ & $(28) /(30)$ & $13 / 15$ & $6 / 9$ & $11 /-$ & $(20 / 25)$ \\
\hline KSM-Fe-28 & $12 / 13$ & $29 / 32.2$ & $19 / 20$ & $7 / 9$ & $11 / 12$ & $22 / 25$ \\
\hline KSM-Fe-30 & $8 / 11$ & $29 / 30$ & $12 / 17$ & $7 / 8$ & $11 /-$ & $21 /-$ \\
\hline KSM-Fe-32 & $12 /-$ & $30 / 30.2$ & $12 / 14$ & $6 / 9$ & $11 /-$ & $21 / 22$ \\
\hline KSM-Fe-36 & $12 /-$ & $28 / 30$ & $14 / 19$ & $7 / 9$ & $10 / 11$ & $20 / 21$ \\
\hline KSM-Fe-42 & $11 / 13$ & $30 / 30.2$ & $15 / 17$ & $7 / 9$ & $11 /-$ & $21 / 23$ \\
\hline KSM-Fe-43 & $11 / 12$ & $30 / 32.2$ & $12 / 13$ & 9.3/- & $(10) / 13$ & $(23 /-)$ \\
\hline KSM-Fe-48 & $8 / 12$ & - & $(13 / 14)$ & $7 / 9.3$ & $11 /(12)$ & $(20 /-)$ \\
\hline KSM-Fe-51 & $9 / 13$ & $32.2 / 33.2$ & $12 / 15$ & 9/9.3 & $(11) / 13$ & $20 / 24$ \\
\hline KS2-Fe-8 3 & $9 / 11$ & $28 / 32.2$ & $12 / 14$ & 9.3/- & $10 / 13$ & $21 / 23$ \\
\hline KS2-Fe-26 & $8 / 12$ & $28 / 29$ & $14 / 15$ & $8 / 9.3$ & $12 /-$ & $23 / 26$ \\
\hline KS5-Fe-16 & $8 / 14$ & $30.2 /-$ & $14 / 16$ & $6 /-$ & $13 /-$ & $(22 /-)$ \\
\hline KSM-Hu-9 & $11 /-$ & $28 /-$ & $15 / 19$ & $6 / 9$ & $10 /-$ & $20 / 22$ \\
\hline KSM-Hu-10 & $11 / 12$ & $30 / 31.2$ & $13 / 16$ & $6 / 8$ & $11 / 12$ & $23 / 23.2$ \\
\hline KS2-Ti-19 & $8 / 12$ & $27 / 29$ & $14 / 19$ & 9/9.3 & $10 / 12$ & $22 / 24$ \\
\hline KS3-Mx-1 & $10 / 12$ & $30 / 30.2$ & $15 / 17$ & $6 / 9.3$ & $11 / 12$ & $21 / 25$ \\
\hline
\end{tabular}




\subsection{Geschlechterverteilung}

Die morphologischen und genetischen Ansätze der Geschlechtsdiagnostik (vgl. Kap. 1.3.) ergänzen sich zu einem einheitlichen Bild: Nur wenige Skelettelemente weisen eine geringe Robustizität auf und fallen daher tendenziell in das weibliche Spektrum (Abb. 4.6 und 4.7).

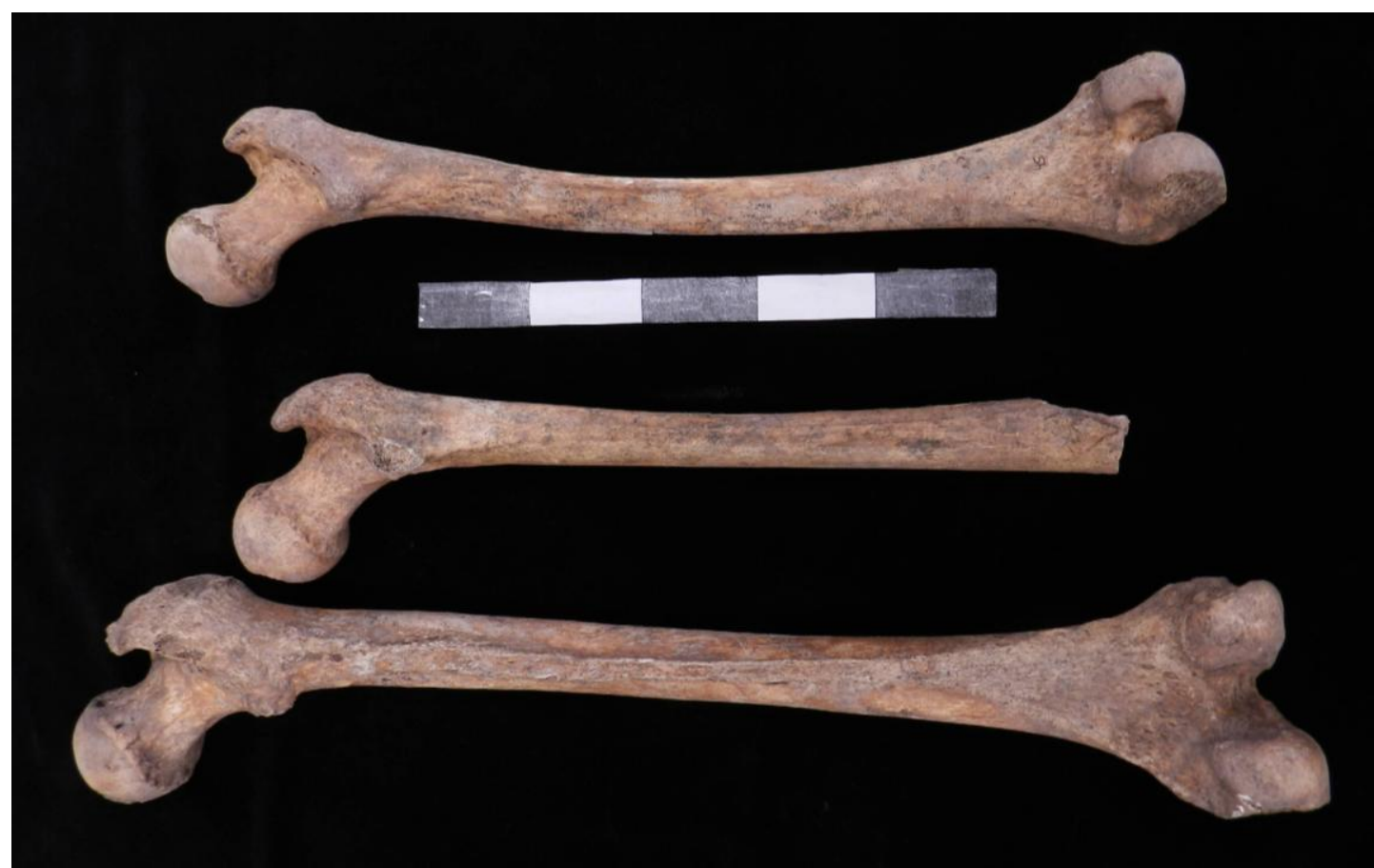

Abbildung 4.6: Drei rechte Femora von posterior. Das unterste Femur (KS6-Fe-16) ist durch die sehr robuste Linea aspera (Muskelansatz in der Mitte der Diaphyse) und seine Größe eindeutig männlich. Das Femur in der Mitte (KS6-Fe-16) ist dagegen deutlich graziler, die Geschlechtsbestimmt anhand der Morphologie nur tendenziell männlich. Das oberste Femur (KSM-Fe-22) weist neben den geringen Muskelmarken noch einen kleineren Collo-Diaphysenwinkel auf und wurde als weiblich bestimmt.

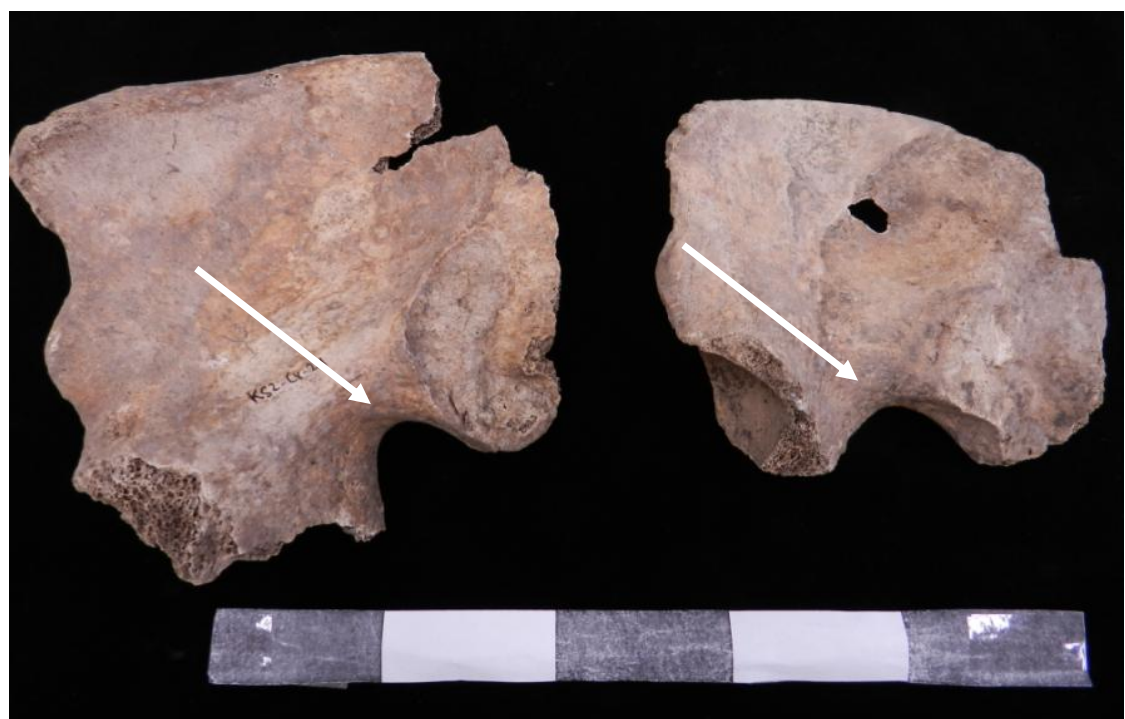

Abbildung 4.7: Zwei rechte Ossa ilia. Das Linke weist eine enge Incisura ischiadica major (Pfeil) und einen einfachen Arc composé auf und kann folglich als männlich bestimmt werden. Das Recht besitzt eine weite Incisura und einen doppelten Arc composé, was für ein weibliches Individuum spricht. 
Von den genetisch untersuchten Knochen der 126 Individuen wies nur das DNAExtrakt des Femurs KSM-Fe-22 keine Y-spezifischen Signale (Amelogenin wie auch Y-chromosomale STRs, vgl. Kap. 4.6.2.) auf (Abb. 4.8).

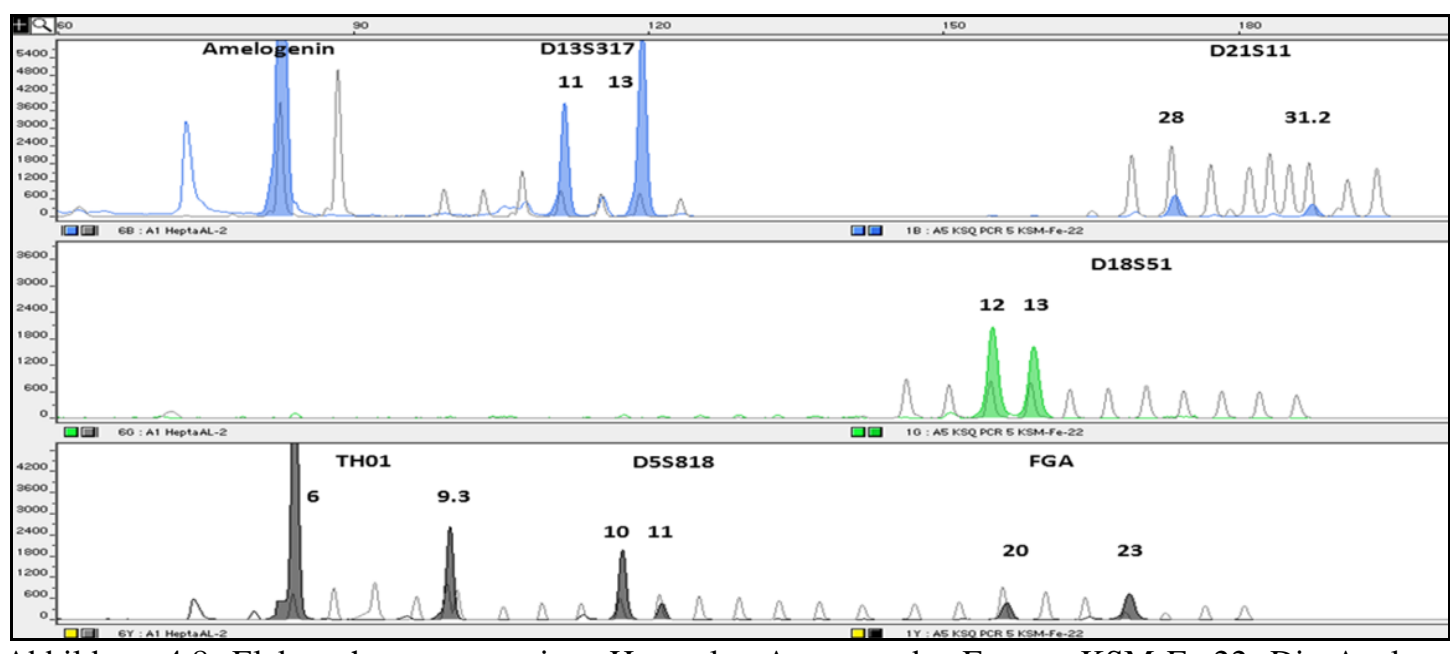

Abbildung 4.8: Elektropherogramm eines Heptaplex-Ansatzes des Femurs KSM-Fe-22. Die Analyse zeigt ein vollständiges Profil und gleichzeitig kein Y-spezifisches Signal von Amelogenin.

Die nachfolgende Sexplex (vgl. Kap. 3.4.5.) erbrachte heterozygote Ergebnisse von X-chromosomalen STRs, was die Anwesenheit von zwei X-Chromosomen belegt und somit der Nachweis einer Frau erbracht wurde (Abb. 4.9).

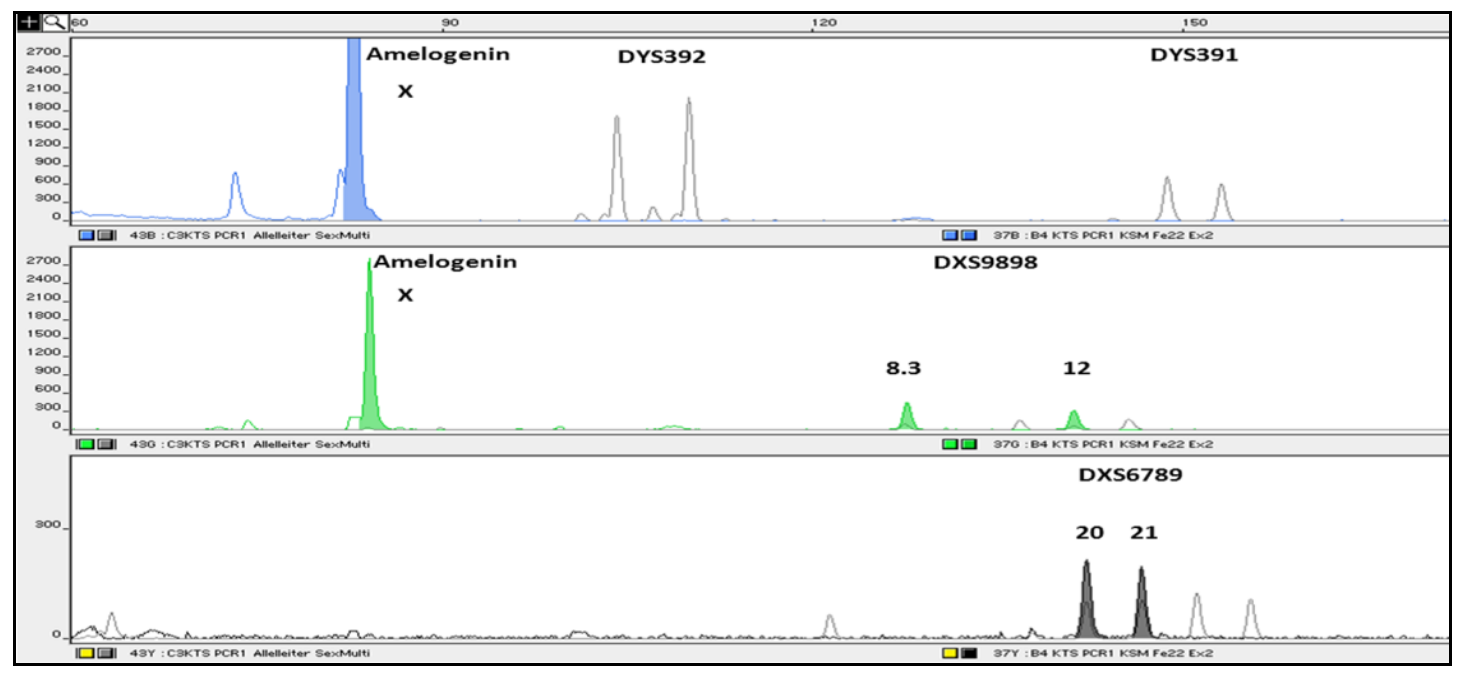

Abbildung 4.9: Elektropherogramm eines Sexplex-Ansatzes des Femurs KSM-Fe-22. Die Analyse zeigt heterozygote Ergebnisse in den X-chromosomalen Markern und keine Y-spezifischen Ergebnisse, was die Diagnose, dass es sich um eine Frau handelt, verifiziert.

Somit ergibt sich ein Geschlechterverhältnis von 125 Männern zu einer Frau.

\section{$\underline{\text { Interpretation }}$}

Das Geschlechterverhältnis weicht stark von dem einer normalen Bevölkerung ab und zeigt, dass es sich bei dem Massengrab um eine Sonderbestattung handelt. Da es sich fast ausschließlich um männliche Individuen handelt, könnte ein militärischer oder klösterlicher Kontext in Betracht kommen. 


\subsection{Altersverteilung}

Die Altersdiagnose wurde ebenfalls auf zwei sich ergänzende Weisen durchgeführt. Die morphologische Diagnostik war in vielen Fällen nur eingeschränkt möglich, weil notwenige Skelettelemente fehlten oder beschädigt waren. Das Leitmerkmal der Komplexen Methode (vgl. Kap. 1.3.), die Symphyse, war in den meisten Fälle nicht vorhanden bzw. konnten durch den hohe Fragmentierungsgrad keinem Individuum zugeordnet werden. Dies resultiert in eine sehr grobe Schätzung des Sterbealters der Individuen. Das häufigste Kriterium, das genutzt werden konnte, war die Verknöcherung der Schädelnähte (Abb. 4.10).
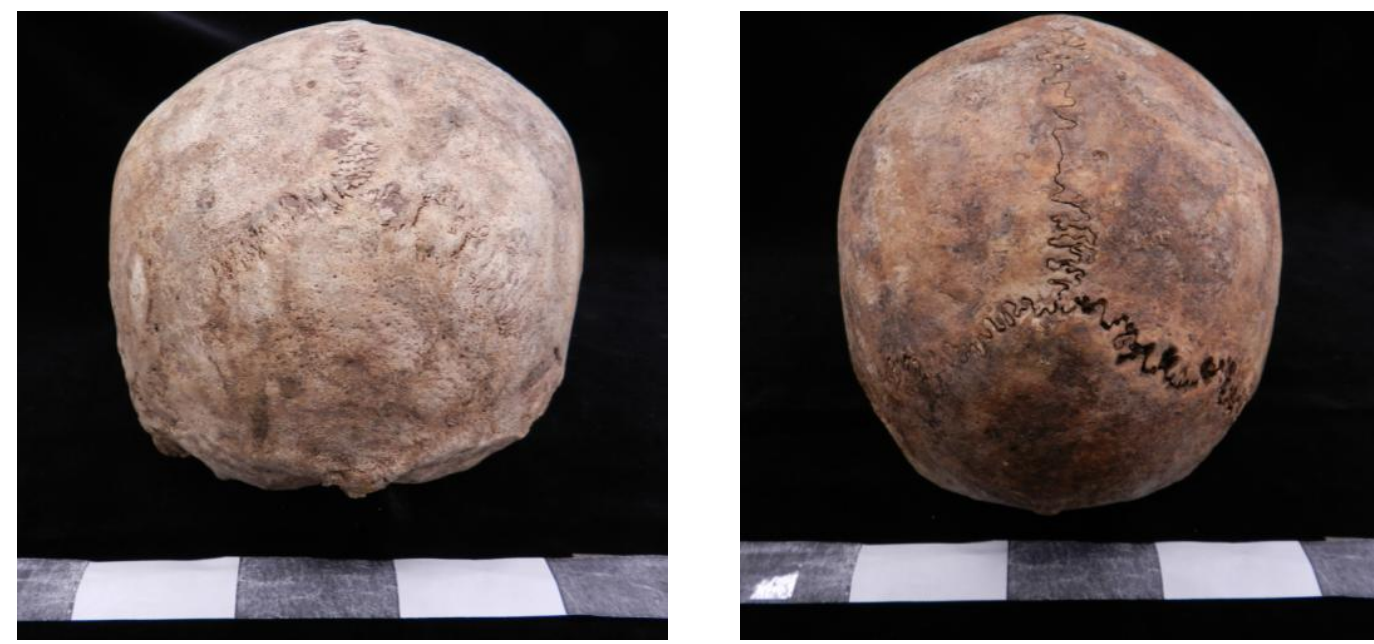

Abbildung 4.10: Zwei Schädel von posterior. Beim linken Schädel sind die Sutura sagittalis und die Sutura lambdoidea ectocranial bereits deutlich verknöchert und teilweise nicht mehr sichtbar (geschätztes Alter zwischen 30 und 60), während diese beim rechten Schädel noch durchgängig erkennbar sind (geschätztes Alter zwischen 20 und 40) (vgl. Kap. 1.3.).

Bei einigen Individuen waren verschiedene Epiphysen noch frei bzw. die Epiphysenfugen noch sichtbar, was eine sehr genaue Altersdiagnose erlaubt (Abb. 4.11). Dies betraf jedoch nur etwa 10 Individuen, während bei den restlichen die Epiphysen bereits alle angewachsen waren.

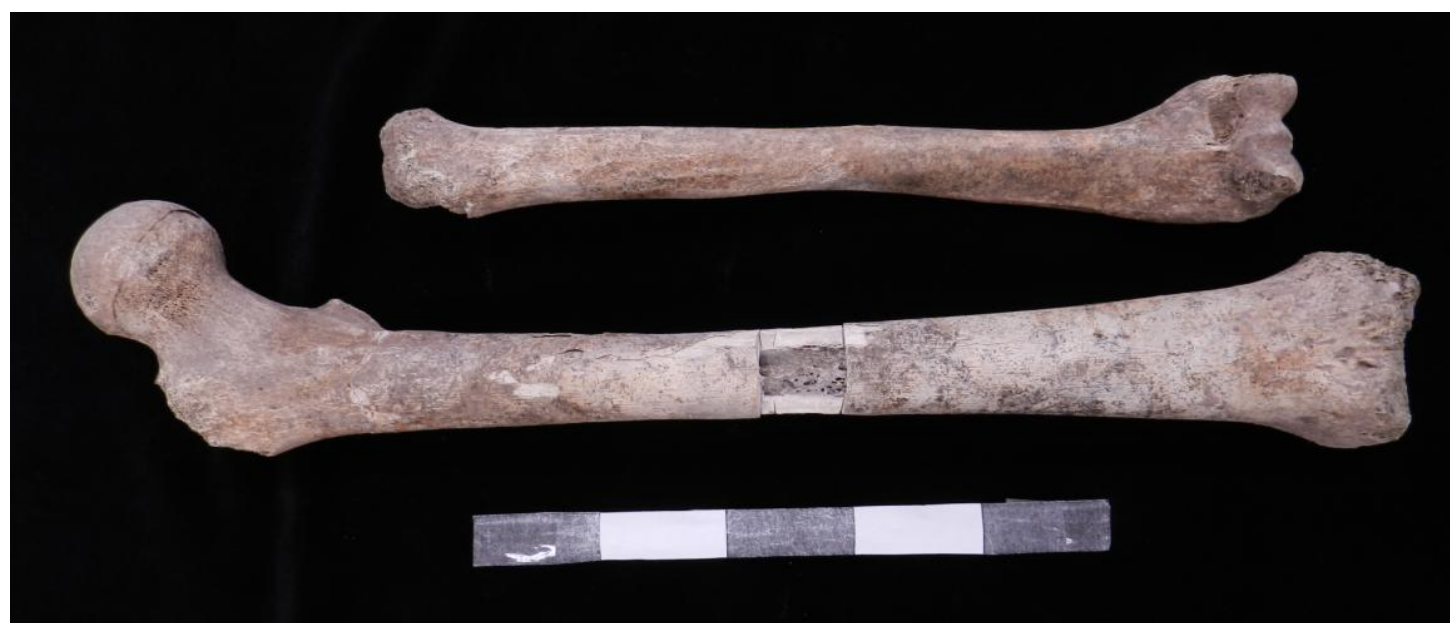

Abbildung 4.11: Langknochen des Individuums KS06. Durch den Epiphysenstatus lässt sich das Sterbealter auf etwa 18-20 Jahre eingrenzen (vgl. auch Abb. 1.5). 
In der histologischen Untersuchung ließ sich die Altersdiagnose durch die Beurteilung des regelhaften Knochenumbaus genauer eingrenzen. Das Beispiel in Abb. 4.12 zeigt das Individuum KS43. Die Schädelnähte sind alle noch sichtbar, die Zahnabrasion ist gering, dies weist auf ein relativ junges Sterbealter hin. Durch das Fehlen der Symphyse ist jedoch eine genauere Eingrenzung nicht möglich, so dass das Individuum morphologisch lediglich als ,adult“ klassifiziert werden konnte. Eine histologische Untersuchung des Femurs KS2-Fe-09 ergab durch die unregelhafte Osteonenform und den hohen Anteil an Lamellenknochen, dass das Individuum das frühadulte Alter erreicht hat.

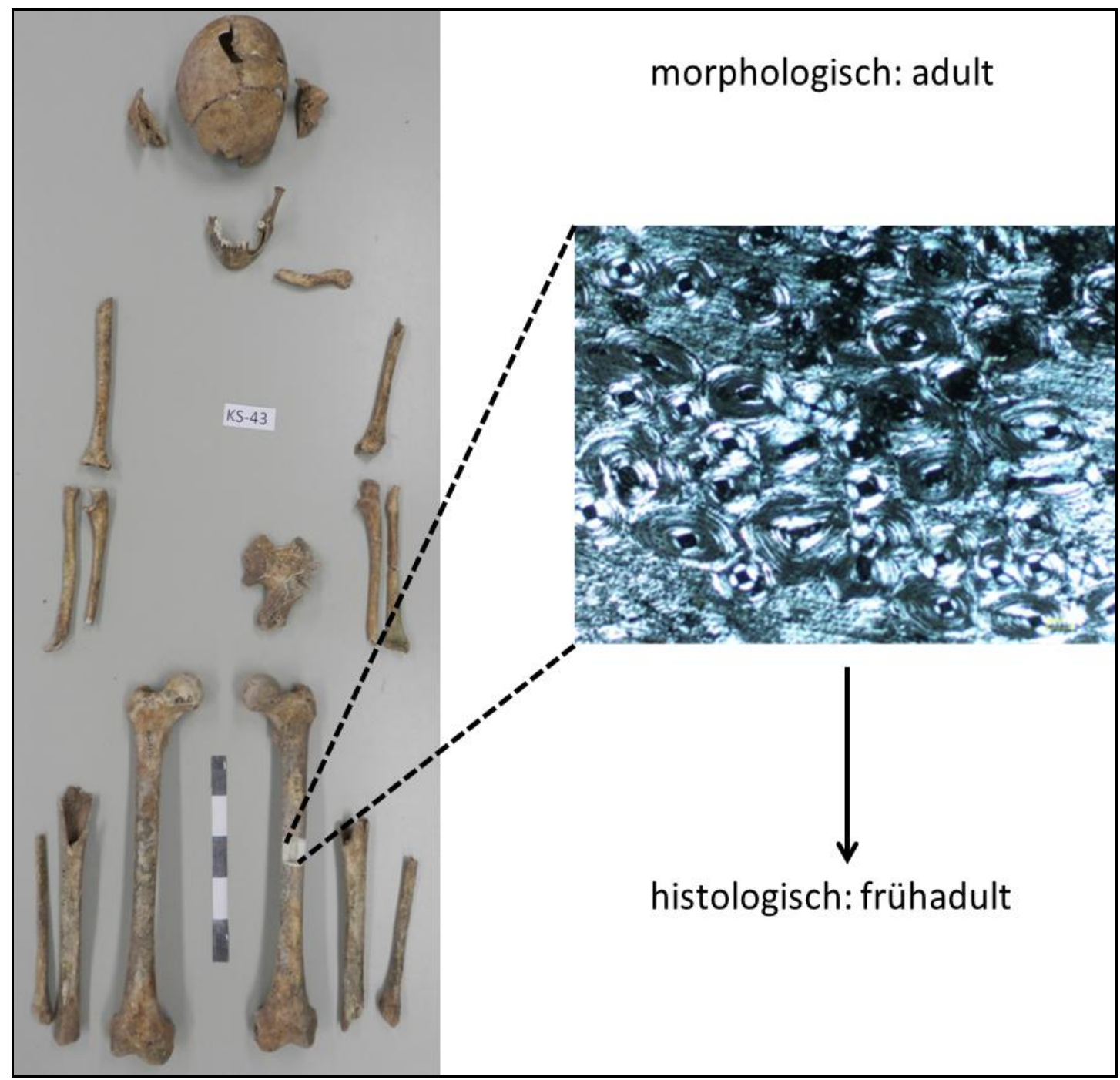

Abbildung 4.12: Schema der Altersdiagnose. Während die morphologischen Methoden oft nur grobe Schätzungen erlauben, konnte durch die histologische Untersuchung ein genaueres Sterbealter ermittelt werden. (Histologisches Bild: 40fach vergrößert mit Polfilter)

Morphologische und histologische Analysen kommen zu den gleichen Ergebnissen. Eine Übersicht über die Ergebnisse aller Untersuchungen aller Individuen zeigt die Tabelle 4.3. Für die endgültige Altersdiagnose wurde meistens der histologischen Altersdiagnose aufgrund der genaueren Eingrenzung der Vorzug gegeben. 
Ergebnisse - Kapitel 4.3.

Tabelle 4.3: Altersverteilung der Individuen anhand morphologischer und histologischer Untersuchungen. Morph $=$ morphologisch, hist. $=$ histologisch. Ad $=$ adult, juv $=$ juvenil, mat $=$ matur. Abkürzung vor der Altersstufe: $\mathrm{f}=$ früh, $\mathrm{m}=$ mittel, $\mathrm{s}=$ spät. Fortsetzung nächste Seite.

\begin{tabular}{|c|c|c|c|c|c|c|c|}
\hline Ind. & $\begin{array}{c}\text { Alter } \\
\text { (morph). }\end{array}$ & Alter (hist.) & Alter & Ind. & $\begin{array}{c}\text { Alter } \\
\text { (morph.) }\end{array}$ & $\begin{array}{c}\text { Alter } \\
\text { (hist.) }\end{array}$ & Alter \\
\hline KS01 & ad-fmat & fmat-mmat & fmat & KS59 & fad & fad & fad \\
\hline KS02 & fad & fad-mad & fad & KS60 & fad & juv-fad & fad \\
\hline KS03 & sjuv-fad & fad-mad & fad & KS61 & ad-mat & fad & fad \\
\hline KS04 & juv-fad & juv & juv & KS62 & fad-mad & $\mathrm{fad}$ & fad \\
\hline KS05 & fad-mad & $\mathrm{fad}$ & fad & KS63 & sad & $\operatorname{mad}$ & mad-sad \\
\hline KS06 & sjuv-fad & sjuv & sjuv & KS64 & sjuv-mad & fad & fad \\
\hline KS07 & fad & fad-mad & fad & KS65 & $\mathrm{ad}$ & mad & mad \\
\hline KS08 & $\operatorname{mad}$ & $\mathrm{fad}$ & fad-mad & KS66 & juv-fad & $\mathrm{fad}$ & fad \\
\hline KS09 & fad & juv-fad & fad & KS67 & $\mathrm{ad}$ & $\mathrm{mad}$ & mad \\
\hline KS10 & fad-mad & juv-fad & fad & KS68 & $\mathrm{ad}$ & mad & mad \\
\hline KS11 & fad-ad & juv-fad & fad & KS69 & fad & sjuv & sjuv-fad \\
\hline KS12 & sjuv-fad & sjuv-fad & sjuv-fad & KS70 & fad & sjuv-fad & fad \\
\hline KS13 & sad-fmat & $\mathrm{sad}$ & sad & KS71 & $\mathrm{ad}$ & $\mathrm{sad}$ & sad \\
\hline KS14 & sjuv & sjuv & sjuv & KS72 & $\mathrm{ad}$ & juv-fad & fad \\
\hline KS15 & mad-sad & $\operatorname{mad}$ & mad & KS73 & $\mathrm{ad}$ & mad & mad \\
\hline KS16 & $\operatorname{mad}$ & fad-mad & $\operatorname{mad}$ & KS74 & sad-mat & $\mathrm{sad}$ & sad \\
\hline KS17 & fad-mad & $\operatorname{mad}$ & $\operatorname{mad}$ & KS75 & sad & $\operatorname{mad}$ & mad-sad \\
\hline KS18 & $\operatorname{mad}$ & fad-mad & mad & KS76 & ad-mat & fad & fad \\
\hline KS19 & $\mathrm{ad}$ & sjuv-fad & fad & KS77 & $\mathrm{ad}$ & juv-fad & fad \\
\hline KS20 & juv-ad & $\mathrm{mad}$ & mad & KS78 & ad-mat & $\mathrm{mad}$ & mad \\
\hline KS21 & fad-mad & mad-sad & mad & KS79 & fad-mad & fad-mad & fad-mad \\
\hline KS22 & juv-ad & juv-fad & fad & KS80 & fad-mad & fad & fad \\
\hline KS23 & ad-mat & $\operatorname{mad}$ & mad & KS81 & $\mathrm{ad}$ & fad & fad \\
\hline KS24 & ad-mat & $\operatorname{mad}$ & mad & KS82 & fad & sjuv-fad & fad \\
\hline KS25 & $\mathrm{ad}$ & $\operatorname{mad}$ & mad & KS83 & juv-ad & $\mathrm{fad}$ & fad \\
\hline KS26 & $\mathrm{ad}$ & juv-mad & fad & KS84 & ad-mat & $\mathrm{fad}$ & fad \\
\hline KS27 & $\mathrm{ad}$ & fad-mad & fad & KS85 & $\mathrm{ad}$ & sad & sad \\
\hline KS28 & fad-mad & fad-mad & fad-mad & KS86 & $\mathrm{ad}$ & fad & fad \\
\hline KS29 & juv-fad & juv-fad & sjuv-fad & KS87 & ad-mat & $\operatorname{mad}$ & mad \\
\hline KS30 & mat & sad-fmat & fmat & KS88 & $\mathrm{ad}$ & $\operatorname{mad}$ & $\operatorname{mad}$ \\
\hline KS31 & ad-mat & sjuv-fad & fad & KS89 & fad-mad & fad-mad & fad-mad \\
\hline KS32 & juv-fad & sjuv & sjuv & KS90 & $\mathrm{ad}$ & $\mathrm{fad}$ & fad \\
\hline KS33 & ad-mat & $\operatorname{mad}$ & mad & KS91 & $\mathrm{ad}$ & $\mathrm{fad}$ & fad \\
\hline KS34 & juv-fad & fad-mad & fad & KS92 & ad-mat & sad-fmat & sad \\
\hline KS35 & juv-fad & juv-fad & sjuv-fad & KS93 & $\mathrm{ad}$ & $\operatorname{mad}$ & mad \\
\hline KS36 & $\operatorname{mad}$ & mad-sad & mad & KS94 & ad-mat & $\operatorname{mad}$ & mad \\
\hline KS37 & sad-mat & $\mathrm{ad}$ & sad & KS95 & ad-mat & mad & mad \\
\hline KS38 & ad-mat & $\mathrm{fad}(-\mathrm{mad})$ & fad & KS96 & ad-mat & $\operatorname{mad}$ & mad \\
\hline KS39 & ad-mat & $\operatorname{mad}$ & $\operatorname{mad}$ & KS97 & $\mathrm{ad}$ & juv-fad & fad \\
\hline KS40 & $(\mathrm{ad})-\mathrm{mat}$ & (mad-)sad & sad & KS98 & fad & fad-mad & fad \\
\hline KS41 & ad-mat & $\mathrm{mad}$ & mad & KS99 & fad-mad & juv-fad & fad \\
\hline KS42 & fad-mad & mad-sad & mad & KS100 & juv & juv-fad & sjuv \\
\hline KS43 & $\mathrm{ad}$ & fad(-mad) & fad & KS101 & $\mathrm{ad}$ & fad & fad \\
\hline KS44 & ad-mat & $\operatorname{mad}$ & mad & KS102 & $\mathrm{ad}$ & $\mathrm{mad}$ & mad \\
\hline KS45 & sjuv-fad & fad-mad & fad & KS103 & $\mathrm{ad}$ & $\mathrm{fad}$ & fad \\
\hline KS46 & $\mathrm{ad}$ & juv-ad & fad & KS104 & $\mathrm{ad}$ & mad & mad \\
\hline KS47 & sjuv-fad & fad-mad & fad & KS3-Fe-20 & fad & juv-fad & sjuv-fad \\
\hline KS48 & $\mathrm{ad}$ & (fad-)mad & mad & KS3-Fe-28 & $\mathrm{ad}$ & fad & fad \\
\hline KS49 & fad & fad & fad & KS4-Fe-23 & $\mathrm{ad}$ & fad & fad \\
\hline KS50 & fad-mad & fad-mad & fad-mad & KSM-Fe-21 & $\mathrm{ad}$ & $\mathrm{fad}$ & fad \\
\hline KS51 & juv-fad & fad-mad & fad & KSM-Fe-23 & $\mathrm{ad}$ & $\mathrm{fad}$ & fad \\
\hline KS52 & $\mathrm{ad}$ & juv-fad & fad & KSM-Fe-25 & $\mathrm{ad}$ & $\mathrm{fad}$ & fad \\
\hline KS53 & $\mathrm{ad}$ & $\mathrm{fad}(-\mathrm{mad})$ & fad & KSM-Fe-27 & $\mathrm{ad}$ & $\operatorname{mad}$ & $\operatorname{mad}$ \\
\hline KS54 & fad-mad & $\mathrm{fad}$ & fad & KSM-Fe-28 & $\mathrm{ad}$ & fad-mad & fad-mad \\
\hline KS55 & fad-mad & $\operatorname{mad}$ & mad & KSM-Fe-30 & sjuv & sjuv & sjuv \\
\hline KS56 & juv-fad & fad-mad & fad & KSM-Fe-32 & $\mathrm{ad}$ & $\mathrm{fad}$ & fad \\
\hline KS57 & juv-ad & fad-mad & fad & KSM-Fe-36 & $\mathrm{ad}$ & mad-sad & mad-sad \\
\hline KS58 & fad-mad & fad & fad & KSM-Fe-42 & $\mathrm{ad}$ & sad & sad \\
\hline
\end{tabular}




\begin{tabular}{|c|c|c|c|c|c|c|c|}
\hline Ind. & $\begin{array}{c}\text { Alter } \\
\text { (morph). }\end{array}$ & $\begin{array}{l}\text { Alter } \\
\text { (hist.) }\end{array}$ & Alter & Ind. & $\begin{array}{c}\text { Alter } \\
\text { (morph.) }\end{array}$ & $\begin{array}{l}\text { Alter } \\
\text { (hist.) }\end{array}$ & Alter \\
\hline KSM-Fe-43 & $\mathrm{ad}$ & $\operatorname{mad}$ & $\operatorname{mad}$ & KS5-Fe-16 & $\mathrm{ad}$ & fad & fad \\
\hline KSM-Fe-48 & $\mathrm{ad}$ & $\mathrm{mad}$ & mad & KSM-Hu-9 & ad & $\mathrm{mad}$ & mad \\
\hline KSM-Fe-51 & $\mathrm{ad}$ & $\mathrm{fad}$ & fad & KSM-Hu-10 & $\mathrm{ad}$ & $\operatorname{mad}$ & mad \\
\hline KS2-Fe-8 & $\mathrm{ad}$ & fad & fad & KS2-Ti-19 & $\mathrm{ad}$ & - & ad \\
\hline KS2-Fe-26 & $\mathrm{ad}$ & mad & mad & KS3-Mx-1 & ad & - & ad \\
\hline
\end{tabular}

Die jüngsten Individuen des Kollektivs sind dem spätjuvenilen (16-20 Jahre) Lebensalter zuzuordnen (z.B. KS06, KS14 und KS32), die ältesten dem frühen Maturitas (40 - 46 Jahre, z.B. KS01, KS30). Für das Individuum KS2-Ti-19 und KS3-Mx-1 konnte lediglich die Altersklasse Adultas festgestellt werden. Die Altersverteilung ist jedoch nicht gleichmäßig, sondern stark einseitig: mehr als $80 \%$ der Individuen sind im frühen bis mittleren Adultas (etwa 20-34 Jahre) verstorben (Tab. 4.4).

Tabelle 4.4: Altersverteilung im Kasseler Kollektiv. Die Mehrheit der Individuen ist im jungen Erwachsenenalter verstorben. Für die Aufteilung in eine Altersklasse wurden die Individuen der Klasse sjuv-fad, fad-mad und mad-sad gleichmäßig aufgeteilt. Bei der Diagnose ,adult“ wurden je 0,3den Altersklassen fad und sad und 0,4 der Altersklasse mad hinzuaddiert. Abkürzungen siehe Tabelle 4.3.

\begin{tabular}{c|c|c|c|c|c|c|c|c|c|c} 
Klasse & sjuv & $\begin{array}{c}\text { sjuv- } \\
\text { fad }\end{array}$ & fad & $\begin{array}{c}\text { fad- } \\
\text { mad }\end{array}$ & mad & $\begin{array}{c}\text { mad- } \\
\text { sad }\end{array}$ & sad & $\begin{array}{c}\text { sad- } \\
\text { fmat }\end{array}$ & fmat & $\Sigma$ \\
\hline \hline Anzahl & 6 & 5 & 58 & 6 & 36 & 3 & 8 & 0 & 2 & 124 \\
\hline Prozent & 4,8 & 4,0 & 46,8 & 4,8 & 29,0 & 2,4 & 6,5 & 0 & 2,4 & 100 \\
\hline & juv & \multicolumn{2}{|c|}{ fad } & & mad & sad & fmat & \\
& & & & & & & & & \\
\hline Anzahl & 8,5 & 64,1 & 41,3 & 10,1 & 2 & 126 \\
\hline Prozent & 6,7 & & 50,9 & & 32,8 & & 8,0 & 1,6 & 100
\end{tabular}

\section{$\underline{\text { Interpretation }}$}

Im Vergleich zu anderen Bestattungen überwiegend männlicher Individuen zeigt sich deutlich, dass der hohe Anteil von jungen Individuen auf einen militärischen Kontext hindeutet. Während in klösterlichen Zusammenhängen Individuen im späten Adultas und Maturitas überwiegen, erreicht die Sterblichkeit in militärischen Kontexten ihr Maximum im frühen Adultas (Abb. 4.13).

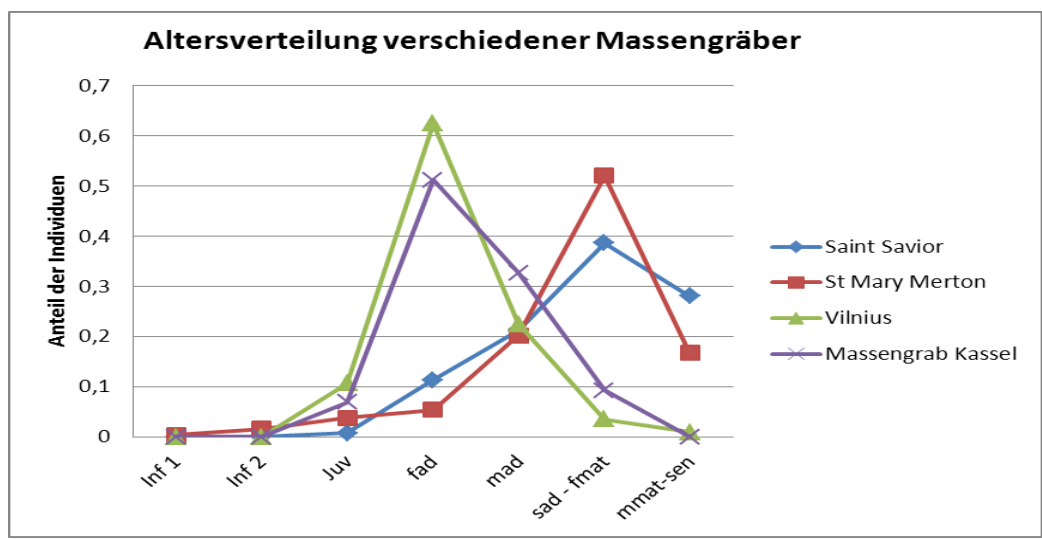

Abbildung 4.13: Altersverteilung verschiedener Massengräber beispielhaft für unterschiedliche Kontexte. Saint Savior, St Mary Merton = Bestattungen nahe Klöster (Daten nach www.museumoflondon.org.uk); Vilnius $=$ Massengrab napoleonischer Soldaten (vgl. Signoli et al. 2004) 


\subsection{Körperhöhenrekonstruktion}

Aufgrund des hohen Fragmentierungsgrads der Skelettelemente war die Rekonstruktion der Körperhöhe nur für 58 Individuen möglich. Tabelle 4.5 zeigt die gemessene Länge der Langknochen je Individuum. Waren sowohl linker als auch rechter Knochen zugeordnet, ist der Mittelwert angegeben. Die letzte Spalte gibt die errechnete Durchschnittsgröße des Individuums nach Pearson (1899) an, der Standardfehler wird mit $\pm 3-4 \mathrm{~cm}$ angegeben.

Tabelle 4.5: Gemessene Länge der Langknochen und errechnete, gemittelte Körperhöhe der Individuen. Kursiv geschrieben ist das weibliche Individuum KS98. Fortsetzung nächste Seite.

\begin{tabular}{|c|c|c|c|c|c|}
\hline Individuum & Femur (F1) & Tibia (T1) & Humerus (H1) & Radius (R1) & $\begin{array}{c}\text { gemittelte } \\
\text { Durchschnittsgröße }\end{array}$ \\
\hline KS01 & 44,4 & & 36 & & 159 \\
\hline KSO2 & 49 & & 33,7 & 24,8 & 167 \\
\hline KSO3 & 40,7 & & 29,2 & & 161 \\
\hline KSO4 & & & 29,5 & & 161 \\
\hline KS05 & 46,1 & 36,7 & 31,9 & 23,8 & 165 \\
\hline KS10 & & & & 25 & 167 \\
\hline KS15 & 52,4 & & 36,3 & & 178 \\
\hline KS16 & 44,2 & & 33,7 & & 166 \\
\hline KS17 & & 40,2 & 34,4 & & 173 \\
\hline KS19 & 45,9 & 36,4 & & & 167 \\
\hline KS20 & & & & 23,4 & 162 \\
\hline KS21 & 46,7 & 40,2 & 33,6 & & 170 \\
\hline KS23 & 47 & & 34,1 & 24,5 & 169 \\
\hline KS24 & 50,7 & 40,6 & & & 176 \\
\hline KS25 & 49,7 & 40,1 & & 25 & 174 \\
\hline KS26 & 47,7 & 36,2 & & & 168 \\
\hline KS27 & 44,3 & & & & 164 \\
\hline KS28 & 47,2 & 37 & 35,1 & & 170 \\
\hline KS29 & 41,4 & & & & 159 \\
\hline KS30 & 46,5 & 38,6 & 33,9 & 24,5 & 168 \\
\hline KS31 & & & 31,9 & & 162 \\
\hline KS32 & & 36,2 & 31,9 & 22,9 & 163 \\
\hline KS33 & 48,0 & 34,9 & & & 168 \\
\hline KS34 & & & 33,5 & & 167 \\
\hline KS36 & 46,2 & 37,3 & 33,3 & & 167 \\
\hline KS37 & 47,5 & & & 25,5 & 170 \\
\hline KS38 & & & & 23,8 & 163 \\
\hline KS39 & 49,1 & & 32,0 & 25,4 & 170 \\
\hline KS40 & 51,7 & & & & 178 \\
\hline KS41 & 49,6 & & & & 174 \\
\hline KS42 & 47,8 & 41,2 & 34,2 & & 172 \\
\hline KS43 & 44,9 & & & & 165 \\
\hline KS44 & & & & 27,2 & 175 \\
\hline
\end{tabular}




\begin{tabular}{|c|c|c|c|c|c|}
\hline Individuum & Femur (F1) & Tibia (T1) & Humerus (H1) & Radius (R1) & $\begin{array}{c}\text { gemittelte } \\
\text { Durchschnittsgröße } \\
\end{array}$ \\
\hline KS45 & 44,9 & & 29,9 & & 162 \\
\hline KS46 & 45,2 & & & & 166 \\
\hline KS47 & 44,8 & & & 24,8 & 166 \\
\hline KS48 & & & & 24,2 & 165 \\
\hline KS50 & & & 33,8 & 24,9 & 168 \\
\hline KS51 & & 34,8 & & & 161 \\
\hline KS58 & & & 32,7 & & 165 \\
\hline KS59 & 44,9 & & 33,9 & & 166 \\
\hline KS63 & & & 33,5 & & 167 \\
\hline KS64 & & 34,3 & 33,6 & & 164 \\
\hline KS65 & & 37,5 & 32,9 & 24,8 & 167 \\
\hline KS72 & & & 34 & 24,7 & 168 \\
\hline KS73 & & & & 27,6 & 176 \\
\hline KS75 & 47,0 & & 32,7 & & 167 \\
\hline KS77 & & 36,3 & & & 165 \\
\hline KS79 & 48,0 & & 34,5 & & 172 \\
\hline KS80 & & & 32,2 & 23,3 & 163 \\
\hline KS81 & 42,8 & & & & 161 \\
\hline KS82 & & & & 23,2 & 161 \\
\hline KS89 & & & 29,9 & & 157 \\
\hline KS94 & & & 32,2 & & 165 \\
\hline KS96 & 43,0 & & 31,9 & 24 & 163 \\
\hline KS98 & 41,8 & & & & 154 \\
\hline KS99 & 45,9 & & & & 168 \\
\hline KS102 & 49,6 & & & & 175 \\
\hline Mittelwert & 46,5 & 37,6 & 33,0 & 24,6 & 167 \\
\hline Median & 46,7 & 37 & 33,5 & 24,6 & 167 \\
\hline
\end{tabular}

Das größte Individuum KS15 besaß eine Körperhöhe von etwa $1,78 \mathrm{~m} \pm 3,5 \mathrm{~cm}$, das kleinste männliche Individuum KS89 lediglich $1,57 \mathrm{~m} \pm 3,5 \mathrm{~cm}$. Das weibliche Individuum KS98 war etwa $1,54 \mathrm{~m} \pm 3,5 \mathrm{~cm}$ groß. Die errechnete durchschnittliche Körperhöhe beträgt etwa $1,67 \mathrm{~m}$.

\section{Interpretation}

Die durchschnittliche Köperhöhe entspricht der Erwartung für Individuen aus dem 19. Jahrhundert (Siegmund 2010). Auch das weibliche Individuum liegt in etwa bei der durchschnittliche Körperhöhe von 1,55m (Siegmund 2010). Die Rekrutierungsdaten aus dieser Zeit, die für verschiedene Länder erhalten sind, liegen ebenfalls um diesen Wert (so z.B. für Frankreich von 1,66m, Komlos 1994). Da sowohl Mittelwert als auch Median in dem Kollektiv fast deckungsgleich sind, scheinen die Werte normalverteilt zu sein. 


\subsection{Abweichungen von der Regelanatomie}

Innerhalb des Skelettkollektivs ließen sich einige Auffälligkeiten finden, die gehäuft beobachtet werden konnten und oft in den Zusammenhang mit starker körperlicher Belastung und / oder Mangelernährung der Individuen gebracht werden können. Die meisten Besonderheiten betreffen jedoch nur einzelne bzw. wenige Individuen. Im Weiteren konnten keine Hinweise auf definitive Todesursachen, etwa durch Gewalteinwirkung, festgestellt werden. Auf den folgenden Seiten sind die Funde nach Häufigkeit absteigend sortiert dargestellt:

Die mit Abstand häufigste Diagnose stellten periostale Reaktionen der unteren Extremität, besonders der Tibiae, dar. Nahezu jede Tibia (148 von 179, 82,7\%) war mindestens leicht betroffen, wobei in der Regel großflächige Streifungen am Skelettelement auftraten (Abb. 4.14). Auch die Mehrheit der Femora (79,2\%) wies periostale Reaktionen auf, die meistens aber nicht derart stark ausgeprägt waren (Abb. 4.15). Diese unspezifische Reaktion des Knochens kann ihren Ursprung in Mangelernährung, physischem Stress oder infektiösen Prozessen (z.B. Syphilis) haben (vgl. Kap. 1.3.).

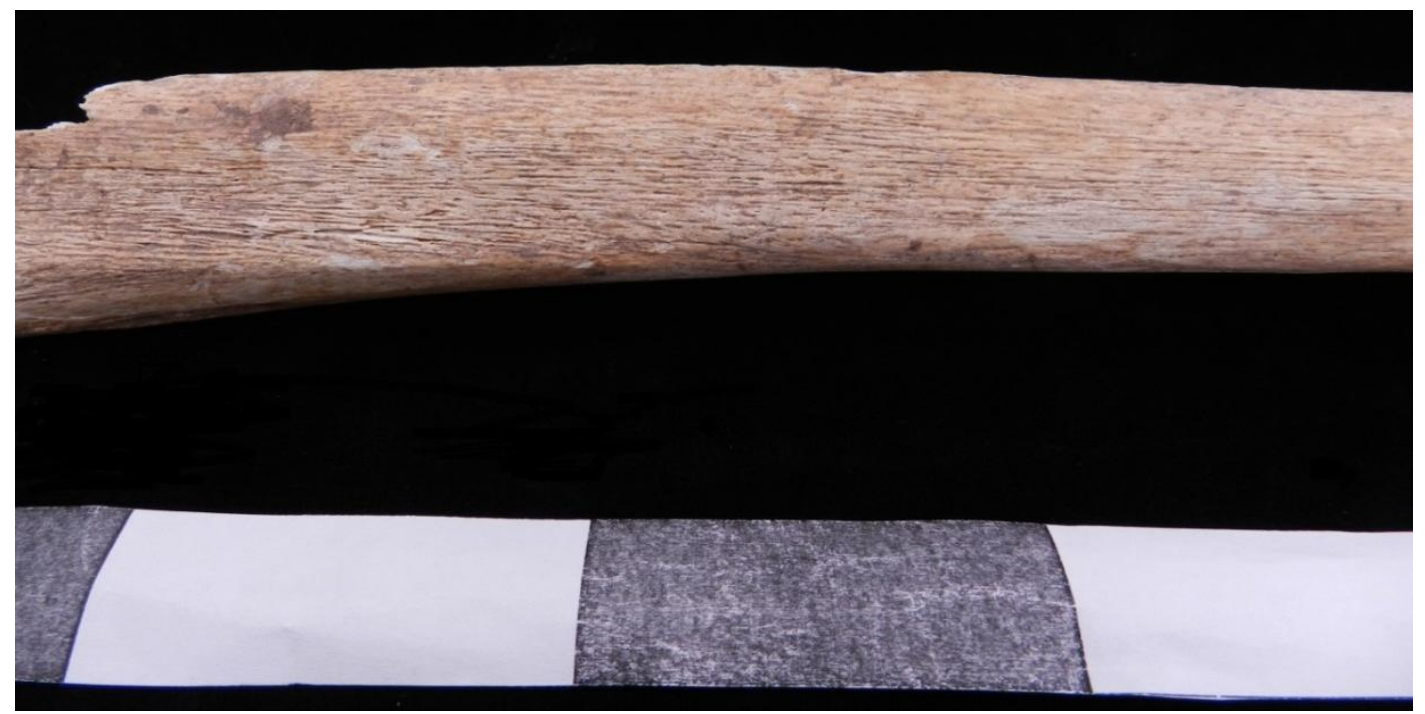

Abbildung 4.14: Periostale Reaktion an einer Tibia (Sicht von lateral).

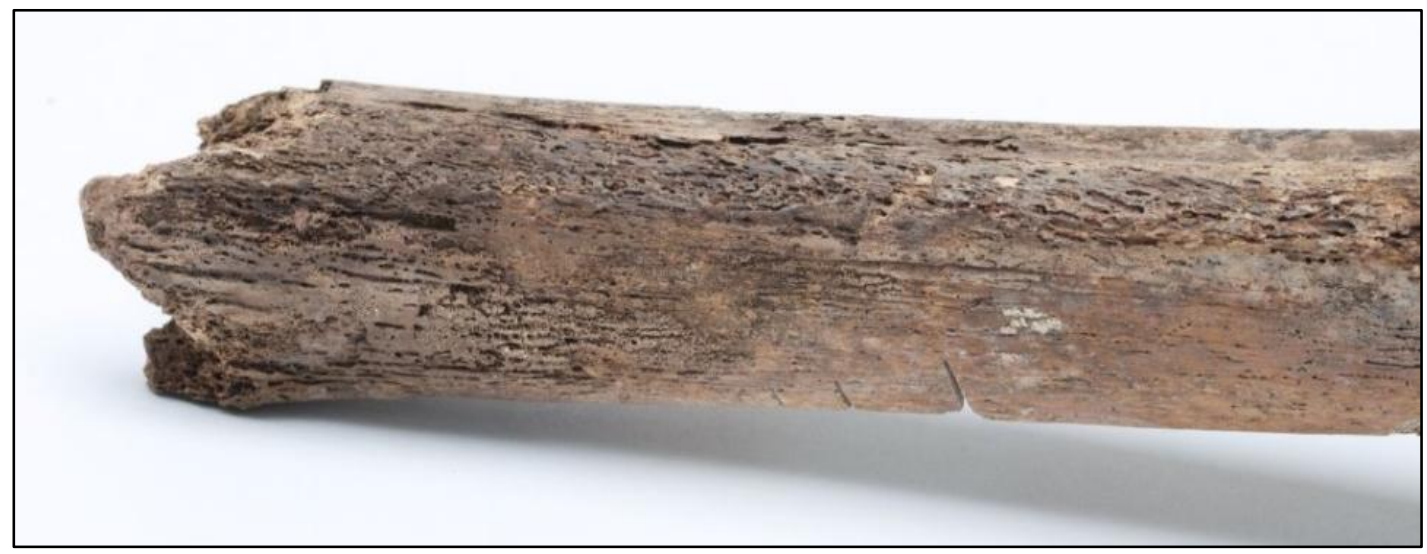

Abbildung 4.15: Periostale Reaktion an einem Femur, Ansicht von posterior (Foto: Peter Mansfeld, Naturkundemuseum Kassel) 
Ebenfalls gehäuft traten Pathologien der Zähne auf. Von den 93 gefundenen Mandibulae wiesen 52 (55,9\%) Zähne mit Karies auf, dabei 39 (41,9\%) an maximal zwei Zähnen. Bei 38 Mandibulae (40,8\%) konnte ein intravitaler Zahnverlust beobachtet werden, davon hatten sieben Individuen bereits mehr als fünf Zähne verloren (Abb. 4.16). Ein Individuum zeigte einen fast kompletten intravitalen Zahnverlust. Ebenfalls 52 Mandibulae wiesen Zähne mit Zahnstein auf, bei $22(23,7 \%)$ wurden Schmelzhypoplasien gefunden (Abb. 4.17) für eine detaillierte Beschreibung siehe auch Stötzel 2013).

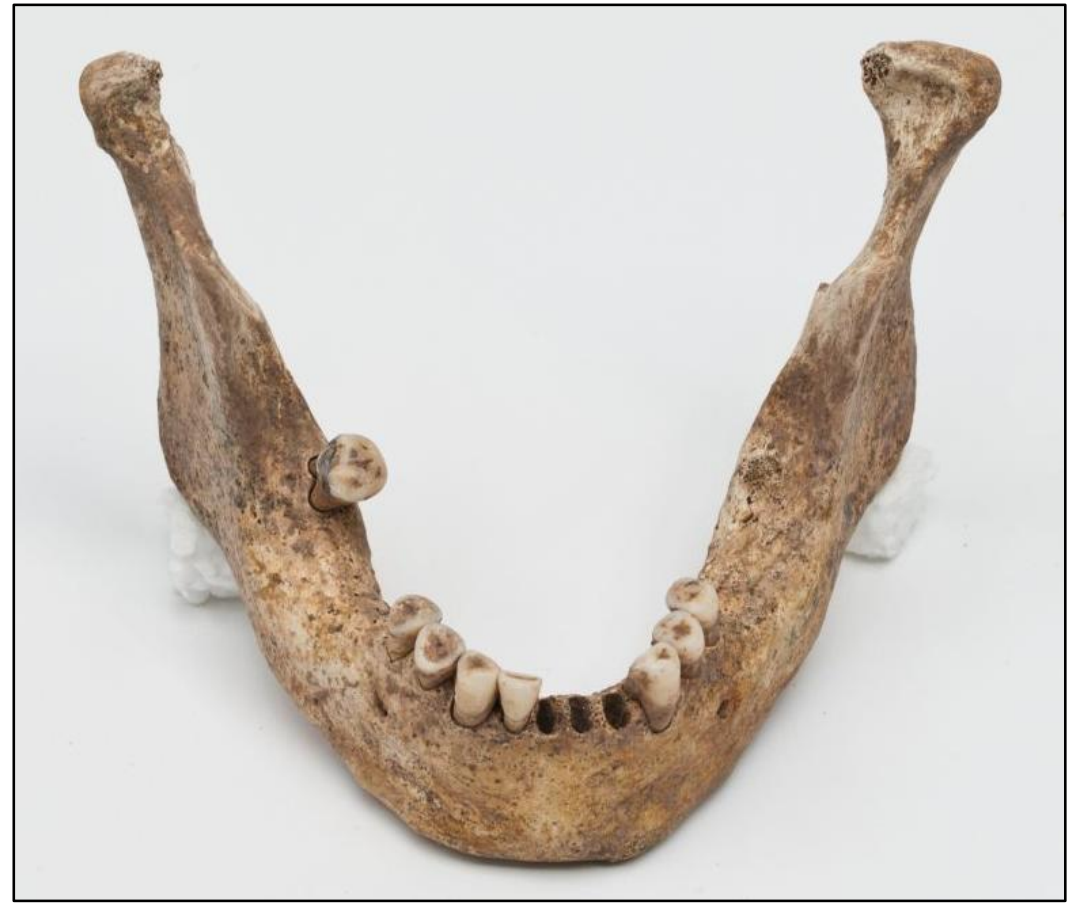

Abbildung 4.16: Mandibula mit intravitalem Zahnverlust fast aller Molaren (Foto: Peter Mansfeld, Naturkundemuseum Kassel).

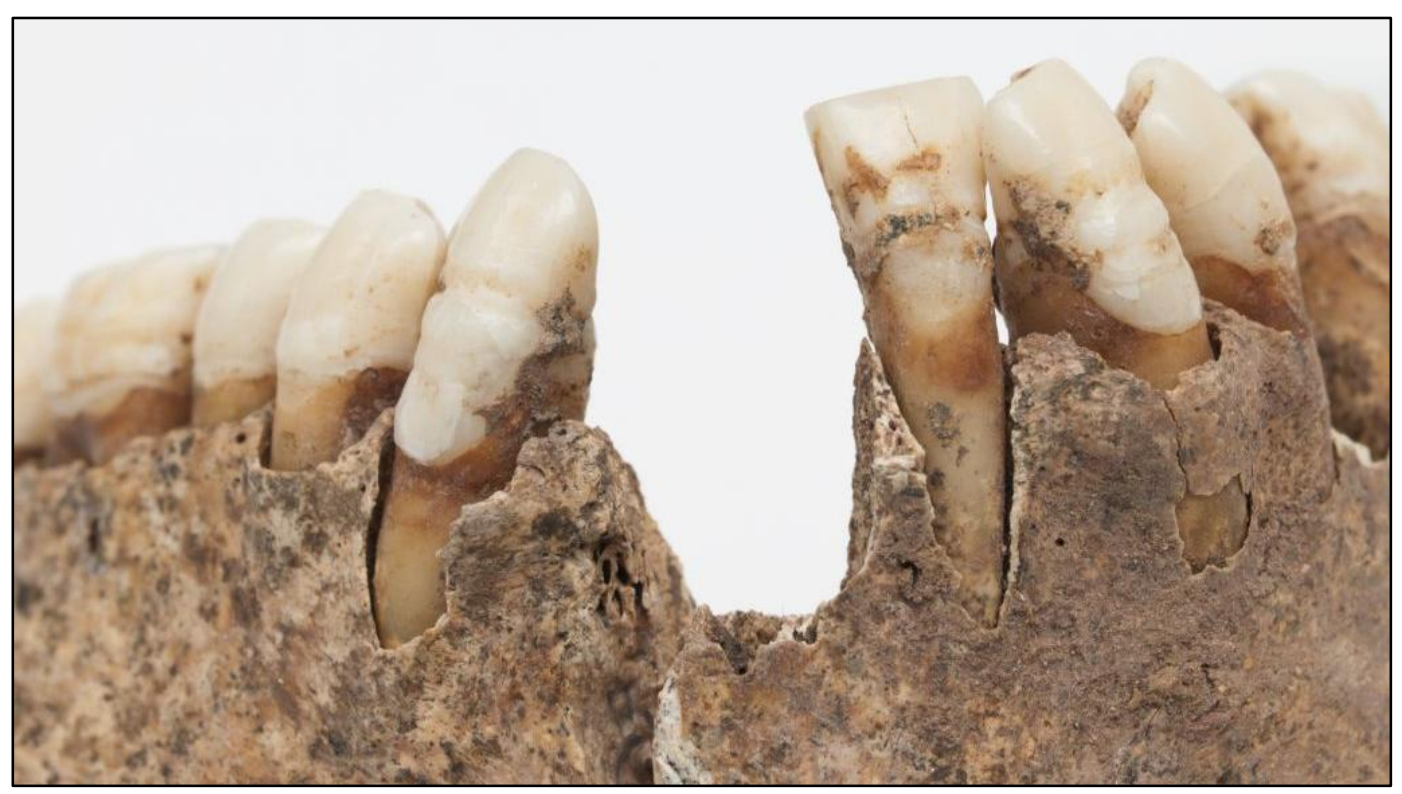

Abbildung 4.17: Nahaufnahme einer Mandibula. Die Zähne zeigen deutliche Schmelzhypoplasien (wellige Struktur des Schmelzes), die Folge einer gestörten Schmelzbildung in der Kindheit, etwa durch Mangelernährung oder Infektionskrankheiten (Foto: Peter Mansfeld, Naturkundemuseum Kassel). 
Von 930 Zähnen, die isoliert vorlagen oder in nicht zugeordneten Maxillenfragmenten steckten, wiesen 216 (23,2\%) Zahnstein, 171 (18,4\%) Schmelzhypoplasien und 91 (9,7\%) Karies auf. In fünf Fällen konnte eine apikale Zystenbildung (Abb. 4.18, oben links) und drei Fällen eine Paradontitis beobachtet werden. An vier Maxillenfragmenten ließen sich noch Zahnfehlstellungen feststellen (Abb. 4.18, unten links). An einigen Maxillenfragmenten gab es Hinweise auf Sinusitis (Nasennebenhöhlenentzündung). An einem Maxillenfragment fand sich ein mikrodonter Zahn. Es konnten keine Hinweise auf Zahnbehandlungen festgestellt werden.
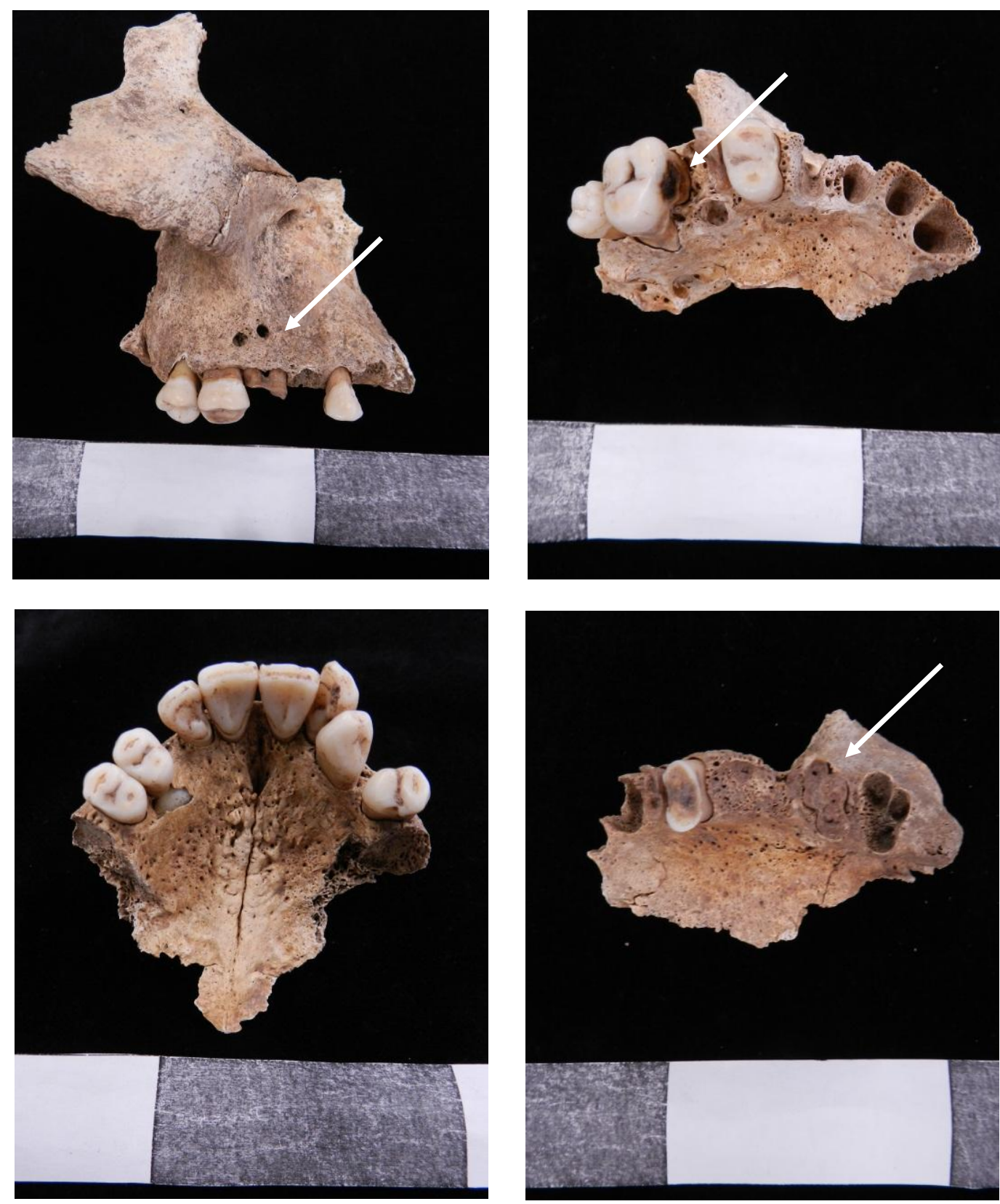

Abbildung 4.18: Pathologische Prozesse an Maxillenfragmenten. Oben links: Zerstörter Zahn mit apikaler Zystenbildung (Pfeil). Oben rechts: Karies am zweiten rechten Molaren (Pfeil). Unten links: Zahnfehlstellungen. Unten rechts: Intravitaler Zahnverlust vom zweiten linken Prämolaren und ersten Molaren, Zerstörung des zweiten Molaren (Pfeil). 
Die am häufigste beobachtete Veränderung der Wirbelsäule betrafen degenerative Veränderungen der Wirbelkörperränder. Von 1616 Wirbeln, die zumindest zu teilweise rekonstruierten Wirbelsäulen oder Wirbelsäulenabschnitten zusammensortiert werden konnten (Abb. 4.19), wiesen 734 (45,4\%) mindestens leichte degenerative Veränderungen auf. Osteophyten wurden an 675 (41,8\%) Wirbeln festgestellt (Abb. 4.18) und 363 (22,5\%) wiesen Abdrücke von Schmorl'schen Knorpelknötchen auf. Zusätzlich wurden verknöcherte Bänder (416 Wirbel, 25,7\%), eingedrückte Wirbelkörper (259 Wirbel, 16\%) und Vertiefungen unterhalb der Rippenansätze (121 von 731 Thorakalwirbeln $[16,6 \%]$ ) beobachtet. Neun Wirbel zeigten Spuren von Traumata und zehn wiesen Eburnisationen auf (für eine detaillierte Beschreibung siehe auch Flux 2013). Die hohe Inzidenz dieser Auffälligkeiten deutet auf eine hohe körperliche Belastung der Individuen hin.

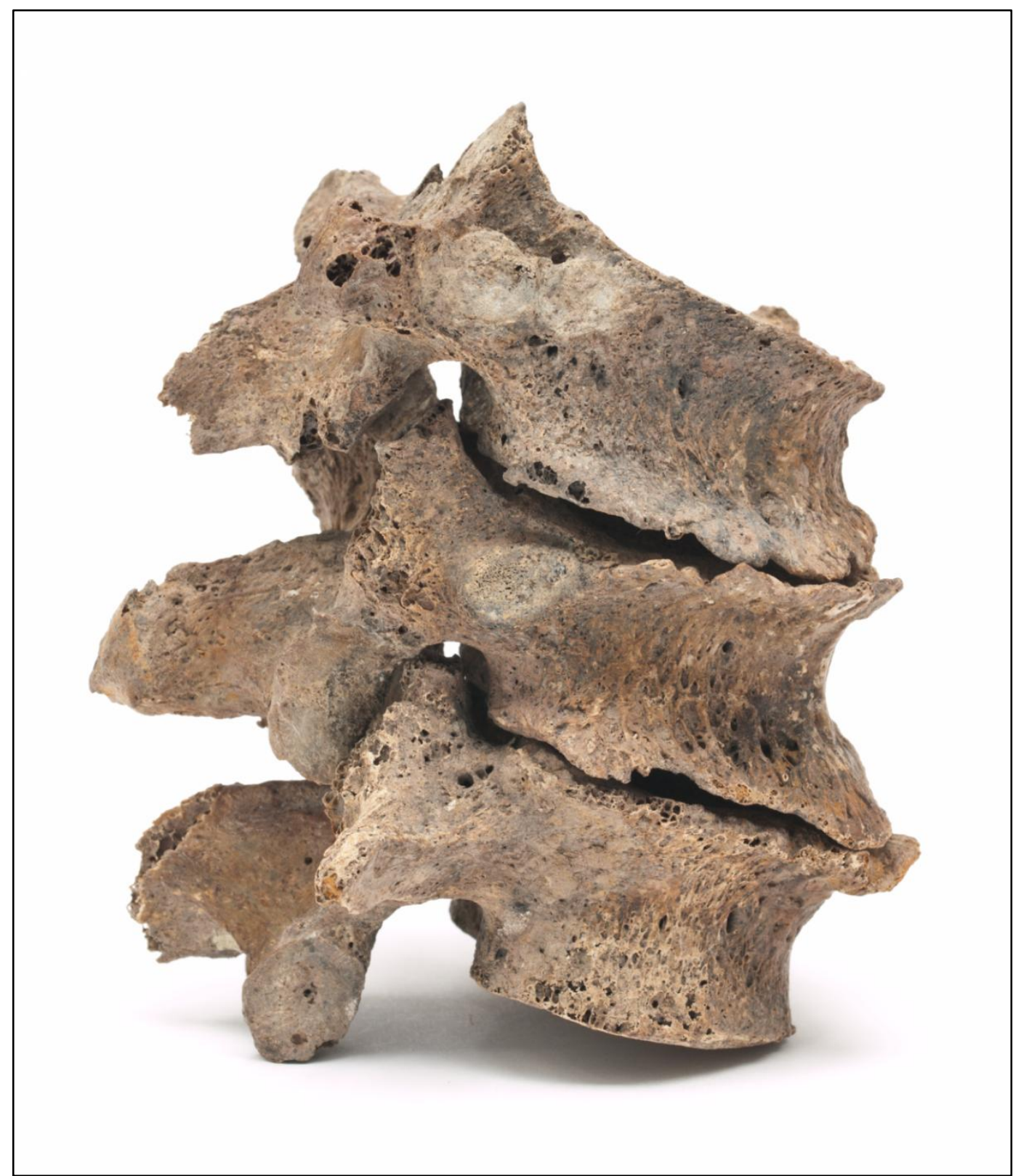

Abbildung 4.19: Thorakalwirbel 11 und 12 und Lumbalwirbel 1 mit deutlicher Osteophytenbildung (Foto: Peter Mansfeld, Naturkundemuseum Kassel) 
10 Schädel/-fragmente $(10,6 \%)$ wiesen Cribra orbitalia auf, die aufgrund von Eisenmangel oder entzündliche Prozesse entstehen (Abb. 4.20). Sieben weitere zeigten leichte Porositäten der Orbitadächer. 29\% der Schädel zeigten ectocranial Porositäten, die auf chronischen Läusebefall deuten könnten (siehe auch Stötzel 2013).

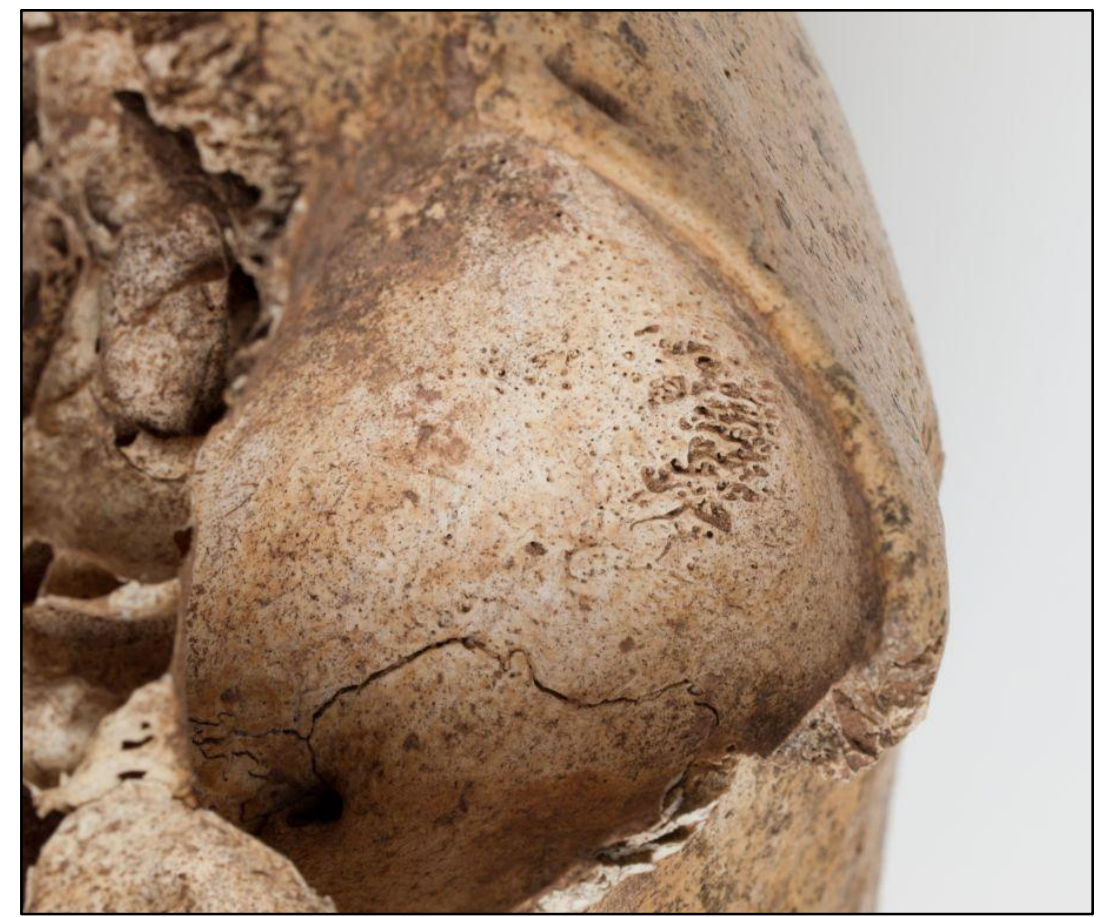

Abbildung 4.20: Cribra orbitalia (hier streifige Strukturauslöschung) aufgrund von Eisenmangel (Foto: Peter Mansfeld, Naturkundemuseum Kassel)

An einigen Claviculae war die Ansatzstelle des Ligamentum costaclaviculare stark vertieft (Abb. 4.21), was auf eine erhöhte Belastung des oberen Brustkorbs, etwa durch schweres Lastentragen, hinweist.

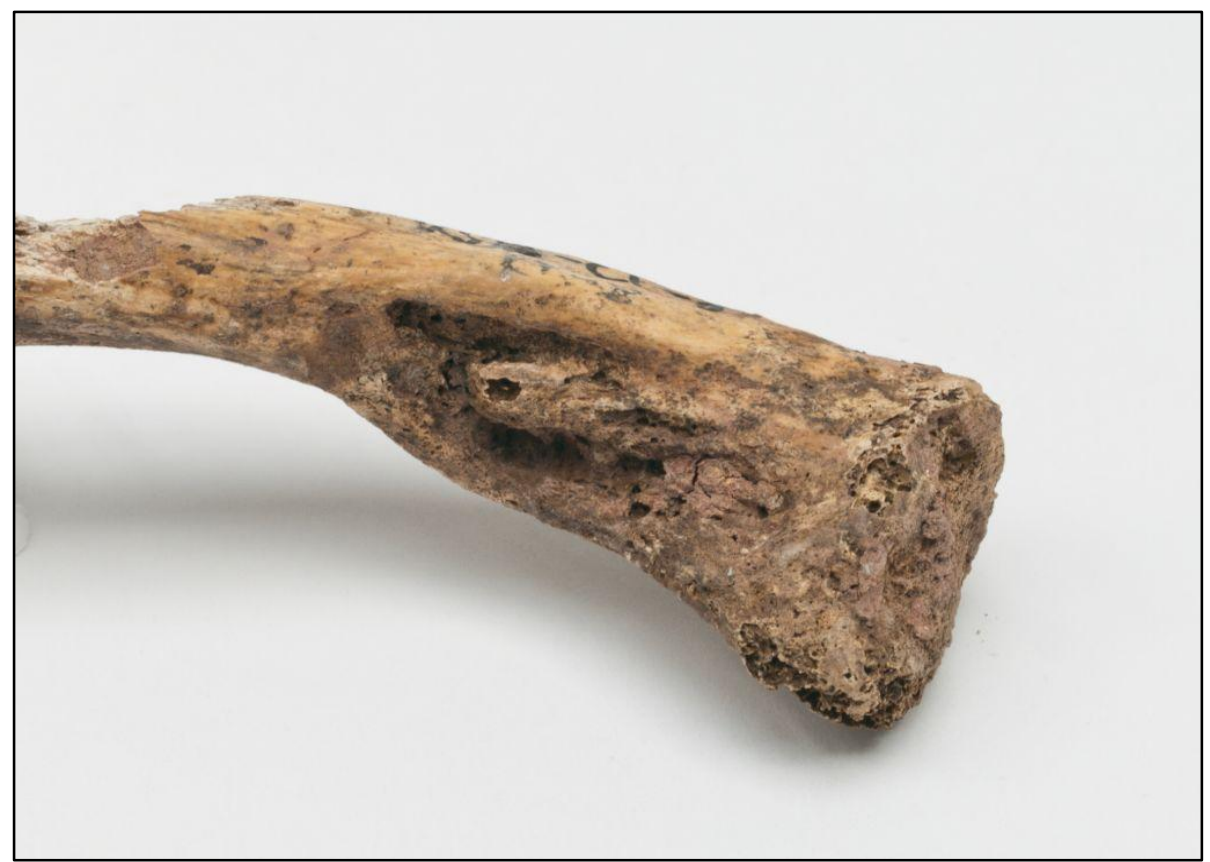

Abbildung 4.21: Sternales Ende einer Clavicula mit stark vertiefter Ansatzstelle des Ligamentum costaclavicuale (Foto: Peter Mansfeld, Naturkundemuseum Kassel) 
Einige Rippenfragmente zeigten starke arthrotische Veränderungen an den Ansätzen für die Wirbel (Abb. 4.22), was ebenfalls Hinweis auf eine starke Belastung auf den Brustkorb z.B. durch Lastentragen sein kann. Weitere zeigten Anzeichen einer Pleuritis (Rippenfellentzündung). Außerdem wurden einige verknöcherte Rippenknorpel gefunden, was ein Zeichen für ein fortgeschrittenes Lebensalter (i.d.R. ab dem frühe Maturitas) ist.

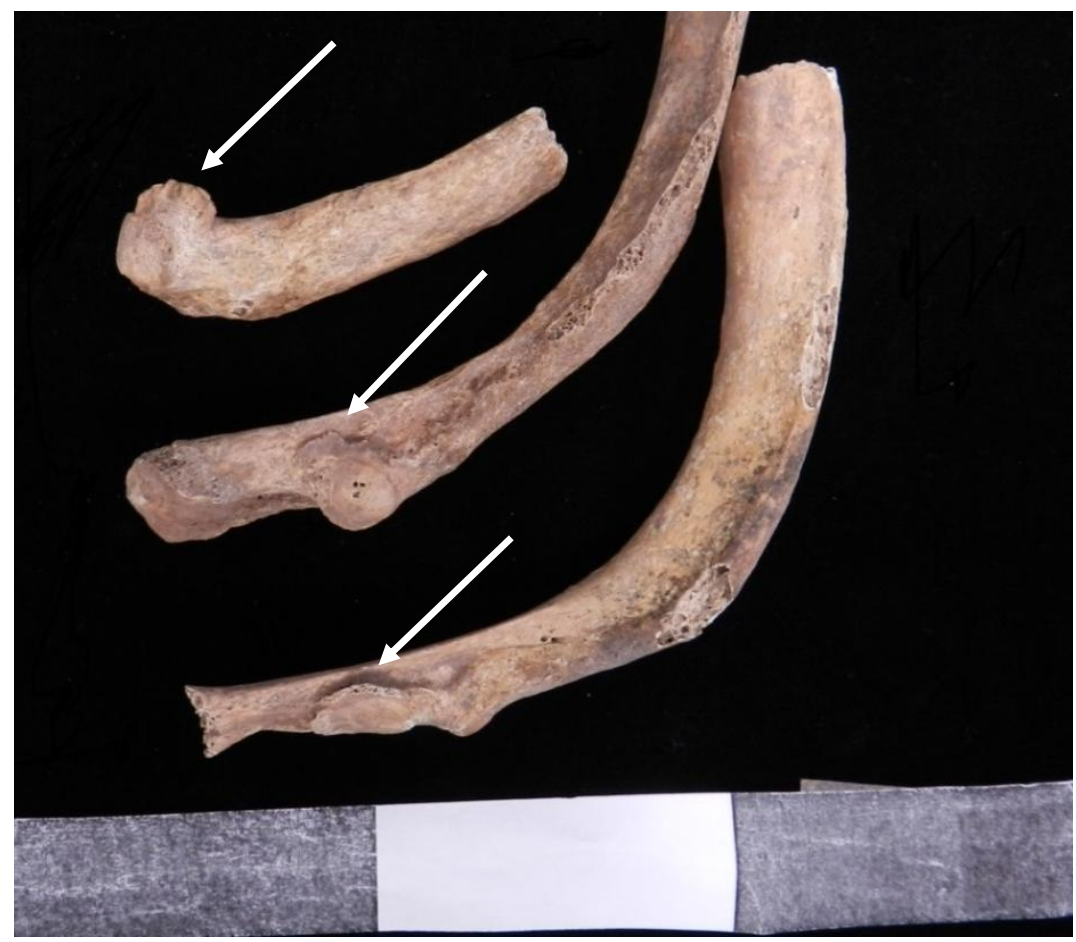

Abbildung 4.22: Arthrotische Veränderungen einiger Rippenfragmente an den Ansätzen der Wirbel.

Darüber hinaus gab es weitere Besonderheiten, die jedoch nur vereinzelt auftreten und daher individualspezifisch sind. Eine Tibia wies Anzeichen einer Knochenmarksentzündung (Osteomyelitis) auf (Abb. 4.23), eine Scapula war durch eine Entzündung stark verändert. Im Weiteren wurde ein verwachsener zweiter und dritter Halswirbel gefunden und ein Schädelfragment wies ein Osteom auf. Von den Mittelfußknochen wies einer einen Ermüdungsbruch auf. Ein Caput femoris sowie die proximalen Epiphysen eines Ulna/Radius-Paares waren stark arthrotisch verändert. Ein Talus/Calcaneus-Paar wies deutliche Randleistenbildung der Gelenkflächen auf. Ein Schädel wies endocranial, etwa mittig der Sutura sagittalis einen entzündlichen Herd auf, wobei auch die Diploe stellenweise stark verdickt war. Ein weiterer Schädel wies an der linken Seite des Os frontale eine Kerbe auf, welche klar abgegrenzte Kanten zum umgebenen Knochen besaß.

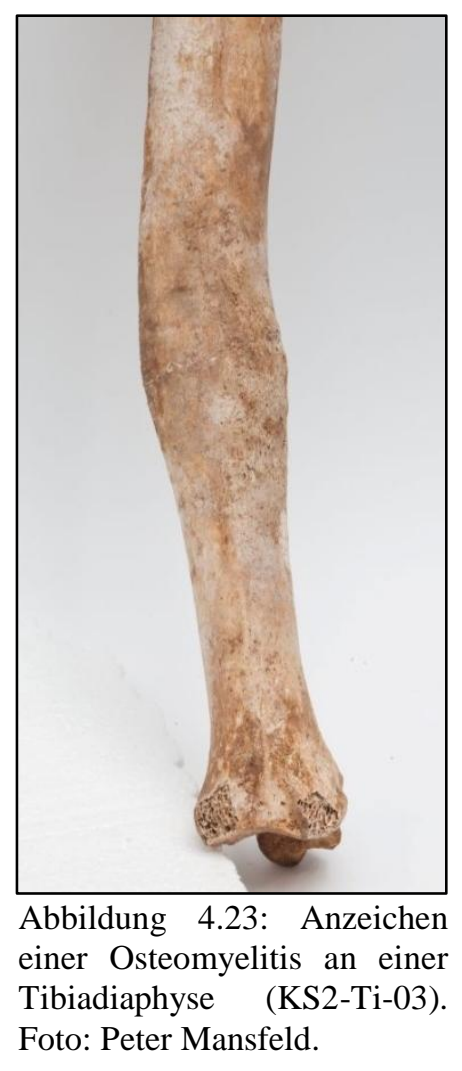


Zweimal konnte eine radioulnare Synostose festgestellt werden (Abb. 4.23), wobei der Unterarm zum einen in Pronations- und zum anderen in Supinationsstellung arretiert worden ist. Es fanden sich weiterhin Hinweise auf zwei traumatische Ereignisse: ein gut verheilter Bruch eines Humerus und ein schlecht verheilter Bruch einer Tibia (Abb. 4.24). Außerdem wurde an zwei Schädeln Trepanationen festgestellt (Abb. 4.24), die vermutlich mit einem Trepan beigebracht und von den Individuen - zumindest eine gewisse Zeit - überlebt worden sind. Diese Besonderheiten lassen darauf schließen, dass diese Individuen Zugang zu einer zumindest rudimentären ärztlichen Versorgung hatten.

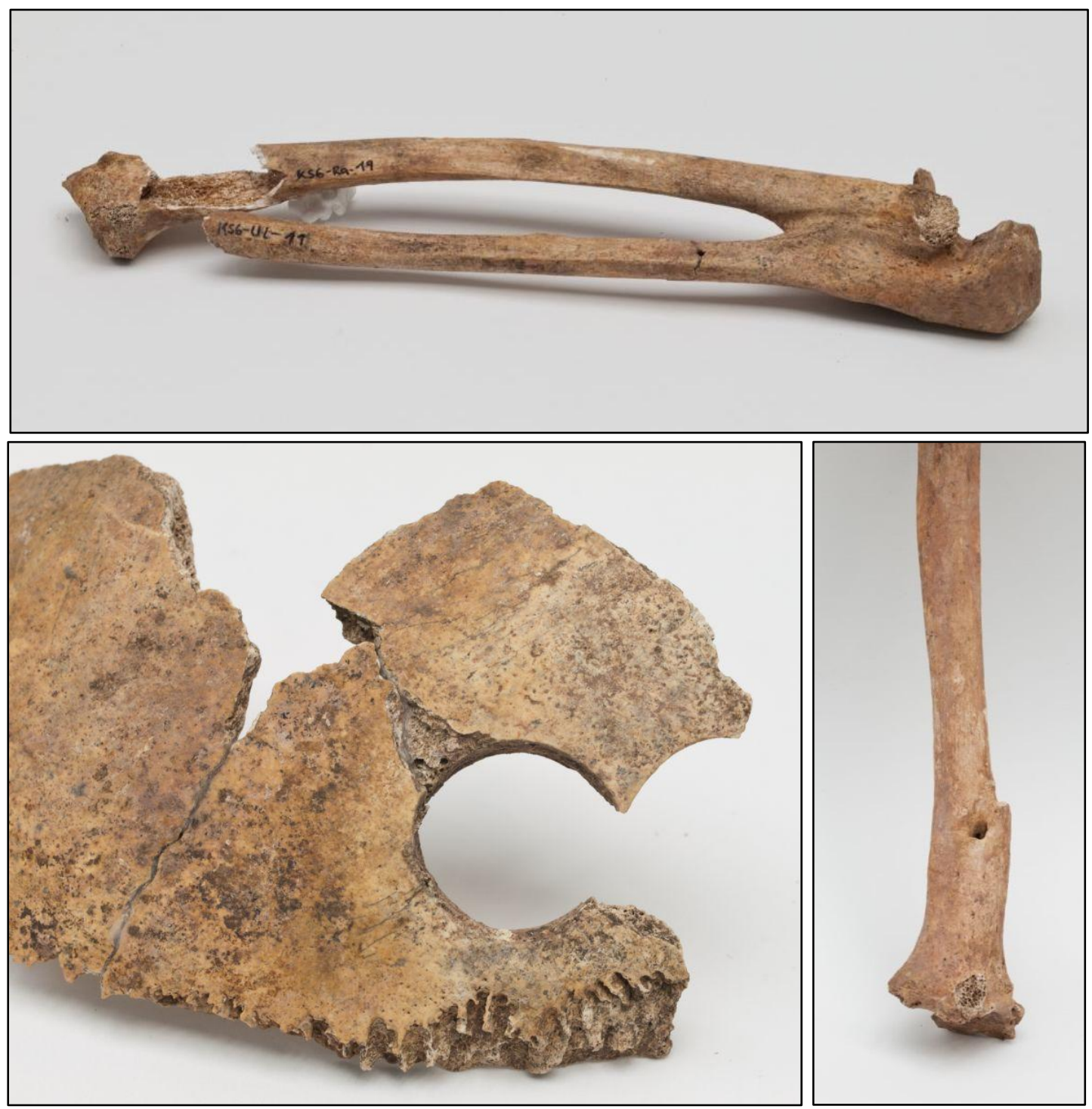

Abbildung 4.24: Oben: Radioulnare Synostose: Am Ellenbogengelenk sind Radius und Ulna verwachsen, vermutlich nach einem Trauma und anschließend zu langer Arretierung der Gelenks (KS6Ul-11, KS6-Ra-19). Unten links: Schädelfragment (isoliert) mit Trepanation, wobei zwei Bohrungen zu erkennen sind. Die Ränder sind von neuem Knochen überwachsen, was auf ein Überleben der Prozedur hinweist. Unten rechts: Schlecht verheilter Bruch einer Tibia (KS2-Ti-02). Fotos: Peter Mansfeld, Naturkundemuseum Kassel. 
Auch in der Mikrostruktur der Knochen gab es einige Auffälligkeiten. In einigen der untersuchten Knochenquerschnitte zeigten sich deutliche Unregelmäßigkeiten der Strukturen: Während einige Bereiche fast frei von Osteonen waren und nur Lamellenknochen zeigten, wiesen direkt angrenzende Bereiche eine hohe Osteonendichte auf (Abb. 4.25). Eine histologische Altersdiagnose wurde so erschwert, da sich in der Regel die Osteone relativ gleichmäßig vom Endost Richtung Periost über den gesamten Querschnitt ausbreiten. Die Bereiche mit hohem Anteil an Lamellenknochen wurden als persistierend gewertet und das Auftreten der Unregelmäßigkeiten mit einer verzögerten / gestörten Knochenumbaurate interpretiert, dessen Ursache Mangelernährung oder physiologischer Stress sein könnte.
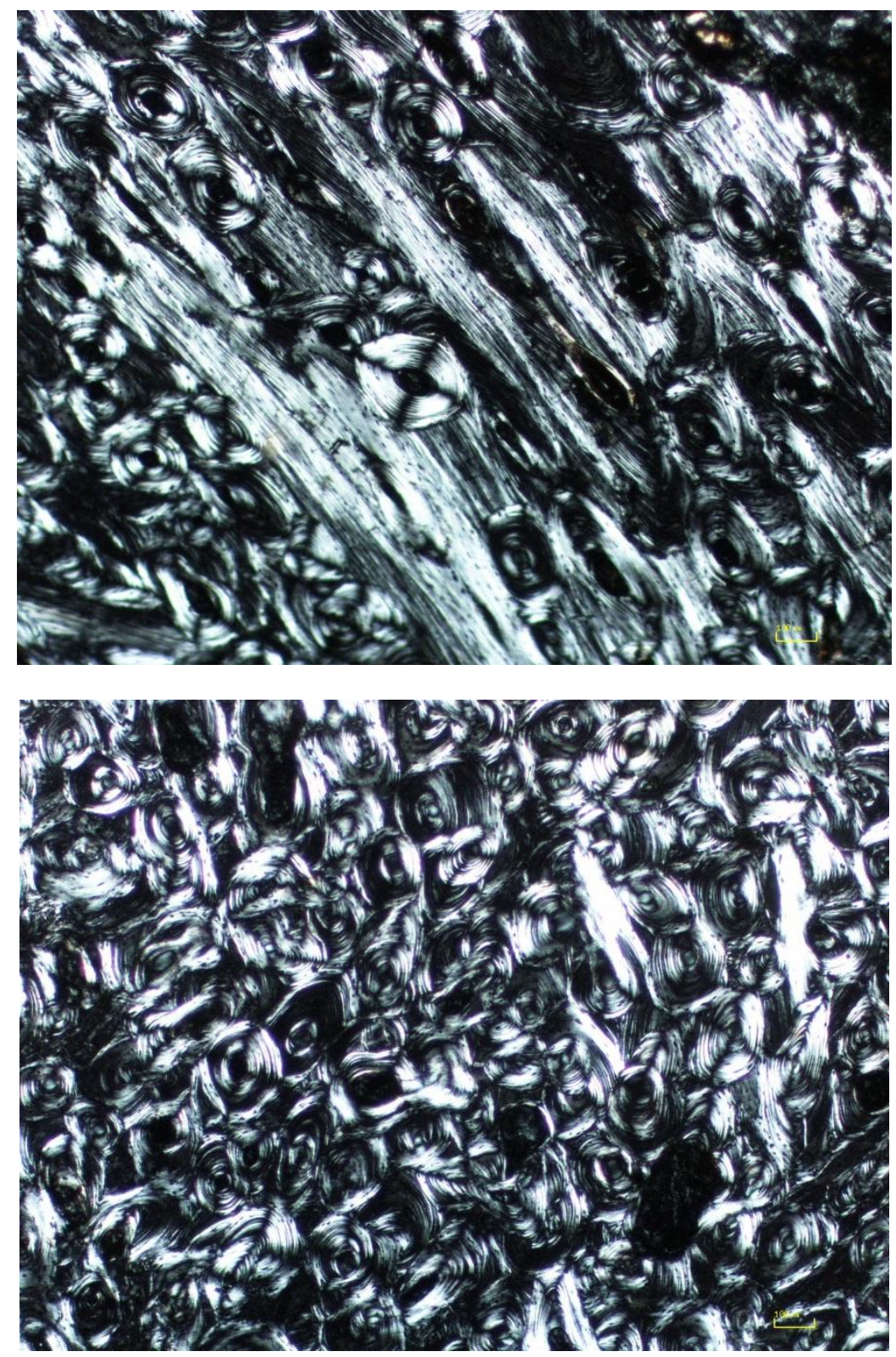

Abbildung 4.25: Aufnahmen der Mikrostrukturen des Femurquerschnitts KS4-Fe-09 unter 40-facher Vergrößerung und Polfilter. In der oberen Aufnahme finden sich wenige Osteone und noch viel Lamellenknochen, in der unteren Aufnahme sind die Osteone dicht gedrängt, was die Altersdiagnose erschwert. 


\subsection{Geographische Herkunftsbestimmung}

\subsubsection{Auswertung autosomaler Allelfrequenzen}

Eine populationsgenetische Auswertung der beobachteten und erwarteten Heterozygotie der autosomalen STR-Systeme (vgl. Tab. 4.2) der 109 vollständig typisierten Individuen zeigte keine signifikante Abweichung vom Hardy-Weinberg-Equilibrium, wobei der p-Wert von D13S317 nahe an der Signifikanz liegt (Tab. 4.6).

Tabelle 4.6: Beobachtete und erwartete Heterozygotie der Individuen aus dem Massengrab. Es zeigt sich keine signifikante Abweichung vom Hardy-Weinberg-Gleichgewicht $(\mathrm{p}>0,05)$.

\begin{tabular}{c|c|c|c|c} 
Locus & beobachtet & erwartet & p-Wert & Standardabweichung \\
\hline \hline D13S317 & 0,77982 & 0,79182 & 0,05702 & 0,00024 \\
\hline D21S11 & 0,91743 & 0,85520 & 0,95647 & 0,00018 \\
\hline D18S51 & 0,90826 & 0,88145 & 0,21472 & 0,00028 \\
\hline TH01 & 0,77982 & 0,78151 & 0,60681 & 0,00045 \\
\hline D5S818 & 0,60550 & 0,67476 & 0,30659 & 0,00042 \\
\hline FGA & 0,86239 & 0,86661 & 0,65700 & 0,00039
\end{tabular}

Da keine Hinweise auf eine erhöhte Verwandtschaft innerhalb der Serie gefunden werden können, kann die Kasseler Serie als Stichprobe einer männlichen Bevölkerung angesehen werden. Die nachfolgende Tabelle 4.7 zeigt die ermittelten Allelfrequenzen der einzelnen Systeme über die Individuen. Dem zugrunde liegt eine Auszählung, bei der homozygote Ergebnisse dann als wirklich homozygot aufgenommen wurden, wenn der genetische Fingerabdruck vollständig und auch die längeren Systeme reproduzierbare, heterozygote Ergebnisse zeigen. Allele wurden nur dann aufgenommen, wenn sie in den Wiederholungsamplifikationen reproduzierbar waren. Besonders in den Systemen TH01, D13S317 und D5S818 fällt die Häufung einiger weniger Allele auf, während in den anderen Systemen die Allele relativ gleichmäßig verteilt sind. Die höchste Frequenz weist mit 39,11\% das Allel 12 in D5S818 auf. 
Tabelle 4.7: Allelverteilung in der Kasseler Serie je STR-System. Zahlen sind Prozentangaben, in Klammer steht die absolute Anzahl an gefundenen Allelen.

\begin{tabular}{|c|c|c|c|c|c|c|}
\hline Allel & TH01 & D13S317 & D5S818 & D18S51 & FGA & D21S11 \\
\hline 5 & $0,39(1)$ & & & & & \\
\hline 6 & $20,24(51)$ & & & & & \\
\hline 7 & $19,84(50)$ & & & & & \\
\hline 8 & $11,51(29)$ & $11,91(30)$ & & & & \\
\hline 9 & $14,29(36)$ & $6,75(17)$ & $0,40(1)$ & & & \\
\hline 9.3 & $32,94(83)$ & & & & & \\
\hline 10 & $0,79(2)$ & $6,75(17)$ & 5,65 (14) & $1,67(4)$ & & \\
\hline 11 & & $27,78(70)$ & $38,71(96)$ & $2,5(6)$ & & \\
\hline 12 & & $31,75(80)$ & $39,11(97)$ & $15,42(37)$ & & \\
\hline 13 & & $11,91(30)$ & $14,92(37)$ & $12,92(31)$ & & \\
\hline 14 & & $3,17(8)$ & $0,81(2)$ & $14,58(35)$ & & \\
\hline 15 & & & $0,40(1)$ & $16,25(39)$ & & \\
\hline 16 & & & & $12,50(30)$ & & \\
\hline 17 & & & & $8,33(20)$ & & \\
\hline 18 & & & & $7,50(18)$ & $1,29(3)$ & \\
\hline 19 & & & & $3,33(8)$ & 6,03 (14) & \\
\hline 20 & & & & $2,92(7)$ & $12,93(30)$ & \\
\hline 21 & & & & $0,83(2)$ & $16,81(39)$ & \\
\hline 21.2 & & & & & $0,86(2)$ & \\
\hline 22 & & & & $0,83(2)$ & $16,81(39)$ & \\
\hline 22.2 & & & & & $0,43(1)$ & \\
\hline 23 & & & & $0,41(1)$ & $13,79(32)$ & \\
\hline 23.2 & & & & & $1,72(4)$ & \\
\hline 24 & & & & & $17,67(41)$ & \\
\hline 25 & & & & & 8,19 (19) & \\
\hline 26 & & & & & $3,45(8)$ & \\
\hline 27 & & & & & & $4,31(10)$ \\
\hline 28 & & & & & & $16,81(39)$ \\
\hline 29 & & & & & & $21,98(51)$ \\
\hline 30 & & & & & & $21,55(50)$ \\
\hline 30.2 & & & & & & 4,31 (10) \\
\hline 31 & & & & & & $6,47(15)$ \\
\hline 31.2 & & & & & & $10,34(24)$ \\
\hline 32 & & & & & & $2,16(5)$ \\
\hline 32.2 & & & & & & $7,33(17)$ \\
\hline 33.2 & & & & & & $4,74(11)$ \\
\hline$\sum \sum$ & $100(252)$ & $100(252)$ & $100(248)$ & $100(240)$ & $100(232)$ & $100(232)$ \\
\hline
\end{tabular}

Die Frequenzen wurden mit den Allelfrequenzen verschiedener europäischer Bevölkerungen verglichen. Dazu wurde mit Hilfe der Frequenzen der Datenbank ALLST*R (http://allstr.de/allstr/home.seam) der Erwartungswert bei n Allelen errechnet (siehe auch die Excel-Tabelle Frequenzdaten.xlsx auf der beigefügten $\mathrm{CD}$ ) und diese Häufigkeitsverteilungen mit Hilfe des Chi-Quadrat-Tests gegeneinander verglichen. Der Auswertung liegt die Annahme zugrunde, dass sich die Individuen eine gemeinsame Herkunftsregion teilen. Dabei wurde die Bonferroni-Korrektur durch die Kumulierung des $\alpha$-Fehlers beim multiplen Testen angewendet und nur solche Vergleiche als signifikant unterschiedlich betrachtet, deren $\alpha \leq \alpha / \mathrm{k}(\mathrm{k}=\mathrm{An}-$ zahl der durchgeführten Tests). 
$\underline{\mathrm{TH} 01}$

Die Datenbank weist für das System TH01 folgende Allelverteilung auf (Tab. 4.8):

Tabelle 4.8: Allelverteilung des Systems TH01 in europäischen Bevölkerungen, basierend auf $n$ typisierten Individuen (Datenbank ALLST*R)

\begin{tabular}{lcccccc} 
Land & $\mathbf{5 6}$ & $\mathbf{7}$ & $\mathbf{8}$ & $\mathbf{9}$ & $\mathbf{2 9 . 3}$ & $\mathbf{n}$ \\
\hline \hline Belgien & 0,2387 & 0,1347 & 0,1347 & 0,1449 & 0,347 & 245 \\
\hline Deutschland & 0,2264 & 0,1604 & 0,1131 & 0,1655 & 0,3346 & 7373 \\
\hline Frankreich & 0,2374 & 0,1816 & 0,1145 & 0,1564 & 0,3101 & 179 \\
\hline Schweden & 0,2674 & 0,1142 & 0,1196 & 0,1821 & 0,3167 & 786 \\
\hline Russland & 0,3466 & 0,1889 & 0,1022 & 0,0956 & 0,2667 & 225 \\
Niederlande & 0,237 & 0,2059 & 0,1042 & 0,1427 & 0,3102 & 403
\end{tabular}

Für das System wurden 252 Allele in der Kasseler Serie erfolgreich typisiert. Der Erwartungswert in den verschiedenen Populationen beträgt demnach (Tab. 4.9):

Tabelle 4.9: Erwartungswert der Allelanzahl bei 252 erfolgreich typisierten Allelen in den europäischen Bevölkerungen aus Tabelle 4.8)

\begin{tabular}{lccccc} 
Land & $\mathbf{6}$ & $\mathbf{7}$ & $\mathbf{8}$ & $\mathbf{9}$ & $\geq \mathbf{9 . 3}$ \\
\hline \hline Belgien & 60 & 34 & 34 & 37 & 87 \\
\hline Deutschland & 57 & 40 & 29 & 42 & 84 \\
\hline Frankreich & 60 & 46 & 29 & 39 & 78 \\
\hline Schweden & 67 & 29 & 30 & 46 & 80 \\
\hline Russland & 87 & 48 & 26 & 24 & 67 \\
\hline Niederlande & 60 & 52 & 26 & 36 & 78 \\
\hline Massengrab KS & 52 & 50 & 29 & 36 & 85
\end{tabular}

Der Test zwischen den Häufigkeiten aus dem Massengrab und der russischen Häufigkeit $\left(\mathrm{p}=0,00004, \chi^{2}=25,346, \mathrm{df}=4\right)$ sowie der schwedische Frequenz $(\mathrm{p}=$ $0,0003, \chi^{2}=21,085, \mathrm{df}=4$ ) ergibt einen signifikanten Unterschied. Alle weiteren Vergleiche waren nicht signifikant $(\mathrm{p}>0,05)$.

\section{D13S317}

Die Datenbank weist für das System D13S317 folgende Allelverteilung auf (Tab. 4.10):

Tabelle 4.10: Allelverteilung des Systems D13S317 in europäischen Bevölkerungen, basierend auf n typisierten Individuen (Datenbank ALLST*R)

\begin{tabular}{lcccccccc} 
Land & $\mathbf{8}$ & $\mathbf{9}$ & $\mathbf{1 0}$ & $\mathbf{1 1}$ & $\mathbf{1 2}$ & $\mathbf{1 3}$ & $\geq \mathbf{1 4}$ & $\mathbf{n}$ \\
\hline \hline Belgien & 0,1073 & 0,0924 & 0,0703 & 0,3053 & 0,277 & 0,0957 & 0,052 & 298 \\
\hline Deutschland & 0,1416 & 0,0752 & 0,0519 & 0,3075 & 0,2836 & 0,1006 & 0,0396 & 1319 \\
\hline Russland & 0,1436 & 0,0891 & 0,0619 & 0,3711 & 0,2091 & 0,0803 & 0,0449 & 679 \\
\hline Italien & 0,132 & 0,073 & 0,064 & 0,313 & 0,293 & 0,09 & 0,035 & 833 \\
\hline Weißrussland & 0,162 & 0,069 & 0,037 & 0,338 & 0,213 & 0,148 & 0,033 & 212
\end{tabular}

Für das System wurden 252 Allele in der Kasseler Serie erfolgreich typisiert. Der Erwartungswert in den verschiedenen Populationen beträgt demnach (Tab. 4.11): 
Tabelle 4.11: Erwartungswert der Allelanzahl bei 252 erfolgreich typisierten Allelen in den europäischen Bevölkerungen aus Tabelle 4.10)

\begin{tabular}{lccccccc} 
Land & $\mathbf{8}$ & $\mathbf{9}$ & $\mathbf{1 0}$ & $\mathbf{1 1}$ & $\mathbf{1 2}$ & $\mathbf{1 3}$ & $\geq \mathbf{1 4}$ \\
\hline \hline Belgien & 27 & 23 & 18 & 77 & 70 & 24 & 13 \\
Deutschland & 36 & 19 & 13 & 77 & 71 & 25 & 10 \\
\hline Russland & 36 & 22 & 16 & 94 & 53 & 20 & 11 \\
\hline Italien & 33 & 18 & 16 & 79 & 74 & 23 & 9 \\
\hline Weißrussland & 41 & 17 & 9 & 85 & 54 & 37 & 8 \\
\hline Massengrab KS & 30 & 17 & 17 & 70 & 80 & 30 & 8
\end{tabular}

Der Test zwischen den Häufigkeiten aus dem Massengrab und der weißrussischen Häufigkeit ( $\left.\mathrm{p}=0,00018, \chi^{2}=26,552, \mathrm{df}=6\right)$ und der russischen Verteilung $(\mathrm{p}=$ $0,00010, \chi^{2}=27,899$, df $=6$ ) ergibt einen signifikanten Unterschied, alle anderen Tests sind nicht signifikant $(\mathrm{p} \geq 0,2)$.

\section{$\underline{\mathrm{D} 5 \mathrm{~S} 818}$}

Die Datenbank weist für das System D5S818 folgende Allelverteilung auf (Tab. 4.12):

Tabelle 4.12: Allelverteilung des Systems D5S818 in europäischen Bevölkerungen, basierend auf n typisierten Individuen (Datenbank ALLST*R)

\begin{tabular}{lccccccc} 
Land & $\mathbf{5 9}$ & $\mathbf{1 0}$ & $\mathbf{1 1}$ & $\mathbf{1 2}$ & $\mathbf{1 3}$ & $\mathbf{2 1 4}$ & $\mathbf{n}$ \\
\hline Belgien & 0,044 & 0,054 & 0,356 & 0,369 & 0,162 & 0,015 & 222 \\
\hline Deutschland & 0,0481 & 0,0685 & 0,3376 & 0,3613 & 0,1719 & 0,0126 & 2334 \\
\hline Italien & 0,045 & 0,109 & 0,326 & 0,299 & 0,206 & 0,015 & 618 \\
\hline Schweden & 0,0485 & 0,0704 & 0,3277 & 0,3641 & 0,1699 & 0,0194 & 206 \\
\hline Russland & 0,0584 & 0,0858 & 0,3496 & 0,3271 & 0,1642 & 0,0149 & 402
\end{tabular}

Für das System wurden 248 Allele in der Kasseler Serie erfolgreich typisiert. Der Erwartungswert in den verschiedenen Populationen beträgt demnach (Tab. 4.13):

Tabelle 4.13: Erwartungswert der Allelanzahl bei 242 erfolgreich typisierten Allelen in den europäischen Bevölkerungen aus Tabelle 4.12)

\begin{tabular}{lcccccc} 
Land & $\leq \mathbf{9}$ & $\mathbf{1 0}$ & $\mathbf{1 1}$ & $\mathbf{1 2}$ & $\mathbf{1 3}$ & $\mathbf{\geq 1 4}$ \\
\hline Belgien & 11 & 13 & 88 & 92 & 40 & 4 \\
\hline Deutschland & 12 & 17 & 84 & 90 & 43 & 3 \\
\hline Italien & 11 & 27 & 81 & 74 & 51 & 4 \\
\hline Schweden & 12 & 17 & 81 & 90 & 42 & 5 \\
\hline Russland & 14 & 21 & 87 & 81 & 41 & 4 \\
\hline Massengrab KS & 1 & 14 & 96 & 97 & 37 & 3
\end{tabular}

Wegen der deutlichen Unterrepräsentation des Allels 9 in der Kasseler Serie wurde beim Einzelvergleich eine signifikanter Unterschied zur russischen $\left(p=0,0018, \chi^{2}=\right.$ $19,137, \mathrm{df}=5)$, italienischen $\left(\mathrm{p}=0,00002, \chi^{2}=29,37, \mathrm{df}=5\right)$ und schwedischen $(\mathrm{p}=$ $0,0090, \chi^{2}=15,33, \mathrm{df}=5$ ) Allelverteilung gefunden. 


\section{D18S51}

Die Datenbank weist für das System D18S51 folgende Allelverteilung auf (Tab. 4.14):

Tabelle 4.14: Allelverteilung des Systems D18S51 in europäischen Bevölkerungen, basierend auf $n$ typisierten Individuen (Datenbank ALLST*R). B = Belgien, D = Deutschland, F = Frankreich, I = Italien, BEL = Weißrussland

\begin{tabular}{crrrrrrrrrrr} 
Land & \multicolumn{1}{c}{$\mathbf{1 1}$} & $\mathbf{1 2}$ & $\mathbf{1 3}$ & \multicolumn{1}{c}{$\mathbf{1 4}$} & $\mathbf{1 5}$ & $\mathbf{1 6}$ & $\mathbf{1 7}$ & $\mathbf{1 8}$ & $\mathbf{1 9}$ & $\mathbf{2 2 0}$ & \multicolumn{1}{c}{$\mathbf{n}$} \\
\hline \hline B & 0,024 & 0,126 & 0,137 & 0,164 & 0,137 & 0,149 & 0,11 & 0,068 & 0,041 & 0,044 & 222 \\
\hline D & 0,02 & 0,134 & 0,1296 & 0,1613 & 0,1478 & 0,1367 & 0,1121 & 0,0705 & 0,04 & 0,048 & 4586 \\
\hline F & 0,013 & 0,142 & 0,135 & 0,159 & 0,138 & 0,124 & 0,12 & 0,079 & 0,044 & 0,046 & 229 \\
\hline I & 0,025 & 0,17 & 0,141 & 0,175 & 0,135 & 0,135 & 0,09 & 0,059 & 0,036 & 0,034 & 785 \\
\hline BEL & 0,022 & 0,12 & 0,125 & 0,152 & 0,152 & 0,168 & 0,087 & 0,087 & 0,049 & 0,038 & 212
\end{tabular}

Für das System wurden 240 Allele in der Kasseler Serie erfolgreich typisiert. Der Erwartungswert in den verschiedenen Populationen beträgt demnach (Tab. 4.15):

Tabelle 4.15: Erwartungswert der Allelanzahl bei 238 erfolgreich typisierten Allelen in den europäischen Bevölkerungen aus Tabelle 4.14)

\begin{tabular}{ccccccccccc} 
Land & $\leq \mathbf{1 1}$ & $\mathbf{1 2}$ & $\mathbf{1 3}$ & $\mathbf{1 4}$ & $\mathbf{1 5}$ & $\mathbf{1 6}$ & $\mathbf{1 7}$ & $\mathbf{1 8}$ & $\mathbf{1 9}$ & $\geq \mathbf{2 0}$ \\
\hline \hline B & 6 & 30 & 33 & 39 & 33 & 36 & 26 & 16 & 10 & 10 \\
D & 5 & 32 & 31 & 39 & 35 & 33 & 27 & 17 & 10 & 11 \\
\hline F & 4 & 34 & 32 & 37 & 33 & 30 & 29 & 19 & 11 & 11 \\
\hline I & 6 & 41 & 34 & 42 & 32 & 32 & 22 & 14 & 9 & 8 \\
\hline BEL & 5 & 29 & 30 & 36 & 36 & 40 & 21 & 21 & 12 & 9 \\
\hline KS & 10 & 37 & 31 & 35 & 39 & 30 & 20 & 18 & 8 & 12
\end{tabular}

Der Test ergab keinen signifikanten Unterschied in der Allelverteilung $(\mathrm{p} \geq 0,11)$.

\section{$\underline{\text { FGA }}$}

Für das System FGA wurden die Interallele aufgrund der geringen Frequenz mit jeweiligen Vollallelen zusammengefasst. Die Frequenzen in der Datenbank ergeben folgende Verteilung (Tab. 4.16):

Tabelle 4.16: Allelverteilung des Systems FGA in europäischen Bevölkerungen, basierend auf $\mathrm{n}$ typisierten Individuen (Datenbank ALLST*R). B = Belgien, NL = Niederlande, $\mathrm{D}=$ Deutschland, $\mathrm{S}=$ Schweden, RUS = Russland

\begin{tabular}{ccccccccccc} 
Land & $\mathbf{1 8}$ & $\mathbf{1 9}$ & $\mathbf{2 0}$ & $\mathbf{2 1 / 2 1 . 2}$ & $\mathbf{2 2 / 2 2 . 2}$ & $\mathbf{2 3 / 2 3 . 2}$ & $\mathbf{2 4}$ & $\mathbf{2 5}$ & $\mathbf{2 2 6}$ & $\mathbf{n}$ \\
\hline B & 0,016 & 0,032 & 0,133 & 0,173 & 0,22 & 0,157 & 0,146 & 0,07 & 0,053 & 444 \\
\hline NL & 0,015 & 0,059 & 0,137 & 0,18 & 0,166 & 0,144 & 0,154 & 0,083 & 0,062 & 205 \\
\hline D & 0,011 & 0,069 & 0,1358 & 0,1747 & 0,1957 & 0,1378 & 0,1314 & 0,0843 & 0,0603 & 1709 \\
\hline S & 0,0218 & 0,0752 & 0,1553 & 0,1893 & 0,1456 & 0,1384 & 0,1384 & 0,0825 & 0,0535 & 206 \\
\hline RUS & 0,011 & 0,071 & 0,154 & 0,164 & 0,196 & 0,152 & 0,129 & 0,085 & 0,038 & 402
\end{tabular}

Für das System wurden 232 Allele in der Kasseler Serie erfolgreich typisiert. Der Erwartungswert in den verschiedenen Populationen beträgt demnach (Tab. 4.17): 
Tabelle 4.17: Erwartungswert der Allelanzahl bei 234 erfolgreich typisierten Allelen in den europäischen Bevölkerungen aus Tabelle 4.16)

\begin{tabular}{lccccccccc} 
Land & $\mathbf{1 8}$ & $\mathbf{1 9}$ & $\mathbf{2 0}$ & $\mathbf{2 1 / 2 1 . 2}$ & $\mathbf{2 2 / 2 2 . 2}$ & $\mathbf{2 3 / 2 3 . 2}$ & $\mathbf{2 4}$ & $\mathbf{2 5}$ & $\mathbf{2 6}$ \\
\hline \hline Belgien & 4 & 7 & 31 & 40 & 51 & 36 & 34 & 16 & 12 \\
\hline Niederlande & 3 & 14 & 32 & 42 & 39 & 33 & 36 & 19 & 14 \\
\hline Deutschland & 3 & 16 & 32 & 41 & 45 & 32 & 30 & 20 & 14 \\
\hline Schweden & 5 & 17 & 36 & 44 & 34 & 32 & 32 & 19 & 12 \\
\hline Russland & 3 & 16 & 36 & 38 & 45 & 35 & 30 & 20 & 9 \\
\hline Massengrab KS & 3 & 14 & 30 & 41 & 40 & 36 & 41 & 19 & 8
\end{tabular}

Alle Einzelvergleiche waren nicht signifikant $(p \geq 0,111)$.

\section{$\underline{\mathrm{D} 21 \mathrm{~S} 11}$}

Die Datenbank weist für das System D21S11 folgende Allelverteilung auf (Tab. 4.18):

Tabelle 4.18: Allelverteilung des Systems D21S11 in europäischen Bevölkerungen, basierend auf n typisierten Individuen (Datenbank ALLST*R)

\begin{tabular}{lccccccccccc} 
Land & $\leq \mathbf{2 7}$ & $\mathbf{2 8}$ & $\mathbf{2 9}$ & $\mathbf{3 0}$ & $\mathbf{3 0 . 2}$ & $\mathbf{3 1}$ & $\mathbf{3 1 . 2}$ & $\mathbf{3 2}$ & $\mathbf{3 2 . 2}$ & $\geq \mathbf{3 3}$ & $\mathbf{n}$ \\
\hline \hline Belgien & 0,03 & 0,155 & 0,236 & 0,264 & 0,011 & 0,083 & 0,074 & 0,027 & 0,079 & 0,041 & 222 \\
\hline Deutschland & 0,032 & 0,176 & 0,222 & 0,227 & 0,048 & 0,053 & 0,108 & 0,013 & 0,078 & 0,043 & 500 \\
\hline Frankreich & 0,051 & 0,142 & 0,237 & 0,244 & 0,024 & 0,052 & 0,117 & 0,017 & 0,067 & 0,049 & 232 \\
\hline Italien & 0,031 & 0,151 & 0,225 & 0,231 & 0,035 & 0,056 & 0,094 & 0,015 & 0,117 & 0,045 & 786 \\
\hline Russland & 0,024 & 0,144 & 0,208 & 0,259 & 0,057 & 0,078 & 0,076 & 0,02 & 0,087 & 0,047 & 402
\end{tabular}

Für das System wurden 232 Allele in der Kasseler Serie erfolgreich typisiert. Der Erwartungswert in den verschiedenen Populationen beträgt demnach (Tab. 4.19):

Tabelle 4.19: Erwartungswert der Allelanzahl bei 232 erfolgreich typisierten Allelen in den europäischen Bevölkerungen aus Tabelle 4.18)

\begin{tabular}{lcccccccccc} 
Land & $\leq \mathbf{2 7}$ & $\mathbf{2 8}$ & $\mathbf{2 9}$ & $\mathbf{3 0}$ & $\mathbf{3 0 . 2}$ & $\mathbf{3 1}$ & $\mathbf{3 1 . 2}$ & $\mathbf{3 2}$ & $\mathbf{3 2 . 2}$ & $\mathbf{2 3 3}$ \\
\hline \hline Belgien & 7 & 36 & 55 & 61 & 3 & 19 & 17 & 6 & 18 & 10 \\
\hline Deutschland & 7 & 41 & 52 & 53 & 11 & 12 & 25 & 3 & 18 & 10 \\
\hline Frankreich & 12 & 33 & 55 & 57 & 6 & 12 & 27 & 4 & 16 & 11 \\
\hline Italien & 7 & 35 & 52 & 54 & 8 & 13 & 22 & 3 & 27 & 10 \\
\hline Russland & 6 & 33 & 48 & 60 & 13 & 18 & 18 & 5 & 20 & 11 \\
\hline Massengrab KS & 10 & 39 & 51 & 50 & 10 & 15 & 24 & 5 & 17 & 11
\end{tabular}

Alle Einzelvergleiche waren nicht signifikant ( $\mathrm{p} \geq 0,4142)$.

Zusammenfassend lassen sich signifikante Unterschiede in den drei Systemen TH01, D13S317 und D5S818 zu osteuropäischen Populationen, in TH01 und D5S818 zu einer nordeuropäischen und in D5S818 zu einer südeuropäischen Population finden. Dadurch deutet sich eine Herkunft der Individuen aus Westeuropa an. Die Allelfrequenzen als auch die Heterozygotenraten entsprechen denen einer Zufallsstichprobe einer Bevölkerung und es lässt sich kein Hinweis auf erhöhte Verwandtschaftsgrade (wie etwa in Inzuchtpopulationen) finden. 


\subsubsection{Auswertung Y-chromosomaler STRs}

Die gute DNA-Erhaltung resultierte in den meisten Fällen in eine (fast) vollständige Typisierung der Y-Haplotypen (Abb. 4.26). Das häufigste fehlende System DYS389II ist auch das längste in der Multiplex, was eine direkte Folge der DNADegradierungsprozesse sein dürfte. Bei 75 von 125 Individuen (60\%) war trotz der Produktlänge von über 200 Basen eine Typisierung möglich.

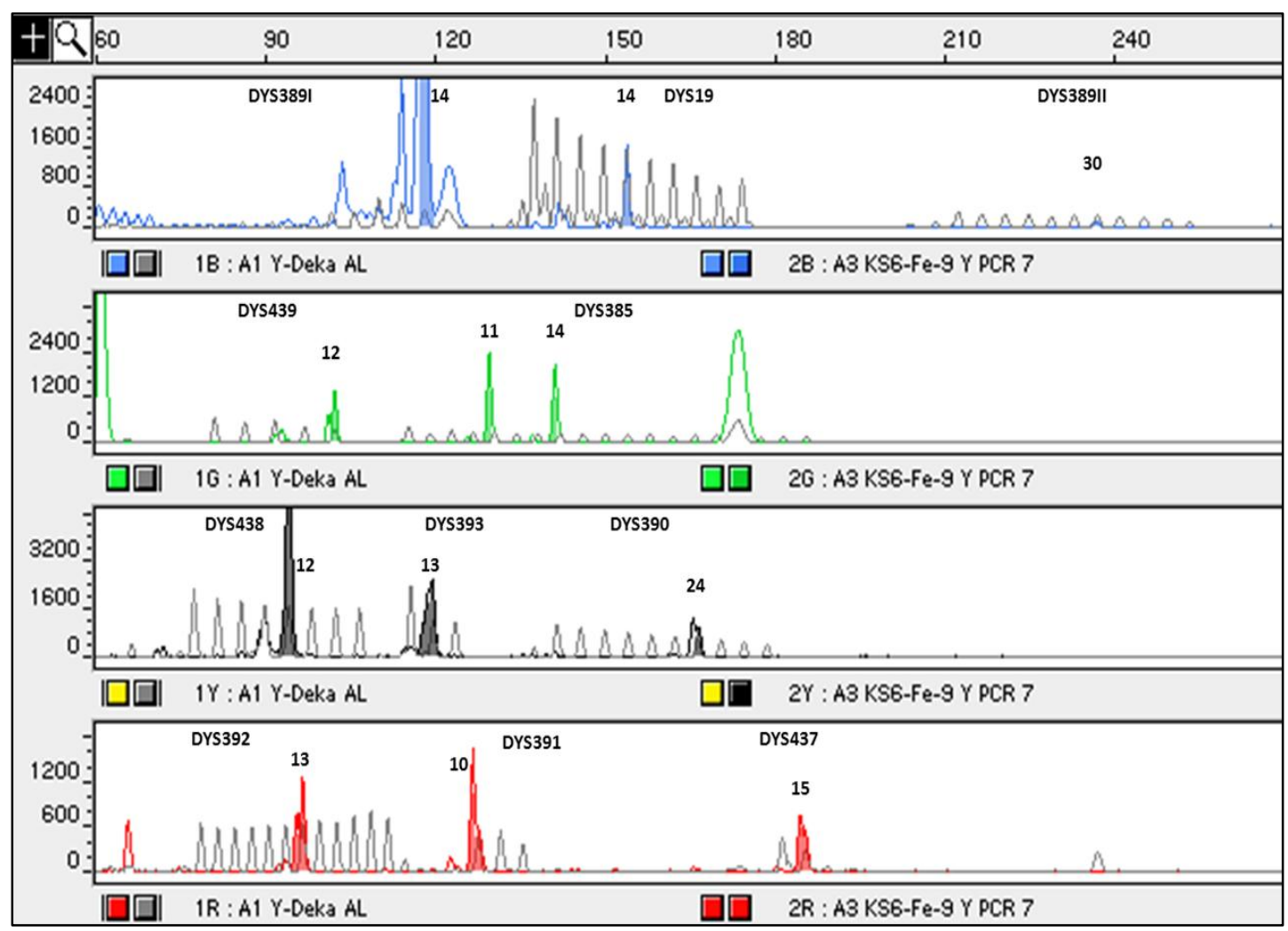

Abbildung 4.26: Elektropherogramm einer Amplifikation der Probe KS6-Fe-9. Die Probe zeigte eine vollständige Typisierung in allen Systemen. Deutlich zu sehen ist das Ungleichgewicht im Doppelsystem DYS389I und II (blaue Farbspur): während das kürzere DYS389I extrem hohe Fluoreszenz aufweist, ist das längere DYS389II kaum zu erkennen.

Nur bei einigen Individuen (KS03, KS42, KS48, KS49, KS54) konnten wenige STRs amplifiziert werden. Dabei decken sich die Ergebnisse mit denen aus der Amplifikation von autosomaler DNA: zeigte ein Individuum bereits nur unvollständige Ergebnisse in der Heptaplex (vgl. Tabelle 4.2), wurden auch nur unvollständige YHaplotypen generiert.

Tabelle 4.20 zeigt die Konsensus-Haplotypen und die statistisch wahrscheinlichste Haplogruppe (nach Athey 2005) aller untersuchten Individuen. Die Tabelle beinhaltet auch die Daten, die von Quosigk (2013) erhoben worden sind. Die Ergebnisse jeder Einzelamplifikation und der jeweilige Bearbeiter kann in der Tabelle Einzelamplifikationen.xlsx auf der beigefügten CD eingesehen werden. Für den KonsensusHaplotypen wurden nur Allele aufgenommen, die reproduzierbar waren (siehe auch die Excel-Tabelle Konsensus und Amova.xlsx auf der beigefügten CD). 
Ergebnisse - Kapitel 4.6.

Tabelle 4.20: Konsensus-Haplotyp und statistische Haplogruppe nach Athey (2006). Aus Platzgründen fehlt die Bezeichnung „DYS“ vor den Systemen. Hg = Haplogruppe; W. = Wahrscheinlichkeit. Fortsetzung auf den nächsten zwei Seiten.

\begin{tabular}{|c|c|c|c|c|c|c|c|c|c|c|c|c|c|c|}
\hline Ind. & 3891 & 19 & 38911 & 438 & $385 a$ & $385 b$ & 439 & 393 & 390 & 392 & 391 & 437 & Hg. & w. \\
\hline KSO1 & 13 & 15 & 30 & 10 & 15 & 15 & 11 & 14 & 23 & 12 & 10 & 14 & $\mid 2 b 1$ & 100 \\
\hline KSO2 & 13 & 14 & 28 & 12 & 11 & 15 & 13 & 15 & 24 & 13 & 11 & 15 & $\mathrm{R} 1 \mathrm{~b}$ & 100 \\
\hline KSO3 & 14 & - & - & - & - & - & 12 & 14 & - & - & 11 & - & - & - \\
\hline KSO4 & 13 & 14 & - & 12 & 11 & 14 & 12 & 13 & 23 & 13 & 10 & 15 & $\mathrm{R} 1 \mathrm{~b}$ & 100 \\
\hline KS05 & 13 & 14 & 29 & 12 & 11 & 14 & 12 & 13 & 24 & 13 & 10 & 15 & $\mathrm{R} 1 \mathrm{~b}$ & 100 \\
\hline KSO6 & 13 & 14 & - & 12 & 11 & 15 & 10 & 12 & 24 & 13 & 12 & 15 & $\mathrm{R} 1 \mathrm{~b}$ & 100 \\
\hline KS07 & 13 & 16 & - & 10 & 12 & 16 & 11 & 13 & 23 & 12 & 10 & 15 & $12 \mathrm{a}$ & 97,2 \\
\hline KS08 & 13 & 14 & - & 12 & 12 & 14 & 12 & 13 & 24 & 13 & 11 & 15 & $\mathrm{R} 1 \mathrm{~b}$ & 100 \\
\hline KSO9 & 12 & 14 & 28 & 12 & 11 & 14 & 11 & 13 & 23 & 13 & 10 & 15 & $\mathrm{R} 1 \mathrm{~b}$ & 100 \\
\hline KS10 & 12 & 16 & 30 & 11 & 14 & 15 & 11 & 13 & 23 & 11 & 11 & 16 & G2a & 79 \\
\hline KS11 & 13 & 14 & 29 & 12 & 14 & 14 & 13 & 13 & 24 & 13 & 11 & 14 & $\mathrm{R} 1 \mathrm{~b}$ & 99,2 \\
\hline KS12 & 13 & 14 & 29 & 12 & 11 & 14 & 12 & 12 & 23 & 13 & 11 & 15 & R1b & 100 \\
\hline KS13 & 13 & 14 & 30 & 10 & 13 & 14 & 11 & 13 & 22 & 11 & 10 & 16 & 11 & 98,8 \\
\hline KS14 & 13 & 14 & 29 & 10 & 11 & 14 & 11 & 13 & 24 & 12 & 10 & 15 & $\mathrm{R} 1 \mathrm{~b}$ & 100 \\
\hline KS15 & 13 & 15 & 29 & 9 & 13 & 17 & 12 & 12 & 25 & 11 & 10 & 16 & $\mathrm{~J} 2$ & 99,7 \\
\hline KS16 & 14 & 14 & 30 & 12 & 11 & 14 & 11 & 13 & 24 & 13 & 11 & 15 & $\mathrm{R} 1 \mathrm{~b}$ & 100 \\
\hline KS17 & 13 & 15 & - & 9 & 11 & 14 & 11 & 13 & 23 & 13 & 10 & 14 & $\mathrm{~T}$ & 94,6 \\
\hline KS18 & 13 & 14 & - & 11 & 14 & 14 & 10 & 13 & 25 & 11 & 10 & - & R1a & 93,2 \\
\hline KS19 & 13 & 14 & 29 & 12 & 12 & 14 & 12 & 13 & 24 & 13 & 10 & 15 & R1b & 100 \\
\hline KS20 & 13 & 14 & 28 & 12 & 11 & 13 & 12 & 13 & 24 & 13 & 11 & 15 & $\mathrm{R} 1 \mathrm{~b}$ & 100 \\
\hline KS21 & 13 & 14 & 28 & 12 & 11 & 14 & 12 & 13 & 23 & 13 & 11 & 15 & $\mathrm{R} 1 \mathrm{~b}$ & 100 \\
\hline KS22 & 13 & 15 & 30 & 11 & 11 & 14 & 10 & 13 & 25 & 11 & 11 & 14 & R1a & 100 \\
\hline KS23 & 13 & 15 & - & 12 & 11 & 14 & 12 & 12 & 24 & 13 & 11 & 15 & $\mathrm{R} 1 \mathrm{~b}$ & 100 \\
\hline KS24 & 12 & 14 & 28 & 10 & 13 & 14 & 11 & 13 & 22 & 11 & 10 & 16 & 11 & 99,9 \\
\hline KS25 & 13 & 14 & - & 12 & 11 & 15 & 11 & 13 & 25 & 13 & 10 & 15 & R1b & 100 \\
\hline KS26 & 13 & 14 & 30 & 10 & 13 & 16 & 11 & 12 & 22 & 11 & 10 & 14 & $\mathrm{~J} 1$ & 85,9 \\
\hline KS27 & 13 & 14 & - & 12 & 12 & 13 & 12 & 13 & 24 & 13 & 11 & 15 & $\mathrm{R} 1 \mathrm{~b}$ & 100 \\
\hline KS28 & 13 & 13 & - & 10 & 15 & 16 & 12 & 13 & 24 & 11 & 10 & 14 & $\mathrm{E} 1 \mathrm{~b} 1 \mathrm{~b}$ & 99,9 \\
\hline KS29 & 13 & 12 & 29 & 13 & 12 & 14 & 12 & 13 & 24 & 13 & 11 & 14 & R1b & 100 \\
\hline KS30 & 13 & 14 & 29 & 11 & 10 & 14 & 12 & 13 & 23 & 13 & 11 & 15 & R1b & 100 \\
\hline KS31 & 13 & 15 & 29 & 13 & 12 & 15 & 11 & 13 & 24 & 13 & 11 & 15 & R1b & 100 \\
\hline KS32 & 14 & 15 & 31 & 11 & 11 & 16 & 10 & 13 & 25 & 11 & 10 & 14 & R1a & 100 \\
\hline KS33 & 15 & 14 & 31 & 12 & 12 & 15 & 12 & 13 & 23 & 13 & 11 & 15 & R1b & 99,8 \\
\hline KS34 & 14 & 14 & 29 & 12 & 11 & 14 & 11 & 13 & 25 & 13 & 11 & 15 & R1b & 100 \\
\hline KS35 & 12 & 14 & 28 & 10 & 13 & 14 & 11 & 12 & 22 & 11 & 10 & 15 & 11 & 98,3 \\
\hline KS36 & 13 & 14 & 29 & 12 & 11 & 16 & 12 & 13 & 24 & 14 & 11 & 14 & $\mathrm{R} 1 \mathrm{~b}$ & 100 \\
\hline KS37 & 13 & 14 & 29 & 12 & 11 & 14 & 12 & 13 & 24 & 13 & 11 & 15 & $\mathrm{R} 1 \mathrm{~b}$ & 100 \\
\hline KS38 & 13 & 13 & - & 10 & 10 & 16 & 12 & 13 & 24 & 11 & 10 & 14 & E1b1b & 80,1 \\
\hline KS39 & 13 & 14 & 29 & 12 & 12 & 14 & 12 & 13 & 24 & 13 & 11 & 15 & R1b & 100 \\
\hline KS40 & 13 & 14 & - & 12 & 11 & 15 & 12 & 13 & 24 & 13 & 11 & 15 & R1b & 100 \\
\hline
\end{tabular}


Ergebnisse - Kapitel 4.6.

\begin{tabular}{|c|c|c|c|c|c|c|c|c|c|c|c|c|c|c|}
\hline Ind. & 3891 & 19 & 389II & 438 & $385 a$ & $385 b$ & 439 & 393 & 390 & 392 & 391 & 437 & $\mathrm{Hg}$. & w. \\
\hline KS41 & 14 & 14 & 30 & 12 & 11 & 14 & 12 & 13 & 23 & 11 & 11 & 14 & R1b & 100 \\
\hline KS42 & 13 & - & - & - & - & - & 12 & - & - & - & 11 & - & - & - \\
\hline KS43 & 13 & 14 & 29 & 12 & 11 & 13 & 12 & 12 & 24 & 13 & 10 & 15 & R1b & 100 \\
\hline KS44 & 13 & 14 & - & 12 & 12 & 14 & 12 & 13 & 24 & 13 & 11 & 15 & R1b & 100 \\
\hline KS45 & 14 & 14 & - & 12 & 12 & 14 & 12 & 13 & 24 & 13 & 10 & 14 & R1b & 100 \\
\hline KS46 & 12 & - & - & 10 & 14 & 16 & 11 & 14 & 22 & 11 & 10 & - & G2a & 98 \\
\hline KS47 & 12 & 14 & - & 12 & 11 & 14 & 12 & 14 & - & 13 & 11 & - & R1b & 100 \\
\hline KS48 & 14 & - & - & - & - & - & - & 14 & - & - & - & - & - & - \\
\hline KS49 & 14 & - & - & - & - & - & 10 & 12 & - & 10 & 10 & - & - & - \\
\hline KS50 & 13 & - & - & 10 & - & - & 12 & 14 & - & 12 & 11 & - & $\mid 2 \mathrm{~b} 1$ & 88,6 \\
\hline KS51 & 12 & 14 & 29 & 10 & 13 & 18 & 11 & 12 & 23 & 11 & 10 & - & $\mathrm{J} 1$ & 99,1 \\
\hline KS52 & 14 & 14 & 30 & 12 & 11 & 14 & 13 & 13 & 24 & 13 & 11 & 14 & R1b & 100 \\
\hline KS53 & 13 & - & - & 10 & - & - & 11 & 14 & - & 13 & 10 & 14 & $12 \mathrm{~b} 1$ & 95,2 \\
\hline KS54 & - & - & - & - & - & - & 13 & - & - & - & - & - & - & - \\
\hline KS55 & 13 & 14 & 29 & 12 & 11 & 14 & 11 & 13 & 24 & 13 & 10 & 14 & $\mathrm{R} 1 \mathrm{~b}$ & 100 \\
\hline KS56 & 13 & 14 & - & 12 & 11 & 14 & 11 & 13 & 23 & 13 & 10 & 15 & R1b & 100 \\
\hline KS57 & 13 & 14 & 29 & 12 & 11 & 13 & 11 & 13 & 24 & 15 & 10 & 15 & R1b & 100 \\
\hline KS58 & 13 & 13 & 30 & 10 & 14 & 18 & 11 & 13 & 22 & 12 & 10 & 14 & E1b1b & 84 \\
\hline KS59 & 13 & - & - & - & 11 & 18 & 12 & 13 & 22 & 12 & 10 & 14 & $Q$ & 95 \\
\hline KS60 & 14 & 16 & 31 & 12 & 12 & 13 & 12 & 13 & 24 & 13 & 10 & 15 & R1b & 93,2 \\
\hline KS61 & 13 & 14 & 29 & 12 & 11 & 15 & 12 & 13 & 24 & 13 & 11 & 15 & $\mathrm{R} 1 \mathrm{~b}$ & 100 \\
\hline KS62 & 14 & 14 & 30 & 12 & 11 & 14 & 12 & 13 & 23 & 13 & 11 & 15 & R1b & 100 \\
\hline KS63 & 13 & 14 & - & 12 & 11 & 14 & 12 & 13 & 24 & 13 & 11 & 15 & R1b & 100 \\
\hline KS64 & 14 & 15 & 30 & 11 & 11 & 20 & 10 & 13 & 25 & 11 & 11 & 14 & R1a & 99,1 \\
\hline KS65 & 13 & - & - & 12 & 11 & 14 & 13 & 13 & & 13 & 12 & - & R1b & 100 \\
\hline KS66 & 13 & 14 & - & 11 & 14 & 15 & 11 & 14 & 23 & 12 & 10 & 14 & $12 \mathrm{~b} 1$ & 93,1 \\
\hline KS67 & 13 & 14 & 31 & 12 & 11 & 14 & 12 & 12 & 24 & 13 & 11 & 15 & R1b & 100 \\
\hline KS68 & 13 & 14 & 29 & 12 & 11 & 13 & 12 & 13 & 24 & 13 & 10 & 15 & $\mathrm{R} 1 \mathrm{~b}$ & 100 \\
\hline KS69 & 14 & & - & 12 & 11 & 14 & 12 & 13 & 24 & 13 & 11 & - & R1b & 100 \\
\hline KS70 & 12 & 14 & 28 & 12 & 12 & 14 & 10 & 13 & 24 & 13 & 11 & 15 & R1b & 100 \\
\hline KS71 & 13 & 15 & 29 & 12 & 11 & 14 & 13 & 15 & - & 13 & 10 & 15 & R1b & 100 \\
\hline KS72 & 13 & 14 & - & 12 & 11 & 15 & 11 & 13 & 24 & 11 & 11 & 15 & R1b & 99,4 \\
\hline KS73 & 13 & 15 & 29 & 12 & 11 & 15 & 13 & 13 & 24 & 13 & 10 & 15 & $\mathrm{R} 1 \mathrm{~b}$ & 100 \\
\hline KS74 & 12 & 14 & 28 & 10 & 13 & 14 & 11 & 12 & 22 & 11 & 10 & 16 & $\mid 1$ & 99,8 \\
\hline KS75 & 14 & 14 & 30 & 12 & 11 & 14 & 12 & 13 & 24 & 13 & 10 & 15 & R1b & 100 \\
\hline KS76 & 14 & 15 & - & 9 & 13 & 14 & 12 & 13 & 22 & 11 & 10 & 14 & $J 2$ & 97,1 \\
\hline KS77 & 10 & 14 & 26 & 12 & 11 & 11 & 11 & 13 & 23 & 13 & 10 & 15 & R1b & 100 \\
\hline KS78 & 13 & 14 & 29 & 12 & 11 & 14 & 11 & 13 & 24 & 13 & 11 & 14 & R1b & 100 \\
\hline KS79 & 12 & 14 & 28 & 9 & 13 & 15 & 11 & 12 & 23 & 11 & 10 & 15 & $\mathrm{~J} 2$ & 100 \\
\hline KS80 & 12 & 15 & 28 & 10 & 13 & 15 & 12 & 13 & 23 & 11 & 10 & 16 & 11 & 93,9 \\
\hline KS81 & 14 & 15 & 31 & 10 & 15 & 15 & 11 & 15 & 23 & 12 & 10 & 14 & $12 \mathrm{~b} 1$ & 100 \\
\hline KS82 & 12 & - & - & 12 & 11 & - & 12 & 13 & 24 & 13 & 11 & 15 & R1b & 100 \\
\hline KS83 & 13 & 14 & - & 12 & 11 & 14 & 13 & 13 & 24 & 13 & 11 & 15 & R1b & 100 \\
\hline
\end{tabular}


Ergebnisse - Kapitel 4.6.

\begin{tabular}{|c|c|c|c|c|c|c|c|c|c|c|c|c|c|c|}
\hline Ind. & 3891 & 19 & 38911 & 438 & $385 a$ & 385b & 439 & 393 & 390 & 392 & 391 & 437 & $\mathrm{Hg}$. & w. \\
\hline KS84 & 14 & 14 & 30 & 12 & 13 & 14 & 13 & 13 & 24 & 13 & 10 & 15 & R1b & 100 \\
\hline KS85 & 13 & 15 & - & 12 & 11 & 14 & 12 & 12 & 24 & 13 & 11 & 15 & R1b & 100 \\
\hline KS86 & 10 & 14 & 26 & 12 & 15 & 16 & 12 & 13 & 23 & 13 & 11 & 15 & R1b & 100 \\
\hline KS87 & 13 & 14 & 29 & 12 & 12 & 14 & 12 & 12 & & 13 & 11 & 15 & R1b & 100 \\
\hline KS88 & 14 & 13 & 32 & 10 & 15 & 15 & 12 & 12 & 24 & 11 & 10 & 14 & E1b1b & 98,8 \\
\hline KS89 & 13 & 14 & 29 & 12 & 11 & 15 & 12 & 13 & 24 & 13 & 11 & 15 & R1b & 100 \\
\hline KS90 & 13 & 14 & 29 & 10 & 13 & 15 & 11 & 12 & 23 & 11 & 10 & 16 & 11 & 95,7 \\
\hline KS91 & 13 & 14 & 29 & 12 & 11 & 14 & 12 & 13 & 25 & 13 & 11 & 15 & R1b & 100 \\
\hline KS92 & 13 & 15 & 29 & 11 & 11 & 14 & 10 & 12 & 24 & 11 & 11 & 14 & R1a & 100 \\
\hline KS93 & 13 & 14 & - & 9 & 14 & 16 & 13 & 13 & 23 & 13 & 9 & 14 & $\mathrm{~T}$ & 100 \\
\hline KS94 & 12 & 16 & - & 11 & 14 & 15 & 11 & 13 & 23 & 11 & 11 & 16 & 11 & 76,3 \\
\hline KS95 & 14 & 14 & 32 & 10 & 11 & 15 & 11 & 14 & 23 & 12 & 10 & 14 & $12 \mathrm{~b} 1$ & 100 \\
\hline KS96 & 13 & 14 & - & 10 & 13 & 18 & 11 & 12 & 23 & 11 & 10 & 14 & $\mathrm{~J} 1$ & 99,9 \\
\hline KS97 & 13 & 15 & 31 & 10 & 15 & 15 & 11 & 15 & 24 & 12 & 10 & 14 & $12 \mathrm{~b} 1$ & 100 \\
\hline KS98 & \multicolumn{14}{|c|}{ weiblich } \\
\hline KS99 & 13 & 14 & 29 & 12 & 11 & 14 & 11 & 13 & 24 & 13 & 11 & 15 & R1b & 100 \\
\hline KS100 & 14 & 14 & 29 & 12 & 11 & 13 & 11 & 13 & 23 & 14 & 11 & 15 & R1b & 99,9 \\
\hline KS101 & 14 & 14 & 32 & 10 & 15 & 15 & 11 & 14 & 23 & 12 & 10 & 14 & $12 \mathrm{~b} 1$ & 100 \\
\hline KS102 & 14 & 14 & 30 & 12 & 12 & 14 & 12 & 13 & 24 & 14 & 10 & 15 & R1b & 100 \\
\hline KS103 & 14 & 14 & 30 & 11 & 11 & 14 & 12 & 13 & 24 & 13 & 11 & 14 & R1b & 99,6 \\
\hline KS104 & 13 & 14 & 29 & 12 & 11 & 14 & 11 & 13 & 25 & 13 & 11 & 15 & R1b & 100 \\
\hline KS3-Fe-20 & 13 & 13 & - & 10 & 17 & 19 & 11 & 13 & 24 & 11 & 10 & 14 & E1b1b & 100 \\
\hline KS3-Fe-28 & 13 & - & 29 & 12 & 11 & - & 12 & 13 & 24 & 13 & 10 & - & R1b & 100 \\
\hline KS4-Fe-23 & 12 & 13 & - & 10 & - & 18 & 10 & 13 & 24 & 11 & 10 & 14 & E1b1b & 100 \\
\hline KSM-Fe-21 & 13 & 14 & - & 12 & 11 & 15 & 12 & 13 & 25 & 13 & 10 & 14 & R1b & 100 \\
\hline KSM-Fe-23 & 12 & - & - & 10 & 13 & 18 & 12 & 12 & - & 11 & 10 & 14 & J1 & 96,2 \\
\hline KSM-Fe-25 & 14 & 13 & - & 10 & 13 & 14 & 10 & 13 & 24 & 11 & 9 & 14 & E1b1b & 100 \\
\hline KSM-Fe-27 & 13 & 14 & 30 & 12 & 11 & 14 & 13 & 13 & 24 & 13 & 10 & 15 & R1b & 100 \\
\hline KSM-Fe-28 & 13 & 15 & - & 9 & 13 & 16 & 12 & 12 & 23 & 11 & 9 & - & $J 2$ & 99,8 \\
\hline KSM-Fe-30 & 13 & 15 & 29 & 9 & 13 & 15 & 12 & 12 & 24 & 11 & 9 & 14 & $J 2$ & 99,6 \\
\hline KSM-Fe-32 & 13 & 14 & - & 12 & 11 & 15 & 12 & 12 & 23 & 13 & 11 & 15 & R1b & 100 \\
\hline KSM-Fe-36 & 12 & 14 & 28 & 12 & 11 & 14 & 13 & 13 & 24 & 13 & 11 & 15 & R1b & 100 \\
\hline KSM-Fe-42 & 13 & 17 & 29 & 11 & 11 & 14 & 10 & 13 & 25 & 11 & 10 & 14 & R1a & 100 \\
\hline KSM-Fe-43 & 12 & 16 & - & 9 & 13 & 16 & 11 & 12 & - & 11 & 10 & 15 & $\mathrm{~J} 2$ & 98,7 \\
\hline KSM-Fe-48 & 13 & 14 & - & 12 & 10 & - & 12 & 13 & 23 & 13 & 11 & - & R1b & 99,9 \\
\hline KSM-Fe-51 & 13 & 14 & - & 12 & 11 & 14 & 11 & 13 & 24 & 12 & 11 & 15 & R1b & 100 \\
\hline KS2-Fe-8 3 & 13 & 15 & - & 13 & 11 & 15 & 12 & 13 & 23 & 13 & 11 & 15 & R1b & 100 \\
\hline KS2-Fe-26 & 13 & 14 & 30 & 12 & 11 & 14 & 12 & 13 & 24 & 13 & 11 & 15 & R1b & 100 \\
\hline KS5-Fe-16 & 13 & 14 & - & 12 & 11 & 14 & 11 & 13 & 24 & 14 & 11 & 14 & R1b & 100 \\
\hline KSM-Hu-9 & 13 & 14 & 30 & 12 & 12 & 14 & 12 & 13 & 24 & 13 & 11 & 15 & R1b & 100 \\
\hline KSM-Hu-10 & 12 & 16 & 30 & 11 & 11 & 14 & 10 & 14 & 25 & 11 & 11 & 14 & R1a & 100 \\
\hline KS2-Ti-19 & 13 & 13 & 30 & 12 & 10 & 13 & 13 & 12 & 24 & 13 & 11 & 14 & R1b & 99 \\
\hline KS3-Mx-1 & 13 & 13 & - & 12 & 11 & 15 & 12 & 13 & - & 13 & 12 & 15 & R1b & 100 \\
\hline
\end{tabular}


Die statistische Auswertung der Ergebnisse teilte sich zum einen nach Haplogruppen und zum anderen nach Haplotypen.

\section{$\underline{\text { Y-Haplogruppen }}$}

Im Kollektiv konnte für 120 der 125 Individuen die zugehörige Haplogruppe ermittelt werden. Nur für fünf Individuen (KS03, KS42, KS48, KS49, KS54) konnten nicht ausreichend Allele typisiert werden, um eine Haplogruppe sicher zu bestimmen. Die Bestimmungssicherheiten für 115 Individuen lagen über 90\%, nur für fünf zwischen $75 \%$ und 90\%. Insgesamt wurden elf verschiedene Haplogruppen gefunden, wobei die westeuropäische Haplogruppe R1b mit Abstand die häufigste ist. Die Verteilung stellt sich wie folgt dar (Tab. 4.21):

Tabelle 4.21: Haplogruppenverteilung im Kollektiv. Hg = Haplogruppe

\begin{tabular}{cccccccccccc} 
Hg & R1b & R1a & E1b1b & I1 & I2b1 & I2a & J1 & J2 & G2a & T & Q \\
\hline \hline Anzahl & 75 & 7 & 7 & 7 & 8 & 1 & 4 & 6 & 2 & 2 & 1 \\
$\%$ & 62,5 & 5,8 & 5,8 & 5,8 & 6,7 & 0,8 & 3,3 & 5 & 1,7 & 1,7 & 0,8
\end{tabular}

Für die weitere statistische Auswertung wurden die Subhaplogruppen I1, I2b1 und I2a zu I sowie J1 und J2 zu J zusammengefasst. Für verschiedene Populationen wurden die Haplogruppenfrequenzen ermittelt (Tab. 4.22):

Tabelle 4.22: Haplogruppenverteilungen in verschiedenen europäischen Populationen.

\begin{tabular}{|c|c|c|c|c|c|c|c|}
\hline Land & R1b & R1a & I & $\mathbf{J}$ & $\mathbf{E}$ & Andere & Literatur \\
\hline Frankreich & 0,61 & 0,025 & 0,155 & 0,08 & 0,07 & 0,06 & $\begin{array}{c}\text { Ramos-Luis et } \\
\text { al. 2009 }\end{array}$ \\
\hline -Elsass & 0,635 & 0,085 & 0,135 & 0,045 & 0,06 & 0,04 & $\begin{array}{l}\text { Ramos-Luis et } \\
\text { al. } 2009\end{array}$ \\
\hline -Rhone-Alpes & 0,665 & 0,05 & 0,11 & 0,025 & 0,05 & 0,1 & $\begin{array}{l}\text { Ramos-Luis et } \\
\text { al. 2009 }\end{array}$ \\
\hline -Auvergne & 0,525 & 0,055 & 0,045 & 0,115 & 0,125 & 0,135 & $\begin{array}{c}\text { Ramos-Luis et } \\
\text { al. 2009 }\end{array}$ \\
\hline Deutschland & 0,445 & 0,16 & 0,22 & 0,045 & 0,055 & 0,075 & $\begin{array}{l}\text { Kayser et al. } \\
2005\end{array}$ \\
\hline$-W e s t$ & 0,47 & 0,09 & 0,215 & 0,05 & 0,08 & 0,095 & $\begin{array}{l}\text { Kayser et al. } \\
2005\end{array}$ \\
\hline -Süd & 0,485 & 0,095 & 0,18 & 0,065 & 0,08 & 0,095 & $\begin{array}{c}\text { Kayser et al. } \\
2005\end{array}$ \\
\hline $\begin{array}{l}\text { Niederlande } \\
\text { (Nord-Brabant) }\end{array}$ & 0,67 & 0,015 & 0,16 & 0,07 & 0,04 & 0,045 & $\begin{array}{l}\text { Larmuseau et } \\
\text { al. } 2011\end{array}$ \\
\hline Schweden & 0,22 & 0,19 & 0,41 & 0,03 & 0,01 & 0,14 & $\begin{array}{c}\text { Tambets et al. } \\
2004\end{array}$ \\
\hline Spanien & 0,69 & 0,02 & 0,07 & 0,095 & 0,07 & 0,055 & $\begin{array}{l}\text { Flores et al. } \\
2004\end{array}$ \\
\hline $\begin{array}{l}\text { Belgien } \\
\text { (Antwerpen) }\end{array}$ & 0,625 & 0,042 & 0,208 & 0,028 & 0,069 & 0,028 & $\begin{array}{l}\text { Larmuseau et } \\
\text { al. } 2011\end{array}$ \\
\hline $\begin{array}{l}\text { Russland } \\
\text { (West) }\end{array}$ & 0,075 & 0,465 & 0,175 & 0,034 & 0,05 & 0,201 & $\begin{array}{c}\text { Balanovksy et } \\
\text { al. 2008 }\end{array}$ \\
\hline Polen & 0,16 & 0,55 & 0,16 & 0,035 & 0,05 & 0,045 & $\begin{array}{c}\text { Kayser et al. } \\
2005\end{array}$ \\
\hline Italien & 0,485 & 0,045 & 0,14 & 0,1 & 0,1 & 0,13 & $\begin{array}{l}\text { Brisighelli et } \\
\quad \text { al } 2012\end{array}$ \\
\hline
\end{tabular}


Für 120 Individuen ergeben sich daraus folgende gerundete Erwartungswerte (Tab. 4.23):

Tabelle 4.23: Erwartungswerte für die Haplogruppen bei 120 Individuen für die europäischen Populationen aus Tab. 4.21.

\begin{tabular}{l|c|c|c|c|c|c} 
Land & R1b & R1a & I & J & E & Andere \\
\hline Frankreich & 73 & 3 & 19 & 10 & 8 & 7 \\
\hline -Elsass & 76 & 10 & 16 & 5 & 7 & 5 \\
\hline -Rhône-Alpes & 80 & 6 & 13 & 3 & 6 & 12 \\
\hline -Auvergne & 63 & 7 & 5 & 14 & 15 & 16 \\
\hline Deutschland & 53 & 19 & 26 & 5 & 7 & 9 \\
\hline -West & 56 & 11 & 26 & 6 & 10 & 11 \\
\hline -Süd & 58 & 11 & 22 & 8 & 10 & 11 \\
\hline $\begin{array}{l}\text { Niederlande } \\
\text { (Nord-Brabant) }\end{array}$ & 80 & 2 & 19 & 8 & 5 & 5 \\
\hline Schweden & 26 & 23 & 49 & 4 & 1 & 17 \\
\hline Spanien & 83 & 2 & 8 & 11 & 8 & 7 \\
\hline $\begin{array}{l}\text { Belgien } \\
\text { (Antwerpen) }\end{array}$ & 75 & 5 & 25 & 3 & 8 & 3 \\
\hline Russland (West) & 9 & 56 & 21 & 4 & 6 & 24 \\
\hline Polen & 19 & 66 & 19 & 4 & 6 & 5 \\
\hline Italien & 58 & 5 & 17 & 12 & 12 & 16 \\
\hline Massengrab KS & $\mathbf{7 5}$ & $\mathbf{7}$ & $\mathbf{1 6}$ & $\mathbf{1 0}$ & $\mathbf{7}$ & $\mathbf{5}$
\end{tabular}

Mit Hilfe des $\chi^{2}$-Tests wurden die Häufigkeiten miteinander verglichen. Dabei ergaben sich folgende p-Werte (Tab. 4.24):

Tabelle 4.24: $\chi^{2}$ - und p-Werte beim paarweisen Vergleich der Kasseler Haplotypen zu den der verschiedenen Populationen.

\begin{tabular}{l|c:c} 
KS vs. Land & $\chi^{\mathbf{2}}$ & p-Wert \\
\hline \hline Frankreich & 6,663 & 0,2469 \\
\hline -Elsass & 4,958 & 0,4211 \\
\hline -Rhône-Alpes & 21,633 & 0,0006 \\
\hline -Auvergne & 36,174 & 0,0000 \\
\hline Deutschland & 26,307 & 0,0000 \\
\hline -West & 18,157 & 0,0028 \\
\hline -Süd & 12,917 & 0,0242 \\
\hline $\begin{array}{l}\text { Niederlande } \\
\text { (Nord-Brabant) }\end{array}$ & 17,261 & 0,0040 \\
\hline Schweden & 170,520 & 0,0000 \\
\hline $\begin{array}{l}\text { Spanien } \\
\text { Belgien } \\
\text { (Antwerpen) }\end{array}$ & 17,221 & 0,0041 \\
\hline $\begin{array}{l}\text { Russland } \\
\text { (West) }\end{array}$ & 18,099 & 0,0028 \\
\hline Polen & 223,650 & 0,0000 \\
\hline Italien & 14,981 & 0,0104 \\
\hline
\end{tabular}


Der Test ergab signifikante Unterschiede zu den meisten europäischen Populationen. Auch innerhalb Frankreichs bestehen signifikante Unterschiede zu bestimmten Subpopulationen, etwa der Bevölkerung der Auvergne oder der Region Rhône-Alpes. Die größte Ähnlichkeit besteht zu der Bevölkerung des Elsass.

\section{$\underline{\text { Y-Haplotypen }}$}

Mit Hilfe der Datenbank YHRD und dem dort verfügbaren AMOVA-Tool wurden die Haplotypen mit verschiedenen europäischen Populationen verglichen. Für den Vergleich wurde das System DYS389II aufgrund der unvollständigen Typisierung sowie Individuen mit unvollständigen Haplotypen komplett herausgenommen, da fehlende Werte künstliche Distanzen erzeugen. Für die verbliebenen elf Systeme wurden 101 Individuen vollständig typisiert (siehe auch die Excel-Tabelle Konsensus und Amova.xlsx [Reiter AMOVA] auf der beigefügten CD).

In einer ersten Analyse wurden 10 Populationen aus ganz Europa mit der Kasseler Serie verglichen (Abb. 4.27). Konkret waren dies Granada (Spanien), Toulouse (Frankreich), Biella Piedmont (Italien), Strasbourg (Frankreich), Noord-Brabant (Niederlande), Berlin (Deutschland), Blekinge (Südschweden), Västerbotten (Nordschweden), Warschau (Polen) und Moskau (Russland).

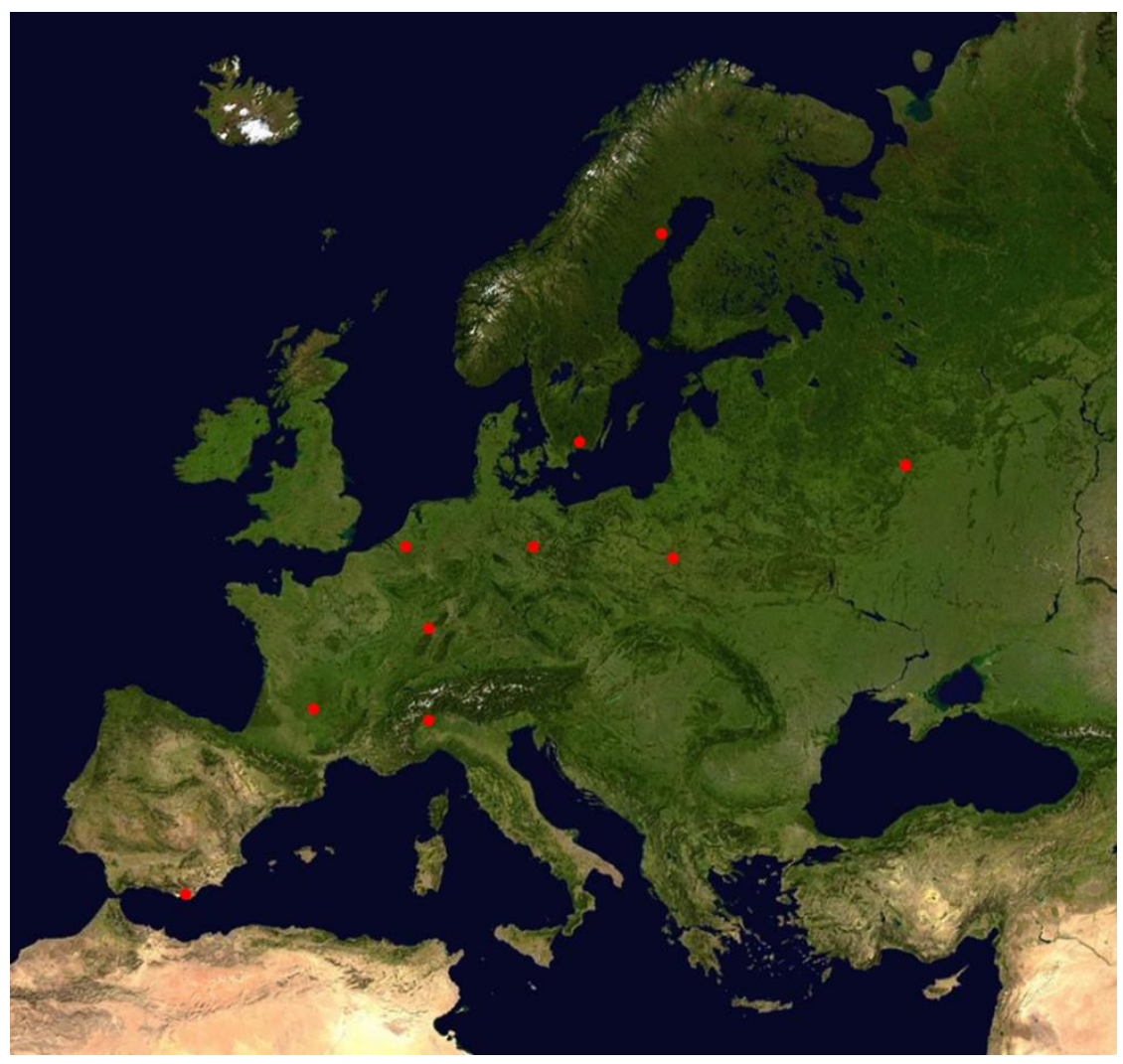

Abbildung 4.27: Übersicht der Populationen in der AMOVA-Analyse über Europa. (Karte von wikipedia, bearbeitet) 
Die AMOVA mit 10.000 Permutationen ergibt folgende Distanzmatrix (Tab. 4.25):

Tabelle 4.25: Distanzmatrix der AMOVA-Berechnung. Im Rechteck unterhalb der Diagonalen ist der $\mathrm{R}_{\mathrm{ST}}$-Wert dargestellt, oberhalb der zugehörige p-Wert. In Fett/kursiv unterlegt sind nicht signifikante Unterschiede zur Kasseler Serie.

\begin{tabular}{|c|c|c|c|c|c|c|c|c|c|c|c|}
\hline Population & Berlin & Biella & Blek. & Gran. & Brab. & Smol. & Strasb. & Toul. & Västerb. & War. & Mass. \\
\hline Berlin & - & & & & & & & & & & \\
\hline Biella & 0.0426 & - & 0.0120 & 0.3383 & & & & & & 0.0000 & 0.0761 \\
\hline Blekinge & 0.0359 & 0.0445 & - & & 0.0001 & & & & & & 0.0000 \\
\hline Granada & & & & - & & & & & & & 0.1996 \\
\hline Brabant & 0.0619 & 0.0064 & 0.1046 & 0.0105 & - & 0.0000 & 0.2551 & 0.3536 & 0.0000 & 0.0000 & 0.2467 \\
\hline Smolensk & 0.0455 & 0.1489 & 0.1451 & 0.1260 & 0.1816 & - & 0.0000 & 0.0000 & 0.0001 & 0.2045 & 0.0000 \\
\hline Strasbourg & & & & & 0.0024 & & - & 0.9774 & 0.0076 & & 0.7045 \\
\hline Toulouse & 0.0365 & -0.0092 & & & & & & - & & & 0.3466 \\
\hline Västerbotten & 0.0531 & 0.0512 & 0.0092 & 0.0617 & 0.1060 & 0.1202 & 0.0521 & 0.0606 & - & 0.0000 & 0.0000 \\
\hline Warsaw & & 0.1650 & 0.1505 & & 0.1731 & 0.0049 & & & & - & 0.0000 \\
\hline Massengrab & 0.0553 & 0.0114 & 0.1053 & 0.0031 & 0.0022 & 0.1553 & -0.0049 & 0.0006 & 0.1009 & 0.1551 & - \\
\hline
\end{tabular}

Die geringste Distanz wurde zur Population aus Strasbourg ermittelt. Weitere nicht signifikante Unterschiede gab es zu den Populationen aus Toulouse, Brabant, Granada und Biella Piedmont. Im NJ-Baum wird die Kasseler Serie zusammen mit Brabant und Strasbourg geclustert (Abb. 4.28).

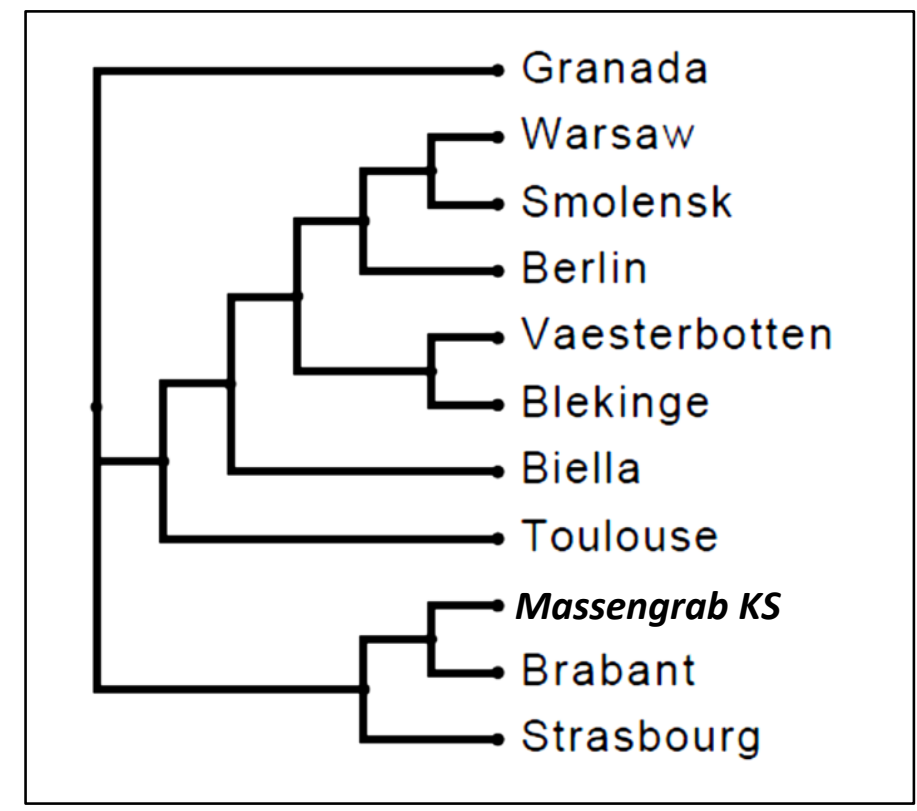

Abbildung 4.28: Phylogenetischer Baum berechnet nach $\mathrm{NJ}$ Methode. Kassel clustert mit den Populationen aus Brabant und Strasbourg. 
Aufbauend auf diesen Ergebnissen wurden in einer zweiten AMOVA nur Populationen aus Mitteleuropa miteinander verglichen. In dieser Analyse wurden Populationen aus Deutschland (Köln, Stuttgart), Frankreich (Lille, Marseille, Toulouse, Strasbourg), Benelux (Noord-Brabant, Walloon), der Schweiz (Zürich) und Italien (Trino Piedmont) mit der Kasseler Serie verglichen (Abb. 4.29).

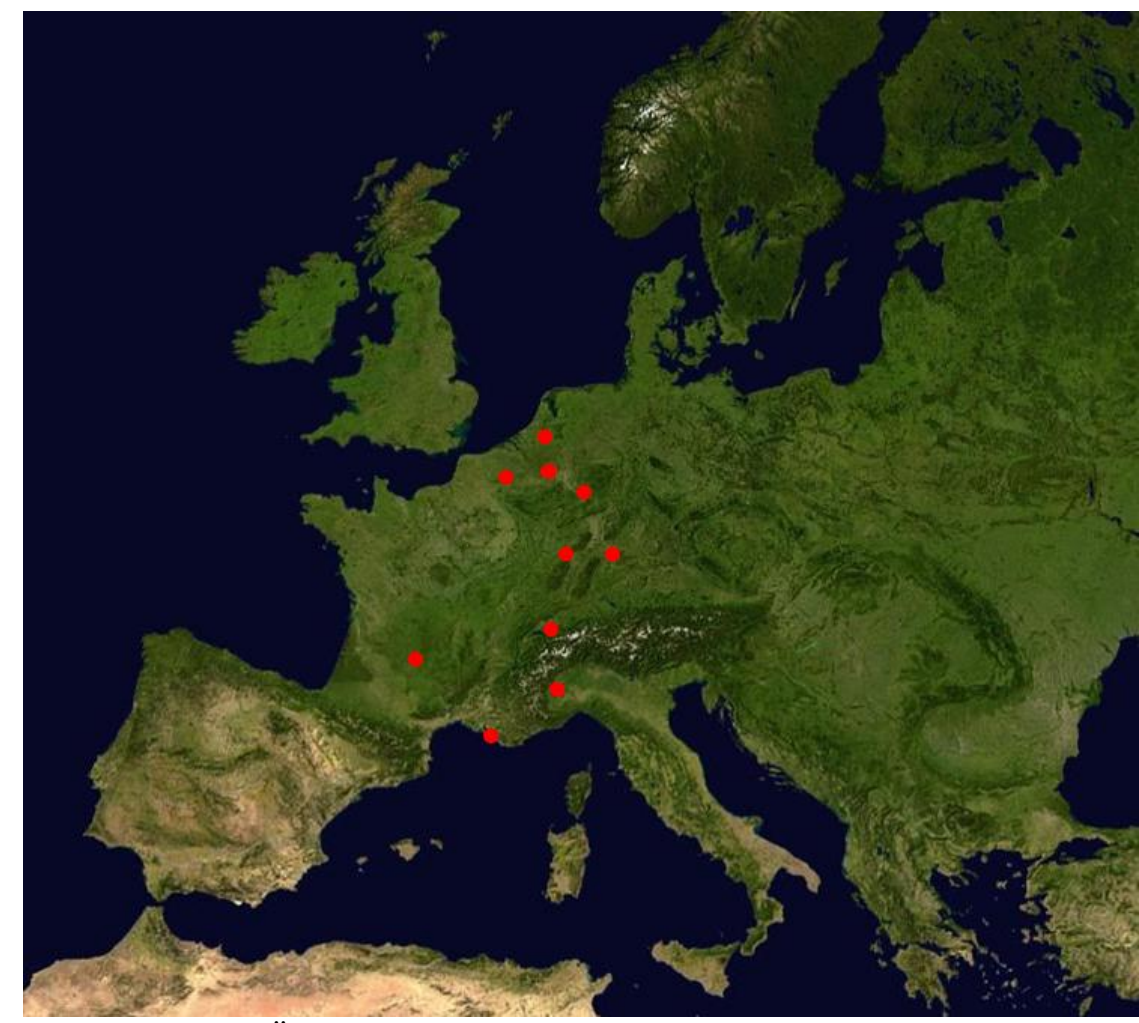

Abbildung 4.29: Übersicht der Populationen in der zweiten AMOVA-Analyse über Europa. (Karte von wikipedia, bearbeitet)

Die AMOVA mit 10.000 Permutationen ergibt folgende Distanzmatrix (Tab. 4.26):

Tabelle 4.26: Distanzmatrix der zweiten AMOVA-Berechnung. Im Rechteck unterhalb der Diagonalen ist der $\mathrm{R}_{\mathrm{ST}}$-Wert dargestellt, oberhalb der zugehörige p-Wert. In Fett/kursiv unterlegt sind nicht signifikante Unterschiede zur Kasseler Serie.

\begin{tabular}{c||c|c|c|c|c|c|c|c|c|c|c} 
Population & Col. & Lille & Mars. & Brab. & Strasb. & Stutt. & Switz. & Toul. & Trino & Wall. & Mass. \\
\hline \hline Cologne & - & 0.6275 & 0.1319 & 0.0093 & 0.2136 & 0.2890 & 0.1669 & 0.3506 & 0.0008 & 0.4192 & 0.0126 \\
Lille & -0.0026 & - & 0.6868 & 0.3595 & 0.9410 & 0.4232 & 0.6101 & 0.8780 & 0.0363 & 0.8413 & $\mathbf{0 . 4 4 7 9}$ \\
\hline Marseille & 0.0082 & -0.0076 & - & 0.2156 & 0.8602 & 0.2038 & 0.3838 & 0.8312 & 0.2363 & 0.5418 & $\mathbf{0 . 1 8 2 9}$ \\
\hline Brabant & 0.0127 & 0.0002 & 0.0051 & - & 0.2559 & 0.0047 & 0.1550 & 0.3543 & 0.0053 & 0.4919 & $\mathbf{0 . 2 4 4 9}$ \\
\hline Strasbourg & 0.0027 & -0.0097 & -0.0110 & 0.0024 & - & 0.1468 & 0.3516 & 0.9762 & 0.1025 & 0.8033 & $\mathbf{0 . 7 0 3 9}$ \\
\hline Stuttgart & 0.0003 & -0.0006 & 0.0048 & 0.0160 & 0.0044 & - & 0.2771 & 0.3854 & 0.0051 & 0.3026 & 0.0031 \\
\hline Switzerland & 0.0022 & -0.0035 & -0.0007 & 0.0042 & 0.0004 & 0.0008 & - & 0.6458 & 0.0181 & 0.4914 & 0.0321 \\
\hline Toulouse & 0.0005 & -0.0091 & -0.0108 & 0.0001 & -0.0110 & -0.0002 & -0.0041 & - & 0.1169 & 0.9219 & $\mathbf{0 . 3 3 3 9}$ \\
\hline Trino & 0.0470 & 0.0316 & 0.0056 & 0.0576 & 0.0182 & 0.0353 & 0.0320 & 0.0157 & - & 0.1108 & 0.0056 \\
\hline Walloon & -0.0009 & -0.0109 & -0.0063 & -0.0032 & -0.0103 & 0.0016 & -0.0031 & -0.0136 & 0.0212 & - & $\mathbf{0 . 6 3 3 8}$ \\
\hline Massengrab & 0.0134 & $\mathbf{- 0 . 0 0 1 2}$ & $\mathbf{0 . 0 0 6 8}$ & $\mathbf{0 . 0 0 2 2}$ & $\mathbf{- 0 . 0 0 4 9}$ & 0.0202 & 0.0137 & $\mathbf{0 . 0 0 0 6}$ & 0.0510 & $\mathbf{- 0 . 0 0 5 6}$ & -
\end{tabular}


Der geringste Unterschied besteht zu den Populationen aus Walloon und Strasbourg. Alle französischen Populationen weisen keinen signifikanten Unterschied auf. Im NJ-Baum findet sich Kassel in einem Cluster mit den Benelux-Populationen (Abb. 4.30).

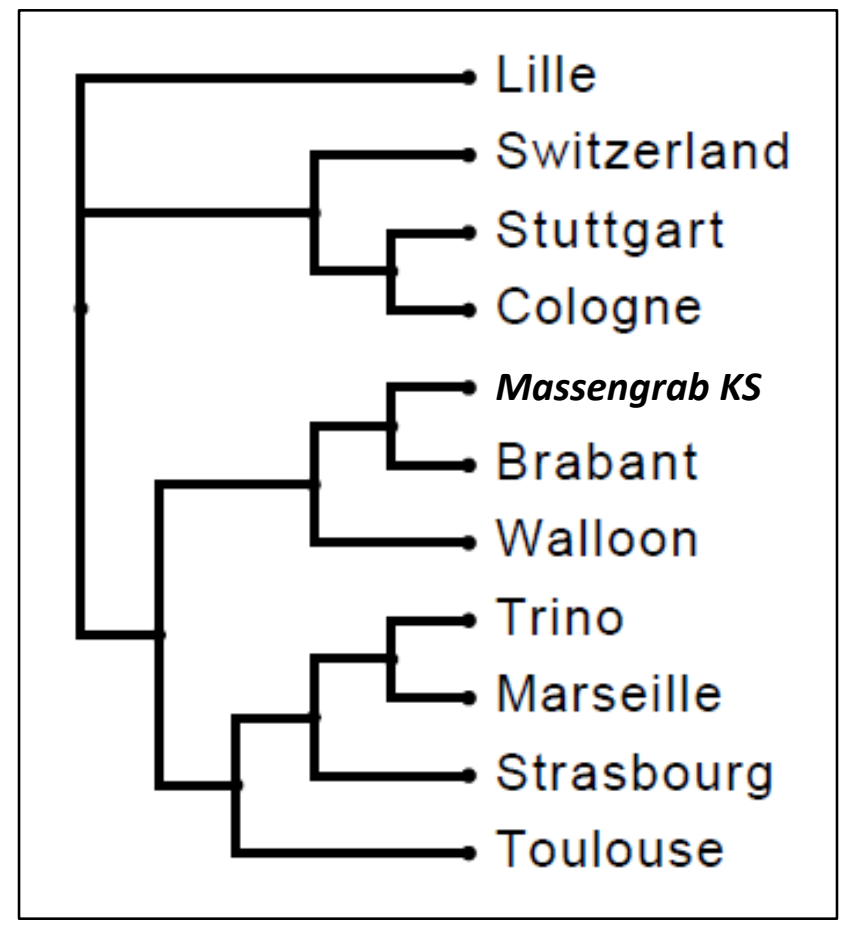

Abbildung 4.30: Phylogenetischer Baum berechnet nach NJ-Methode. Kassel clustert mit den Populationen aus den Benelux-Ländern.

Zusammenfassend zeigen sowohl die Haplogruppen- als auch die Haplotypenvergleiche in eine Richtung: die Haplogruppen deuten Frankreich bzw. das Elsass als Herkunftsgebiet an, genauso wie die Haplotypen die Benelux-Länder bzw. französische Populationen aufzeigen. Italienische und spanische Populationen sind in den Haplogruppenanalysen signifikant verschieden, in der Haplotypenvergleich prinzipiell möglich. Signifikante Unterschiede stehen zu allen Populationen östlich des Rheins.

\section{$\underline{\text { Interpretation }}$}

Mit den Analysen kann gezeigt werden, dass die Individuen des Kollektivs, als Gruppe betrachtet, keinen lokalen Ursprung hat, sondern vermutlich aus einer Region westlich des Rheins, höchstwahrscheinlich dem Elsass und / oder den südlichen Benelux-Ländern stammen. 


\subsection{Nachweis humanpathogener Bakterien-DNA}

Das in Zusammenarbeit mit Johanna Schröder entwickelte Nachweissystem bakterieller DNA zeigte nach einigen Test- und Optimierungs-PCRs die aus den Datenbanken ermittelten Ergebnisse. Die Kontrollproben mit menschlicher DNA und DNAExtrakten aus Bodenproben zeigten wie erwartet keine Produkte im entsprechenden Längenbereich. Abbildung 4.31 zeigt die Produkte der Duplex mit B. quintana- und R. prowazekii-spezifischen Primern (vgl. Tabelle 3.9). Abbildung 4.32 zeigt eine PCR mit verschiedenen menschlichen Kontrollproben, Bodenextrakten und Negativsowie Positivkontrollen der Triplex-PCR mit Salmonella enterica- und Borrelia recurrentis-spezifischen Primern (vgl. Tabelle 3.10). Informationen zu Einzelamplifikationen und jeweiligem Bearbeiter sind in der Tabelle Einzelamplifikationen.xlsx auf der CD zu finden.

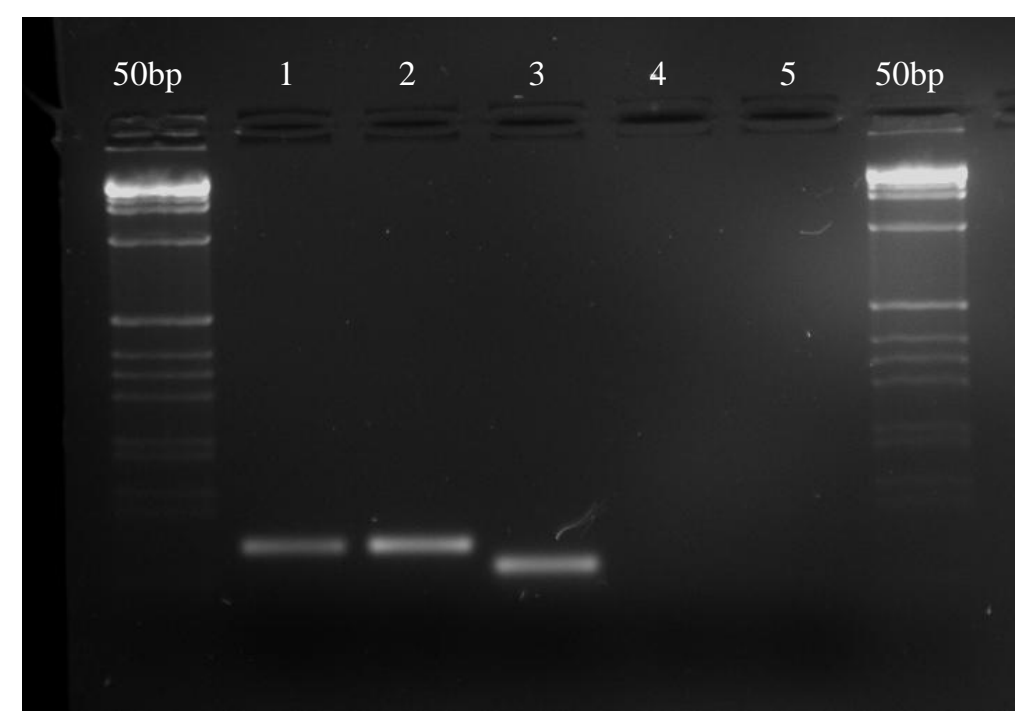

Abbildung 4.31: Länge der Produkte der Duplex bei Anwesenheit von B. quintana (1 und 2) und R. prowazekii-DNA (3). Bei DNA-Extrakten von Bodenproben (4 und 5) zeigten sich keine Produkte. (PCR-Ansatz Schröder)

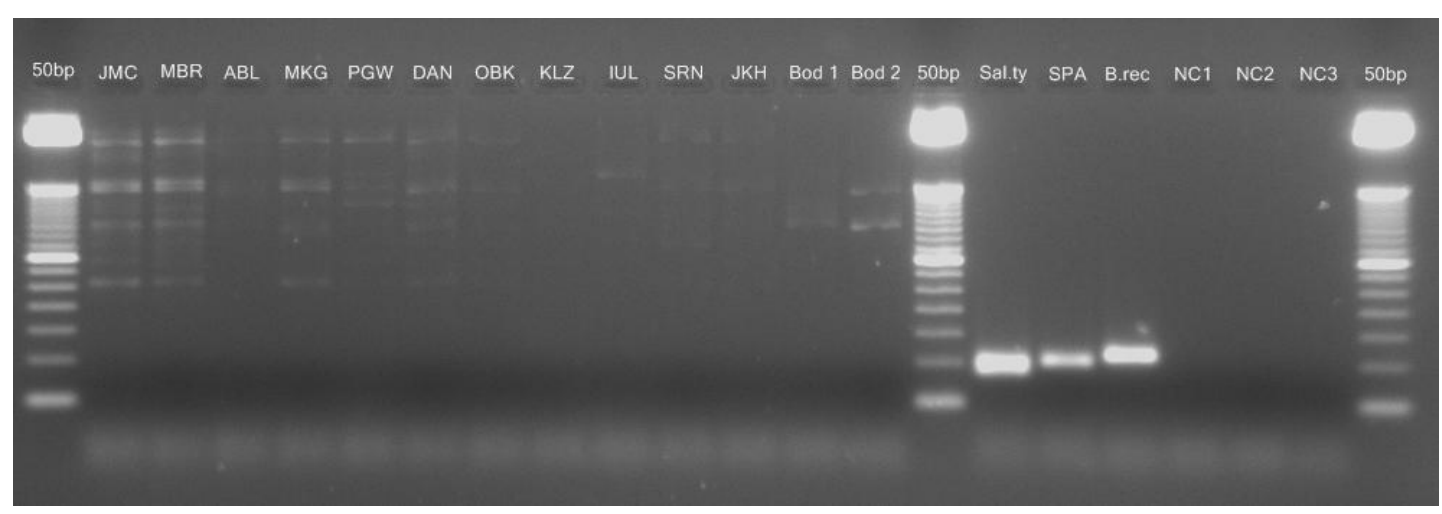

Abbildung 4.32: Amplifikation mit den Primern der Triplex. Bei den menschlichen Kontrollproben (Dreibuchstabenkürzel) und Bodenproben (Bod) treten längere, unspezifische Produkte auf, die aber deutlich von den spezifischen Produkten der Humanpathogenen (Sal.ty, SPA, B.rec) unterscheidbar sind. (PCR-Ansatz Schröder) 
Die Amplifikation mit Extrakten der Kasseler Individuen hatte in ersten Tests ergeben, dass bei drei Individuen Bartonella quintana-DNA nachgewiesen werden konnte (vgl. Abb. 4.33), wobei die Reproduktion in zwei Fällen erst nach mehrmaligen Versuchen erfolgreich war (Grumbkow et al. 2011).

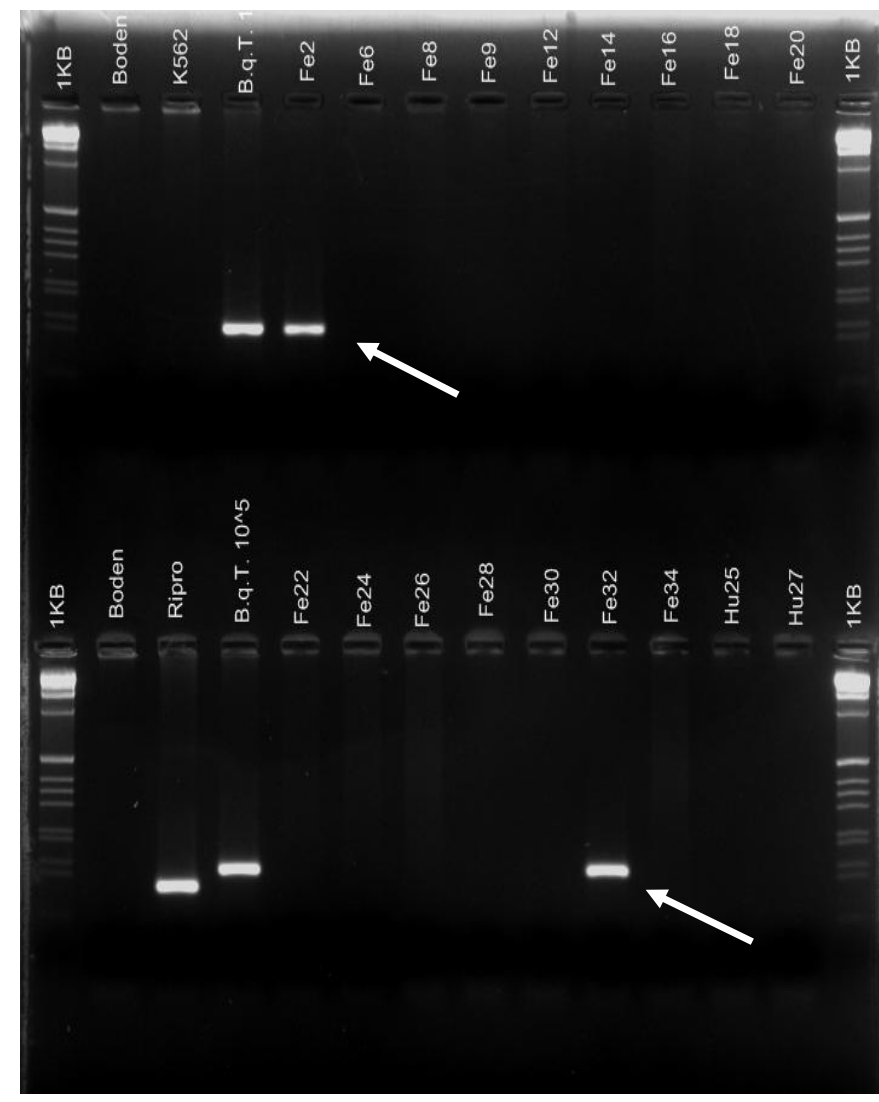

Abbildung 4.33: Agarosegelbild einer PCR für den Bartonella / Rickettsia-Nachweis. In zwei Extrakten ( $\mathrm{Fe} 2$ und $\mathrm{Fe} 32$, Pfeile) zeigt sich ein Produkt der erwarteten Länge des Bartonella-Fragments. Boden $=$ Bodenprobe, Ripro, B.q.T $=$ Positivkontrollen, $\mathrm{Fe}=$ Femur, $1 \mathrm{~KB}=$ Längenstandard

Die Sequenzierung und anschließende BLAST-Suche bestätigte, dass es sich bei den erhaltenen Fragmenten um B. quintana-DNA handelt (Abb. 4.34).

\begin{tabular}{|c|c|c|c|c|c|c|}
\hline \multicolumn{7}{|l|}{ Sequences producing significant alignments: } \\
\hline \multicolumn{7}{|l|}{ 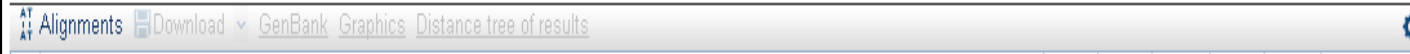 } \\
\hline Description & $\begin{array}{l}\text { Max } \\
\text { score }\end{array}$ & $\begin{array}{l}\text { Total } \\
\text { score }\end{array}$ & $\begin{array}{l}\text { Query } \\
\text { cover }\end{array}$ & \begin{tabular}{c|c}
$E$ \\
value
\end{tabular} & Ident & Accession \\
\hline$\square$ Bartonella quintana str. Toulouse, complete genome & 189 & 189 & $99 \%$ & $10-451$ & $100 \%$ & EX897700.1 \\
\hline Bartonella guintana hemin-binding protein $\mathrm{E}$ (hbp E) gene, complete cds & 189 & 189 & $99 \%$ & $1 \mathrm{e}-451$ & $100 \%$ & AY126675.1 \\
\hline 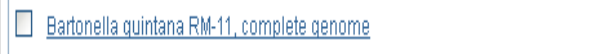 & 161 & 161 & $99 \%$ & $3 e-37$ & $95 \%$ & CP003784.1 \\
\hline$\square$ Bartonella grahamii as4aup, complete genome & 104 & 104 & $71 \%$ & $5 e-20$ & $92 \%$ & $\underline{C P 001562.1}$ \\
\hline$\square$ Eattonella tribocorum CIP 105476 complete genome, type strain CIP 105476 & 78.7 & 78.7 & $78 \%$ & $3 \mathrm{e}-12$ & $84 \%$ & AM260525.1 \\
\hline
\end{tabular}

Abbildung 4.34: Ergebnisse der BLAST-Suche. Die amplifizierte Sequenz findet sich so nur bei Bartonella quintana. 
Trotz kürzerer Produktlängen im Vergleich zu den ersten Tests konnten keine weiteren Infektionen mit Bartonella oder Rickettsia nachgewiesen werden (vgl. Schröder 2013).

Bei der Anwendung der Triplex-Primer stellte sich heraus, dass es durch die CoExtraktion von Mikroorganismen-DNA zu verhältnismäßig vielen unspezifischen Produkten kommt. Dennoch lassen sich diese von den spezifischen Produkten aufgrund ihrer Länge unterscheiden. Wie sich zeigte, war der Hauptverursacher dafür das Primerpaar für den Genort STY0312. Diese unspezifischen Produkte treten nicht auf, sobald spezifische Salmonellen-DNA im Extrakt vorliegt (Abb.4.35, [*]).

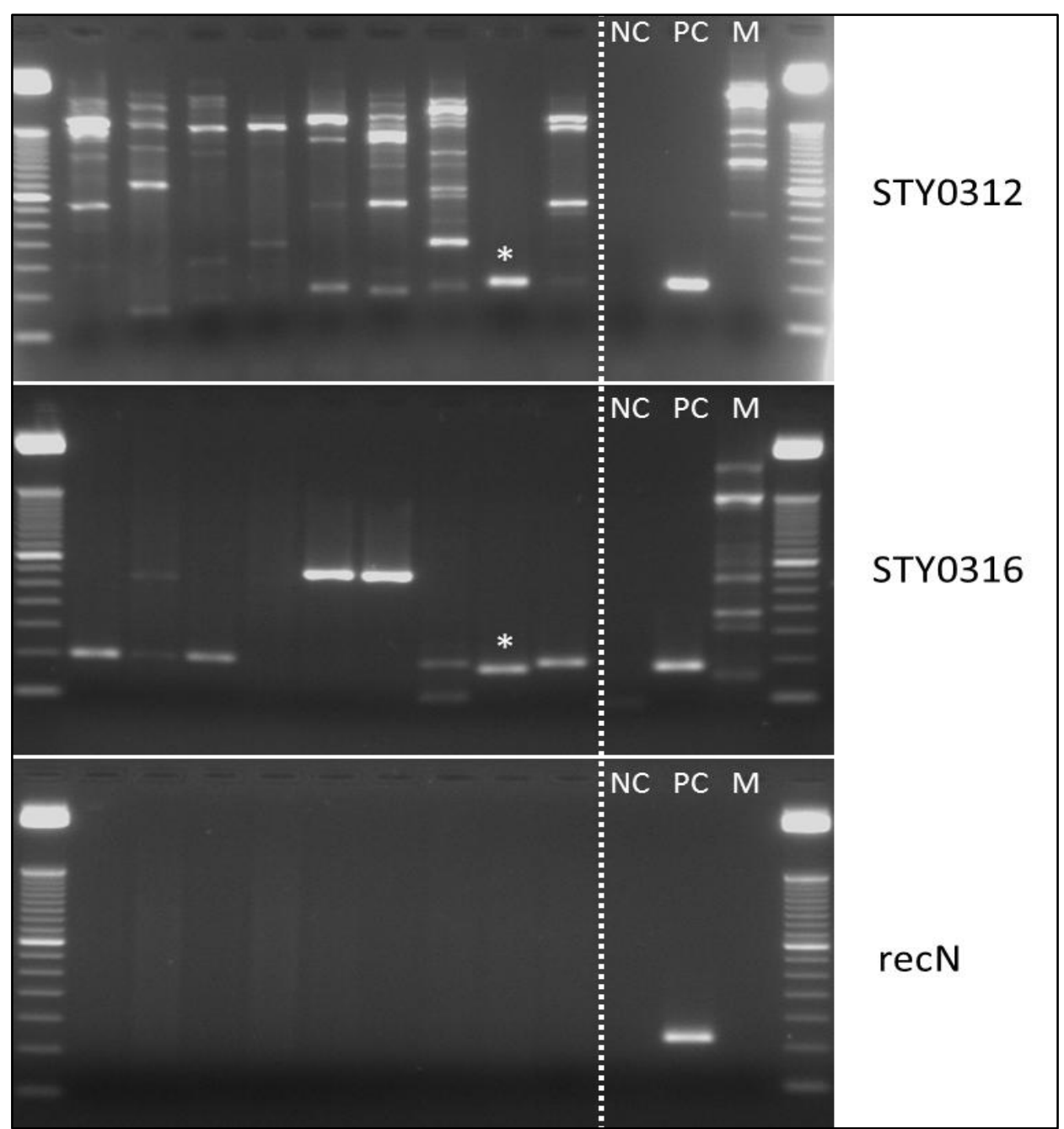

Abbildung 4.35: Einzelamplifikationen der Triplex-Primer (vgl. Tab. 3.9). Links der gestrichelten Linie sind Amplifikationen mit Extrakten aufgetragen (je Position die gleiche Probe über die Ansätze). Während bei dem Primerpaar für recN keine unspezifischen Produkte auftreten, zeigen die STY-Primer z.T. sehr lange unspezifische Produkte. Diese treten nicht auf, sobald Salmonella-DNA im Extrakt vorhanden ist (*). Durch ihren Längenunterschied sind die spezifischen Produkte als solche zu identifizieren. NC $=$ Negativkontrolle, $\mathrm{PC}=$ Positivkontrolle, $\mathrm{M}=$ rezente menschliche Kontrolle. (PCRAnsatz Schröder)

Die Primer des Genorts STY0312 wurden deswegen im Folgenden in SingleplexAnsätzen amplifiziert, während die anderen beiden als Duplex zusammengefasst wurden. 
In dem Extrakt der Probe KS3-Fe-11 konnten Salmonella-spezifische Banden reproduzierbar amplifiziert werden (vgl. Abb. 4.35, [*]). Die Anwesenheit der zwei Fragmente für Salmonellenspezies zeigt an, dass es sich dabei um die Spezies Salmonella typhi handelt. Im Weiteren konnte im Extrakt des Knochens KSM-Hu-9 der Salmonellen-Genort STY0312 amplifiziert werden (Abb. 4.36). Dieses Ergebnis konnte jedoch trotz mehrmaliger Wiederholung nicht reproduziert werden. An dieser Stelle kann nicht bestimmt werden, um welche Salmonellen-Spezies (S. typhi, paratyphi A oder S. weltevreden) es sich dabei konkret handelt.

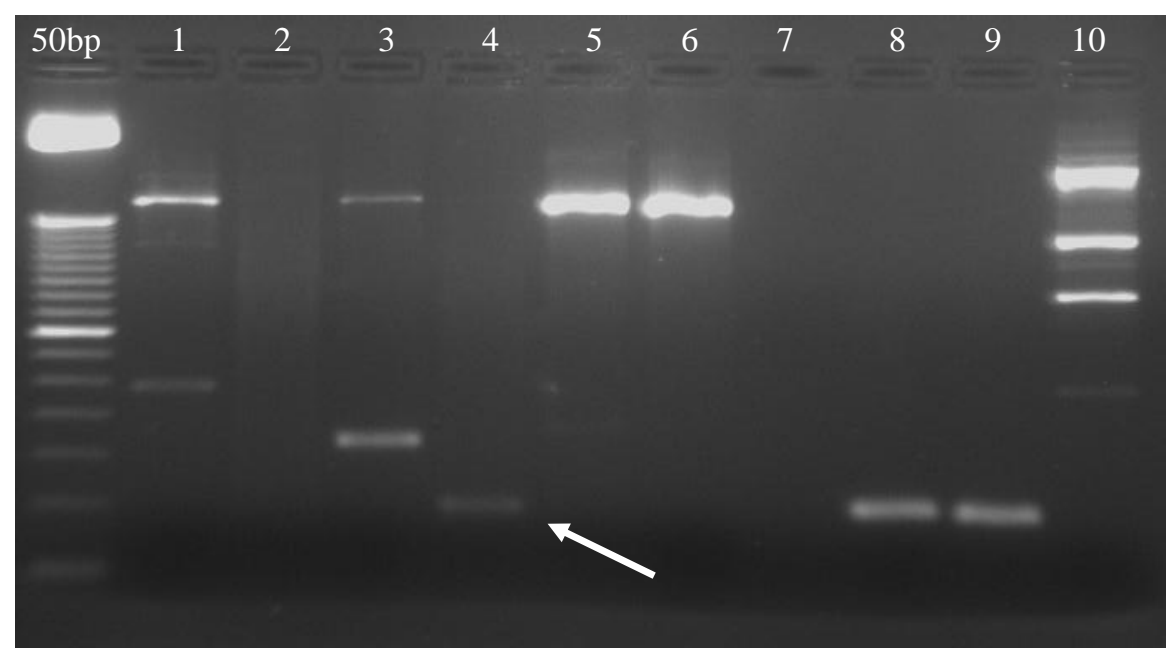

Abbildung 4.36: Agarosegeldbild einer Amplifikation mit Primern des Genorts STY0312. Im Extrakt des Knochens KSM-Hu-9 (4) wurde Salmonellenspezifische DNA amplifiziert (Pfeil). 8 und 9 zeigen Positivkontrollen, 10 eine rezente menschliche Kontrolle. 50bp = Längenstandard.

Die Sequenzierung der Fragmente und anschließend BLAST-Suche bei NCBI ergab, dass es sich um Salmonella-DNA handelt (Abb. 4.37).

\begin{tabular}{|c|c|c|c|c|c|c|}
\hline \multicolumn{7}{|l|}{ Sequences producing significant alignments: } \\
\hline \multicolumn{7}{|l|}{ 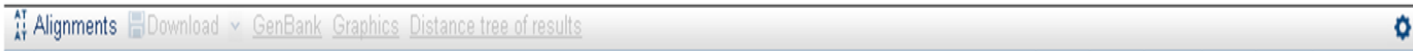 } \\
\hline Description & $\begin{array}{l}\text { Max } \\
\text { score }\end{array}$ & $\begin{array}{l}\text { Total } \\
\text { score }\end{array}$ & $\begin{array}{l}\text { Query } \\
\text { cover }\end{array}$ & $\begin{array}{c}E \\
\text { value }\end{array}$ & Ident & Accession \\
\hline Salmonella enterica subsp. enterica serovar Tiphi str. CT18, complete chromosome & 185 & 185 & $100 \%$ & $18-44$ & $100 \%$ & AL513382.1 \\
\hline S Salmonella enterica subsp. enterica serovar Typhi stt. P. Str-12, complete genome & 185 & 185 & $100 \%$ & $1 e-44$ & $100 \%$ & $\underline{\mathrm{CP} 003278.1}$ \\
\hline S Salmonella enterica strain GIFU10007 thpe VI secretion system gene ciluster, partial secuence & 185 & 185 & $100 \%$ & $1 e-44$ & $100 \%$ & $\underline{\mathrm{J} F 766712.1}$ \\
\hline ( Salmonella enterica subsp. enterica serovar Weltereden str. 2007-60-3289-1 complete genome, contia 5 & 174 & 174 & $100 \%$ & $3 e-41$ & $98 \%$ & $\underline{\text { FR775192.1 }}$ \\
\hline 口 Salmonella enterica subsp. enterica serovar Paratyphi A str. AKU 12601 complete genome, strain AKU 12601 & 169 & 169 & $100 \%$ & $2 e \cdot 39$ & $97 \%$ & FM200053.1 \\
\hline [ Salmonella enterica subsp. enterica serovar Paravophi A str. ATCC 9150 , complete genome & 169 & 169 & $100 \%$ & 28.39 & $97 \%$ & $\mathrm{CP} 000026.1$ \\
\hline
\end{tabular}

Abbildung 4.37: Ergebnisse der BLAST-Suche. Die amplifizierte Sequenz findet sich so nur bei Salmonella typhi bzw. S. paratyphi A. Durch die zusätzliche Amplifikation des Genorts STY0316 konnte die Spezies als $S$. typhi bestimmt werden. 
Zur Überprüfung auf Inhibitoren in den DNA-Extrakten wurden einige PCR-Ansätze der Extrakte mit geringen Mengen an rezenter Bakterien-DNA versetzt. Dabei konnte keine Beeinträchtigung des Amplifikationserfolgs beobachtet werden (Abb. 4.38).

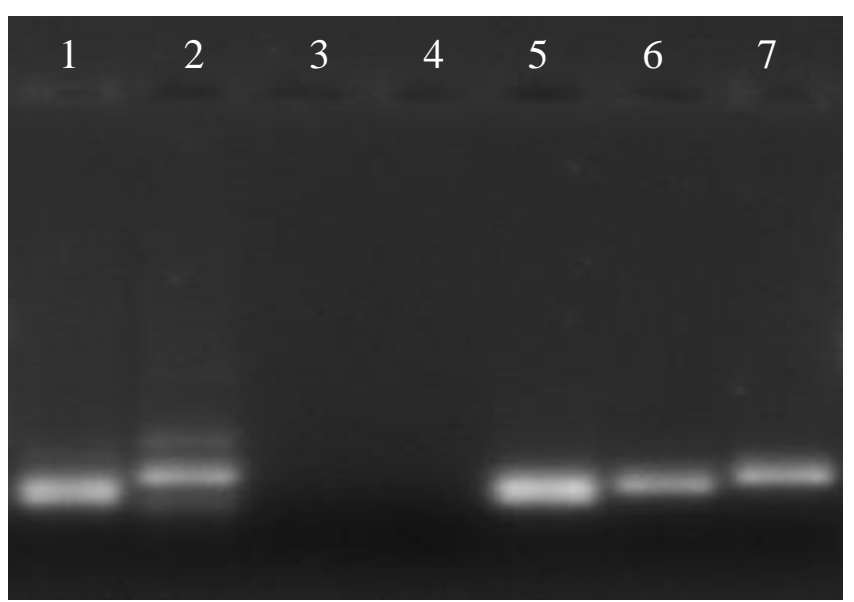

Abbildung 4.38: Agarosegelbild eines Tests auf Inhibition. Mit minimalen Mengen an Bakterien-DNA versetzte PCRAnsätze zweier Extrakte (1 \& 2) zeigen vergleichbaren Amplifikationserfolg wie die Positivkontrollen (5 - 7). Proben 3 und 4 zeigen Negativkontrollen.

\section{$\underline{\text { Interpretation }}$}

Der Nachweis von Sequenzen humanpathogener Bakterien in DNA-Extrakten der Individuen zeigt, dass die Individuen mit diesen Erregern infiziert gewesen waren. Folglich kann ein Zusammenhang mit dem in der Historie erwähnten Nervenfieber angenommen werden. Die zum Teil schwierige Reproduzierbarkeit der Ergebnisse zeigt, dass die DNA der Pathogene nur noch in kleinsten Mengen vorliegt. 


\subsection{Zusammenführung und Kontextualisierung}

Die Interpretation, dass die Individuen Angehörige der französischen Armee waren, die während eines „Nervenfieber"-Ausbruchs verstorben sind, wird durch die anthropologische Bearbeitung in allen Fällen unterstützt. Im Weiteren zeigen die Untersuchungen, dass die Individuen zu Lebzeiten unter körperlicher Belastung, Mangelernährung und schlechten hygienischen Bedingungen litten.

Die Ergebnisse der Untersuchungen zeigen, dass sich unter den 126 untersuchten Individuen nur eine Frau befindet, über $80 \%$ der Individuen sind im jungen Erwachsenenalter verstorben. Ein militärischer Kontext liegt daher nahe. Die gefundenen Abweichungen der Regelanatomie können durch ihre Häufigkeit und die Homogenität der Individuen bzgl. Alter und Geschlecht entsprechend interpretiert werden, obwohl sich ihre Zuordnung zu einzelnen Individuen aufgrund des hohen Fragmentierungsgrades als schwierig gestaltete. Die hohe Anzahl an Belastungserscheinungen, besonders auf die untere Extremität und die Wirbelsäule, teilweise auch auf Claviculae, in einem Kollektiv von überwiegend jungen Männern zeigt, dass die Individuen dauerhaft physischer Belastung ausgesetzt waren. Das Auftreten von Cribra orbitalia lassen eine ungenügende oder einseitige Ernährung vermuten. Auch die unregelhafte Mikrostruktur der Femurkompakta könnte durch eine Dauerbelastung oder Mangelernährung erklärt werden. Die bei fast $30 \%$ der Schädel festgestellten ectocranialen Porositäten könnten u.a. durch chronischen Läusebefall hervorgerufen werden und deuten schlechte hygienische Bedingungen an. Trotzdem lassen sich Hinweise auf rudimentäre ärztlicher Versorgung finden, wobei besonders die Trepanationen zu erwähnen sind. All dies passt gut ins Bild des militärischen Lebens im frühen 19. Jahrhundert und zeigt eindeutige Parallelen zu ähnlichen Massengräbern.

Die weiteren Untersuchungen zeigen, dass die Individuen als männliche Stichprobe einer damaligen Bevölkerung gesehen werden können. Die Körperhöhenverteilung ist annähernd normalverteilt und liegt mit einer mittleren Körperhöhe von 1,67m genau um den zu erwartenden Wert einer Population aus dem 19. Jahrhundert. Die untersuchten autosomalen Marker weisen keinen signifikanten Unterschied vom Hardy-Weinberg-Gleichgewicht auf.

Nimmt man eine gemeinsame Herkunft der Individuen an, weisen die Analysen der Y-Haplotypen und -gruppen auf eine nicht lokale Bevölkerung hin. Die statistische Auswertung zeigt die höchsten Ähnlichkeiten zu der elsässischen Bevölkerung, wobei bei der Betrachtung der Y-Haplotypen nicht signifikante Unterschiede auch zu weiteren französischen Populationen sowie der Bevölkerung der Benelux-Länder vorliegen. Die deckt sich mit den Recherchen der Historiker und bestätigt die Theorie, dass es sich um elsässische und / oder luxemburgische Soldaten gehandelt hat.

Das Fehlen von morphologisch eindeutigen identifizierbaren Todesursachen sowie der Nachweis von humanpathogenen Bakterien in einigen Knochen unterstützen das postulierte Seuchengeschehen. Dass der Nachweis von bakteriellen Sequenzen nur 
bei wenigen Individuen gelang, ist dabei vermutlich auf geringe Anzahl intakter Zielsequenzen und die Limitierung der PCR-gestützten Methodik zurückzuführen.

Zusammen mit dem ermittelten Alter der Individuen von etwa 200 Jahren (vgl. Kap. 1.1.) und den historischen Überlieferungen kann die Identität der Toten als napoleonische Soldaten als gesichert gelten. Darüber hinaus fanden sich viele Hinweise auf die Lebensumstände, welche durch die historischen Berichte (vgl. Kap. 1.2.) gestützt werden und somit einen sehr detaillierten Einblick auf das militärische Leben im frühen 19. Jahrhundert ermöglichen. Auf Grundlage der hier vorgestellten Ergebnisse, der historischen Recherchen und rekonstruierten Ereignisse wurde im Naturkundemuseum im Ottoneum (Kassel) eine Ausstellung über die Ereignisse im Jahr 1813 konzipiert. Dafür wurden auch zwei der Individuen dieser Arbeit lebensgetreu nachgebaut: KS14 war ein Jugendlicher zwischen 17 und 20 Jahren, KS23 ein mitteladulter Mann. Auf Basis der Schädelmorphologie und der Körperhöhe konnte die ungefähre Statur der Individuen rekonstruiert werden; historische Untersuchungen ermittelten die wahrscheinlich getragenen Uniformen. Die Ausstellung läuft bis Mai 2014.

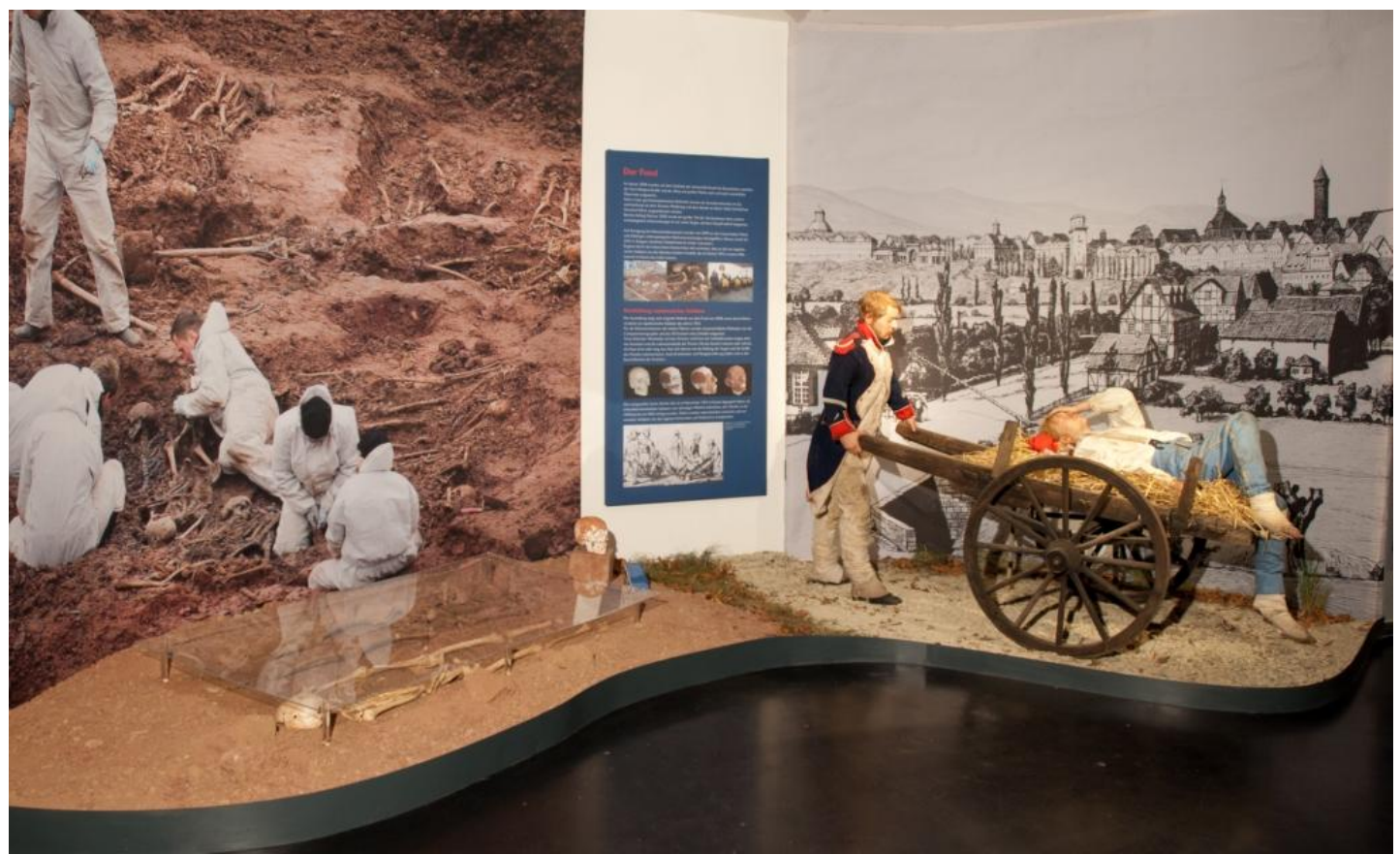

Abbildung 4.38: Blick in die Ausstellung im Naturkundemuseum im Ottoneum. (Foto: Peter Mansfeld, Naturkundemuseum Kassel.) 
Ergebnisse - Kapitel 4.8.

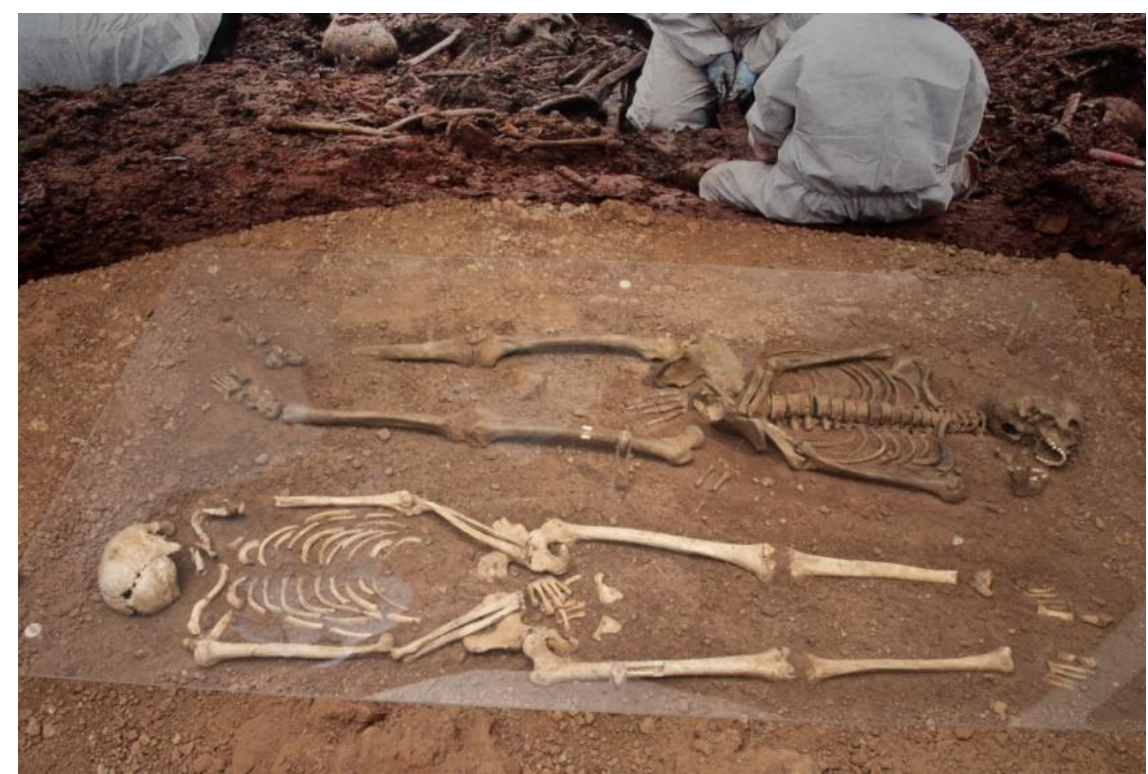

Abbildung 4.39: Skelette der rekonstruierten Individuen KS14 (vorne) und KS23. (Foto: Peter Mansfeld, Naturkundemuseum Kassel.)

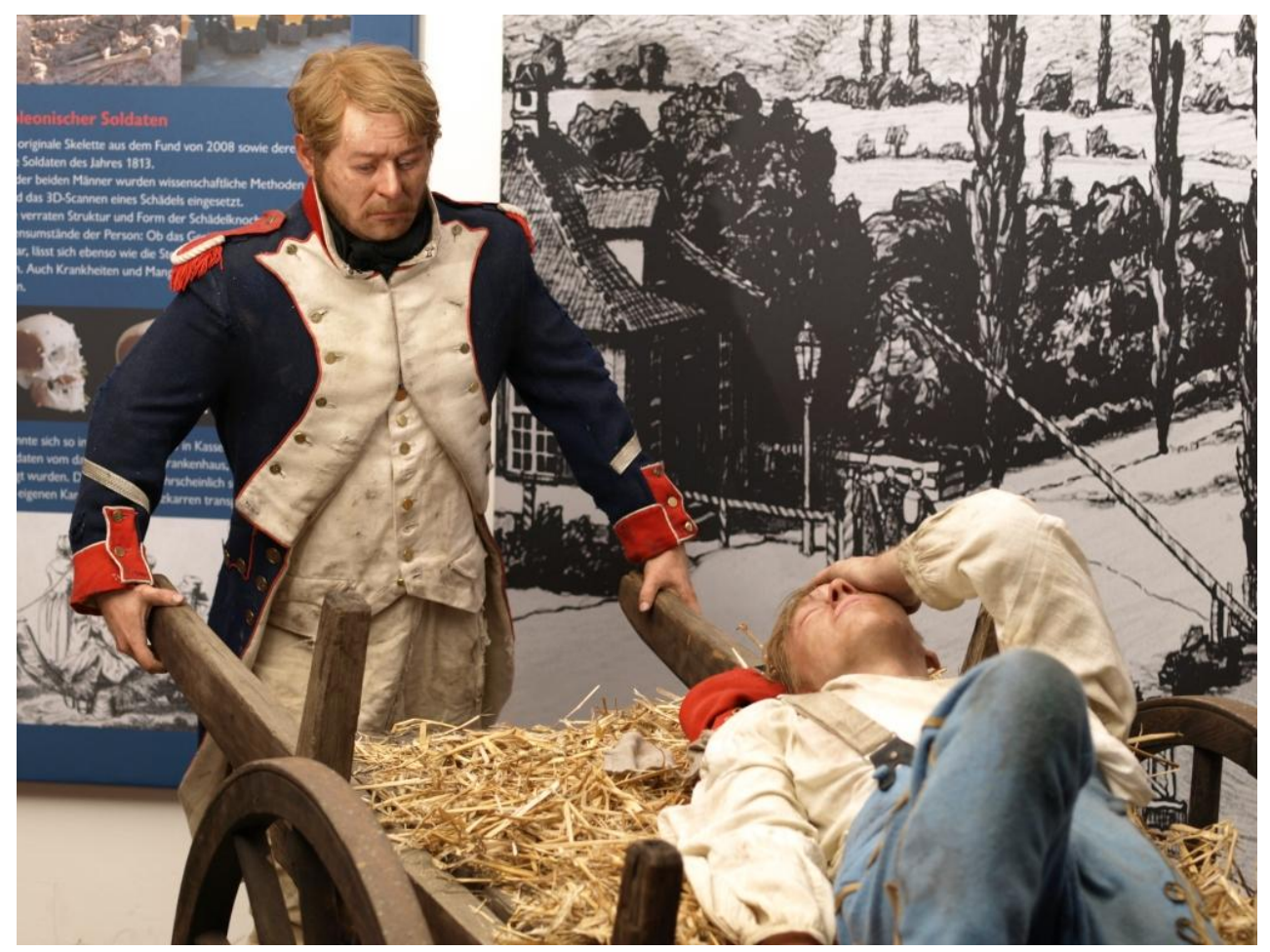

Abbildung 4.40: Nachgebildete Individuen mit authentischer Uniform. Die Szene soll den Transport in das Notlazarett darstellen. (Foto: Peter Mansfeld, Naturkundemuseum Kassel.) 


\section{Diskussion}

\subsection{Bestandsaufnahme und Mindestindividuenzahl}

Bereits in der Bestandsaufnahme der Langknochen zeigte sich, dass ein starkes Ungleichgewicht zwischen den Knochentypen herrscht, wobei die größeren Langknochen in der Überzahl vorliegen. Darüber hinaus weisen die meisten Knochen aus dem Massengrab postmortale Beschädigungen auf, z.T. sind nur Diaphysenfragmente überliefert. Von den fragileren Elementen, etwa Fibulae, Schädel oder Scapulae, liegen nur wenige unbeschadet vor. Der schlechte Zustand kann dabei teilweise durch den Bergungsprozess und die anschließende Lagerung erklärt werden. Die Polizeischüler, die im Januar bei schlechtem Wetter und mehr oder weniger unter Zeitdruck die Knochen bargen, können nicht als qualifiziertes Bergungspersonal gelten. Die Wiederbestattung in einfachen Särgen, die durch den Erddruck eingebrochen waren, dürfte für einen Teil der Beschädigungen verantwortlich sein. Dennoch gibt es auch Hinweise, dass das Massengrab schon bei der Ausgrabung im Januar 2008 gestört vorlag:

Nach einigen Augenzeugenberichten sind die gefundenen Skelette nur ein Teil eines ursprünglich größeren Grabes gewesen, das bereits früher gestört wurde. Dabei geht die älteste Erwähnung auf die Zeit nach dem Ersten Weltkrieg zurück, als Kinder auf dem Gelände Höhlen gebaut haben und dabei auf Gebeine gestoßen sein sollen. Zeitungsartikel aus dem Jahr 1936 berichten von einem großen Skelettfund in der Bernhardistraße beim Neubau der Henschelwerke, die sich auf dem Grundstück etwas nördlich der aktuellen Knochenfunde befanden (Kasseler Neuesten Nachrichten vom 21./22.10.1936). Insgesamt ist von etwa 50 Skeletten die Rede. Was mit den damals gefundenen Skeletten geschehen ist, ist jedoch nicht überliefert. Ein weiteres Ereignis, das den Fundort betrifft, fand ein paar Jahre später statt: Im Zweiten Weltkrieg wurde das Areal der Henschelwerke von Bomben getroffen.

Somit ist es höchst wahrscheinlich, dass die vorliegenden Skelettelemente ein weiterer Teil der Knochenfunde aus den 30er Jahren ist, der vermutlich auch noch durch Bombentreffer gestört wurde. Auch die Diskrepanz zwischen morphologisch und genetisch ermittelter Mindestindividuenzahl könnte auf eine bereits gestörte Fundsituation hinweisen. Während nur 106 linke bzw. rechte Femora gefunden wurden, konnten genetisch 126 Individuen identifiziert werden. Somit können nicht alle Individuen repräsentativ überliefert worden sein. 22 Knochen konnten bisher mit keinen weiteren Skelettelementen assoziiert werden. Insgesamt ist durch die historischen Begebenheiten sowie die Fund- und Bergungssituation das Knochenmaterial stark in Mitleidenschaft gezogen worden. Wie viele Informationen dadurch zerstört wurden, lässt sich nicht abschätzen.

Durch den hohen Fragmentierungsgrad der Knochen war eine sichere Zuordnung der Skelettelemente zu einem Individuum nur bedingt möglich. So z.B. wird die Rekonstruktion von Extremitäten entscheidend durch die Überprüfung auf funktionale Ge- 
lenke gestützt, was bei zerstörten Epiphysen unmöglich ist. Andere Kriterien wie allgemeine Robustizität oder Färbung müssen folglich herangezogen werden, diese sind aber in ihrer Aussagekraft vergleichsweise eingeschränkt. Zuordnungen von beispielsweise Wirbel(säulen), Becken- oder Schädelfragmente können kaum morphologisch überprüft werden.

Die Möglichkeit der genetischen Analysen, also des genetischen Fingerabdrucks, wäre daher das Mittel der Wahl, um unsichere Zuordnungen zu überprüfen. Erst durch die Genetik war es möglich, die Mindestindividuenzahl mit 126 anzugeben und so deutlich mehr als die morphologisch nachgewiesene Mindestindividuenzahl zu identifizieren. Das Auftreten von Kontaminationsereignissen war dabei nur in ganz vereinzelten Amplifikationen zu beobachten und konnte sofort auf den jeweiligen Bearbeiter zurückgeführt werden. Durch das Einhalten der strengen Regeln für die Arbeit mit aDNA und die Reproduzierbarkeit der Ergebnisse können diese daher als authentisch gelten. Der durchschnittlich sehr gute DNA-Erhalt in den Knochen ermöglichte bei einer stichprobenartigen Überprüfung (Holzgräfe 2013) in vielen Fällen die sichere Zuordnung von Skelettelementen und könnte theoretisch bei allen Elementen angewendet werden. Der Nachteil wäre dabei jedoch nicht nur, dass es sich um eine zeit- und kostenintensive Methode handelt, sie ist zusätzlich auch invasiv und benötigt eine gewisse Menge Ausgangsmaterial. Im Weiteren konnte bereits bei Holzgräfe (2013) gezeigt werden, dass die Wahrscheinlichkeit einer schlechten DNA-Erhaltung in anderen Skelettelementen außer Femora in diesem Kollektiv deutlich höher liegt. Für spongiöse Knochentypen, etwa Becken oder Wirbel, sind daher auch die genetischen Analysen weniger erfolgsversprechend. Letztendlich muss die Zuordnung der Skelettelemente in einigen Fällen unsicher bleiben. Aufgrund der Homogenität der Individuen bzgl. Alter und Geschlecht ist die endgültige Zuordnung, etwa von Abweichungen der Regelanatomie, aufgrund der Häufigkeiten jedoch für eine Interpretation nicht unbedingt entscheidend (vgl. Kap. 5.3).

Neben den menschlichen Knochen konnten auch einzelne Tierknochen gefunden werden. Dabei es handelt sich nur um vereinzelt auftretende Knochen unterschiedlicher Spezies und Individuen, meist von Schweinen oder Pferden. Ob diese Knochen zusammen mit den Individuen bestattet worden sind, oder schon vorher im Boden lagen, ist ungewiss. Da bei Grabungen immer wieder solche zufälligen Funde von Nutztierresten auftreten, gerade in der Nähe von Siedlungen, ist ein direkter Zusammenhang mit dem Massengrab unwahrscheinlich.

\subsection{Biologische Basisdaten}

Insgesamt zeigt sich, dass die Individuen aus dem Kasseler Massengrab mit den napoleonischen Truppen aus Vilnius (s.u.) vergleichbar sind und das Kollektiv genau den Erwartungen eines militärischen Kontexts des frühen 19. Jahrhunderts entspricht. Auf eine methodenkritische Diskussion wird an dieser Stelle verzichtet, da das verwendete Methodenrepertoire als etabliert gelten kann und ohne Modifikationen angewendet wurde. 
Die zwei sich ergänzenden Methoden für die Ermittlung des Sterbealters und des Geschlechts der Individuen zeigen trotz des hohen Fragmentierungsgrads ein sehr detailliertes Bild des Kollektivs: Von 126 Individuen ließ sich nur eines als weiblich identifizieren, über $80 \%$ der Individuen sind zwischen dem 20. und 30. Lebensjahr verstorben. Überreste von Kindern und sehr alter Individuen fehlen völlig. Ein militärischer Hintergrund der Individuen liegt somit nahe (vgl. Kap. 4.2. und 4.3.).

Durch den Fragmentierungsgrad sowie die in einigen Fällen unsichere Zuordnung wurde gerade die Ermittlung des Sterbealters durch die histologischen Untersuchungen entscheidend gestützt. Während bei jugendlichen Individuen durch die morphologischen Kriterien das Sterbealter sehr genau bestimmt werden konnte, liefern bei Erwachsenen die histologischen Untersuchungen zuverlässige Näherungen. Ähnlich verhält es sich bei der Geschlechtsdiagnose. Zwar fallen nur wenige Skelettelemente morphologisch in das Spektrum weiblicher Individuen, doch letztlich liefern die genetischen Untersuchungen die Bestätigung, dass sich unter den Individuen mindestens eine Frau befindet.

Die gefundene Alters- und Geschlechtsverteilung bestätigt die Tendenzen aus den ersten Stichproben der Rechtsmedizin Gießen und der Anthropologie Mainz und sorgt dennoch für neue Erkenntnisse. Nicht alle Individuen sind jung verstorben, es befinden sich mehrere Individuen fortgeschrittenen Alters darunter. Ein Vergleich zu dem Massengrab napoleonischer Truppen, das in Vilnius, Litauen, gefunden wurde und auf das Jahr 1812 datiert werden konnte, zeigt jedoch eine sehr ähnliche Verteilung (Signoli et al. 2004): von den 430 Individuen, von denen das Sterbealter genauer bestimmt werden konnte, waren $46(10,7 \%)$ unter 20 Jahre alt, $326(75,8 \%)$ zwischen 20 und 30 Jahre alt, 58 (13,5\%) waren älter (darunter 8 [1,6\%] in der Altersklasse Maturitas). Das jüngste Individuum war ca. 15 Jahre alt. Dies deckt sich auffallend mit der Altersverteilung des Kasseler Kollektivs.

Im Kollektiv befanden sich auch die Überreste einer jungen Frau. Wie sie zu den restlichen Individuen stand, kann an dieser Stelle nicht definitiv beantwortet werden. Ein mögliches Szenario ist, dass die Frau zum Tross der Truppen gehörte und selbst eine Fremde in Kassel war. Frauen waren damals ein integraler Bestandteil der französischen Armee und wurden als cantinières, blanchisseuses et vivandières bezeichnet; ihre Aufgaben war das Kochen, Waschen, die medizinische Assistenz oder der Verkauf von Waren (Signoli et al. 2004, vgl. Kap. 1.2.). Im erwähnten Massengrab aus Vilnius war das Geschlechterverhältnis 29 Frauen zu 1338 Männern (2,1\%), welches damit sogar einen höheren Frauenanteil aufweist als im Kasseler Kollektiv. Durch ihre Assoziation mit den französischen Truppen wäre die Frau dann bei einer Infektion ebenfalls in das Notlazarett eingeliefert worden (vgl. Kap. 1.1.). Allerdings ist nicht bekannt, ob ein solcher Tross zur fraglichen Zeit im Winter 1813 auch in Kassel war. Weiterhin erwähnen die historischen Unterlagen keine Unterbringung von Frauen in dem Lazarett, sondern nur Soldaten (persönliches Gespräch v. Klobuczynski). Eine weitere Möglichkeit wäre, dass die Frau zum Pflegepersonal im Lazarett gehörte und sich ebenfalls mit dem Nervenfieber angesteckt hatte (vgl. Kap. 
1.1.). Sollte sie jedoch aus Kassel selbst stammen, wäre es auffällig, dass sieanonym im Massengrab mitbestattet wurde und keine reguläre Bestattung erhielt, wobei vielfältigste Gründe (Armut, familienlos, etc.) dafür in Betracht kämen. Letztendlich bleiben jedoch beide Szenarien reine Spekulation. Ein möglicher weiterführender Untersuchungsansatz könnte in der Erstellung einer Strontiumisotopensignatur für eine Herkunftsbestimmung liegen (Kap. 5.4.). Zumindest Hinweise auf die Herkunft der Frau könnten damit erlangt werden, welche eines der Szenarien untermauern könnten (vgl. Kap. 5.3.).

Insgesamt konnten nur bei 58 Individuen intakte Skelettelemente für eine Körperhöhenbestimmung herangezogen werden. Die mittlere errechnete Körperhöhe beträgt etwa $1,67 \mathrm{~m}$ und liegt damit nahe der zu erwartenden Durchschnittsgröße für das beginnende 19. Jahrhundert (z.B. Komlos 1994). Gerade in militärischen Kontexten sind über lange Zeiträume sehr genaue Körperhöhendaten der Soldaten überliefert, so dass die Daten des Kollektivs mit vielen Referenzdaten verglichen werden können. So ist beispielsweise für Dänemark zum Beginn des 19. Jahrhunderts eine durchschnittliche Körperhöhe von etwa 1,65m - 1,67m, für Frankreich von 1,66m und für Schweden von 1,65m überliefert (Komlos 1994). Nach Komlos und Cinnirella schwanken die Werte von Soldaten verschiedener Länder im 18. Jahrhundert zwischen 1,64 und 1,68m (Komlos und Cinnirella 2005). Da Mittelwert und Median im Kollektiv nahe beieinander liegen, kann zusätzlich eine Normalverteilung der Körperhöhe angenommen werden, wie man dies bei einer Stichprobe einer normalen Bevölkerung erwarten würde. Auch die Körperhöhe des weiblichen Individuums entspricht mit etwa 1,54m ziemlich genau den Erwartungen für Frauen (1,55m, Siegmund 2010).

\subsection{Abweichungen von der Regelanatomie}

Die gefundenen Auffälligkeiten zeigen in ihrer Gesamtheit, dass die Individuen physischer Belastung, Mangelernährung und / oder Infektionskrankheiten ausgesetzt waren. Auffällig ist, dass morphologisch keine Hinweise auf eine mögliche Todesursache gefunden werden konnten. Zwar wurden einige, meist individualspezifische Pathologien identifiziert, allerdings kann keine davon als definitive Todesursache gelten.

Die häufigste Diagnose stellen die fast durchgehend auftretenden periostalen Reaktionen an den unteren Extremitäten dar. Die Frequenz ist ungewöhnlich hoch und zeigt die Belastung der Individuen besonders deutlich. Für ihr Auftreten könnten sowohl Mangelernährung, physischer Stress sowie Infektionskrankheiten ursächlich sein (vgl. z.B. Ortner 2003).

Die hohe Frequenz von Zahnpathologien könnte Hinweise auf einseitige und / oder Mangelernährung sowie schlechte hygienische Bedingungen liefern. Dabei muss jedoch beachtet werden, dass eine hohe Rate an Auffälligkeiten der Zähne im Mittelalter und der frühen Neuzeit durchaus normal war und keine Besonderheit dieses 
Kollektivs darstellen. Durch den Mangel an oraler Hygiene sowie qualitativ schlechterer Nahrung traten Karies, Zahnstein und Zahnverlust in deutlich erhöhtem Maße als heutzutage auf. Ein Vergleich mit dem Massengrab aus Vilnius zeigt ähnliche Frequenzen in allen Zahnpathologien (Palubeckaite et al. 2006). Auch das Auftreten der Schmelzhypoplasien, die Hinweise auf Stress oder Mangelernährung in der frühen Kindheit liefern, waren in historischen Bevölkerungen häufig vertreten (Eickhoff und Schopper 2012).

Eine weitere Besonderheit stellen die vertieften Ansatzstellen der Ligamenta costaclavicularia der Claviculae dar, die bei vielen Individuen auftraten. Weiterhin fanden sich arthrotischen Veränderungen an Wirbelansatzstellen der Rippen und degenerativen Veränderungen an der Wirbelsäule, welche z.B. durch schweres Lastentragen hervorgerufen werden kann. Zu napoleonischer Zeit wurde die gesamte Ausrüstung eines (einfachen) Soldaten in Tornistern auf dem Rücken transportiert, die dadurch entsprechend schwer waren; historische Quellen geben das durchschnittliche Gewicht eines Tornisters mit 33 Pfund 12 Unzen (etwa 17kg) an (von Segur 1835). Diese Dauerbelastung könnte somit die gefundenen Auffälligkeiten und deren Häufigkeit im Kollektiv erklären. Die Anwesenheit von Cribra orbitalia ist ein deutliches Zeichen für eine Mangelernährung, wobei nur etwa 10\% der Individuen eine Cribra aufwiesen. Die ectocranialen Porösitäten an vielen Schädeln könnten ein Hinweis auf einen chronischen Läusebefall sein, der mit schlechten hygienischen Bedingungen einhergeht. In Europa war der Läusebefall bis ins 19. Jahrhundert hinein extrem häufig und konnte auch für das Massengrab aus Vilnius gezeigt werden (Araujo et al. 2000, Raoult et al. 2006).

Weitere Auffälligkeiten betreffen zwei verheilte Brüche, zwei Trepanationen sowie zwei radioulnare Synostosen, die Hinweise auf eine rudimentäre ärztliche Versorgung liefern. Gerade die Trepanation war zu Beginn des 19. Jahrhunderts noch weit verbreitet und ein häufig angewandtes Mittel, das auch ohne primäre Verletzungen des Schädels angewandt wurde. Erst Mitte des 19. Jahrhunderts entwickelte sich eine kritischere Sicht auf das Verfahren (Povacz 2007). Die Synostosen der Unterarmknochen, einmal in Pronations- und einmal in Supinationsstellung, wurden wahrscheinlich durch ein Trauma und anschließende Arretierung hervorgerufen. Die gefundenen Auffälligkeiten könnten zu Individuen gehören, die verwundet worden sind, das Lazarett aber ,geheilt“" verlassen konnten (sog. Rekonvaleszente).

Alle Abweichungen von der Regelanatomie stehen in Konkordanz mit der Theorie eines militärischen Kontexts aus dem frühen 19. Jahrhundert. Da alle Individuen sich in Geschlecht und Alter ähneln, können die Belastungserscheinungen (z.B. der Wirbelsäule) trotz unsicherer Zuordnung aufgrund ihrer Häufung als überwiegend pathologisch identifiziert werden. Die Individuen waren folglich erheblicher physischer Belastung, Mangelernährung und vermutlich schlechten hygienischen Bedingungen ausgesetzt gewesen. Die Parallelen zu ähnlichen Massengräbern, ganz besonders dem napoleonischer Soldaten in Vilnius, und den historischen Überlieferungen (vgl. Kap. 1.2.) sind unverkennbar. 


\subsection{Geographische Herkunftsbestimmung}

Die Allelfrequenzen der autosomalen STR-Systeme weisen keinen signifikanten Unterschied zum Hardy-Weinberg-Gleichgewicht auf, zeigen jedoch eine Verteilung, wie man sie in westeuropäischen Populationen erwarten würde. Gleichzeitig gibt es signifikante Abweichungen in mehreren Systemen von Verteilungen osteuropäischer Populationen sowie in einem System zu einer nord- bzw. südeuropäischen Population. Folglich können zwei Ableitungen gemacht werden: Zum einen kann das Kasseler Massengrab tatsächlich als „Populationsstichprobe“ gelten, d.h. es gibt keine Hinweise auf z.B. einen hohen Verwandtschaftsgrad im Kollektiv. Zum anderen liegt eine Herkunft der Individuen, als Gruppe betrachtet, aus Westeuropa nahe. Bereits auf dieser Ebene zeigen sich deutliche Tendenzen der Herkunft der Skelette, welche durch die Bestimmung der Y-Haplotypen und -gruppen zusätzlich eingegrenzt werden konnte.

Der gute DNA-Erhalt ermöglichte die vollständige Typisierung von elf Ychromosomalen Systemen für 101 Individuen, was für historische Populationen eine enorme Stichprobe darstellt. Dabei wurde streng nach den Kriterien für aDNAAnalysen gearbeitet und es flossen nur die Allele in die Berechnung ein, die reproduzierbar waren. Die statistischen Auswertungen der Y-chromosomalen Haplotypen und -gruppen zeigen deutliche Unterschiede zu Populationen östlich des Rheins und zu südeuropäischen Populationen sowie größte Ähnlichkeiten zur Bevölkerung des Elsass. Auf der Ebene der Haplotypen besteht kein signifikanter Unterschied zu französischen Populationen und Bevölkerungen der Beneluxländer (Roewer et al. 2005). Für diese Berechnungen gelten jedoch auch einige Einschränkungen und Grundannahmen, welche die Aussagekraft etwas einschränken:

Zunächst wird für die Berechnungen einer möglichen Herkunft für die Individuen eine gemeinsame Herkunft angenommen, obwohl dies an dieser Stelle nicht zu beweisen ist. Zwar deuten die historischen Überlieferungen darauf hin, dass es sich bei den Individuen um Truppenteile einer Region, nämlich dem Elsass bzw. Luxemburg, handelt (persönliches Gespräch v. Klobuczynski). Ob einzelne Individuen aber aus einer ganz anderen Region, etwa Schweden oder Russland, stammen, lässt sich durch die durchgeführten Berechnungen nicht zeigen. Die genaue Herkunft der einzelnen Individuen anhand molekulargenetischer Marker herauszufinden ist unmöglich. Lediglich zwischen den einzelnen Kontinenten gibt es hinreichend viele Unterschiede, die eine Einteilung einzelner Individuen in verschiedene Metapopulationen zulassen. Innerhalb Europas gibt es keine scharfen Grenzen zwischen den Populationen, es fallen lediglich einige relativ isoliert lebende Bevölkerungsgruppen auf, wie etwa die Basken oder die Saami (z.B. Richards 2002), jedoch gibt es auch hier keine eindeutigen genetischen Marker, die ein einzelnes Individuum als sicher zugehörig identifizieren würde. Selbst die Analyse einzelner Y-Haplotpyen, deren regionale Vorkommen durch große Datenbanken gut dokumentiert ist, kann für eine Herkunftsbestimmung problematisch sein (King et al. 2007). So bleibt die Herkunft für das einzelne Individuum auf genetische Weise unbestimmbar. 
Eine andere Möglichkeit der Herkunftsbestimmung wäre jedoch durch die Analyse der stabilen Isotope gegeben: das natürliche Verhältnis von verschiedenen Isotopen eines Elementes zueinander kann stark variieren; dieses Verhältnis findet sich durch Nahrungsaufnahme auch im Körper wieder. Dabei kann durch die Analyse sogenannter schwerer Elemente (z.B. 87/86-Strontium) eine geographische Herkunftsbestimmung erfolgen, während die Analyse leichter Elemente (z.B. Kohlenstoff und Stickstoff) u.a. eine Aussage über Nahrungsgewohnheiten zulässt. Durch den Vergleich von Verhältnissen schwerer Elementisotope verschiedener Gewebe kann darüber hinaus ein zeitlicher Rahmen des Ortswechsels relativ zum Todeszeitpunkt des Individuums bestimmt werden: Während die Milch- und Dauerzähne jeweils nur einmal gebildet werden und so das Isotopenverhältnis, das am Ort der Kindheit vorliegt, aufgenommen und konserviert wird, unterliegen Knochen einem kontinuierlichen Umbauprozess, in dessen Zuge auch das Isotopenverhältnis den lokalen Gegebenheiten angeglichen wird (Stadlbauer et al. 2007). Durch einen Vergleich der Verhältnisse in den Zähnen und Knochen mit dem natürlichen Verhältnis am Auffindeort der Skelette kann so festgestellt werden, ob zu Lebzeiten ein Ortswechsel stattgefunden hat und wenn ja, in welchem Zeitraum vor dem Tod der Individuen sowie in welcher Region das gefundene Isotopenverhältnis dem Natürlichen entspricht (Rauch et al. 2007). Da jedoch auch weiter entfernte Regionen durch ähnliche Geologie ähnliche Isotopenverhältnisse aufweisen können (Voerkelius et al. 2010), ist dies nur sinnvoll anzuwenden, wenn eine vermutete Herkunftsregion überprüft werden soll. Individuen beispielsweise innerhalb von Europa zu verorten, wäre damit fast unmöglich. Die Überprüfung, ob die Individuen aus dem Elsass kommen könnten, dagegen schon.

Im Weiteren muss man beim Y-chromosomalen Vergleich bedenken, dass eine historische Population vorliegt: der Vergleich mit rezenten Frequenzen ist problematisch, da man nicht ohne weiteres annehmen kann, dass damals dieselben Frequenzen innerhalb von Europa vorlagen, wie sie es heute tun. Bevölkerungsbewegungen und demographische Entwicklungen können zu einer deutlichen Verschiebung der Haplogruppenfrequenzen innerhalb der letzten Jahrhunderte beigetragen haben (z.B. Ambrosio et al. 2010, Noveletto 2007, Pereira et al. 2000). Hinzu kommt, dass in dieser Arbeit die Y-Haplogruppen durch die Haplotypen berechnet wurden; diese Berechnung stütze sich jedoch ebenfalls auf rezenten Datensätzen (Athey 2005). Da SNPs, die für die Haplogruppeneinteilung verwendet werden, und STRs unabhängig voneinander mutieren, könnte ein heutiger Zusammenhang für eine historische Population nicht gegolten haben. Lediglich die geringen Mutationsraten beider Systeme und der geringe zeitliche Abstand der Kasseler Serie lassen den Rückschluss von Haplotypen auf Haplogruppen anhand rezenter Daten authentisch erscheinen. Eine gezielte Untersuchung von Haplogruppenfrequenzen und Y-Haplotypen in historischen Populationen könnte dieses Problem lösen, derzeit gibt es jedoch einen Mangel an Referenzpopulationen. Zu dieser Problematik sei erwähnt, dass die Haplogruppenfrequenzen herangezogen werden, um die Besiedlung Europas zu erklären. Damit wird vorausgesetzt, dass seit der postglazialen (Neu-)Besiedlung Europas sowie der 
Neolithisierung vor etwa 10.000 Jahren die Frequenzen nur gering durch die oben genannten Ereignisse beeinflusst worden sind, zumindest im kontinentalen Maßstab (Semino et al. 2000, Underhill et al. 2000, Soares et al. 2010). Seit Mitte der 1990er Jahre werden mt- und Y-Haplogruppen für die Besiedlungsgeschichte einzelner Länder oder Regionen herangezogen, dabei werden nur sehr selten Ereignisse der letzten Jahrhunderte als Erklärung bemüht, meistens sind es Jahrtausende (siehe dazu Roewer et al. 2005). Bisher gibt es nur vereinzelt Hinweise auf die Richtigkeit dieser Annahmen. So z.B. wurden in einer Studie von Csanyi et al. (2008) an einem hochmittelalterlichen Skelettkollektiv aus Ungarn keine signifikanten Unterschiede zu einer heutigen ungarischen Population in Bezug auf die Haplogruppenverteilung gefunden. Auch die Herkunft zeitlich älterer Individuen als das Kasseler Skelettkollektiv wurde aufgrund heutiger Haplogruppenverteilung eingeordnet, so z.B. durch Fu et al. (2009) an einem Kollektiv aus dem 13. Jahrhundert. Aus der Studie von Roewer et al. (2005) geht hervor, dass die Kolonisierungsversuche von westeuropäischen Populationen nach Osten keine signifikanten Spuren in Osteuropa hinterlassen haben und dass das 20. Jahrhundert zu einer Homogenisierung der vorher eher variableren genetischen Landschaft geführt haben soll. In Hinblick auf diese Studien erhält ein Vergleich rezenter Frequenzen mit einer geschätzt 200 Jahre alten Population eine solide Grundlage, auch wenn das grundlegende Problem weiterhin besteht.

\subsection{Hinweise auf die Todesursache}

Anhand der morphologischen Untersuchungen konnte kein ultimativer Hinweis auf die Todesursache der Individuen gefunden werden. An einigen Maxillenfragmenten konnte ein Hinweis auf apikale Zystenbildung gefunden werden, was durch die Gefahr einer Sepsis als mögliche Todesursache in Betracht kommen könnte, dies betraf jedoch nur fünf Individuen. Im Weiteren konnte jedoch ein allgemein schlechter gesundheitlicher Zustand aufgezeigt werden. In diesem Zusammenhang lieferte der molekulargenetische Nachweis von Humanpathogenen einen entscheidenden Hinweis. Bei drei Individuen konnte Bartonella quintana, bei einem Individuum Salmonella typhi und bei einem weiteren Individuum Salmonella enterica spec. nachgewiesen werden.

Die PCR-gestützten Nachweissysteme basieren dabei auf der Spezifität der Primer, so dass falsch-positive Ergebnisse vermieden werden sollten. Da zwar in der Theorie die Primer nur bei Anwesenheit der spezifischen Erreger-DNA amplifizieren, das System aber neu entwickelt wurde und keine Referenzen vorliegen, wurden die Produkte sequenziert und so bestätigt, dass es sich tatsächlich um die spezifische DNA handelt. Die Koamplifikation von Bodenextrakten und menschlicher Kontroll-DNA soll zeigen, dass nur bei Anwesenheit von spezifischer Erreger-DNA das System amplifizieren kann und falsch-positive Ergebnisse nicht zu befürchten sind. Dabei sollen die Bodenextrakte die mikrobielle Fauna repräsentieren, welcher die Knochen ausgesetzt waren. Da im Gegensatz zum menschlichen Erbgut die genetische Variabilität der Mikrooganismen erst im Ansatz bekannt ist, ist es durchaus möglich, dass zwar laut Datenbanken ein entwickeltes Primerset spezifisch ist, ein noch nicht er- 
fasstes bodenlebendes Bakterium jedoch eine ähnliche genetische Ausstattung besitzt wie der eigentlich nachzuweisende Erreger bzw. sich Gene mit diesem teilt.

Eine Kontamination durch die Positivkontrollen wurde umgangen, indem Proben und Kontrolle zeitlich und räumlich getrennt voneinander pipettiert wurden, d.h. erst nachdem die Individuenproben fertig angesetzt und verschlossen waren, wurden die Positivkontrollen in einem anderen Raum pipettiert. Alle diese Ergebnisse und Vorsichtsmaßnahmen authentifizieren die positiven Nachweise in den Extrakten, so dass davon ausgegangen werden kann, dass zumindest ein Teil der Individuen mit Bartonella quintana und / oder Salmonella typhi infiziert war. Die Interpretation negativer Ergebnisse ist weniger eindeutig.

"The absence of evidence is not the evidence of absence."

- Carl Sagan, Comlos

Die Tatsache, dass nur bei wenigen Individuen Bartonella und Salmonella nachgewiesen werden konnte, bedeutet nicht, dass die übrigen Individuen nicht infiziert gewesen sein könnten. Es ist durchaus möglich, dass die Zielsequenz in so geringen Mengen vorliegt, dass sie nicht mehr nachgewiesen werden kann bzw. durch DNADegradierung keine intakten Zielsequenzen mehr vorliegen. Dasselbe gilt auch für die anderen untersuchten Bakterienspezies, die nicht nachgewiesen werden konnten. Dass die erfolgreiche Amplifikation in zwei Fällen nur nach mehreren Versuchen und in einem Fall gar nicht reproduzierbar war, spricht dafür, dass in den Extrakten sehr wenige intakte Zielsequenzen vorliegen und die Menge an Erreger-DNA knapp oberhalb der Nachweisgrenze liegt. Die erfolgreiche Amplifikation nach Beladen von Proben mit sehr wenig rezenter Bakterien-DNA zeigt, dass in den Extrakten keine bzw. wenig Inhibitoren vorliegen. Die Wahrscheinlichkeit eines falsch-negativen Ergebnisses aufgrund von PCR-Inhibitoren ist daher gering, da jedoch nicht alle Extrakte explizit getestet wurden, kann dies nicht völlig ausgeschlossen werden.

Im Weiteren ist aber auch denkbar, dass die gesuchte Zielsequenz bzw. die Primerbindungsstellen in den historischen Bakterienstämmen abweichend vorlagen. Da die Mutationsrate von Bakterien im Allgemeinen höher ist als bei eukaryotischen Organismen, könnten in 200 Jahren erheblich mehr Mutationen aufgetreten sein, die auch als konservativ geltende Gene betroffen haben könnten. Das Testen mit mehreren Primern für verschiedene Genorte einer Spezies könnte dabei die Wahrscheinlichkeit eines falsch-negativen Ergebnisses aufgrund von Mutationsereignissen stark verringern. Aus Zeit- und Kostengründen wurde in dieser Arbeit jedoch darauf verzichtet.

Zwar ist die ultimative Todesursache nicht mehr zu rekonstruieren, jedoch gibt die Anwesenheit von Humanpathogenen entscheidende Hinweise. Heutzutage zählen Bartonellen und Salmonellen aufgrund der enormen Fortschritte in der Medizin zu den weniger tödlichen Fiebererkrankungen, für geschwächte Menschen ist die Erkrankung jedoch immer noch ernst. Besonders das lang anhaltende Fieber stellt ohne entsprechende Gegenmaßnahmen eine Gefahr dar. Der allgemein schlechte Zustand der Individuen ist anhand der gefundenen morphologischen Auffälligkeiten gut do- 
kumentiert. Unter diesen Umständen stellt eine Infektion mit Bartonella quintana oder Salmonella typhi ein großes Risiko dar. In diesem Zusammenhang ist auch die Beschreibung der Symptomatik des Nervenfiebers interessant, das vom zuständigen Arzt als ,äußert ansteckend und gutartig“ beschrieben wurde (vgl. Kap. 1.1.). Gerade die Beschreibung als gutartig könnte ein Hinweis auf eine Bartonelleninfektion geben, da anscheinend zwar viele Individuen infiziert, aber verhältnismäßig wenig daran verstorben waren. Eine Infektion mit einem tödlicheren Bakterium, etwa Rickettsia prowazekii, wäre wahrscheinlich nicht als gutartig klassifiziert worden.

Bartonella und Salmonella nutzen dabei unterschiedliche Übertragungswege für eine Infektion, die jedoch beide aus schlechten hygienischen Bedingungen resultieren. Während Bartonella die Kleiderlaus für eine Infektion nutzt, findet eine Übertragung von Salmonella hauptsächlich über kontaminierte Lebensmittel statt. Da die Zustände im Notlazarett katastrophal gewesen sein müssen (vgl. Kap. 1.1.), können beide Übertragungswege plausibel nachvollzogen werden. Raoult et al. wiesen 2006 neben Bartonella auch Rickettsia prowazekii-DNA in napoleonischen Truppen nach, was die simultane Anwesenheit von mehreren Bakterienspezies in der Armee belegt. Die zeitliche und räumliche Trennung der untersuchten Individuen aus Kassel zu den Individuen aus Vilnius lässt es plausibel erscheinen, dass nicht unbedingt dieselben Bakterien in beiden Truppenteilen vertreten waren. Gerade das tödlichere Rickettsia könnte durch seine Aggressivität im Gegensatz zum ungefährlicheren Bartonella einen Nachteil in der Ausbreitung gehabt haben. Da Bartonella bei großen Truppenbewegungen durch den allgemeine Läusebefall massenhaft auftrat (belegt ist dies z.B. im 1. Weltkrieg, Karem et al. 2000), könnte es auch bei napoleonischen Truppen ein generelles Phänomen gewesen sein. Im Gegensatz dazu könnte Salmonella durch seinen Übertragungsweg spezifisch für das Kasseler Kollektiv sein. Aufgrund der ähnlichen Symptomatik und der bruchstückhaften Überlieferungen kann zu diesem Zeitpunkt jedoch nicht gesagt werden, ob eines, und wenn ja welches, der Bakterien der Hauptverursacher des tödlichen Typhus-Ausbruchs gewesen ist.

Außerdem könnten weitere Erkrankungen im Notlazarett eine Rolle gespielt haben, die nicht im Zuge dieser Arbeit untersucht worden sind. Einen Untersuchungsansatz könnten die neuen Sequenziermethoden des Next-Generation-Sequencing liefern. Gerade bei sehr wenig DNA und starker Fragmentierung bieten diese Methoden entscheidende Vorteile gegenüber den PCR-gestützten Amplifikationen. 


\section{Zusammenfassung}

Im Januar 2008 stießen Bauarbeiter auf dem Gelände der Universität Kassel auf ein Massengrab, dessen Existenz und Geschichte in Vergessenheit gerieten war. Nur mit Hilfe von ersten wissenschaftlichen Analysen und Indizien aus der Stadtgeschichte konnte die These aufgestellt werden, dass es sich bei den Individuen um napoleonische Soldaten handelt, die vermutlich in einem Notlazarett an einer Epidemie eines „Nervenfiebers“ verstorben waren. Die Individuen wurden unsachgemäß geborgen und in sechs Särgen auf dem Hauptfriedhof von Kassel wiederbestattet.

In dieser Arbeit war es möglich, zum ersten Mal die Knochenfunde aus Kassel in ihrer Gesamtheit wissenschaftlich-anthropologisch zu untersuchen. Die ultimativen Ziele dabei waren, Hinweise auf die Identität der Toten, Lebensumstände und mögliche Todesursachen zu finden und somit die aufgestellten Thesen zu untermauern oder zu widerlegen. Insgesamt kamen verschiedenste Methoden, von der klassischmorphologischen Begutachtung über histologische Untersuchungen bis zu molekulargenetischen Analysen, zum Einsatz.

Nach den vorbereitenden Maßnahmen zeigte sich, dass anstatt der aus Presseberichten erwarteten 60 Individuen insgesamt mindestens 126 Individuen dort bestattet lagen. Die große Mehrheit der Individuen waren Männer in den Altersklassen frühes bis mittleres Adultas, wobei sich auch mindestens eine junge Frau im Massengrab befand. Die mittlere Körperhöhe entsprach denen einer Bevölkerung aus dem frühen 19. Jahrhundert.

Während eine Vielzahl von individualspezifischen Pathologien gefunden wurde, treten einige Diagnosen deutlich gehäuft auf. Dazu gehören u.a. periostale Reaktionen der unteren Extremitäten, degenerative Veränderungen an Wirbeln, Belastungserscheinungen an Claviculae, Cribra orbitalia und Zahnpathologien. Die Veränderungen zeigen deutlich, dass die Individuen unter physischem Stress bzw. Dauerbelastung sowie vermutlich schlechten hygienischen Bedingungen und z.T. unter Mangelernährung gelitten haben, was sich mit Berichten über das militärische Leben im frühen 19. Jahrhundert deckt.

Insgesamt konnten von 109 Individuen vollständige autosomale STR-Profile generiert werden. Dabei zeigte sich, dass diese Systeme im Hardy-WeinbergGleichgewicht liegen und daher die Individuen als männliche Bevölkerungsstichprobe gesehen werden können. Die Frequenzen der autosomalen Allele zeigten in einigen Fällen signifikante Abweichungen zu den Frequenzen ost-, süd- und nordeuropäischer Vergleichspopulationen. Von 101 Individuen konnten vollständige YHaplotypen generiert werden, wobei das in dieser Analyse längste System DYS389II aus der weiteren Auswertung herausgelassen wurde. Die statistische Auswertung mit der Grundannahme einer gemeinsamen Herkunft zeigte, dass die Individuen des Massengrabs den heutigen Bevölkerungen der Beneluxländer und des östlichen Frankreichs am ähnlichsten sind. Es bestehen signifikante Unterschiede zu rezenten 
Populationen östlich des Rheins und Südeuropas. Damit konnte eine nicht lokale Herkunft der Individuen gezeigt und die Herkunft auf ein Gebiet westlich des Rheins belegt werden.

Der Nachweis von humanpathogenen Bakterien-Sequenzen in DNA-Extrakten der Individuen zeigte, dass die Individuen zu Lebzeiten mit Erregern infiziert waren, die zur damaligen Zeit unter der Sammeldiagnose „Typhus“ zusammengefasst waren. In einigen Extrakten konnte dabei Bartonella quintana gefunden werden, das durch die Kleiderlaus übertragen wird und der Auslöser des Fünf-Tage-Fiebers ist. Das Bakterium war bereits in früheren Zusammenhängen mit napoleonischen Truppen nachgewiesen worden und auch war bei Soldaten der Weltkriege weit verbreitet. In einem weiteren Extrakt wurde Salmonella typhi bzw. Salmonella enterica spec. identifiziert, das hauptsächlich durch kontaminierte Lebensmittel übertragen wird und den heute so bezeichneten Typhus hervorruft. Durch das gemeinsame Auftreten von mehreren Bakterien im Kasseler Kollektiv kann nicht geklärt werden, ob und welches Bakterium der Hauptauslöser des historischen Nervenfiebers im Notlazarett gewesen ist.

Alle Ergebnisse zeigen ein sehr detailliertes Bild der Individuen aus dem Massengrab und decken sich mit den Informationen der Historiker, die parallel zu dieser Arbeit gefunden worden sind: Demnach empfahl Napoleon Bonaparte kurz vor seiner Niederlage im Jahr 1813 seinem Bruder Jerôme in Kassel, aufgrund der unsicheren Lage elsässische und luxemburgische Truppen zu seinem Schutz in die Stadt zu holen. Nach Jerômes Flucht und dem Zusammenbruchs des Königreichs waren die Soldaten Kriegsgefangene in der Stadt, die gleichzeitig Ort enormer Truppenbewegungen war. Durch mangelnde Hygiene und schlechte medizinische Versorgung brach im eingerichteten Notlazarett, das sich in der Nähe des Auffindeorts des Massengrabs befand, ein hochansteckendes „Nervenfieber“ aus.

Die vorliegende Arbeit trug somit entscheidend dazu bei, die Identität der Toten, ihre Lebens- und Todesumstände abschließend zu klären. 


\section{Literatur}

Acsadi G, Nemeskeri J (1970) History of human life span and mortality. Akademiai Kiado, Budapest

Adler CP (1983) Knochenkrankheiten. Georg-Thieme-Verlag Springer, Berlin, Heidelberg, New York.

Alcantara V, Rolain J-M, Eduardo AG, Raul MJ, Raoult D (2009) Molecular detection of Bartonella quintana in human body lice from Mexico City. Europ Soc Clin Microbiol Infect Dis, Vol. 15 (Suppl. 2), 93-94.

Alonso A, Andelinovic S, Martin P et al. (2001) DNA typing from skeletal remains: Evaluation of multiplex and megaplex STR systems on DNA isolated from bone and teeth samples. CMJ 42:260-6.

Ambrosio B, Dugoujon JM, Hernandez C, et al. (2010) The Andalusian population from Huelva reveals a high diversification of Y-DNA paternal lineages from haplogroup E: Identifying human male movements within the Mediterranean space. Ann Hum Biol 37 (1): 86 - 107.

Araujo A, Ferreiraet LF, Guidon N, Maues Da Serra Freire N, Reinhard KJ, Dittmar K (2000) Ten thousand years of head lice infection. Parasitol Today 16(7):269.

Athey TW (2005) Haplogroup Prediction from Y-STR Values Using an AlleleFrequency Approach. J Genet Geneal 1:1-7.

Athey TW (2006) Haplogroup Prediction from Y-STR Values Using a BayesianAllele-Frequency Approach. J Genet Geneal 2:34-39.

Baca M, Doan K, Sobczyk M, Stankovic A, Weglenksi P (2012) Ancient DNA reveals kinship burial patterns of a pre-Columbian Andean community. BMC Geneti 13:30.

Badro DA, Douaihy B, Haber M et al. (2013) Y-chromosome and mtDNA genetics reveal significant contrasts in affinities of modern Middle Eastern populations with European and African populations. PloS One 8(1):e54616.

Bär W, Brinkmann B, Budowle B, Carracedo A, Gill P, Lincoln P, Mayr W, Olaisen B (1997) DNA recommendations. Further report of the DNA Commission of the ISFH regarding the use of short tandem repeat systems. Int. J. Legal Med 110: $175-176$.

Balanovsky O, Rootsi S, Pshenichnov A, Kivisild T, Churnosov M, Evseeva I, Pocheshkhova E, Boldyreva M, Yankovsky N, Balanovska E, Villems R (2008) 
Two sources of the Russian patrilineal heritage in their Eurasian context. Am J Hum Genet 82(1):236-50.

Baron H, Hummel S, and Herrmann B. (1996) Mycobacterium tuberculosis Complex DNA in Ancient Human Bones. J Archaeo Sci 23: 667-671.

Behar DM, van Oven M, Rosset S, Metspalu M, Loogväli EL, Silva NM, Kivisild T, Torroni A, Villems R (2012) A "Copernican" reassessment of the human mitochondrial DNA tree from its root. Am J Hum Genet 90(4):675-684.

Blaze E (ohne Jahresangabe) Souvenirs d'un Officier de la Grande Armée. Fayard P.s.d., Paris.

Bornman DM, Hester ME, Schuetter JM, Kasoji MD et al. (2013) Short-read, highthroughput sequencing technology for STR genotyping. BioTechniques Rapid Dispatches DOI: 10.2144/000113857.

Bos KI, Schuenemann VJ, Golding GB et al. (2011) A draft genome of Yersinia pestis from victims of the Black Death. Nature 478(7370):506-10.

Bouakaze C, Keyser C, Crubezi e, Montagnon D, Ludes B (2009) Pigment phenotype and biogeographical ancestry from ancient skeletal remains: inferences from multiplexed autosomal SNP analysis. Int J Lega Med 123:315-25.

Bramanti B, Thomas MG, Haak W, et al. (2009) Genetic discontinuity between local hunter-gatherers and central Europe's first farmers. Science 326(5949):137-40.

Brankatschk K, Blom J, Goesmann A, Smits THM, Duffy B (2011) Genome of a European Fresh-Vegetable Food Safety Outbreak Strain of Salmonella enterica subsp. enterica Serovar Wetefreden. J Bacteriol 193(8): 2066.

Brisighelli F, Álvarez-Iglesias V, Fondevila M, Blanco-Verea A, Carracedo A, Pascali VL, Capelli C, Salas A (2012) Uniparental markers of contemporary Italian population reveals details on its pre-Roman heritage. PloS One 7(12):e50794.

Brothwell DR (1972) Digging up bones: The excavation, treatment and study of human skeletal remains. Trustees of the British Museum, London.

Brouqui P, Lascola B, Roux V, Raoult D (1999) Chronic Bartonella quintana bacteremia in homeless patients. N Engl J Med. 340:184-9.

Butler JM (2005) Forensic DNA typing. Academic Press, London. 
Capelli C, Tschentscher F, Pascali VL (2003) "Ancient" protocols for the crime scene? Similarities and differences between forensic genetics and ancient DNA analysis. Forensic Science International 131:59-64.

Carli-Thiele P (1996) Spuren von Mangelerkrankungen an steinzeitlichen Kinderskeletten. Fortschritte in der Paläopathologie und Osteoarchäologie. Goltze, Göttingen.

Cavalli-Sforza, L Edwards AW (1967) Phylogenetic analysis. Models and estimation procedures. Am.J.Hum.Genet. 19 [3]: 233-257.

Cooper A und Poinar HN (2000) Ancient DNA: Do it right or not at all. Science 289:1139.

Csanyi B, Bogacsi-Szabo E, Tömory G (2008) Y-Chromosome Analysis of Ancient Hungarian and Two Modern Hungarian-Speaking Populations from the Carpathian Basin. Ann Hum Genet 72, 519 - 534.

Czarny J, Grzybowksi T, Derenko M V, Malyarchuk B A, Sliwka D M (2005) Genetic variation of 15 STR loci (D3S1358, vWA, FGA, TH01, TPOX, CSF1PO, D5S818, D13S317, D7S820, D16S539, D2S1338, D8S1179, D21S11, D18S51, and D19S433) in populations of north and central Poland. Forensic Sci Int, Vol. 147 , Issue 1, $97-100$

Deguilloux MF, Soler L, Pemonge MH, Scarre C, Joussaume R, Laporte L (2011) News from the West: ancient DANN from a French megalithic burial chamber. Am J phys Anthropol 144(1):108-18.

Der Sarkissian C, Balanovski O, Brandt G et al. (2013) Ancient DNA reveals prehistoric gene-flow from siberia in the complex human population history of north East europe. PloS Genet 9(2):e1003296.

Dicks E (2012) Geschlechtsbestimmung isolierter Skelettelemente eines neuzeitlichen katholischen Friedhofs aus Göttingen mit einer Multiplex X/Y-PCR. Bachelorarbeit, Biologische Fakultät der Universität Göttingen.

Donoghue HD, Spiegelman M, Greenblatt CL et al. (2004) Tuberculosis: from prehistory to Robert Koch, as revealed by ancient DNA. Lancet Infect Dis. 4 (9):584-92.

Drancourt M, Tran-Hung L, Courtin J, Lumley Hd, Raoult D (2005) Bartonella quintana in a 4000-year-old human tooth. J Infect Dis 191(4):607-11. 
Egyed B, Füredi S, Angyal M, Balogh I, Kalmar L, Padar Z (2006a) Analysis of the population heterogeneity in Hungary using fifteen forensically informative STR markers Forensic Science International, Vol. 158, Issue 2, 244 - 249.

Egyed B, Füredi S, Padar Z (2006b) Population genetic study in two Transylvanian populations using forensically informative autosomal and Y-chromosomal STR markers. Forensic Science International, Vol. 164, Issue 2, 257 - 265.

Eickhoff F, Schopper S (2012) 1636- ihre letzte Schlacht: Leben im dreißigjährigen Krieg. Theiss. Stuttgart.

Excoffier L, Smouse PE, Quattro JM (1992) Analysis of molecular variance inferred from metric distances among DNA haplotypes: application to human mitochondrial DNA restriction data. Genetics 131 [2]: 479-491.

Excoffier L, Schneider S (2005) Arlequin ver. 3.0: An integrated software package for population genetics data analysis. Evolutionary Bioinformatics Online 1:4750 .

Fehren-Schmitz L, Reindel M, Cagigao ET, Hummel S, Herrmann B (2010) PreColumbian population dynamics in coastal southern Peru. A diachronic investigation of mtDNA pattern in the Palpa region by ancient DNA analysis. Am J Phys Anthropol 141(2):208-221.

Fehren-Schmitz L, Warnberg O, Reindel M, Seidenberg V, Tomasto-Cagigao E, IslaCuadrado J, Hummel S, Herrmann B (2011) Diachronic investigations of mitochondrial and Y-chromosomal genetic markers in pre-Columbian Andean highlanders from South Peru. Ann Hum Genet 75(2):266-83.

Flores C, Maca-Meyer N, González AM, Oefner PJ, Shen P, Pérez JA, Rojas A, Larruga JM, Underhill PA (2004) Reduced genetic structure of the Iberian peninsula revealed by $\mathrm{Y}$-chromosome analysis: implications for population demography. Eur J Hum Genet 12(10):855-63.

Flux AL (2013) Rekonstruktion von Wirbelsäulen zur Erfassung degenerativer und pathologischer Prozesse in der frühneuzeitlichen Skelettserie Kassel. Bachelorarbeit, Biologische Fakultät der Georg-August-Universität, Göttingen.

Fornaciari G, Giuffra V, Ferroglio E, Bianucci R (2010) Malaria was “the killer” of Francesco I de' Medici (1531-1587). Am J Med 123(6):586-9.

Foucault C, Brouqui P, Raoult D (2006) Bartonella quintana Characteristics and Clinical Management. Em Infect Dis, Vol. 12, No. 2, 217 - 223. 
Frances F, Portoles O, Gonzalez JI, Coltell O, Verdu F, Castello A, Corella D (2007) Amelogenin test: From forensics to quality control in clinical and biochemical genomics. Clin Chim Acta. 386 (1-2):53-6.

Fu Y, Xie C, Xu X et al. (2009) Ancient DNA Analysis of Human Remains From the Upper Capital City of Kublai Khan. Am J Phys Anthro 138:23 - 29.

Fu Q, Rudan P, Pääbo S, Krause J (2012) Complete mitochondrial genomes reveal neolithic expansion into Europe. PloS One 7(3):e32473.

Gaiber M, Esteban E, Moral P, et al. (2010) STR genetic diversity in a Mediterranean population from the south of the Iberian Peninsula. Ann Hum Bio 37(2):256-66.

Garrigan D, Hammer M F (2006) Reconstructing human origins in the genomic era. Nature reviews Genetics 7:669-680.

Gill JH (1998) A Soldier for Napoleon. The Campaigns of Lieutenant Franz Joseph Hausmann $-7^{\text {th }}$ Bavarian Infantry. Greenhill Books, London.

Gilbert MTP, Drautz DI, Lesk AM et al. (2008) Intraspecific phylogenetic analysis of Siberian woolly mammoths using complete mitochondrial genomes. PNAS 105:8327-8332.

Goodwin W, Linacre A, Hadi S (2011) An Introduction to Forensic Genetics. WileyBlackwell, Chichester, UK.

Großkopf B (2004) Leichenbrand - Biologisches und kulturhistorisches Quellenmaterial zur Rekonstruktion vor- und frühgeschichtlicher Populationen und ihrer Funeralpraktiken. Dissertation, Fakultät für Geschichte, Kunst- und Orientwissenschaften, Universität Leipzig.

Grumbkow P (2010) Molekulargenetische Analysen zur Identifikation einer Gruppe von Bestatteten aus einem Massengrab in Kassel / Hessen. Diplomarbeit, Biologische Fakultät, Georg-August-Universität Göttingen.

Grumbkow P, Zipp A, Seidenberg V, Fehren-Schmitz L, Kempf VAJ, Groß U, and Hummel S (2011) Evidence of Bartonella quintana infections in skeletons of a historical mass grave in Kassel, Germany. Am J Physic Anthro 146(1):134-7.

Grumbkow P, Zipp A, Großkopf B, Fueldner K, and Hummel S (2012) Analyses to help identify individuals from a historical mass grave in Kassel, Germany. Anthropol Anz Vol 69 (1):1-43 
Grugni V, Battaglie V, Hooshiar Kashani B et al. (2012) Ancient migratory events in the Middle East: new clues from the Y-chromosome variation of modern Iranians. PloS One (7):e41252.

Grupe G, Christiansen K, Schröder I, Wittwer-Backofen U (2005) Anthropologie. Einführendes Lehrbuch. Springer, Berlin, Heidelberg.

Haak W, Forster P, Bramanti B et al. (2005) Ancient DNA from the first European farmers in 7500-year-old Neolitic sites. Science 310:1016-1018.

Haak W, Balanovsi O, Sanchez JJ et al. (2010) Ancient DNA from European early neolithic farmers reveals their near eastern affinities. PloS One 8(11):e1000536.

Haas CJ, Zink A, Palfi G, Szeimies U, Nerlich AG (2000) Detection of leprosy in ancient human skeletal remains by molecular identification of Mycobacterium leprae. Am J Clin Pathol 114(3):428-36.

Haensch S, Bianucci R, Signoli M et al. (2010) Distinct clones of Yersinia pestis caused the black death. PLoS Pathog 6(10):e1001134.

Hagelberg E, Sykes B, Hedges R (1989) Ancient bone DNA amplified. Nature 342:485-485.

Harper KN, Zuckerman MK, Harper ML, Kingston JD, Armelagos GJ (2011) The Origin and Antiquity of Syphilis Revisited: An Appraisal of Old World PreColumbian Evidence for Treponemal Infection. Yearbook of Physical Anthropology, 54, 99-133.

Hawass Z, Ismail S. Selim A, et al. (2012) Revisiting the harem conspiracy and death of Ramesses III: anthropological, forensic, radiological, and genetic study. BMJ 345:e8268.

Herrmann B, Grupe G, Hummel S, Piepenbrink H, Schutkowski H (1990) Prähistorische Anthropologie: Leitfaden der Feld- und Labormethoden. Springer Verlag, Berlin, Heidelberg.

Herrmann B und Hummel S (Hrsg.) (1993) Ancient DNA. Springer, New York, Berlin, Heidelberg.

Hervella M, Izagirre N, Alonso S, Fregel R, Alonso A, Cabrera VM, de la Rua C (2012) Ancient DNA from hunter-gatherer and farmer groups from Northern Span supports a random disersion model fort he Neolithic expansion into Europe. PloS One 7(4):e34417.

Hofreiter M, Serre D, Peonar HN et al. (2001) Ancient DNA. Nat Rev Genet 2:3539. 
Hofreiter M, Münzel S, Conard NJ et al. (2007) Sudden replacement of cave bear mitochondrial DNA in the late Pleistocene. Curr Biol 17:R122-3.

Holtmeyer A (1923) Die Bau- und Kunstdenkmäler im Regierungsbezirk Cassel, Kreis Cassel-Stadt (Band 6). Marburg

Holzgräfe M (2013) Genetic examination of morphologically assigned skeletal elements from an early modern mass grave in Kassel/ Hesse. Masterarbeit, Biologische Fakultät der Georg-August-Universität, Göttingen.

Huhn, S (2008) Woher stammten die Lübecker? Bestimmung der regionalen Herkunft männlicher Individuen aus zwei hochmittelalterlichen Skelettkollektiven der Hansestadt Lübeck durch die Analyse von Y-STR Haplotypen. Diplomarbeit, Biologische Fakultät der Georg-August-Universität, Göttingen.

Hummel S, Herrmann B (1991) Y-Chromosome specific DNA Amplified in Ancient Human Bone. Naturwissenschaften 78:266-267.

Hummel S (2003) Ancient DNA Typing. Methods, Strategies, and Applications. Springer, New York, Berlin, Heidelberg.

Hunger H (1978) Liegezeitbestimmung an Skelettfunden im Erdboden. In: Leopold D, Hunger H (Hrsg.) Identifikation. Springer, Berlin, Heidelberg, New York.

Karem KL, Paddock CD, Regnery RL (2000) Bartonella henselae, B. quintana, and B. bacilliformes: historical pathogens of emerging significance. Microbes Infect 2:1193-1205.

Kayser M, Roewer L, Hedman M et al. (2000) Characteristics and frequency of germline mutations at microsatellite loci from the human $\mathrm{Y}$ chromosome, as revealed by direct observation in father/son pairs. Am J Hum Genet 66:15801588.

Kayser M, Lao O, Anslinger K, Augustin C, Bargel G, Edelmann J, Elias S, Heinrich M, Henke J, Henke L, Hohoff C, et al. (2005) Significant genetic differentiation between Poland and Germany follows present-day political borders, as revealed by Y-chromosome analysis. Hum Genet 117(5):428-43.

Keller A, Graefen A, Ball M et al. (2012) New insights into the Tyrolean iceman's origin and phenotype as inferred by whole-genome sequencing. Nat Commun 3:698.

Khairat R, Ball M, Chang CC, Bianucci R, Nerlich AG, Trautmann M, Ismail S, Shanab GM, Karim AM, Gad YZ, Pusch CM (2013) First insights into the 
metagenome of Egyptian mummies using next-generation sequencing. J Appl Genet. DOI. 10.1007/s13353-013-0145-1

Kim NY, Lee HY, Park MJ, Yang WI, Shin KJ (2011) A genetic investigation of Korean mummies from the Joseon Dynasty. Mol Biol Rep 38(1):115-21.

King T, Humphrey LT, Hillson S (2005) Linear enamel hypoplasias as indicators of systemic physiological stress: evidence from two known age-at-death and sex populations from postmedieval London. Am J Phys Anthropol 128(3):547-59.

King TE, Parkin EJ, Swinflied G et al. (2007) Africans in Yorkshire? The deepestrooting clade of the Y phylogeny within an English genealogy. Eur J Hum Genet 15(3):288-93.

Kitchin P A, Szotyori Z, Fromholc C, Almond N (1990) Avoidance of false positives. Nature 344: 201.

Koeppen AH (2011) Friedreich's ataxia: pathology, pathogenesis, and molecular genetics. In: Journal of the neurological sciences 303 (1-2): 1-12.

Komlos J (1994) Stature, Living Standards, and Economic Development: Essays in Anthropometric History. University of Chicago Press, Chicago.

Komlos J, Cinnirella F (2005) European Heights in the Early 18th Century. Munich discussion Paper No. 2005-5. Online at http://epub.ub.uni-muenchen.de/572/

Kostrzewski J (1949) The epidemiology of trench fever. Bull Acad Pol Sci (Med) 7:233-63.

Kwok S (1990) Procedures to minimize PCR-product carry-over. In: Innis M A, Gelfand D, Sninsky J J, White T J (eds.) PCR protocols: A guide to methods and applications. Academic Press, San Diego, S. 142 - 145.

Lacan M, Keyser C, Ricout FX, Brucato N, Tarru J, Bosch A, Guilaine J, Crubzy E, Ludes B (2011) Ancient DNA suggests theleading role played by men in the Neolithic dissemination. PNAS 108(45):18255-9.

Larmuseau MHD, Vanderheyden N, Jacobs M, Coomans M, Larno L, Decorte R (2011) Micro-geographic distribution of Y-chromosomal variation in the centralwestern European region Brabant. Forensic Sci Int: Genetics 5: 95-99.

Lassen C, Hummel S, Herrmann B (2000) Molecular sex identification of stillborn and neonate individuals ("Traufkinder") from the bural site Aegerten. Anthropol Anz 58:1-8. 
Lee EJ, Makarewicz C, Renneberg R et al. (2012) Emerging genetic patterns of the European Neolithic: perspectives from a late Neolithic Bell Beaker burial site in Germany. Am J Phys Anthropol 148(4):571-9.

Lell JT, Wallace DC (2000) The Peopling of Europe from the Maternal and Paternal Perspectives. Am J Hum Genet 67:1376 - 1381.

Li H, Zhao X, Zhao Y, Li C, Si D, Zhou H, Cui Y (2011) Genetic characteristics and migration history of a bronze culture population in the West Liao-River valley revealed by ancient DNA. J Hum Genet 56(12):815-22.

Linz U, Degenhardt H (1990) Die Polymerase-Kettenreaktion - Ein Überblick. Naturwissenschaften 77: 515-530.

Loogväli E-L, Roostalu U, Malyarchik BA, (2004) Disuniting Uniformity: A Pied Cladistic Canvas of mtDNA Haplogroup H in Eurasia. Mol Biol and Evol 21 (11): $2012-2021$.

Martin R, Saller K (1959) Lehrbuch der Anthropologie. Fischer, Stuttgart.

Matheson CD, Vernon KK, Lahti A, Fratpietro R et al. (2009) Molecular exploration of the first-century Tomb of the Shroud in Akeldama, Jerusalem. PLoS One 4 (12):e8319.

Mayer, KJ (2008) Napoleons Soldaten. Alltag in der Grande Armée. Geschichte erzählt: Bd. 12, 1. Auflage, Primus Verlag, Seite 7.

Melchior L, Kivilsild T, Lynnerup N, Dissing J (2008) Evidence of authentic DNA from Danish Viking Age skeletons untouched by humans for 1,000 years. PloS One 3(5):e2214.

Melchior L, Lynnerup N, Siegismund HR, et al. (2010) Genetic Diversity among Ancient Nordic Populations. PLoS One 5(7):e11898.

Moodley Y, Linz B, Yamaoka Y et al. (2009) The peopling of the Pacific from a bacterial perspective. Science 323(5913):527-30.

Müller-Scholtz S (2003) “Genetische Spurensuche” in Rumänien. Untersuchung und genetische Charakterisierung humaner Populationen aus Rumänien und Sibirien mit drei polymorphen autosomalen DNS-Markern. Dissertation. Universität Hamburg.

Nakahori Y, Takenaka O, Nakagome Y (1991) A human X-Y homologous region encodes "amelogenin". Genomics 9(2):264-9. 
Nerlich AG, Schraut B, Dittrich S, Jelinek T, Zink AR (2008) Plasmodium falciparum in ancient Egypt. Emerg Infect Dis 14(8):1317-9.

Nerlich AG und Lösch S (2009) Paleopathology of human tuberculosis and the potential role of climate. Interdiscip Perspect Infect Dis. 2009:437187. Epub 2009 Apr 5.

Nguyen-Hieu T, Aboudharam G, Signoli M, Rigeade C, Drancourt M, Raoult D (2010) Evidence of a louse-borne outbreak involving tyhus in Douai, 1710 - 1712 during the war of Spanish succssion. PloS One 5(10): e15405.

Nikitin AG, Newton JR, Potekhina ID (2012) Mitochondrial haplogroup C in ancient mitochondrial DNA from Ukraine extends the presence of East Eurasian genetic lineages in Neolithic Central and Eastern Europe. J Hum Genet 57(9):610-2.

Noveletto A (2007) Y chromosome variation in Europe: Continental and local processes in the formation of the extant gene pool. Ann Hum Biol 34 (2): 139 172.

Novontny V (1972) Geschlechtsmerkmale und Geschlechtsbestimmung auf dem Hüftbein (Os coxae). Konference europskych antrop, 21 p, Prag.

Nunez C, Sosa C, Baeta M et al. (2011) Genetic analysis of 7 medieval skeletons from the Aragonese Pyrenees. Croat Med J 52(3):336-43.

Ohta T, Kimura M (1973) A model of mutation appropriate to estimate the number of electrophoretically detectable alleles in a genetic population. Genet. Res. 22: 201-204.

Ortner DJ (2003) Identification of Pathological Conditions in Human Skeletal Remains. Academic Press, London, San Diego.

Pala M, Olivieri A, Achilli A et al. (2012) Mitochondrial DNA signals of late glacial recolonization of Europe from near eastern refugia. Am J Hum Genet 90(5):91524.

Palfi G, Bereczki Z, Ortner DJ, Dutour O (2012) Juvenile cases of skeletal tuberculosis from the Terry Anatomical Collection (Smithsonian Institution, Washington, D.C., USA). Acta Biologica Szegediensis 56(1):1-12.

Palubeckaite Z, Jankauskas R, Ardagna Y, Macia Y, Rigeade C, Signoli M, Dutour O (2006) Dental Status of Napoleon's Great Army's (1812) Mass Burial of Soldiers in Vilnius: Childhood Peculiarities and Adult Dietary Habits. Int J Osteoarchaeology 16: 355-365. 
Papagrigorakis MJ, Yapijakis C, Synodinos PN, Baziotopoulou-Valavani E (2006) DNA examination of ancient dental pulp incriminated typhoid fever as a probable cause of the Plague of Athens. Int J Infect Dis 10(3):206-14.

Papagrigorakis MJ, Synodinos PN, Yapijakis C (2007) Ancient typhoid epidemic reveals possible ancestral strain of Salmonella enterica serovar Typhi. Infect Genet Evol 7(1):126-7.

Pearson K (1899) Mathematical contributions to the theory of evolution. V. On the reconstruction of the stature of prehistoric races. Phil Transact R Soc London. Ser A vol 192: 169-245.

Pereira L, Prata M J, Amorim A (2000) Diversity of mtDNA lineages in Portugal: not a genetic edge of European variation. Ann Hum Genet 64 (Pt 6):491 - 506.

Pereira R, Phillips C, Pinto N, Santos C, dos Sontos SE, Amorim A, Carracedo A, Gusmao L (2012) Straightforward inference of ancestry and admixture proportions through ancestry-informative insertion deletion multiplexing. PloS One 7(1):e29684.

Pfister D (2008) Entwicklung einer Multiplex-PCR zur Typisierung der STR-Marker FGA, SE33, TH01, D18S51 und D21S11 in stark degradiertem und forensischem Probenmaterial. Diplomarbeit, Biologische Fakultät, Georg-August-Universität Göttingen.

Piderit, F C T (1844) Geschichte der Haupt- und Residenzstadt Kassel. Druck von Döll und Schäfer, Kassel (online).

Pilkington MM, Wilder JA Mendez FL et al. (2008) Contrasting signatures of population growth for mitochondrial DNA and Y chromosomes among human populations in Africa. Mol Biol Evol 25: 517-525.

Povacz F (2007) Geschichte der Unfallchirurgie. Springer Verlag, Berlin, Heiderlberg, New York.

Preacher, KJ (2001) Calculation for the chi-square test: An interactive calculation tool for chi-square tests of goodness of fit and independence [Computer software]. Available from http://quantpsy.org.

Quosigk E (2013) Typification of Y-chromosomal markers to determine regional origin of isolated long bones from an early modern mass grave in Kassel/Hesse. Masterarbeit, Biologische Fakultät der Georg-August-Universität, Göttingen. 
Ramos-Luis E, Blanco-Verea A, Brion M, Van Huffel V, Carracedo A, Sanchez-Diz P (2009) Phylogeography of French male lineages. Forensic Sci Int: Genetics Suppl Series 2: 439-441.

Raoult D, Dutour O, Houhamdi L, et al. (2006) Evidence for Louse-Transmitted Diseases in Soldiers of Napoleon's Grand Army in Vilnius. J Infect Dis 193:11220.

Rauch E, Rummel S, Lehn C, Büttner A (2007) Origin assignment of unidentified corpses by use of stable isotope ratios of light (bio-) and heavy (geo-) elements a case report. Forensic Sci Int. 168 (2-3): 215-8.

Rebala K, Mikulich AI, Tsybovsky IS, Sivakova D, Dzupinkova Z, SzczerkowskaDobosz A, Szczerkowska Z (2007) Y-STR variation among Slavs: evidence for the Slavic homeland in the middle Dnieper basin. J Hum Genet 52(5):406-14.

Regueiro M Rivera L, Damnjanovic T, Lukovic L, Milasin J, Herrera RJ (2012) High levels of Paleolithic Y-chromosome lineages characterize Serbia. Gene 498(1):597.

Reich D, Green RE, Kircher M et al. (2010) Genetic history of an archaic hominin group from Denisova Cave in Siberia. Nature 468(7327):1053-60.

Richards M, Macaulay V, Torroni A, Bandelt H-J (2002) In Search of Geographical Patterns in European Mitochondrial DNA. Am J Hum Genet 71:1168 - 1174.

Robert-Koch-Institut (1997) Aktuelle Daten und Informationen zu Infektionskrankheiten, Epidemiologisches Bulletin 20/1997, 137f.

Robert-Koch-Institut (2007) Arbobakterien (über Arthropoden übertragbare Bakterien) - Stellungnahmen des Arbeitskreises Blut des Bundesministeriums für Gesundheit. Bundesgesundheitsbl- Gesundheitsforsch - Gesundheitsschutz. Vol. 50, Nr. 9, $1192-1207$.

Robert-Koch-Institut - Ratgeber für Ärzte (2011) Ratgeber Infektionskrankheiten, Folge 18: Typhus abdominalis, Paratyphus, http://www.rki.de/DE/Content/Infekt/ EpidBull/Merkblaetter/Ratgeber_Typhus_Paratyphus.html

Röhrig K (Hrsg.) (1906) Unter der Fahne des ersten Napoleon. Jugendgeschichte des Hunsrücker Dorfschullehrers Johann Jakob Röhrig, von ihm selbst erzählt. Altenburg.

Rösing FW (1988) Körperhöhenrekonstruktion aus Skelettmaßen. In: Knußmann R (Hrsg) Anthropologie. Handbuch der vergleichenden Biologie des Menschen Bd I/1, S. 586 - 600. Fischer, Stuttgart, New York. 
Roewer L, Krawczak M, Willuweit S, et al. (2001) Online reference database of European Y-chromosomal short tandem repeat (STR) haplotypes. Forensic Sci Int 118: $106-113$.

Roewer L, Croucer PJP, Willuweit S, et al. (2005) Signature of recent historical events in the European Y-chromosomal STR haplotype distribution. Hum Genet; 116: $279-291$.

Roos RA (2010) Huntington's disease: a clinical review. In: Orphanet journal of rare diseases. Band 5 (1): 40.

Rossbach A, Alt KW (2008) Anthropologische Untersuchungen von Skelettfunden auf dem Universitätsgelände Kassel. Institut für Anthropologie, Johannes Gutenberg- Universität Mainz (Abschlußbericht).

Rothenberg G (2000) Die napoleonischen Kriege. Brandenburgisches Verlagshaus, Königswinter.

Saitou N, Nei M (1987) The neighbor-joining method: a new method for reconstructing phylogenetic trees. Mol Biol Evol 4 [4]: 406 - 425.

Salas A, Carracedo A, Macaulay V, Richards M, Bandelt HJ (2005) A practical guide to mitochondrial DNA error prevention in clinical, forensic, and population genetics. Biochem Biophys Res Commun 335 [3]: 891-899.

Sanger F, Nicklen S, Coulson A R (1977) DNA sequencing with chain-terminating inhibitors. Proc Natl Acad Sci USA 74: 5463 - 5467.

Schilz F (2003) Design einer Multiplex-PCR zur Typisierung von 16 short tandem repeats in degradierter DNA aus forensischem und historischem Probenmaterial. Diplomarbeit, Biologische Fakultät, Georg-August-Universität Göttingen.

Schmetterer L (1966) Mathematische Statistik. Springer, Wien, S. 93.

Schmidt T, Hummel S, Herrmann B (1995) Evidence of contamination in PCR laboratory disposables. Naturwissenschaften 82: $423-431$.

Schmidt D, Hummel S, Herrmann B (2003) Brief Communication: Multiplex X/YPCR Improves Sex Identification in aDNA Analysis. Am J Phys Antropol 121:337-341.

Schröder J (2013) Detection of different pathogens relevant in the context of historical typhoid fever from the early modern skeletal series of Kassel, Hesse. Masterarbeit, Biologische Fakultät der Georg-August-Universität, Göttingen. 
Schuenemann VJ, Bos K, DeWitte S et al. (2011) Targeted enrichment of ancient pathogens yielding the pPCP1 plasmid of Yersinia pestis from victims of the Black Death. PNAS 108(38):E746-52.

Schuenemann VJ, Singh P, Mendum TA, Krause-Kyora B, Jäger G, Bos KI, Herbig A, Economou C, Benjak A, et al. (2013) Genome-Wide Comparison of Medieval and Modern Mycobacterium leprae. Science DOI:10.1126/science.1238286.

Seddon D (2004) Sir William Jenner (1815 - 1898) and Queen Victoria. J Med Biogr. 12 (3): 161-163.

Seidenberg V, Schilz F, Pfister D, Georges L, Fehren-Schmitz L, Hummel S (2012) A new miniSTR heptaplex system for genetic fingerprinting of ancient DNA from archaeological human bone. J Archaeo Sci 39: 3224-3229.

Semino O, Passarino G, Oefner PJ, Lin AA, Arbuzova S, Beckman LE, De Benedictis G, Francalacci P, Kouvatsi A, Limborska S, Marcikiae M, Mika A, Mika B, Primorac D, Santachiara-Benerecetti AS, Cavalli-Sforza LL, Underhill PA (2000) The genetic legacy of Paleolithic Homo sapiens sapiens in extant Europeans: a Y chromosome perspective. Science 290(5494):1155-9.

Shapiro B, Rambaut A, Gilbert MTP (2006) No proof that typoid caused the Plague of Athens (a reply to Papagrigorakis et al.). Int J Infect Dis 10(4):334-5.

Sicard F (1834) Histoire des institutions militaires des Français. J. Corread Jeune, Paris.

Siegmund F (2010) Die Körpergröße der Menschen in der Ur- und Frühgeschichte Mitteleuropas und ein Vergleich ihrer anthropologischen Schätzmethoden. Books on Demand. Norderstedt.

Signoli M, Ardagna Y, Adalian P, Devriendt W, Lalys L, Rigeade C, Vette T, Kuncevicius A, Poskiene J, Barkus A, Palubeckaite Z, Garmus A, Pugaciauskas V, Jankauskas R, Dutour O (2004) Discovery of a mass grave of Napoleonic period in Lithuania (1812, Vilnius). C. R. Palevol 3: 219-227.

Simoni L, Calafell F, Pettener D, Bertranpetit J, Barbujani G (2000) Geographic Patterns of mtDNA Diversity in Europe. Am J Hum Genet 66: 262 - 278.

Slatkin M (1995) A measure of population subdivision based on microsatellite allele frequencies. Genetics 139 [1]: 457-462.

Soares P, Achilli A, Semino O, Davies W, Macaulay V, Bandelt H-J, Torroni A, Richards M R (2010) The Archaeogenetics of Europe. Curr Biol 20, R174- R183. 
Spach DH, Kanter AS, Dougherty MJ, Larson AM, Coyle MB, Brenner DJ (1995) Bartonella (Rochalimaea) quintana bacteremia in inner-city patients with chronic alcoholism. N Engl J Med. 332:424-8.

Stadlbauer C, Reiter C, Patzak B, Stingeder G, Prohaska T (2007) History of individuals of the 18th/19th centuries stored in bones, teeth, and hair analyzed by LA-ICP-MS - a step in attempts to confirm the authenticity of Mozart's skull. Analytical and Bioanalytical Chemnistry 388 (3): 593 - 602.

Stout Sd, Gehlert SJ (1980) The relative accuracy and reliability of histological aging methods. Forensic Sci Int 15(3):181-190.

Stötzel K (2013) Rekonstruktion von Schädeln eines frühneuzeitlichen Massengrabes aus Kassel zur Erfassung demographischer Daten und pathologischer Veränderungen. Bachelorarbeit, Biologische Fakultät der Georg-AugustUniversität, Göttingen.

Sykes, B (1999) The molecular genetics of European ancestry. Philos Trans R Soc Lond B Biol Sci. 354 (1379):131-139.

Tambets K, Rootsi S, Kivisild T, Help H, Serk P, Loogväli EL, Tolk HV, Reidla M, Metspalu E, Pliss L, Balanovsky O, Pshenichnov A, Balanovska E, Gubina M, Zhadanov S, et al. (2004) The western and eastern roots of the Saami--the story of genetic "outliers" told by mitochondrial DNA and Y chromosomes. Am J Hum Genet 74(4):661-82.

Taylor GM, Murphy E, Hapkins R, Rutland P, Chistov Y (2007) First report of Mycobacterium bovis DNA in human remains from the Iron Age. Microbiology 154 (Pt4):1243-9.

Telkkä A, Palkama A, Virtama P (1962) Prediction of the stature from radiographs of long bones in children. J Forens Sci 7: 474-479.

Thangaraj K, Reddy AG, Singh L (2002) Is the amelogenin gene reliable for gender identification in forensic casework and prenatal diagnosis? Int $\mathrm{J}$ Legal Med 116(2):121-3.

Tran TN, Signoli M, Fozzati L, Aboudharam G, Raoult D, Drancourt M (2011) High throughput, multiplexed pathogen detection authenticated plague waves in medieval Venice, Italy. PloS One 6(3): e16735.

Underhill P A, Shen P, Lin AA, Jin L, Passarino G, Yang W H, Kauffman E, BonnéTamir B, Bertranpetit J, Francalacci P, et al. (2000) Y chromosome sequence variation and the history of human populations. Nat. Genet. 26 (3): $358-361$. 
Uytterschaut H (1993) Human bone remodelling and aging. In: Grupe G, Garland AN (eds) Histology of ancient human bone: methods and diagnosis. Seiten 95109, Springer, Berlin, Heidelberg, New York.

van Oers P (2012) Qiagen solutions for the forensic workflow. Präsentation, online verfügbar unter http://www.md2010.org/files/presents/s12/c12-5.pdf, 3.8.2013.

van Oven M, Kayser M (2009) Updated comprehensive phylogenetic tree of global human mitochondrial DNA variation. Hum Mutat 30(2):E386-E394.

Vergnaud G, Li Y, Gorgé O et al. (2007) Analysis of the three Yersinia pestis CRISPR loci provides new tools for phylogenetic studies and possibly for the investigation of ancient DNA. Adv Exp Med Biol. 603:327-38.

Voerkelius S, Lorenz GD, Rummel S, Quetel CR, Heiss G, Baxter M, Brach-Papa C, Deters-Itzelsberger P, Hoelzl S, Hoogewerff J, Pnzevera E, Van Bocxstaele M, Ueckermann H (2010) Strontium isotopic signatures of natural mineral waters, the reference to a simple geological map and its potential for authentication of food. Food Chemistry 118(4):933-940.

Von Holzing KF (1937) Unter Napoleon in Spanien. Denkwürdigkeiten eines badischen Rheinbundoffiziers $(1787-1839)$ aus alten papieren. Hg. von M. Dufner-Greif, Hans Hugo Verlag, Berlin.

Von Segur, (General Graf) L-P (1835) Geschichte Napoleons und der großen Armee im Jahre 1812. Heinrich Hoff, Mannheim (online unter google.books.com).

Wang C, Yan S, Hou Z, Fu W, Xiong M, Han S, Jn L, Li H (2012) Present Y chromosomes reveal the ancestry of Emperor CAO Cao of 1800 years ago. J Hum Genet 57(3):216-8.

Wapler U, Crubézy E, Schultz M (2004) Is Cribra Orbitalia Synonymous With Anemia? Analysis and Interpretation of Cranial Pathology in Sudan. Am J Phys Anthropol 123: 333-339.

Watson CL, Lockwood DN (2009) Single nucleotide polymorphism analysis of European archaeological M. leprae DNA. PLoS One 4(10:e7547.

Werner H (1885) Jean Dominique Larrey: Ein Lebensbild aus der Geschichte der Chirurgie. Kessinger Pub Co (Faksimile Print), Whitefish, Montana.

Wichmann I, Grupe G (2005) Detection of Yersinia pestis DNA in Two early Medieval skeletal finds From Aschheim (Upper Bavaria, 6th Century A.D.). Am J Phys Anthro 126:48-55. 
Wieberg DA, Wescott DJ (2008) Estimating the Timing of Long Bone Fractures: Correlation Between the Postmortem Interval, Bone Moisture Content, and Blunt Force Trauma Fracture Characteristics. J Forensic Sci 53: 1028-1034.

Wilbur AK, Farnbach AW, Knudson KJ, Buikstra JE (2008) Diet, tuberculosis, and the paleopathological record. Curr Anthropol 49(6):963-77.

Willerslev E, Cappellini E, Boomsma W et al. (2007) Ancient biomolecules from deep ice cores reveal a forested southern Greenland. Science 317:111-114.

Wright S (1950) Genetical structure of populations. Nature 166 (4215): 247 - 249.

Wolf HF, Rateitschak EM, Rateitschak KH (Hrsg.) (2004) Farbatlanten der Zahnmedizin 1 -Parodontologie. Thieme Verlag, Stuttgart.

Zimmer DE (1989) Immer größer, immer schneller groß - Über den Jahrhunderttrend. In: Experimente des Lebens. Haffmans Verlag, Zürich, Seiten 131-152.

Zimmer EA (1982) Grenzen des Normalen und Anfänge des Pathologischen im Röntgenbild des Skelettes. Thieme, Stuttgart, New York.

Zink AR, Sola C, Reischl U et al. (2003) Characterization of Mycobacterium tuberculosis complex DNAs from Egyptian mummies by spoligotyping. J Clin Microbiol 41(1):359-67

Zink AR, Grabner W, Nerlich AG (2005) Molecular identification of human tuberculosis in recent and historic bone tissue samples: the role of molecular techniques for the study of historic tuberculosis. Am J Phys Anthropol 126(1):3247.

Zipp A (2010) Morphologische und mikrostrukturelle Untersuchungen zur Identifikation einer Gruppe von Bestatteten aus einem Massengrab in Kassel / Hessen. Diplomarbeit, Biologische Fakultät, Georg-August-Universität Göttingen. 


\section{Anhang}

\subsection{Einheiten und Abkürzungen}

\begin{tabular}{|c|c|}
\hline$\%$ & Prozent \\
\hline${ }^{\circ} \mathrm{C}$ & Grad Celsius \\
\hline$\&$ & und \\
\hline$=$ & gleich \\
\hline Abb. & Abbildung \\
\hline aDNA & ancient DNA \\
\hline AK & Arbeitskonzentration \\
\hline BLAST & Basic Local Alignment Search Tool \\
\hline $\mathrm{bp}$ & Basenpaare \\
\hline bidest. & bidestillata, zweifach destilliert \\
\hline bzw. & beziehungsweise \\
\hline (C) & Copyright \\
\hline ca. & circa \\
\hline $\mathrm{cm}$ & Zentimeter \\
\hline ddNTP & Didesoxynukleosidtriphosphat \\
\hline DNA & desoxyribonucleic acid \\
\hline DNS & Desoxyribonukleinsäure \\
\hline dNTP & Desoxynukleosidtriphosphat \\
\hline d.h. & das heißt \\
\hline EDTA & Ethylendiamintetraacetat \\
\hline engl. & Englisch \\
\hline ent. & enterica \\
\hline et al. & Et alii, und andere \\
\hline evtl. & Eventuell \\
\hline exHT & engl. extended haplotype \\
\hline 6-FAM & 6-Carboxylflourescein \\
\hline $\mathrm{g}$ & Gramm \\
\hline $\mathrm{h}$ & Stunde(n) \\
\hline HEX & 6-Carboxyl-2',4',7',4,7-Hexachlorofluorescein \\
\hline Hrsg. & Herausgeber \\
\hline HVR1 & Hypervariable Region 1 \\
\hline HVR2 & Hypervariable Region 2 \\
\hline Jh. & Jahrhundert \\
\hline Kap. & Kapitel \\
\hline $\mathrm{kb}$ & Kilobasenpaare \\
\hline $\mathrm{kDa}$ & Kilodalton \\
\hline M & molar \\
\hline $\min$ & Minuten \\
\hline
\end{tabular}




\begin{tabular}{|c|c|}
\hline $\min H T$ & engl. minimal haplotype \\
\hline $\mathrm{mg}$ & Milligramm \\
\hline $\mathrm{ml}$ & Milliliter \\
\hline $\mathrm{mt}$ & mitochondrial \\
\hline mtDNA & mitochondriale DNA \\
\hline $\mathrm{n}$ & Stichprobenumfang \\
\hline NED & 2'-Chloro-5'-fluoro-7',8'-benzo-1,4-dichloro-6-carboxyfluorescein \\
\hline ng & Nanogramm \\
\hline $\mathrm{nm}$ & Nanometer \\
\hline Nr. & Nummer \\
\hline$\mu 1$ & Mikroliter \\
\hline PCR & Polymerase Chain Reaktion, Polymerasekettenreaktion \\
\hline $\mathrm{pH}$ & potentia hydrogenii, Protonenaktivitätsexponent \\
\hline @ & amtlich registrierte Marke \\
\hline $\mathrm{rcf}$ & engl. relative centrifugal force (Rel. Zentripetalbeschleunigung) \\
\hline resp. & Respektive \\
\hline rfu & $\begin{array}{l}\text { engl. relative fluorescenct unit( } s \text { ), Maß für die Signalintensität der } \\
\text { Peaks im PAGE-Elektropherogramm }\end{array}$ \\
\hline rpm & engl. rounds per minute \\
\hline ROX & 6-Carboxylrhodamin \\
\hline rRNA & ribosomale RNA \\
\hline s. & siehe \\
\hline S. & Seite \\
\hline S. typhi & Salmonella typhi \\
\hline SDS & engl. sodium dodecylsulfate, Natriumdodecylsulfat \\
\hline sek. & Sekunde(n) \\
\hline ser. & engl.: Serovar, Stamm \\
\hline sog. & so genannt \\
\hline STR & engl. short tandem repeat \\
\hline str. & engl. strain, Stamm \\
\hline STY & Salmonella typhi-Genort \\
\hline Subsp. & Subspezies \\
\hline Tab. & Tabelle \\
\hline Taq & Thermus aquaticus \\
\hline TBE & Tris-Borat-EDTA-Puffer \\
\hline TE & Tris-EDTA-Puffer \\
\hline TM & Trademark \\
\hline Tris & Trihydroxymethylaminomethan \\
\hline u.a. & unter anderem \\
\hline UV & Ultraviolet \\
\hline V & Volt \\
\hline
\end{tabular}




$$
\begin{array}{ll}
\text { v.a. } & \text { vor allem } \\
\text { vgl. } & \text { vergleiche } \\
\text { z.B. } & \text { zum Beispiel }
\end{array}
$$

\subsection{Verwendete Geräte, Chemikalien, Hilfsmittel und Einwegmaterial}

\section{$\underline{\text { Geräte }}$}

- TKA-Lab Reinstwassersystem, Thermo Scientific

- Dremel®MultiтM Handbohrer 395 mit 3,2mm HochgeschwindigkeitsfräserAufsatz

- DNA-Extraktor EZ1, Qiagen

- DNA-Sequenzer Modell 310, PE Applied Biosystems

- DNA Thermal Cycler Typ Mastercycler® gradient, Eppendorf

- DNA Thermal Cycler Typ Mastercycler® personal, Eppendorf

- DNA Thermal Cycler Typ GeneAmp PCR System 9700, PE Applied Biosystems

- Elektrophoresekammern Horizon® 1060 BD (5x8 cm), Gibco BRL

- Elektrophoresekammern Horizon® 1060 BD (11x14 cm), Gibco BRL

- Elektrophoreskammern Midi large horizontal $(15 \times 17 \mathrm{~cm}), \mathrm{G} \& \mathrm{P}$ Kunststofftechnik

- Elektrophoreskammern Mini horizontal (8×10 cm) G\&P Kunststofftechnik

- Gel Jet Imager \& Analyser mit Software IntasGel Capture, Intas

- Glaskapillaren, 310Capillaries 47-cm x 50 um 5/pkg, PE Applied Biosystems

- Kugelschwingmühle Typ MM2 mit Mahlbechern, Retsch

- LightCycler 2.0 ${ }^{\mathrm{TM}}$ Real-Time PCR System, Roche

- Magnetrührer Ikamag® RET, Ikamag® MTC. Ikamag® RH, Janke \& Kunkel Ika-Werk

- QiaVac-System (Vakuumpumpe) inkl. entsprechender Aufsätze

- Quadra 650, Apple Computer Inc.

- Power Macintosh 7100/66, Apple Computer Inc.

- Power Macintosh G3, Apple Computer Inc.

- Präzisionswaage excellence Typ E 1200 S, Sartorius

- Rotator LC-1, Steward

- Sägeschnittmikrotom Leitz SP 1600, Leitz

- Stromversorgung Typ ST606 Electrophoresis Power Supply, Gibco BRL

- Thermomixer Typ 5437, Eppendorf

- Varipetten® Typ 4810, Satz: 0,5-10 $\mu 1,10-100 \mu 1,100-1000 \mu 1$, Eppendorf

- Wasser-Destilliergerät Typ Muldestor, Wagner \& Munz

- Zentrifuge Typ 5402, Eppendorf

- Zentrifuge Typ 5415C, Eppendorf

- Zentrifuge Typ 5415R, Eppendorf 


\section{$\underline{\text { Chemikalien }}$}

- $1 \mathrm{~Kb}$ DNA-Leiter (Molekulargewichtsstandard); Life Technologies

- 310 10X Buffer with EDTA, PE Applied Biosystems

- 310 POP-4 ${ }^{\mathrm{TM}}$ Polymer, PE Applied Biosystems

- 310 POP-6 ${ }^{\mathrm{TM}}$ Polymer, PE Applied Biosystems

- ABI Prism ${ }^{\circledR}$ BigDye® Terminator v1.1 Cycle Sequencing Kit, ABI

- Acrylamid / Bisacrylamid 29:1, 40\% w/v, Rotiphorese ${ }^{\circledR}$, Roth

- Agarose Roti®Agarose, Roth

- Alconox (Detergenz), Aldrich

- Ambion®Wasser, Invitrogen

- AmpliTaq-Gold ${ }^{\mathrm{TM}}$ DNA-Polymerase (5U/ $\left.\mu \mathrm{l}\right)$, Perkin Elmer Cetus

- Ampuwa® (steriles Wasser), Fresenius

- Aqua bidestillata, eigene Herstellung

- Buffer PB, Buffer PE, Qiagen

- Borsäure, p.a., Merck

- Bromphenolblau, p.a., Serva

- Dextran-Blau, Fluka

- DNA Molecular Weight Marker V, Roche

- EDTA (Ethylendinitrotetraacetat Dinatriumsalz-Dihydrat):Titriplex®III, Merck

- Ethanol absolut, p.a., Abgabestelle der Bundesmonopolverwaltung: Zander Göttingen

- Ethidiumbromid, wässrige Lösung $1 \%$ (w/v), 10 mg/ml, Serva

- EZ1 DNA Tissue Kit, Qiagen

- Formamid, Fluka

- GeneAmp® 10x PCR Buffer II \& MgCl2 Solution 25 mM, Perkin Elmer Cetus

- Genescan-500 ${ }^{\mathrm{TM}}$ ROX-Kit (spurinterner Standard, loading buffer), PE Applied Biosystems

- Isopropanol p.a., Merck

- LiChrosolv®, HPLC-Wasser zur Chromatographie, Merck

- MinElute ${ }^{\mathrm{TM}}$ PCR Purification Kit, Qiagen

- NucleoSeq Kit Dye Terminator Removal, Macherey-Nagel

- Qiagen ${ }^{\circledR}$ Multiplex 2x PCR Kit plus, Qiagen

- Proteinase K (Merck)

- TEMED (Tetramethylethylendiamin), Bio-Rad

- Tris (Tri[hydroxymethyl]aminoethan), Trizma ${ }^{\text {TM }}$ Base, p.a., Sigma 


\section{Einwegmaterialien und Hilfsmittel}

- Dental-Diamantsägeblätter Typ Diaflex-T H 350 220, Horico

- Einmaluntersuchungshandschuhe Safeskin Satin Plus Powder-free, KimberleyClark ${ }^{\circledR}$

- Eppendorf Reaktionsgefäße (0,5 ml) safe-lock, Eppendorf

- Eppendorf Reaktionsgefäße (2,0 ml) safe-lock, Eppendorf

- FalconTubes, Sarstedt

- Gesichtsmasken: Surgine face mask, Johnson + Johnson

- Kimwipes® Lite, Kinberley Clark®

- OP-Haube Astronautenform Surgine ${ }^{\circledR}$, Mölnlycke Health Care, Inc.

- Parafilm ${ }^{\circledR}$ M, American National Clan ${ }^{\mathrm{TM}}$

- PE-Zentrifugationsgefäße, Blue Max $^{\mathrm{TM}} 50 \mathrm{ml}$ Conical Tubes 2070, Falcon®

- Pipettenspitzen: blaue Spitzen 1ml, Sarstedt

- Pipettenspitzen: gelbe Spitzen $100 \mu 1$, Sarstedt

- Pipettenspitzen: Standardtips 10 $\mu 1$, Eppendorf

\subsection{Verwendete Software, Internetseiten und Dateien auf der beigefügten CD}

\section{$\underline{\text { Software }}$}

- $\quad$ ABI PRISM® 310 Data Collection (Version 3.1.0) Applied Biosystems

- ABI PRISM® 310 Sequencing Analysis (Version 5.1.1) Applied Biosystems

- ABI PRISM® 310 GeneScan-Analysis (Version 3.1.2) Applied Biosystems

- ABI PRISM® 310 GeneScan-Analysis (Version 2.1) Applied Biosystems

- ABI PRISM® 310 Collection (Version 2.0.2) Applied Biosystems

- $\quad$ EditSeq ${ }^{\mathrm{TM}}$, DNAStar Lasergene 8 (Version 8.0.2) DNAStar Inc.

- $\quad$ PrimerSelect ${ }^{\mathrm{TM}}$, DNAStar Lasergene 8 (Version 8.0.2) DNAStar Inc.

- MegAlign ${ }^{\mathrm{TM}}$, DNAStar Lasergene 8 (Version 8.0.2) DNAStar Inc.

- SeqMan $^{\mathrm{TM} I I,}$ DNAStar Lasergene 8 (Version 8.0.2) DNAStar Inc.

\section{Internetseiten}

http://www.ncbi.nlm.nih.gov

http://www.yhrd.org

http://www.hprg.com/hapest5/

http://www.museumoflondon.org.uk/Collections-Research/LAARC/Centre-forHuman-Bioarchaeology/Database/Medieval+cemeteries/

http://allstr.de/allstr/home.seam

http://www.phylotree.org

http://www.familytreedna.com/faq 
http://ytree.ftdna.com

http://ymap.ftdna.com/cgi-bin/gb2/gbrowse/hs_chrY

http://www.rki.de

http://mobyle.pasteur.fr/cgi-bin/portal.py?form=quicktree

Dateien auf der beigefügten CD

Datenbank_Kassel.mdb

Einzelamplifikationen.xlsx

Frequenzdaten.xlsx

Konsensus und Amova.xlsx

Ordner: Übersichtsfotos Individuen

\subsection{Längenstandards}

$1 \mathrm{~Kb}$ Leiter, Invitrogen, Life Technologies (Größen in bp)

$75-134-154-201-220-298-344-396-506-517-1018-1636-2036-$ $3054-4072-5090-6108-7126-8144-9162-10180-11198-12216$

50bp Leiter, Invitrogen, Life Technologies (Größen in bp)

$50-100-150-200-250-300-350-400-450-500-550-600-650-700-$ $750-800$

GeneScan 600 LIZ, Applied Biosystems (Größen in bp)

$$
\begin{aligned}
& 20-40-60-80-100-114-120-140-160-180-200-214-220-240- \\
& 250-260-280-300-314-320-340-360-380-400-414-420-440-460 \\
& -480-500-514-530-540-560-580-600
\end{aligned}
$$

GeneScan 500 ROX, Applied Biosystems (Größen in bp)

$35-50-75-100-139-150-160-200-250-300-340-350-400-450-$ $490-500$ 


\section{Danksagung}

An dieser Stelle möchte ich mich bei all denen Bedanken, ohne die diese Arbeit nicht in dieser Form durchgeführt hätte können. Wenn ich rückblickend die letzten zwei Jahre betrachte, verdanke ich so vielen so vieles, dass dies ein weiteres Buch füllen würde. Daher an dieser Stelle nur ein paar Worte für diejenigen, mich besonders unterstützt haben:

Zunächst einmal gilt mein aller herzlichster Dank meinen Betreuern Peter Kappeler und Thomas Hörnschemeyer, die bereit waren, sich meiner anzunehmen und mich in diesem Projekt zu unterstützen. Ohne den Durchhaltewillen von Susanne Hummel, die trotz Drittmittelproblematiken an dieses Projekt glaubte und in all dem Verwaltungs- und Lehrstress immer ein offenes Ohr für mich hatte, wäre diese Arbeit nicht realisierbar gewesen.

Natürlich darf ich an dieser Stelle den eigentlichen Initiator nicht vergessen: Kai Füldner war es, der sich von Anfang an dafür einsetzte, dass die Individuen überhaupt mehr Beachtung fanden, und den Kontakt zu uns nach Göttingen herstellte. In diesem Zusammenhang möchte ich auch Birgit Großkopf danken, die mir mit ihrem unermüdlichen Einsatz und Fachwissen stets zur Seite stand. Marlen und besonders Anne vom Naturkundemuseum in Kassel möchte ich für ihr Engagement an dem Projekt auch jenseits der Ausstellung und für die tollste Datenbankpflege überhaupt danken. Von all den Helferlein und fleißigen Bienchen im Institut für Zoologie und Anthropologie möchte ich zu allererst Janine danken. Ohne dich wäre ich schon lange dem Statistikwahnsinn verfallen - du hast mich immer auf den Boden zurückgeholt und mir das wirklich wichtige gezeigt. Silence will fall when the doctor is gone... ;) Sebastian möchte ich für seine unendliche Geduld mit meinem Knochenfimmel danken und dafür, dass er mir die Insekten näher gebracht hat. Jetzt mag ich nicht nur tote Menschen, sondern auch totes Krabbeltier. Lars, du bist der einzige, den ich für meine Distanzmatrizen wirklich begeistern konnte, und der mir in den Wirren der Populationsgenetik den richtigen Weg aufgezeigt hat. Lass dich nicht von Erdbeben piesacken! Ohne Verena wäre das Y-Analysesystem nur halb so schön geworden. Danke, dass du mir mit Rat und Tat zur Seite standst. Durch dich habe ich den 310er zu schätzen gelernt. Hätte Marion nicht so fleißig an den Kasselern gesägt, wäre ich bis heute nicht mit der Histologie fertig. Vielen Dank für deine Mühe, die aufbauenden Gespräche und die dringend nötige Schokolade. Danke Lea, dass ich mich immer bei dir ausheulen durfte, egal wie nichtig die Sache war. Zusammen lässt sich vieles leichter durchstehen - Tschaka!!!!

All den Studenten, die ihre Bachelor- oder Masterarbeit zu dem Kasseler Massengrab geschrieben haben, möchte ich für ihre fleißige Arbeit danken, ihr ward toll!

Am Ende möchte ich mich bei meiner Familie für ihre immerwährende Unterstützung danken. Ich möchte diese Arbeit meine Frau widmen, ohne deren Liebe ich heute dies nicht hätte schreiben können. Mein Schatz, ich liebe dich. 


\section{Lebenslauf}

\section{Persönliche Daten}

$\begin{array}{ll}\text { Name: } & \text { Dipl.-Biol. Philipp v. Grumbkow } \\ \text { Anschrift: } & \text { Kalkrain } 2 \\ & 37290 \text { Meißner } \\ \text { Geburtsdatum: } & 23.03 .1985 \\ \text { Geburtsort: } & \text { Eschwege }\end{array}$

\section{Promotion}

$2012-2013$

Promotionsstudium an der Fakultät für Biologie, GeorgAugust-Universität Göttingen

Thema: Das Leben in der napoleonischen Armee - Interdisziplinäre Untersuchung eines Massengrabes aus Kassel, Hessen

\section{Beruflicher Werdegang}

2011 - heute $\quad$ Vertretung der Akademischen Oberratsstelle (Dr. Hummel), Georg-August-Universität Göttingen

2010 - $2011 \quad$ Wissenschaftlicher Mitarbeiter im Institut für Zoologie und Anthropologie, Abteilung Historische Anthropologie

Wissenschaftlicher Mitarbeiter im Institut für Mikrobiologie und Genetik, Abteilung Bioinformatik, Georg-AugustUniversität Göttingen

2007 - $2010 \quad$ Studentische Hilfskraft im Institut für Mikrobiologie und Genetik, Abteilung Bioinformatik (jeweils im SoSe)

\section{Publikationen}

- v. Grumbkow P, Frommer S, Mazanec J, Kootker L M, Davies G D, Hummel S (2013) Kinship and mobility in 11th-Century A.D. Gammertingen, Germany: an interdisciplinary approach. J Archae Sci 40(10):3768-3776

- Büsse S, von Grumbkow P \& Hörnschemeyer T (2013) Phylogeographic Analysis of the Disjunct Distribution of Relict Dragonflies in Asia - Epiophlebia (Insecta: Odonata). Jahrestagung der Deutschen Gesellschaft für allgemeine und angewandte Entomologie (DGaaE) 2013, Göttingen, Germany.

- Büsse S, von Grumbkow P, Hummel S, Shah DN, Tachamo Shah RD, et al. (2012) Phylogeographic Analysis Elucidates the Influence of the Ice Ages on the Disjunct Distribution of Relict Dragonflies in Asia. PLoS ONE 7(5): e38132. doi:10.1371/journal.pone.0038132.

- Grumbkow P, Zipp A, Großkopf B, Fueldner K, Hummel S (2012) Analyses to help identify individuals from a historical mass grave in Kassel, Germany. Anthropol Anz Vol 69 (1):1-43. 
- Grumbkow P, Zipp A, Seidenberg V, Fehren-Schmitz L, Kempf VAJ, Groß U, Hummel S (2011) Evidence of Bartonella quintana infections in skeletons of a historical mass grave in Kassel, Germany. Am J Physic Anthropol 146(1):134-7.

\section{Studium}

2005 - 2010 Studium der Biologie, Georg-August-Universität Göttingen

Abschluss: Diplom (1,0 mit Auszeichnung)

Prüfungsfächer: Anthropologie (HF), Humangenetik, Biochemie

Thema der Diplomarbeit: Molekulargenetische Untersuchungen zur Identifikation einer Gruppe von Bestatteten aus einem Massengrab aus Kassel, Hessen

\section{Zivildienst}

$2004-2005$

Zivildienst beim Deutschen Roten Kreuz, Eschwege

\section{Schulische Ausbildung}

$2001-2004$

Oberstufengymnasium Eschwege, Abschluss Abitur (1,9) 